UNIVERSIDADE DE SÃO PAULO

FACULDADE DE ECONOMIA, ADMINISTRAÇÃO E CONTABILIDADE

DEPARTAMENTO DE ECONOMIA

PROGRAMA DE PÓS-GRADUAÇÃO EM ECONOMIA

DESIGUALDADES SOCIAIS NA UTILIZAÇÃO DE CUIDADOS DE SAÚDE NO BRASIL E SEUS DETERMINANTES

JACQUELINE NOGUEIRA CAMBOTA

ORIENTADORA: Prof. ${ }^{\mathrm{a}}$ Dr. ${ }^{\mathrm{a}}$ FABIANA FONTES ROCHA

São Paulo

2012 
Prof. Dr. João Grandino Rodas

Reitor da Universidade de São Paulo

Prof. Dr. Reinaldo Guerreiro

Diretor da Faculdade de Economia, Administração e Contabilidade

Prof. Dr. Denisard Cnéio de Oliveira Alves

Chefe do Departamento de Economia

Prof. Dr. Pedro Garcia Duarte

Coordenador do Programa de Pós-Graduação em Economia 


\section{DESIGUALDADES SOCIAIS NA UTILIZAÇÃO DE CUIDADOS DE SAÚDE NO BRASIL E SEUS DETERMINANTES}

Tese apresentada ao Programa de PósGraduação em Economia da Faculdade de Economia, Administração e Contabilidade da Universidade de São Paulo, para obtenção do título de Doutor em Ciências.

Orientadora: Prof. ${ }^{\text {a }}$ Dr. $^{\text {a }}$ Fabiana Fontes Rocha

Versão Corrigida

(versão original disponível na Faculdade de Economia, Administração e Contabilidade)

São Paulo 


\section{FICHA CATALOGRÁFICA}

Elaborada pela Seção de Processamento Técnico do SBD/FEA/USP

Cambota, Jacqueline Nogueira

Desigualdades sociais na utilização de cuidados de saúde no Brasil e seus determinantes / Jacqueline Nogueira Cambota. - São Paulo, 2012. $108 \mathrm{p}$.

Tese (Doutorado) - Universidade de São Paulo, 2012. Orientador: Fabiana Fontes Rocha.

1. Economia da saúde 2. Equidade 3. Acesso aos serviços de saúde I. Universidade de São Paulo. Faculdade de Economia, Administração e Contabilidade. II. Título.

$$
\text { CDD - 330.1556 }
$$




\section{AGRADECIMENTOS}

A Deus, que nunca me desamparou.

Ao meu marido, Paulo Pontes, grande companheiro nesta jornada.

À Prof. ${ }^{a}$ Dr. ${ }^{a}$ Fabiana Rocha, por sua dedicação e paciência ao longo da realização deste trabalho e, sobretudo, por me apresentar ao tema deste estudo pelo qual desenvolvi grande motivação.

À minha mãe, Ivoneide, por sempre ter nos ensinado o valor da educação.

À Babi por tornar a execução deste trabalho menos árdua.

À minha irmã Patrícia, por sua amizade.

À Faculdade de Economia, Administração e Contabilidade da Universidade de São Paulo, pela oportunidade de realização deste trabalho.

À CAPES pela concessão da bolsa de doutorado.

Aos professores Dr. Antonio Campino e Dr. ${ }^{\text {a }}$ Maria Dolores Diaz por suas contribuições na banca de qualificação.

Ao Superintendente do Etene, José Narciso Sobrinho, pelo empenho em conseguir uma licença para que eu pudesse finalizar este trabalho.

Aos colegas do Banco do Nordeste, por sua generosidade quando precisei me ausentar de minhas atividades.

Aos funcionários da secretária de pós-graduação e da coordenação de pós-graduação em economia, por sua presteza.

Aos colegas da FEA pela convivência ao longo do curso de doutorado. 


\section{RESUMO}

A equidade na utilização de cuidados de saúde deve ser considerada como questão central em qualquer política de saúde que pretenda contribuir para uma sociedade mais justa. Desse modo, o objetivo desta tese é analisar o desempenho da entrega de cuidados no Brasil em termos de equidade por meio de violações do princípio de equidade horizontal na utilização dos serviços de cuidados de saúde e da decomposição dos determinantes da desigualdade na utilização do cuidado relacionada à renda. A desigualdade na distribuição de cuidado médico pela renda é capturada por índices de iniquidade para a utilização de serviços de consultas médicas e internações hospitalares. Esses índices mostram se existem diferenças no uso de serviços de cuidados de saúde entre indivíduos com similares necessidades de saúde. Para explicar as causas da desigualdade, Wagstaff, van Doorslaer e Watanabe (2003) propõem que a medida do grau de desigualdade seja decomposta nas contribuições dos fatores explicativos do uso. A análise também considerou a perspectiva da desigualdade, o que permitiu observar não apenas desigualdades sociais mas também variações regionais na entrega de cuidados de saúde. Os resultados mostraram iniquidade horizontal pró-rico no uso de consultas médicas e pouca evidência de iniquidade no uso de internações. O padrão de iniquidade horizontal no uso se repetiu para todas as regiões, mas regiões menos desenvolvidas como, o Norte e o Nordeste, apresentaram maior grau de iniquidade. A decomposição da desigualdade mostra que contribuições de fatores de necessidades de saúde são principalmente pró-pobre, uma vez que pessoas mais pobres tendem a possuir maiores necessidades de cuidado. Por outro lado, as contribuições dos determinantes sociais foram bastante diversificadas. Renda e escolaridade contribuem para aumentar a distribuição pró-rico no uso de consultas e reduzir a contribuição pró-pobre no uso de internações hospitalares. A contribuição da condição de atividade foi, em geral, própobre, podendo ser explicada pelo maior custo de oportunidade das pessoas ocupadas em procurar cuidados com a saúde. As contribuições dos plano de saúde e das desigualdades regionais são examinadas com maior atenção por serem alvo direto de políticas de saúde. Assim, contribuições pró-rico do plano de saúde e das desigualdades regionais poderiam ser reduzidas, por exemplo, por estratégias com foco em grupos de renda mais baixa e pela ampliação de recursos físicos e humanos das áreas menos desenvolvidas.

Palavras-chave: Equidade horizontal. Utilização de cuidados de saúde. Decomposição. 


\begin{abstract}
Equity in healthcare utilization should be considered as a basic issue at any health policy that you want to contribute to a fairer society. Thus, the aim of this thesis is to analyze the performance of medical care delivery in Brazil in terms of equity through violations of the horizontal equity principle of healthcare use and of the decomposition of the determinants of income-related inequality in the use of medical care. The inequality in the distribution of medical care by income is captured by inequity indices. This indices show if there are differences in the use of healthcare services among individuals with similar health needs. To explain the causes of the income-related inequality, Wagstaff, van Doorslaer, Watanabe (2003) proposed that the measure of the degree of inequality is decomposed into the determinants of use. The analysis also considered the regional perspective of inequality, which allowed us to observe not only social inequalities but also regional variations in the delivery of healthcare. The results find evidence horizontal inequity pro-rich in the utilization of doctor visits and little evidence de inequity in inpatient care use. The pattern of horizontal inequity in use is repeated for all regions, but less developed regions like the North and Northeast had a higher degree of iniquity. The decomposition of inequality shows that contributions of factors of health needs are mainly pro-poor, because poorer people tend to have greater care needs. On the other hand, the contributions of the social determinants were enough diverse. Income and education contributed to increase the pro-rich distribution of use of doctor visits and reduce the distribution pro-poor inpatient care. The contribution of status of activity was mostly pro-poor because probably economically active people have a higher cost of opportunity in seeking healthcare. The contributions from the health insurance and regional inequalities are examined more closely by being a direct target of health policy. Accordingly, contributions pro-rich of health insurance and of regional inequalities could be reduced, for example, by strategies focused on lower income groups and by the expansion of physical and human resources of less developed areas.
\end{abstract}

Keywords: Horizontal equity. Health care utilization. Decomposition. 


\section{LISTA DE TABELAS E QUADRO}

Tabela 2.1 - Desigualdades regionais nos gastos com assistência a saúde no Brasil - 1986...... 28

Tabela 2.2 - Utilização/Acesso a Serviços de Saúde - 1998, 2003 e 2008 ................................. 30

Tabela 2.3 - Qualidade dos Serviços de Saúde - 1998, 2003 e 2008. ....................................... 31

Tabela 4.1 - Distribuição de frequência do número de consultas médicas ................................. 46

Tabela 4.2 - Distribuição de frequência do número de internações hospitalares ...................... 47

Tabela 5.1 - Índices de desigualdade horizontal na utilização total de consultas médicas, Brasil,

Regiões e Unidades da Federação - 1998, 2003 e 2008.......................................................... 58

Tabela 5.2 - Índices de desigualdade horizontal para utilização total de internações

hospitalares, Brasil, Regiões e Unidades da Federação - 1998, 2003 e 2008. ........................... 61

Tabela 5.3 - Contribuição dos determinantes da utilização para a desigualdade no cuidados de

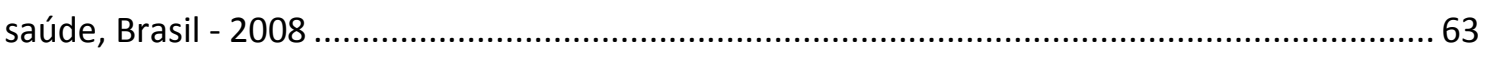

Quadro 4.1 - Definição das variáveis de utilização, de necessidade e de não necessidade .43 


\section{LISTA DE FIGURAS}

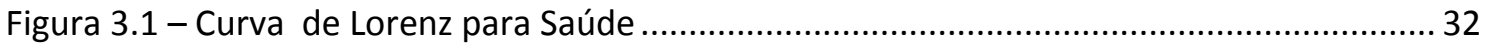

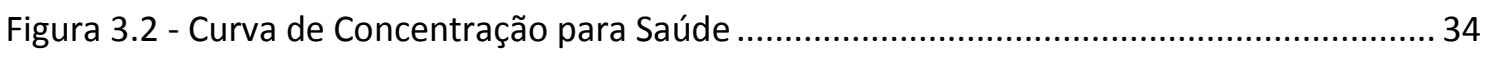

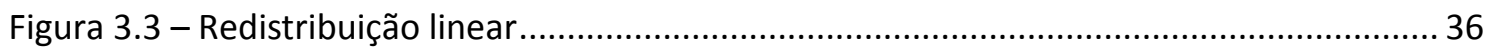




\section{LISTA DE GRÁFICOS}

Gráfico 4.1 - Distribuição da utilização total de consultas médicas............................................ 44

Gráfico 4.2 - Distribuição da utilização total de internações hospitalares ................................. 44

Gráfico 5.1 - Curva de concentração para o atendimento por motivo de consulta - 1998, 2003

e 2008.

Gráfico 5.2 - Curva de concentração para consultas SUS e não SUS, Brasil - 1998, 2003 e 2008.

Gráfico 5.3 - Curva de concentração por motivo de internação, Brasil - 1998, 2003 e 2008. ... 54

Gráfico 5.4 - Curva de concentração para internações SUS e não SUS, Brasil - 1998, 2003 e

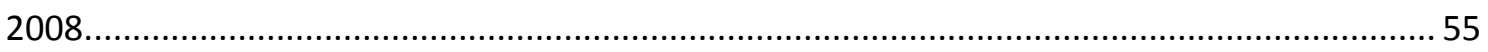

Gráfico 5.5 - Distribuição de médicos (por mil habitantes), regiões e Brasil - 2005 e 2010 ..... 56

Gráfico 5.6 - Distribuição de dentistas (por mil habitantes), regiões e Brasil - 2005 e 2010 .... 56

Gráfico 5.7 - Distribuição de Leitos (por mil habitantes), regiões e Brasil - 2005 e 2010 .......... 57

Gráfico 5.8 - Decomposição da desigualdade na probabilidade de contatar consultas médicas,

Brasil e Regiões - 2008

Gráfico 5.9 - Decomposição da desigualdade na frequência de consultas médicas, Brasil e

Regiões - 2008

Gráfico 5.10 - Decomposição da desigualdade na probabilidade de contatar internações

hospitalares, Brasil e Regiões - 2008

Gráfico 5.11 - Decomposição da desigualdade na frequência de internações hospitalares, Brasil

e Regiões - 2008 


\section{SUMÁRIO}

1 Introdução

2 Desigualdades em cuidados de saúde relacionada à renda ............................................. 17

2.1 As características dos sistemas de saúde estão relacionadas com as desigualdades na

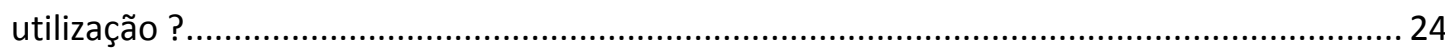

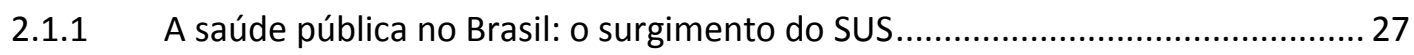

3 Medidas de desigualdade de renda aplicadas à desigualdade em saúde .......................... 32

3.1 Mensuração de desigualdades sociais em saúde ........................................................... 32

3.2 Interpretação de redistribuição para o índice de concentração.................................. 35

3.3 Mensuração de desigualdades horizontais (iniquidades) na utilização de cuidados . 37

3.4 Decomposição da desigualdade na utilização de cuidados ......................................... 38

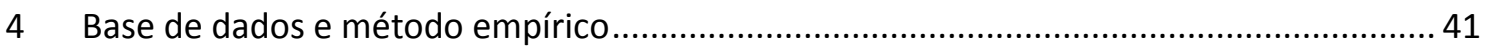

4.1 Base de dados e definição das variáveis ..................................................................... 41

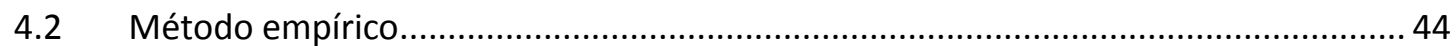

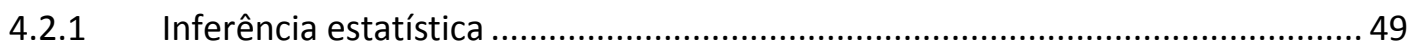

5 Mensuração e Decomposição das Desigualdades Sociais nos Cuidados de saúde............. 51

5.1 Evidências de desigualdades na entrega de cuidados de saúde...................................51

5.2 Evolução das desigualdade sociais na utilização de cuidados de saúde ..................... 57

5.3 Determinantes da desigualdade na utilização de cuidados de saúde..........................63

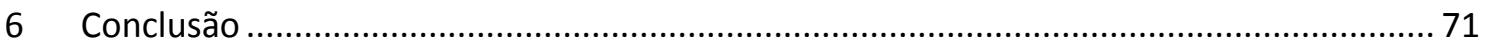

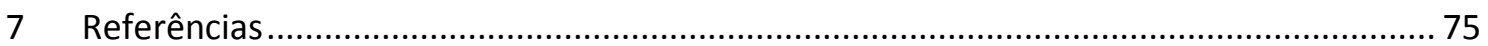

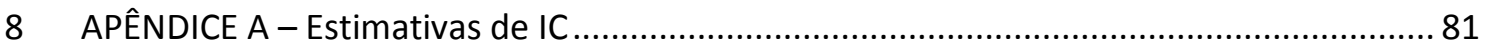

9 APÊNDICE B - Efeitos Marginais dos Determinantes......................................................... 83

10 APÊNDICE C - Contribuição dos determinantes para a desigualdade, Regiões ..............95

11 APÊNDICE D - Distribuição de recursos humanos e físicos - Regiões, UF e Brasil ......... 100

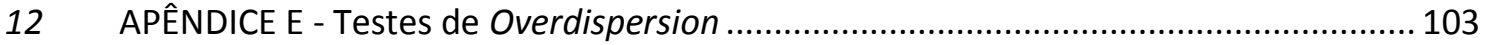

13 APÊNDICE F - Teste de razão de verossimilhança .......................................................... 105

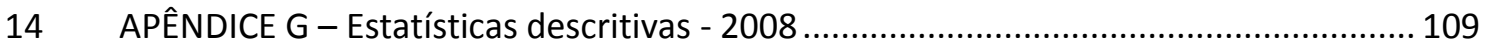

15 ANEXO - Prova da redistribuição linear do IC ............................................................ 110 


\section{INTRODUÇÃo}

A preocupação com a equidade em saúde na Europa aparece desde o pós-guerra, quando ocorreu a expansão do Estado de Bem-Estar Social em vários países europeus. Mas apenas nos anos 1980 é que se tornaram intensas as discussões a cerca da inclusão do princípio de equidade dentro de documentos oficiais de saúde, em razão das diferenças observadas em saúde entre grupos sociais e entre áreas geográficas em um mesmo país por toda parte da Europa.

Nesse período, todos os 32 países europeus membros da Organização Mundial de Saúde traçaram objetivos comuns em relação à equidade em suas políticas de saúde, objetivando a redução das diferenças em saúde entre grupos sociais e áreas geográficas (WHITEHEAD, 2000). Como resultado, durante a década de 1990, vários sistemas de saúde passaram por experiências de reformas, de modo a garantir em sua legislação ou em documentos da política oficial de saúde uma cobertura universal a um conjunto de serviços básicos.

Formulações de políticas voltadas para a equidade exigem a definição desse princípio, entretanto, não existe uma teoria de equidade consensualmente aceita da qual se retire critérios operacionais, uma vez que esses variam em razão dos valores e do momento histórico de cada sociedade. As diferentes necessidades de saúde, decorrentes tanto de características individuais quanto do perfil epidemiológico e do grau de desenvolvimento da sociedade na qual o indivíduo está inserido fazem da equidade em saúde também uma questão de justiça social. ${ }^{1}$

As diferentes definições de equidade encontradas na literatura procuram conciliar o conceito de equidade como justiça distributiva com os objetivos das políticas de saúde. Uma discussão a cerca do conceito de equidade no âmbito da literatura de economia da saúde pode ser encontrada em Culyer e Wagstaff (1993). Os autores argumentam que, embora exista extensa literatura sobre equidade em cuidados de saúde, essa é marcada por uma certa confusão no que concerne ao significado do termo equidade. São exploradas, portanto, quatro definições de equidade no contexto da oferta

\footnotetext{
${ }^{1}$ Sen (2002, p. 660, tradução nossa) argumenta que " qualquer concepção de justiça social que reconheça a necessidade de uma distribuição justa, bem como a formação eficiente de recursos humanos não pode ignorar o papel que a saúde exerce na vida das pessoas e as oportunidades que as pessoas, respectivamente, têm de obter uma boa saúde".
} 
de cuidados de saúde para mostrar como essas definições podem conduzir a várias interpretações, muitas vezes mutuamente incompatíveis.

A primeira interpretação de equidade propõe a igualdade no gasto per capita. Dessa forma, uma distribuição equitativa seria alcançada se o orçamento de serviços de saúde disponível, fosse dividido igualmente entre as áreas geográficas com base no tamanho da população em cada área. Essa definição, contudo, não considera as diferenças de necessidades entre os grupos de individuos e, portanto, não pode ser considerada justa. Desse modo, uma política com foco na equidade deve ser efetuada em função das diferenças nas condições sanitárias e socioeconômicas das populações e das diferentes variações regionais no custo da assistência à saúde.

A segunda definição explora a distribuição de cuidados de acordo com as necessidades de saúde, com duas versões: a equidade horizontal (tratamento igual para necessidades iguais) e a equidade vertical (tratamento preferencial para aqueles com maiores necessidades de saúde). A dificuldade, nesse caso, resulta da mensuração das necessidades de saúde ${ }^{2}$. A literatura empírica procura resolver esse problema usando indicadores relacionados ao perfil demográfico e epidemiológico da população.

A terceira definição diz respeito à igualdade de acesso e é mais comumente encontrada nos documentos de política, mas como ocorre com as necessidades, não existe na literatura uma convergência a respeito do significado do termo acesso. Em discussão sobre os conceitos de acesso e utilização de serviços de saúde, Travassos e Martins definem acesso como um conceito complexo, "muitas vezes empregado de forma imprecisa, e pouco claro na sua relação com o uso de serviços de saúde" (2004, p. 191), enquanto a utilização dos serviços de saúde representa o cerne do funcionamento dos sistemas de saúde.

Finalmente, a quarta definição explora a igualdade nas condições de saúde, que ao contrário das demais definições, que focam na distribuição de recursos, centraliza nos resultados de saúde. Segundo esse conceito, uma distribuição equitativa do cuidado é aquela que possibilita uma distribuição equitativa de saúde. Contudo, como argumentam Travassos et al., faz-se necessário distinguir equidade em saúde de equidade no uso de serviços de saúde, uma vez que "a igualdade no uso de serviços de

\footnotetext{
${ }^{2}$ Apesar da existência de medidas sofisticadas para dimensionar as necessidades de utilização de serviços de saúde, "nenhuma delas consegue captar totalmente todos os aspectos e a complexidade das necessidades de saúde das populações" (Porto, 2003, p. 6 ).
} 
saúde é condição importante, porém, não suficiente para diminuir as desigualdades no adoecer e morrer"(2000, p. 134).

Uma definição mais concisa foi proposta por Whitehead (2000, p. 8) para quem a equidade no cuidado pode ser compreendida como "igual acesso aos cuidados disponíveis para iguais necessidades, utilização igual para igual necessidade e igual qualidade de atendimento para todos". A essa abordagem a literatura convencionou chamar de equidade horizontal, na qual indivíduos com as mesmas necessidades devem ter as mesmas oportunidades de utilizar os serviços de cuidados.

Tal abordagem vem sendo adotada como base para operacionalização da equidade pela maioria dos países, onde a equidade é aplicada como igualdade de oportunidades para utilização de serviços de saúde, ou como igualdade de tratamento para necessidades iguais (van DOORSLAER; WAGSTAFF; RUTTEN, 2000).

No Brasil, a saúde como direito de todos e dever do Estado só foi garantida na CF/88, que com a institucionalização do SUS (Sistema Único de Saúde), passou a oferecer acesso universal, igualitário e integral aos serviços de saúde para toda a população brasileira. Mas não está claro na literatura nacional se o texto constitucional trata ou não de equidade em saúde.

Porto argumenta que "de acordo com a Constituição (1988) e com a legislação que criou o SUS, se infere que o conceito de igualdade de oportunidades de acesso aos serviços de saúde se refere a igualdade de oportunidades para necessidades iguais" e que, portanto, implica em "uma discriminação positiva compensadora das desigualdades existentes nos condicionantes do estado de saúde da população, considerada socialmente injusta" (2002, p. 953, tradução nossa).

Para Nunes et al. "o conceito de equidade em saúde - igual acesso para igual necessidade - embora não explicitado, quer na Constituição quer na sua regulamentação (Leis $n^{\circ} 8080 / 90$ e $n^{\circ} 8142 / 90$ ), contempla a discriminação positiva, de modo a garantir mais direitos a quem tiver mais necessidades" (2001, p. 162).

Por outro lado, Medici aponta que a gratuidade na utilização dos serviços do SUS valoriza a igualdade e não a equidade de acesso, "na medida em que, ao oferecer serviços gratuitos para todos, não leva em consideração que alguns teriam capacidade de pagar e que, com esses recursos, se poderia melhorar a qualidade do acesso dos que não têm capacidade de pagar" (2011, p. 26). Medici assinala, ainda, que a equidade, frequentemente citada como um dos princípios que regem a entrega dos serviços de 
saúde pelo SUS, aparece apenas como um requisito para a forma de participação no custeio no capítulo sobre Seguridade Social da Constituição.

A despeito das divergências em torno do conceito de equidade em saúde, a entrega de serviços de saúde em um País pode ser considerada equitativa, quando há igualdade na utilização para necessidades iguais, independentemente de características sociais (ou de não necessidade) que afetam o uso. Com efeito, as evidências empíricas para o Brasil mostram que, embora o sistema público de saúde brasileiro tenha conseguido avançar em termos de universalidade no atendimento, as desigualdades em saúde permaneceram como um desafio a ser enfrentado em razão do gradiente social na utilização de serviços de saúde.

Medici (2011) observa que, com base em normas internacionais, cada pessoa deveria realizar pelo menos uma consulta médica preventiva por ano. De acordo com dados da PNAD (Pesquisa Nacional por Amostra de Domicílios) de 2008, contudo, $42 \%$ dos indivíduos de menor renda (aqueles sem rendimentos e com menos de um salário mínimo de renda domiciliar per capita) não realizaram nenhuma consulta nos 12 meses anteriores à pesquisa. No grupo de renda mais elevada (mais de cinco salários mínimos de renda domiciliar per capita), contudo, isso ocorre somente com $18 \%$ dos indivíduos.

Barros e Bertoldi (2002) e Neri e Soares (2002) assinalam que pessoas em desvantagem socioeconômica necessitam de maiores cuidados médicos, mas consomem menos serviços de saúde do que pessoas com melhor condição socioeconômica. Esses resultados sugerem a presença de desigualdades nos cuidados de saúde relacionada à renda conforme resultados encontrados por Noronha e Andrade (2002) e Palermo, Portugal e Souza (2005) para a utilização de consultas médicas e internações hospitalares nas regiões Sudeste e Sul, respectivamente. De acordo com esses estudos, a utilização dos serviços de consultas médicas e internações hospitalares nas regiões Sul e Sudeste é maior entre faixas de renda mais elevadas.

Barreiras sociais à utilização também podem surgir pela forma de financiamento dos sistemas de saúde (TRAVASSOS; OLIVEIRA, VIACAVA, 2006). Desse modo, as desigualdades regionais no Brasil surgem como uma dimensão relevante das desigualdades sociais em saúde em virtude da substancial variação regional na oferta de serviços de saúde dada pelo financiamento descentralizado com participação das três esferas do governo (União, estados e municípios). 
Evidências nesse sentido são encontradas em Travassos et al. (2000) e Travassos, Oliveira e Viacava (2006). Os autores mostram que a utilização de serviços de saúde no Brasil sofre influência de desigualdades sociais e geográficas, onde pessoas residentes nas regiões Sudeste e Sul apresentaram maiores chances de uso do que os residentes em outras regiões. Noronha e Andrade (2001), por sua vez, constatam diferenças significativas nas desigualdades sociais na condição de saúde da população entre estados brasileiros.

A participação da iniciativa privada na entrega de serviços de saúde também aparece como elemento relevante da desigualdade social na utilização de cuidados de saúde no Brasil. A atuação suplementar da iniciativa privada duplica o acesso dos indivíduos que podem pagar por um plano de saúde, resultando em sobreutilização dos serviços de cuidados por parte dos usuários de planos de saúde em relação aqueles que utilizam apenas o SUS (TRAVASSOS et al., 2000; ANDRADE; MAIA, 2009, MEDICI, 2011).

A literatura nacional mostra que a utilização de cuidados de saúde é marcada por desigualdades sociais, mas existem poucos estudos que se dedicam a acompanhar a evolução dessas desigualdades, especialmente, daquelas consideradas como iniquidades por serem decorrentes de causas injustas, evitáveis e desnecessárias (WHITEHEAD, 2000). Igualmente escassos são os estudos que explicam as causas das desigualdades na utilização de cuidados de saúde no Brasil.

Em razão das lacunas apresentadas na literatura nacional, o objetivo desta tese é analisar o desempenho da entrega de cuidados de saúde no Brasil em termos de equidade horizontal por meio de metodologias ainda não exploradas na literatura de economia da saúde no Brasil. A análise consistirá em duas partes: a) construção de medidas de desigualdades para indivíduos com as mesmas necessidades de saúde com a finalidade de acompanhar e identificar o padrão de desigualdade relacionada à renda na utilização de serviços de consultas médicas e internações hospitalares e b) explicação das desigualdades na utilização desses serviços pela decomposição das desigualdades com base nos determinantes da utilização de consultas médicas e internações hospitalares.

Para acompanhar a evolução das desigualdades sociais e identificar o padrão de desigualdade relacionada à condição socioeconômica mensurada pela renda, foram 
construídos índices de iniquidade para os três anos (1998, 2003 e 2008) em que estão disponíveis informações sobre utilização de serviços de saúde e para cada unidade da Federação, a fim de considerar a perspectiva regional da desigualdade.

Como esses índices identificam o padrão de desigualdade de uso, mas não o explicam, a desigualdade foi decomposta nos determinantes da utilização, conforme os trabalhos realizados por Wagstaff, van Doorslaer e Watanabe (2003), van Doorslaer e Masseria (2004) e van Doorslaer, Xander e Jones (2004). A decomposição permite que as contribuições para a desigualdade sejam separadas em determinantes de necessidade e sociais, o que possibilita conhecer as fontes das iniquidades na utilização do cuidado.

Ressalta-se que o conhecimento das causas das desigualdades em saúde torna-se fundamental para que as políticas públicas regionais atuem diretamente sobre os determinantes das desigualdades, possibilitando uma utilização mais equitativa entre os grupos de renda e, portanto, uma melhor condição de saúde para a população de regiões mais pobres. Podendo, inclusive, colaborar para uma reduzir a desigualdade de renda inter-regional, uma vez que o estado de saúde afeta a produtividade e, por sua vez, os salários dos indivíduos.

A base de dados são as informações constantes na PNAD, que desde 1998 realizada um suplemento de periodicidade quinquenal com levantamento de dados detalhados sobre saúde da população. Considerando que essa pesquisa possui desenho amostral complexo, fez necessária a adoção do procedimento de bootstrap para amostras complexas para obtenção das estimativas dos erros-padrão dos índices de concentração e dos termos de contribuição dos determinantes da desigualdade. A desconsideração desse desenho poderia conduzir a estimativas viesadas da variância, alterando inclusive a significância dos parâmetros.

Desse modo, a tese está organizada em seis capítulos, além dessa introdução:

O capítulo 2 traz uma discussão sobre as principais evidências de desigualdades na utilização de serviços de cuidado para países da OCDE e o Brasil, com a finalidade de mostrar os caminhos pelos quais surgem as desigualdades no cuidado relacionada à renda. Adicionalmente, se discute o papel dos sistemas de saúde no surgimento dessas desigualdades. 
No capitulo 3, são definidas as medidas de desigualdade social em saúde. Primeiramente, as medidas de desigualdade de renda e que foram usadas, de início, na mensuração de desigualdades em saúde, para depois se chegar aos métodos de mensuração e decomposição das desigualdades sociais em saúde adotados na literatura recente de economia da saúde. Esses últimos são usados para revelar e explicar as desigualdades sociais (iniquidades) na utilização de serviços de cuidados de saúde.

No capítulo 4, realiza-se a descrição da base de dados, que tem como fonte a Pesquisa Nacional por Amostra de Domicílios (PNAD) do IBGE para os anos em que foram levantadas as informações sobre a saúde da população (1998, 2003 e 2008). Neste capítulo, também se definem as variáveis usadas como as medidas de utilização, de necessidade e sociais, e descrevem-se o método econométrico de estimação da demanda por utilização de serviços de saúde e o procedimento para inferência estatística em amostras complexas como a PNAD.

O capitulo 5 traz a discussão dos resultados. Inicialmente, acompanha-se a evolução das desigualdades sociais em uma perspectiva regional. Em seguida, realiza-se para o ano de 2008 a decomposição da desigualdade em determinantes de necessidades e sociais, atribuindo-se a esses últimos as iniquidades ou desigualdades injustas.

Por fim, são realizadas as considerações finais a respeito dos resultados encontrados, bem como algumas sugestões de intervenções para que o sistema público de saúde no Brasil possa finalmente privilegiar a equidade na entrega dos serviços de saúde. 


\section{DESIGUALDADES EM CUIDADOS DE SAÚDE RELACIONADA À RENDA}

A literatura aponta as diferenças socioeconômicas como principal determinante das desigualdades em saúde. Em particular, o papel desempenhado pela renda no surgimento e perpetuação dessas desigualdades aparece como principal linha de investigação em decorrência de diversos veículos pelos quais a renda pode afetar a saúde.

Indivíduos com renda maior podem desfrutar de melhores condições de nutrição, saneamento e cuidado médico. Por outro lado, a saúde também afeta a renda, uma vez que indivíduos com saúde precária têm baixa produtividade e menor probabilidade de alcançar maiores rendimentos.

Marmot (2005) mostra que a renda influencia a saúde por três caminhos: o produto nacional bruto dos países, a renda dos indivíduos e a desigualdade de renda dentro de nações ricas e de áreas geográficas. Para Marmot, se a renda tem um efeito importante na saúde dois tipos de evidências são relevantes, a relação da renda para a saúde entre e dentro de países e a relação da desigualdade de renda para saúde. Os dois tipos de evidências são encontradas na literatura de economia da saúde no Brasil.

Evidências no primeiro sentido são mostradas em Diaz (2003) por meio da mensuração de desigualdades socioeconômicas em saúde e da comparação internacional com outros dez países. Os resultados obtidos mostram que indivíduos em posição inferior na distribuição de renda possuem pior avaliação do estado de saúde autoavaliado e que, apesar dos acentuados contrastes sociais do Brasil, a concentração em saúde no Brasil em razão da renda está situada na mesma faixa daquela apresentada por Estados Unidos, Canadá e Reino Unido. Esse resultado foi explicado pelas diferenças na percepção da própria saúde decorrente do ambiente em que o indivíduo está inserido, bem como do nível de conhecimento e de informações disponíveis.

Em relação à desigualdade de renda não existe consenso na literatura a respeito do papel desempenhado pela desigualdade de renda na desigualdade em saúde no Brasil (MESSIAS, 2003; SZWARCWALD et al., 1999). Em análise mais recente, Noronha e Andrade (2008) encontram evidências de que indivíduos residentes em unidades da Federação com menor desigualdade de renda possuem melhor avaliação de seu estado de saúde, embora o efeito da distribuição de renda sobre a saúde seja de pequena magnitude. 
Essas evidências mostram que as desigualdades em saúde relacionadas à renda constituem iniquidades por serem passíveis de serem evitadas e decorrentes de causas injustas. Assim, o acesso desigual a serviços de cuidados de saúde relacionado à renda, representa uma limitação à capacidade dos indivíduos de adquirem boa saúde. Tendo em vista que a renda representa um fator capacitante ao acesso a serviços de saúde, os países aplicam princípios distributivos em suas políticas de saúde como forma de alcançar a equidade.

De acordo com esses princípios, o financiamento de serviços de saúde deve ser realizado de acordo com a capacidade de pagamento e a utilização deve ser baseada nas necessidades de cuidado. Como o objetivo da equidade no financiamento é a distribuição equitativa de cuidados na população, a análise da equidade apresentada a seguir se deterá as violações do princípio da equidade na utilização de serviços de saúde.

A equidade na utilização requer igualdade no uso para indivíduos com necessidades iguais, independentemente de características de não necessidade que afetam o uso. Esse princípio é conhecido como equidade horizontal na utilização de serviços de saúde, sendo extensamente empregado nas comparações internacionais do cumprimento da equidade.

Para mensurar as iniquidades, são empregados principalmente índices de iniquidade horizontal ${ }^{3}$ (WAGSTAFF; van DOORSLAER, 2000). Outra opção é testar a hipótese nula de ausência de iniquidade horizontal estimando-se uma função demanda da utilização de serviços de saúde por grupos de renda (CAMERON et al.,1998).

Pohlmeier e Ulrich (1995) e Gerdtham (1997) mostraram que o teste para a hipótese de equidade baseado na estimativa de funções demanda por grupo de renda deve ser realizado por modelos de duas partes, uma vez que a decisão de utilização é um processo realizado em etapas (probabilidade de receber cuidado e quantidade de cuidado recebido). Segundo Pohlmeier e Ulrich (1995) as duas etapas da utilização devem ser tratadas de forma distinta, sob pena dos resultados conduzirem a sérios erros de interpretação. Esse argumento foi corroborado por Gerdtham (1997) que, com base

\footnotetext{
${ }^{3}$ Os índices de iniquidade horizontal consideram como iniquidade a desigualdade relacionada à renda remanescente após a padronização por características de necessidade de uso (idade, gênero e fatores de morbidade).
} 
em dados para a Suíça, comprova que os determinantes do uso afetam de forma diferenciada cada etapa da decisão.

Desse modo, espera-se que a influência da renda na desigualdade varie não apenas em função do tipo de serviço (clínico geral, especialidade médica, internação hospitalar, dentre outros), mas também em relação à etapa em que os serviços são utilizados. O paciente aparece naturalmente como o responsável pela decisão inicial de contato e os contatos subsequentes são, em grande parte, direcionados pelo profissional de saúde, que estabelece o tipo e a quantidade de tratamento recebido pelo paciente.

Em estudos para países membros da União Europeia e da OCDE (Organização para a Cooperação e Desenvolvimento Econômico), normalmente, se encontra o fato de que a probabilidade de contato inicial com um clínico geral não recebe muita influencia da renda, aparecendo como igualmente distribuída de acordo com as necessidades. Nos serviços de especialidade médica, entretanto, frequentemente, são observadas desigualdades relacionadas à renda na probabilidade de contato após feito o controle por diferenças de necessidade de uso.

O retrato da desigualdade se altera um pouco na segunda etapa, quando são analisados os contatos subsequentes ocorridos após a primeira visita. Depois de controlar pelas necessidades de uso, a desigualdade na frequência de visitas ao clínico geral, quando estatisticamente significante, mostra-se favorável aos mais pobres. Por sua vez, a frequência de uso de serviços de especialidade médica, na maioria das vezes, é estatisticamente significante e favorável aos mais ricos.

Esses resultados podem ser parcialmente atribuídos às características da entrega dos sistemas de saúde que, geralmente, promovem o acesso universal ao uso de serviços de clínico geral e tem participação menor na entrega de serviços especializados onde é maior a participação dos seguros de saúde ${ }^{4}$. O exame da utilização total desses dois tipos de cuidados ratifica o padrão de desigualdade pró-pobre no uso de serviços de clínico geral e de desigualdade pró-rico para o uso de especialidades médicas.

Em estudo para 12 países da União Européia, van Doorslaer, Koolman e Jones (2004) encontraram substancial iniquidade no uso total (contato inicial mais contatos

\footnotetext{
4 Em geral, nos países da OCDE o encaminhamento ao especialista acontece pelo clínico geral (gatekeeper), resultando em um certo tipo de limitação às visitas ao especialista pelos usuários do sistema público. Essa restrição não é enfrentada pelo grupo mais rico que pode pagar pelo serviços de especialidades do próprio bolso (ou por meio dos seguros de saúde).
} 
subsequentes) de visitas ao clínico geral, que, em oito países, estão concentradas nos grupos mais pobres. Na Bélgica e na Irlanda, os dois países com maior grau de iniquidade, havia discriminação pró-pobre do sistema de saúde, como taxas de copagamento menores para os grupos de renda mais baixa. Apenas para Áustria, Dinamarca, Portugal e Países Baixos, a hipótese de nenhuma iniquidade no uso total não foi rejeitada.

Iniquidades pró-rico são observadas para o uso total de especialidade em quase todos os países estudados, exceto Luxemburgo e Bélgica. Enquanto Luxemburgo foi considerado um caso particular, a distribuição mais igual da Bélgica pode ser atribuída a uma discriminação positiva em relação aos grupos de baixa renda por meio de taxas de copagamento. Portugal e Irlanda tiveram os graus mais elevados de iniquidade. Na Irlanda, o elevado grau de iniquidade está intimamente relacionado a um sistema de saúde duplo relacionado ao nível de renda que incrementa a compra de seguros privados dos grupos de renda mais alta para cobrir as despesas com serviços de especialidade. Em Portugal, além de uma alta parcela da população pagar do próprio bolso (ou por seguros de saúde) pelos serviços especializados, nas áreas mais pobres, o acesso também é restringido pela desigualdade geográfica na distribuição de especialistas.

Van Doorslaer e Masseria (2004) incluem também na análise de iniquidade, a utilização de cuidado hospitalar e as visitas para cuidado bucal. Em muitos dos países estudados não se encontrou evidência de violação da hipótese de nenhuma equidade no uso total de internação. Esse resultado foi parcialmente atribuído a uma distribuição mais simétrica das necessidades de internação. Os países onde foram observadas iniquidades; no entanto, puderam ser divididos em dois grupos, um com iniquidade favorável aos mais ricos e outro com iniquidade favorável aos mais pobres. Não foi possível, porém, identificar as fontes dessas diferenças entre os grupos de renda. Em relação às visitas para cuidado bucal, os autores encontraram iniquidade relativamente elevada a favor dos mais ricos para todos os países, mas com substancial variação entre o grau de iniquidade.

Analisando a utilização de serviços de clínico geral e de serviços especializados (incluindo internação hospitalar) de 21 países da OCDE, van Doorslaer, Masseria e Koolman (2006) encontraram pouca evidência de iniquidade em relação ao primeiro tipo de cuidado médico e, que, quando observada, essa favorece o uso pelos mais 
pobres. Em todos os países analisados, porém, a probabilidade de obter cuidado especializado foi significativamente maior entre pessoas de renda mais elevada, mesmo após serem controladas as diferenças nas necessidades de uso. Esse fenômeno foi maior nos países onde os seguros de saúde e os pagamentos do próprio bolso desempenham um papel relevante no acesso aos serviços especializados.

No Brasil, a atuação suplementar da iniciativa privada na entrega de serviços de saúde também pode ser considerada um elemento-chave da desigualdade na utilização, à medida que amplia a expectativa de utilização dos que possuem melhor condição econômica. De acordo com Andrade e Maia (2009) existe sobreutilização dos usuários de planos de saúde em relação aos usuários do SUS, resultando em risco moral no mercado de seguros privados. Como ressaltado por Jones, Koolman e van Doorslaer (2006), isso corresponde a um dos canais pelos quais os seguros privados podem induzir a uma desigualdade pró-rico na utilização.

Outro aspecto relevante da desigualdade na entrega no Brasil são as desigualdades regionais, que envolvem tanto a dimensão da oferta, decorrente da desigualdade na distribuição geográfica de recursos humanos e físicos, quanto da demanda, resultante da disparidade de renda regional ${ }^{5}$. Almeida et al. (2000) mostraram que, não obstante as medidas regulatórias para aumento da eficiência e redução das desigualdades, a entrega de serviços de cuidados de saúde permanece extremamente desigual dentro do País, encobrindo não apenas uma dimensão socioeconômica, mas também geográfica.

Travassos et al. (2000) analisaram as desigualdades sociais na utilização para três grupos de renda e para pessoas com e sem plano de saúde, com base nas PPV (Pesquisa de Padrões de Vida) de 1989 e 1996/1997. Os resultados apontaram para um aumento do consumo de serviços de saúde por tercil de renda nas regiões Nordeste e Sudeste, controlado por idade, sexo e características de morbidade. Eles mostram ainda que durante esse período a razão das taxas de utilização entre o Sudeste e o Nordeste diminuiu, sugerindo uma queda nas desigualdades regionais. Além disso, a probabilidade de uso de serviços de saúde, controlando por idade, sexo e morbidade, é consideravelmente maior entre pessoas cobertas por planos de saúde do que entre as não cobertas (66\% no Nordeste e $73 \%$ no Sudeste).

\footnotetext{
${ }^{5}$ Van Doorslaer e Masseria (2004) argumentam que disparidades regionais são particularmente relevantes na explicação da desigualdade no uso em países com desigualdade no nível de renda.
} 
Em estudo mais recente, Travassos, Oliveira e Viacava (2006) avaliaram e compararam o padrão de desigualdade geográfica e social no acesso a serviços de saúde no Brasil com dados das PNADs (Pesquisa Nacional por Amostra de Domicílios) de 1998 e 2003. Os resultados encontrados em Travassos et al (2000) são confirmados: o acesso à saúde no Brasil é intensamente influenciado pela condição socioeconômica e pelo local de residência, significando que pessoas com melhor condição econômica e moradoras de regiões mais desenvolvidas tem maiores chances de terem acesso a serviços de saúde do que aqueles que vivem em regiões menos desenvolvidas e com baixa condição econômica. Ao contrário de Travassos et al. (2000), entretanto, os autores encontraram uma redução nas desigualdades sociais e um aumento das desigualdades regionais entre o período de 1998 e 2003.

Noronha e Andrade (2002) e Palermo, Portugal e Souza (2005) investigaram a desigualdade no cuidado com base na utilização dos serviços de consultas médicas e internações hospitalares nas regiões Sul e Sudeste. Em ambas as regiões, após se controlar por características de demanda e oferta do processo de decisão, de uma forma geral, há incremento na probabilidade de consultar um médico à medida que se avança no decil da renda. Por outro lado, a probabilidade de ser internado diminui com a renda. $\mathrm{Na}$ segunda etapa, os resultados foram menos sensíveis ao nível de renda; entretanto, normalmente, a frequência do uso de consultas médicas é maior entre os grupos mais ricos, enquanto os mais pobres possuem maior frequência de internação.

$\mathrm{Na}$ literatura internacional, aos trabalhos que mensuraram a iniquidade se seguiu uma série de estudos que tinham como propósito específico analisar as fontes dessa iniquidade, com destaque para os determinantes sociais. A maioria deles se baseia na decomposição dos determinantes da desigualdade na utilização.

Wagstaff, van Doorslaer e Watanabe (2003), por exemplo, procuraram avaliar as causas das desigualdades na malnutrição no Vietnã. Eles mostraram que as desigualdades entre as distribuições de renda em uma variável saúde de interesse são decorrentes de seus determinantes, portanto, podem ser decompostas em contribuições relativas das variáveis explicativas.

De fato, Gravelle (2003) demonstra que o índice de concentração (medida mais usada para estimativa de desigualdades sociais em saúde) pode ser expresso como uma função de uso individual, em que a desigualdade relacionada à renda é afetada por 
variáveis com efeito direto sobre o cuidados de saúde e que são correlacionadas com a renda.

Van Doorslaer, Xander e Jones (2004) aplicam o enfoque de decomposição para explicar diferenças na utilização de serviços médicos relacionados à renda em 12 países europeus. Esse enfoque, contudo, foi inicialmente desenvolvido para modelos lineares (WAGSTAFF; van DOORSLAER; WATANABE, 2003), mas a utilização de serviços de cuidado deve ser representada por modelos não lineares em decorrência da natureza de contagem dos dados (CAMERON; TRIVEDI, 1986; CAMERON et al.,1988; POHLMEIR; ULRICH, 1994; GERDTHAM, 1997), com o que é sugerido que seja realizada uma aproximação linear pela representação de efeitos marginais.

Van Doorslaer e Masseria (2004) também usaram o enfoque da decomposição para explicar os determinantes das desigualdades em cuidados de saúde, mas fazem a opção por modelos lineares. Os autores argumentam, que embora van Doorslaer et al. (2000) tenham mostrado que os modelos de duas partes estimados por mínimos quadrados produzam resultados muito diferentes dos modelos não lineares, os índices de iniquidade estimados por mínimos quadrados não se diferenciaram de forma significativa daqueles estimados por modelos não lineares.

Não obstante o método de estimação, os dois trabalhados mostraram resultados muito similares: contribuição da renda favorável à utilização de serviços de clínico geral pelos mais pobres e, em geral, desigualdade pró-rico (favorável aos ricos) dos serviços especializados. Outros determinantes sociais também exerceram contribuições relevantes para a desigualdade. Em vários países, a educação contribuiu para uma distribuição pró-rico do uso, ao passo que a condição de atividade no mercado de trabalho em geral exerce uma contribuição pró-pobre. Apareceram ainda como relevantes as contribuições dos seguros de saúde e das disparidades regionais, referidas pelos autores como as de maior relevância, por serem alvo direto de políticas de saúde.

A despeito da persistente desigualdade na utilização de cuidados de saúde observada no Brasil, a investigação de suas causas por meio da contribuição dos determinantes da utilização permanece como uma lacuna na literatura de economia da saúde no Brasil. 


\subsection{As CARACTERÍSTICAS DOS SISTEMAS DE SAÚDE ESTÃo RELACIONADAS COM AS DESIGUALDADES NA UTILIZAÇÃo?}

Uma questão que surge naturalmente dessas evidências está relacionada ao papel que as características dos sistemas de saúde exercem nesses resultados. As evidências para os países da OCDE sugerem que o padrão de iniquidade é mais um fenômeno geral do que resultado das características dos sistemas de saúde, embora algumas particularidades de cada sistema de saúde possam ser apontadas como responsáveis pelas diferenças no grau de iniquidade na utilização dos serviços de saúde entre esses países.

A maioria dos países-membros da OCDE oferta acesso universal a cuidados médicos básicos com o objetivo comum de alcançar a equidade na distribuição de cuidados de saúde. Para o provimento da cobertura de cuidados primários básicos são realizados vários arranjos institucionais, Paris, Devaux e Wei (2010) apontam diferenças na forma de organização dessa cobertura, baseados em survey para 29 países da OCDE:

- $\quad$ Em 13 países, a cobertura é automática para a população inteira e financiada por meio de impostos (Austrália, Canadá, Dinamarca, Finlândia, Islândia, Irlanda, Itália Nova Zelândia, Noruega, Portugal, Espanha, Suécia e Reino Unido). Em alguns deles, a entrega acontece sem qualquer contrapartida financeira por parte do usuário, mas em outros existem taxas de copagamentos pelo uso dos serviços.

- Noutro grupo, a cobertura ocorre na forma de seguro social compulsório para toda ou quase toda a população com financiamento por contribuições sociais relacionadas à renda, frequentemente, complementadas com contribuições do governo. Nesse grupo estão dez países: Áustria, Bélgica, França, Alemanha, Grécia, Hungria, Japão, Coreia, Luxemburgo e Polônia.

- $\quad$ Nos Países Baixos e na Suíça, o seguro de saúde também é compulsório para todos os residentes, mas o financiamento não ocorre por contribuições sociais. Indivíduos pagam prêmios comuns a fundos de seguros privados concorrentes. Para garantir o acesso universal, o mercado de seguros é fortemente regulado pelo governo, que atua na correção de falhas de mercado e na equalização dos riscos entre os seguros privados necessária para gerir custos e ricos.

- $\quad \mathrm{Na}$ Eslovênia e na República Checa, os trabalhadores possuem seguro de saúde obrigatório financiado por empregados e empregadores. O restante da população é 
coberta por pagamentos diretos do governo nacional para as companhias de seguro em nome dos beneficiários.

- $\quad$ O México possui mais da metade da população coberta pela seguridade social, $20 \%$ com coberta por Seguro Popular, programa de saúde direcionado para a população sem cobertura da seguridade social, e $1 \%$ com cobertura privada voluntária.

- A Turquia, que ainda está caminhando para a cobertura universal, possui um sistema de saúde misto dominado pela cobertura obrigatória pela seguridade social que cobre uma parcela da população, enquanto o restante permanece sem seguro.

- Os Estados Unidos não responderam ao survey, mas, Denavas-walt, Proctor e Smith (2011), com base em dados do censo estadunidense de 2010, mostram que a cobertura de saúde norteamerica é principalmente providenciada por seguros de saúde privados. Em 2010, a taxa de cobertura privada era de 64,0 \% da população, dos quais 55,3 \% possuíam plano de seguro de saúde baseado no vínculo empregatício. Outra parcela da população é coberta por programas como o Medicare, que oferece cobertura para pessoas acima de 65 anos (em 2010, esse programa cobriu 14,5\% da população) e o Medicaid que assegura cobertura para população de baixa renda (em 2010, 15,9 \% da população foi benefiada pelo Medicaid).

De forma geral, as diferenças regionais, a cobertura suplementar e/ou duplicativa dos serviços de saúde, o tratamento diferenciado entre grupos de renda e a baixa cobertura por um sistema público de saúde funcionam como barreiras sociais ao acesso a serviços de cuidados de saúde, portanto, são as cararacterísticas dos sistemas que possuem maior potencial para influenciar o desempenho da equidade

As diferenças regionais na organização da entrega em vários países podem providenciar desigualdade na distribuição geográfica dos serviços de cuidados. Nessa categoria, se enquadram Portugal, Itália e Espanha, onde a entrega dos serviços de saúde pública está organizada de forma descentralizada com substancial variação regional na provisão de cuidados com a saúde (OLIVEIRA; BEVAN, 2003; MASSERIA; GIANNONI, 2007; GRANADOS; AGUILERA; MARTÍN, 2007).

Em vários países da OCDE, a cobertura primária básica é complementada por uma fonte secundária, que pode ser complementar, suplementar ou duplicativa. O impacto da cobertura secundária sobre a equidade depende do papel exercido na entrega. As coberturas privadas complementares ou suplementares possuem potencial para melhorar o acesso ao cuidado, mas desigualdades de acesso podem persistir em razão do acesso desigual aos seguros privados. Enquanto, isso, seguros privados 
duplicativos aumentam as iniquidades no acesso e, frequentemente, incrementam os gastos em saúde e aumentam a utilização dos serviços (PARIS; DEVAUX; WEI, 2010).

Em alguns países, o tratamento diferenciado entre grupos de baixa e alta renda para o mesmo nível de necessidade aparece como um dos fatores relevantes nas diferenças de equidade. $\mathrm{O}$ impacto da renda na utilização é maior entre países onde o custo financeiro do acesso difere por nível de renda. Como exemplo, podem ser citadas: a isenção ou taxas diferenciadas sobre a partilha dos custos para os grupos de renda mais baixa na Bélgica e Irlanda, que contribuem para uma maior utilização dos serviços de clínico geral entre esse grupo, e o elevado grau de desigualdade em cuidados nos Estados Unidos em razão da acentuada concentração de indivíduos não segurados entre os grupos de baixa renda ${ }^{6}$.

A despeito da variedade de arranjos institucionais para o provimento de serviços de saúde, a maioria das evidências de desigualdades relacionadas à renda aparece como tendência geral para os países industrializados, onde as características da entrega de cuidado respondem mais pelas diferenças no grau de iniquidade entre países. Um exemplo desse fenômeno pode ser dado pela presença de iniquidades no uso de serviços de especialidade encontrada em quase todos os países da OCDE.

Uma das hipótese usadas para explicar o padrão de iniquidade pró-rico no uso de serviços de especialista é a de que a necessidade de consultar um clínico geral (gatekeeper) para ter acesso a uma consulta com especialista no sistema público de saúde induz a uma menor utilização de especialistas pelos grupos mais pobres. As evidências empíricas, entretanto, não sustentam essa hipótese, uma vez que nem todos os países com gatekeeper apresentam desigualdade na utilização de especialistas favorável aos grupos de renda mais alta (van DOORSLAER; MASSERIA, 2004).

Outra explicação reside no fato de que a maior probabilidade dos grupos de renda mais alta possuir cobertura privada suplementar para um acesso melhor e mais rápido aos serviços de saúde pode não apenas influenciar a decisão de uso dos serviços de especialidade, mas também incentivá-la. Jones, Koolman e van Doorslaer (2006), em estudo realizado para quatro países europeus - Irlanda, Itália, Portugal e Reino Unido comprovam que a probabilidade de ter seguros de saúde privados aumenta com a renda

\footnotetext{
${ }^{6}$ Países com seguro público de saúde possuem maior equidade na utilização do que países em que a oferta é estruturada com base em seguros privados (van DOORSLAER; WAGSTAFF, RUTTEN, 2000; van DOORSLAER; MASSERIA; KOOLMAN, 2006)
} 
e que os seguros possuem associação positiva com a probabilidade de visitar especialistas, o que implica uma contribuição positiva dos seguros privados para a iniquidade horizontal pró-rico no uso de visitas a especialistas.

Tal fato reforça a importância dos fatores sociais como determinantes relevantes das iniquidades na utilização, ao mesmo tempo em que pode explicar a presença de iniquidades em sistemas com cobertura universal abrangente. Nunes et al. (2001, p. 19) argumentam que "a igualdade no direito de acesso, uma característica dos modelos denominados sistema único, ou serviço nacional de saúde ..., não assegura por si só o uso equânime dos meios de prevenção e tratamentos colocados a disposição da sociedade". Sob esse aspecto, citam, como exemplo, o caso britânico, em que as desigualdades em saúde se acentuaram após a instalação do Serviço Nacional de Saúde (NHS).

\subsubsection{A SAÚDE PÚBLICA No BRASIL: O SURGIMENTO DO SUS}

Antes do direito à saúde ser uma garantia de todos os cidadãos brasileiros, apenas as ações de promoção de saúde e prevenção de doenças (campanhas nacionais de vacinação, postos e centros de saúde, pequenos hospitais) eram dirigidas a toda a população em caráter universal. Ações de assistência médico-hospitalar eram prestadas pelo Ministério da Saúde e por instituições filantrópicas, mas somente à parcela da população definida como indigente.

A grande intervenção estatal na área de saúde no Brasil ocorria pelo Instituto Nacional de Previdência Social (INPS) criado em 1966 para unificação dos Institutos de Aposentadorias e Pensões (IAPS) do qual eram associadas diferentes categorias profissionais organizadas. Desse modo, as ações de assistência médico-hospitalar (unidades ambulatoriais especializadas e hospitais de maior complexidade) da previdência social eram dirigidas apenas a trabalhadores do mercado de trabalho formal, enquanto o restante da população ficava sem cobertura de saúde.

Com a criação do Ministério da Previdência e Assistência Social em 1974, o INPS foi desmembrado em mais duas instituições, o Instituto de Administração Financeira da Previdência e Assistência Social (IAPAS) ${ }^{7}$ e o Instituto Nacional da Assistência Médica da Previdência Social (INAMPS), ao qual foi atribuída a

\footnotetext{
${ }^{7}$ Em 1990, o INPS e o IAPAS são fundidos na criação do INSS (Instituto Nacional do Seguro Social) vinculado ao Ministério da Previdência Social.
} 
responsabilidade pela prestação de serviços de assistência médico-hospitalar aos associados da previdência (trabalhadores vinculados a diversas categorias profissionais contribuintes da previdência social).

Desse modo, a assistência médico-hospitalar prestada pelo INAMPS continuava a beneficiar apenas os trabalhadores do mercado de trabalho formal e seus dependentes, tornando a população brasileira segmentada em relação à assistência à saúde em: contribuintes da previdência e seus dependentes que recebiam atendimento pelo INAMPS $^{8}$, os que podiam pagar do próprio bolso pela assistência e os que não tinham direito à assistência.

O foco da assistência nos participantes do mercado de trabalho formal produzia a concentração da oferta nos grandes centros urbanos onde se concentrava a massa de trabalhadores. Para estabelecer a rede de assistência, o INAMPS aplicava recursos nos estados de modo mais ou menos proporcional ao volume de recursos arrecadados e ao número de beneficiários. Em virtude do modelo de assistência vinculado à atividade econômica, a oferta de serviços de saúde ficou marcada por disparidades regionais. Assim, os estados de regiões mais desenvolvidas concentravam maior aplicação de recursos do que os estados de regiões mais pobres.

Tabela 2.1 - Desigualdades regionais nos gastos com assistência a saúde no Brasil 1986

\begin{tabular}{lrr}
\hline Região & $\begin{array}{c}\text { Gasto da região sobre gasto } \\
\text { total do País (\%) }\end{array}$ & \multicolumn{2}{c}{$\begin{array}{c}\text { População da região sobre } \\
\text { população total }\end{array}$} \\
\hline Norte & 2,27 & 5,48 \\
Nordeste & 18,10 & 28,82 \\
Sudeste & 59,28 & 43,79 \\
Sul & 15,14 & 15,12 \\
Centro-Oeste & 5,02 & 6,78 \\
\hline
\end{tabular}

Fonte: INAMPS/Secretaria de Planejamento / DIS - 1987 extraído de Souza (2002, p. 26).

Na tabela 2.1, apresenta-se uma comparação entre os recursos aplicados pelo INAMPS e a distribuição da população em âmbito regional para o ano de 1986. Verifica-se uma clara concentração dos gastos nas regiões mais ricas. A região Sudeste, por exemplo, abrigava $43,8 \%$ da população e recebia aproximadamente $60 \%$ dos recursos transferidos pelo INAMPS aos estados para o custeio de unidades próprias e para a compra de serviços na iniciativa privada por meio de convênios.

\footnotetext{
${ }^{8}$ Além do INAMPS, existiam regimes especiais de assistência criados para militares e funcionários públicos e sistemas complementares de previdência criados para executivos de grandes empresas estatais.
} 
O agravamento das desigualdades de acesso aos serviços de cuidados de saúde decorrente tanto da discriminação do atendimento entre beneficiários e não beneficiários da previdência social quanto da concentração da oferta dos serviços públicos nos grandes centros urbanos motivou uma série de estudos com o objetivo de demonstrar a inadequação do modelo de saúde pública vigente ao atendimento das necessidades da população.

O contexto de repressão política e de censura à imprensa, entretanto, restringiram os resultados desses estudos ao meio acadêmico. Somente em meados dos anos 70, esses estudos começaram a se tornar públicos pela ação de movimentos sociais que, em consonância com a comunidade acadêmica, reivindicavam uma reforma sanitária cujos principais objetivos eram a unificação institucional e a descentralização da ação estatal como passos para a universalização do atendimento.

Dentre as principais medidas da reforma sanitária da década de 1980, se destaca a instituição do Sistema Unificado e Descentralizado de Saúde (SUDS), implantado por meio de convênios entre o INAMPS e os governos estaduais. Nesse período, o INAMPS passou a estabelecer convênios com os governos estaduais e municipais para a prestação de atendimento em caráter universal nas unidades das secretarias estaduais e municipais de saúde.

A unificação institucional consistia no passo mais ousado da reforma no qual se pretendia a incorporação do INAMPS ao Ministério da Saúde.. Essa incorporação, no entanto, só aconteceu no início da década de 1990, pelo Decreto n 99.060 , de 7 de março. Desde então, o INAMPS passou a ser encarregado de prestar assistência integral independentemente de vínculo empregatício.

Os primeiros avanços em relação à descentralização foram iniciados em meados da década de 1970 como resposta à crise financeira da previdência. A descentralização visava à eficiência pela alocação dos recursos segundo as necessidades locais e à ampliação da participação popular em todos os níveis de decisão da política de saúde.

A participação popular na gestão e execução da política de saúde foi garantida pela instituição de duas instâncias colegiadas: a Conferência Nacional de Saúde (realizada a cada quatro anos) e o Conselho Nacional de Saúde (de caráter permanente e deliberativo). Para alcançar uma gestão mais eficiente, foi estabelecido o Fundo de 
Saúde $^{9}$ em cada esfera de governo que tinha como finalidade o depósito e a movimentação financeira dos recursos transferidos pelo SUS.

Nesse contexto de reforma sanitária e de redemocratização do País, o movimento sanitarista conseguiu sua maior conquista dada pela Constituição Federal de 1988 que estabeleceu, em seu Art. 196, "a saúde como direito de todos e dever do Estado ... e o acesso universal e igualitário às ações e serviços para sua promoção, proteção e recuperação. Para o cumprimento dessa garantia, foi instituído o Sistema Único de Saúde (SUS), por meio das leis $8.880 / 90^{10}$ e $8.182 / 90^{11}$, que tratam da reorganização das ações e serviços de saúde quanto à direção e à gestão e ao financiamento, conforme disposto no Art. 198 da CF/88.

Tabela 2.2 - Utilização/Acesso a Serviços de Saúde - 1998, 2003 e 2008

\begin{tabular}{lrrr}
\hline Indicadores de Utilização/Acesso & 1998 & 2003 & 2008 \\
\hline \% de pessoas com principal atendimento pelo SUS & 49,3 & 57,2 & 56,5 \\
\% de pessoas com principal atendimento por plano de saúde & 24,5 & 24,6 & 25,9 \\
Consultas médicas per capita ${ }^{(1)}$ & 2,17 & 2,60 & 2,60 \\
Consultas odontológicas per capita ${ }^{(1)}$ & 0,36 & 0,30 & 0,52 \\
\% de consultas médicas pelo SUS & 52,7 & 60,2 & 61,1 \\
\% de consultas odontológicas pelo SUS & 24,2 & 29,5 & 29,5 \\
Internações/100 habitantes & 6.9 & 7.0 & 7.1 \\
Internações SUS/ 100 habitantes & 4,4 & 4,7 & 4,9 \\
Internações não SUS/ 100 habitantes & 2,5 & 2,3 & 2,2 \\
\hline
\end{tabular}

Fonte: Elaboração da autora com base nas PNADs 1998, 2003 e 2008.

(1) Número de consultas per capita nas duas últimas semanas de referência da PNAD multiplicado por 26.

A extensão do atendimento para toda a população representou o maior ganho do

SUS em relação ao modelo de entrega de cuidado anteriormente vigente. Em 2003, o

SUS passou a responder por mais da metade dos principais atendimentos ${ }^{12}$ de saúde no

País, enquanto a iniciativa privada, financiada por planos de saúde ou por pagamentos diretos do paciente, tiveram sua participação na cobertura do atendimento reduzida (Tabela 2.2).

\footnotetext{
${ }^{9}$ A criação do Fundo de Saúde constituiu uma das exigências para que estados, municípios e o Distrito Federal recebessem de forma regular os recursos federais do Fundo Nacional de Saúde para a operacionalização de seus serviços de saúde.

${ }^{10}$ Também conhecida como Lei Orgânica da Saúde, dispõe sobre as condições para a promoção, proteção e recuperação da saúde, a organização e o financiamento dos serviços correspondentes e dá outras providências.

${ }^{11}$ A lei 8.182/90 trata da participação da comunidade na gestão do sistema e à forma e às condições para as transferências intergovernamentais de recursos no âmbito do SUS.

12 A Pnad identifica como principais atendimentos de saúde: consulta médica, consulta odontológica, atendimento de agente comunitário ou parteira, consulta de outro profissional de saúde, atendimento na farmácia, quimioterapia, radioterapia, hemodiálise, ou hemoterapia, vacinação, injeção, curativo, medicação de pressão ou outro procedimento, cirurgia em ambulatório, gesso ou imobilização, internação hospitalar, exames complementares, somente marcação de consulta ou outros atendimentos.
} 
Entre 1998 e 2003, ocorreram os maiores aumentos nos atendimentos do SUS, com destaque para os incrementos no percentual de atendimento de consultas médicas e odontológicas. Observa-se também que, nesse período, o SUS respondeu por mais da metade da prestação de serviços de consultas médicas e internações hospitalares, enquanto os serviços para cuidados odontológicos foram majoritariamente realizados pela iniciativa privada.

Em relação à percepção dos usuários sobre a qualidade dos serviços prestados, observou-se que não houve muita alteração ao longo do período. A maior parte dos usuários considerou os serviços prestados como bom ou muito bom, sendo a qualidade dos serviços não SUS mais bem avaliada do que a dos serviços SUS (Tabela 2.3).

Tabela 2.3 - Qualidade dos Serviços de Saúde - 1998, 2003 e 2008.

\begin{tabular}{llll}
\hline Indicadores de Qualidade de Saúde & 1998 & 2003 & 2008 \\
\hline \% de atendimentos (SUS) considerado bom/muito bom & 80,4 & 80,5 & 80,5 \\
\% de atendimentos (não SUS) considerado bom/muito bom & 92,6 & 93,9 & 94,2 \\
\% de internações (SUS) considerada boa/muito boa & 84,6 & 84,9 & 83,4 \\
\% de internações (não SUS) considerada boa/muito boa & 92,8 & 93,2 & 93,3 \\
\hline
\end{tabular}

Fonte: Elaboração da autora com base nas Pnads 1998, 2003 e 2008. 


\section{Medidas DE DESigualdade DE RENDA APLiCAdAS À DESIGUALDADE EM SAÚDE}

\subsection{MENSURAÇÃo DE DESIGUALDADES SOCIAIS EM SAÚDE}

A mensuração de desigualdades sociais em saúde inicialmente seguiu de perto a mensuração de desigualdades de renda. Como exemplo, Le Grand (1987) recomenda o uso de métodos aplicados na literatura de desigualdade de renda na avaliação de desigualdade em variáveis de saúde. As medidas mais comumente utilizadas na literatura de desigualdade - range, curva de Lorenz e índice de Gini - não são, contudo, adequadas para mensuração de desigualdades socioeconômicas em saúde por não relacionarem diretamente as desigualdades em saúde com desigualdades na condição socioeconômica.

O range, ao comparar indivíduos que estão no topo com os que estão na base da distribuição da variável saúde de interesse, ignora o que está acontecendo com os grupos intermediários. Além disso, não considera o tamanho dos grupos que estão sendo comparados, podendo ensejar uma miscelânea de resultados quando são realizadas comparações ao longo do tempo ou entre unidade espaciais diferentes.

Figura 3.1 - Curva de Lorenz para Saúde

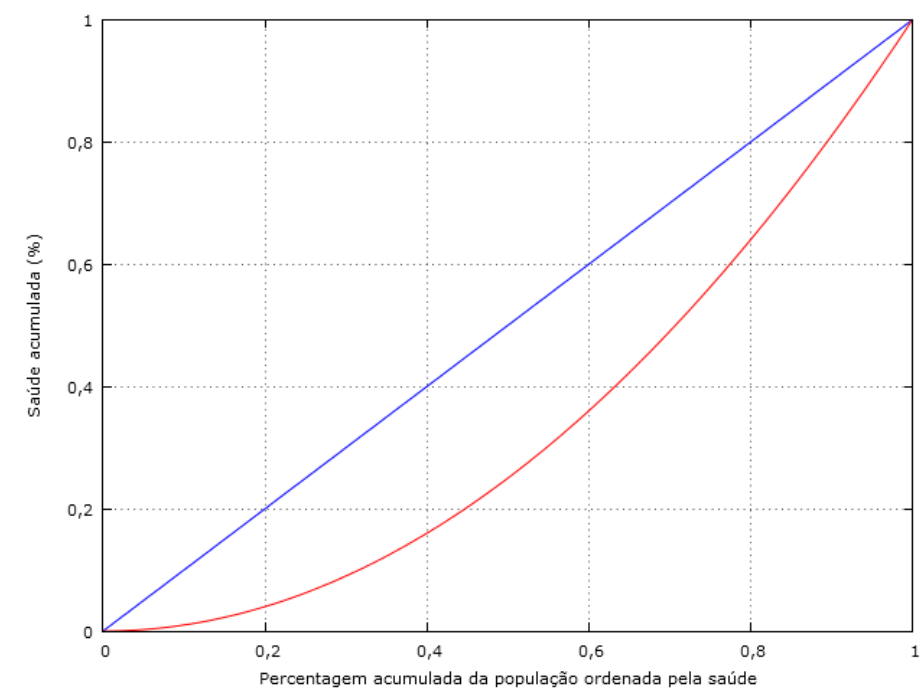

A curva de Lorenz para saúde (Figura 3.1) é uma adaptação da curva de Lorenz para medidas de desigualdades tradicionais. Consiste num gráfico da proporção acumulada da distribuição (começando com a pessoa mais doente e finalizando com a mais saudável) contra a proporção acumulada de saúde. Se a saúde é igualmente distribuída, a curva de Lorenz coincide com a diagonal. Quanto maior a distância entre a curva de Lorenz e a diagonal, maior a desigualdade em saúde. 
O índice de Gini, medida mais popular de desigualdade de renda, corresponde a duas vezes a área entre a diagonal e a curva de Lorenz. Essa medida possui a vantagem de refletir a desigualdade para todas as pessoas e não apenas para os grupos das extremidades da distribuição. Falha, entretanto, como medida de bem-estar social ao não relacionar as desigualdades em saúde às desigualdades socioeconômicas.

Em resenha crítica sobre os métodos de mensuração de desigualdades sociais em saúde, Wagstaff, Paci e van Doorslaer (1991) mostraram que apenas o índice de inclinação (SII), índice de desigualdade relativa (RII) e índice de concentração (IC) devem ser usados na mensuração socioeconômica da desigualdade em saúde, uma vez que apenas essas medidas atendem ao requerimento mínimo de desigualdade ao: (i) refletir a dimensão socioeconômica das desigualdades em saúde; (ii) refletir as experiências da população inteira; e (iii) ser sensível a mudanças na distribuição da população entre os grupos socioeconômicos.

O índice de inclinação (SII) calcula a média da variável saúde de interesse de cada grupo socioeconômico para ordená-los por classe de condição social, definido como a inclinação de uma linha de regressão que mostra a relação entre a variável saúde e sua posição relativa (r) na distribuição socioeconômica. Essa medida é, no entanto, muito sensível à média da variável de interesse, uma vez que se a média da variável saúde dobrar, o SII também dobrará. Dessa forma, as diferenças absolutas dobrarão, enquanto as diferenças relativas permanecerão inalteradas. Isso torna, então, essa medida mais apropriada quando o interesse é capturar mudanças absolutas na variável saúde entre os grupos socioeconômicos.

Quando o interesse são mudanças relativas, o índice de desigualdade relativa (RII) é uma medida mais adequada. Seu valor é obtido dividindo-se o SII pelo nível médio de saúde da população.

Outra forma de capturar desigualdades sociais em variáveis de saúde é dada pelo índice de concentração (IC), que, assim como as medidas anteriormente citadas, mensura a desigualdade em saúde pelo ordenamento dos indivíduos pela condição socioeconômica. Esse índice é obtido de forma similar ao índice de Gini, desenhando uma curva de concentração para a variável saúde de interesse como a proporção acumulada da população (começando com o individuo em maior desvantagem 
socioeconômica e finalizando com aquele em maior vantagem) contra a proporção acumulada de saúde (Figura 3.2).

Figura 3.2 - Curva de Concentração para Saúde

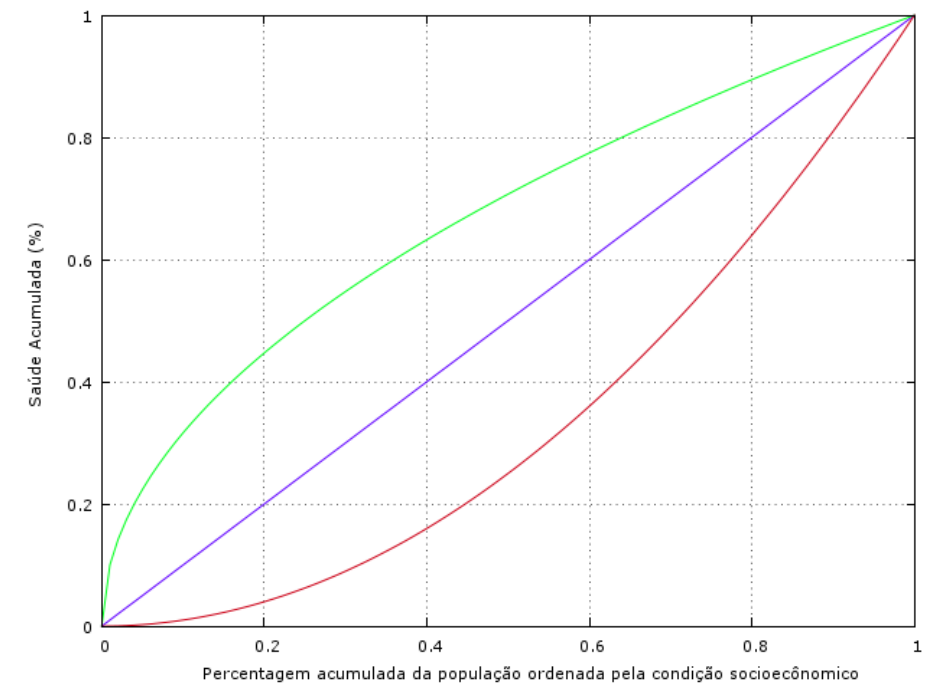

Se a variável de saúde é igualmente distribuída entre os grupos socioeconômicos, a curva de concentração coincide com a diagonal. O $\mathrm{IC}^{13}$ será positivo quando a curva estiver deitada sob a diagonal e negativo quando estiver sobre a diagonal. Se a variável saúde estiver concentrada nas mãos das pessoas em maior desvantagem socioeconômica, o IC assumirá seu valor mais baixo (-1). Se, porém, a variável estiver concentrada nas mãos das pessoas em menor desvantagem socioeconômica; o IC assumirá seu valor mais alto (1). Desse modo, o índice de concentração (IC) para a saúde é definido como duas vezes a área entre a curva de concentração $L(s)$ e a linha de $45^{\circ}$ :

$$
\text { IC }=1-2 \int_{0}^{1} L(s) d s
$$

Por outro lado, a representação do IC em termos da covariância entre a variância da variável saúde e a posição relativa pode ser um meio mais conveniente de computação,

$$
I C=2 \operatorname{cov}(r, y) / \mu
$$

Em que $\operatorname{cov}(\mathrm{r}, \mathrm{y})$ corresponde à covariância entre a posição relativa $(r)$ e o variável de saúde $(y)$, e $\mu$ é a média da variável saúde.

\footnotetext{
${ }^{13}$ O IC conduzirá ao mesmo resultado que o índice de Gini somente se o ordenamento das unidades de análise por saúde for o mesmo da condição socioeconômica, ou seja, o ordenamento das classes por saúde coincidir com o ordenamento por condição socioeconômica.
} 
Nota-se que uma vez que a $\operatorname{cov}(r, y)$ pode ser encontrada por uma regressão de $y$ contra $r$, o IC pode ser reescrito como:

$$
I C=2 \operatorname{var}(r)(\beta / \mu)
$$

Desse resultado, emerge a similaridade entre as três medidas de desigualdades sociais em saúde. Como o RII $(\beta / \mu)$ é igual ao índice de concentração dividido por duas vezes a variância da variável de posição relativa, qualquer uma dessas duas medidas atende aos requerimentos mínimos e são insensíveis a mudanças na média da variável saúde.

Quando se está, porém, interessado em comparações entre unidades geográficas ou ao longo do tempo, a representação visual como desvios da igualdade confere uma vantagem adicional ao IC (WAGSTAFF; PACI; van DOORSLAER, 1991).

\subsection{INTERPRETAÇÃO DE REDISTRIBUIÇÃO PARA O ÍNDICE DE CONCENTRAÇÃO}

Koolman e van Doorslaer (2004) argumentam que, apesar de o índice de concentração (IC) refletir a dimensão socioeconômica da desigualdade em saúde, não fica evidente como seu resultado pode ser usado para fins de política pública. Para isso, sugerem que seja dada uma interpretação de redistribuição a esse índice. A interpretação de redistribuição da variável de interesse é adequada para unidades de saúde, pagamentos de serviços de saúde, número de visitas médicas, dentre outras, com distribuição inteira.

Dada a relação entre covariância e uma regressão de mínimos quadrados ordinários (MQO), o IC pode ser estimado por uma "regressão conveniente", correspondente à regressão de uma transformação da variável saúde contra o rank fracionário da variável classificadora da posição socioeconômica:

$$
\frac{2 \sigma_{r}^{2}}{\bar{y}} y_{i}=\alpha_{1}+\hat{\beta}_{1} r_{i}+\varepsilon_{i}
$$

Em que o coeficiente $\hat{\beta}_{1}$ representa o índice de concentração (IC), $y_{i}$ é a variável saúde de interesse, $\bar{y}=\frac{1}{n} \sum_{i=1}^{n} y_{i}$ é a média dessa variável, $r_{i}$ é o rank fracionário da variável classificadora da posição socioeconômica, $\sigma_{r}^{2}$ é a variância da variável $(r)$. Para a estimativa de $\hat{\beta}_{1}$ deve-se computar primeiramente a variável rank fracionário, definida como

$$
r_{i}=\sum_{j=0}^{i-1} \omega_{j}+\frac{\omega_{i}}{2}
$$


O rank fracionário da posição na condição socioeconômica é definido pela equação (3.5), em que em que $\omega_{i}$ é definido como peso amostral dimensionado para somar 1, com as observações classificadas em ordem crescente da posição na condição socioeconômica, e $\omega_{0}=0$.

Desse modo, Koolman e van Doorslaer (2004) mostraram que, com base na representação do IC pelo $\hat{\beta}_{1}$ pode-se obter um plano de redistribuição linear da variável saúde transformada do lado esquerdo da equação (3.4), que reduzirá $\hat{\beta}_{1}=0$ a zero $(\mathrm{IC}=0)$.

Na Figura 3.3, encontra-se a distribuição linear da posição prevista da variável y transformada que, por definição, passa pelos pontos médios $\left(0.5 ; 2 \sigma_{r}^{2}\right)$. A soma de todos os desvios da média da metade do lado direito da distribuição (área c) é exatamente igual à soma de todos os desvios da média do lado esquerdo da distribuição (área d). Portanto, a igualdade irá requerer que c (e d) seja $(\mathrm{m})$ zero. A área $c /(d+e)$ é a proporção estimada da variável y (transformada) que necessita ser redistribuída da metade mais rica para a mais pobre. Essa área é denominada plano de redistribuição linear $\left(R_{l}\right)$.

Figura 3.3 - Redistribuição linear

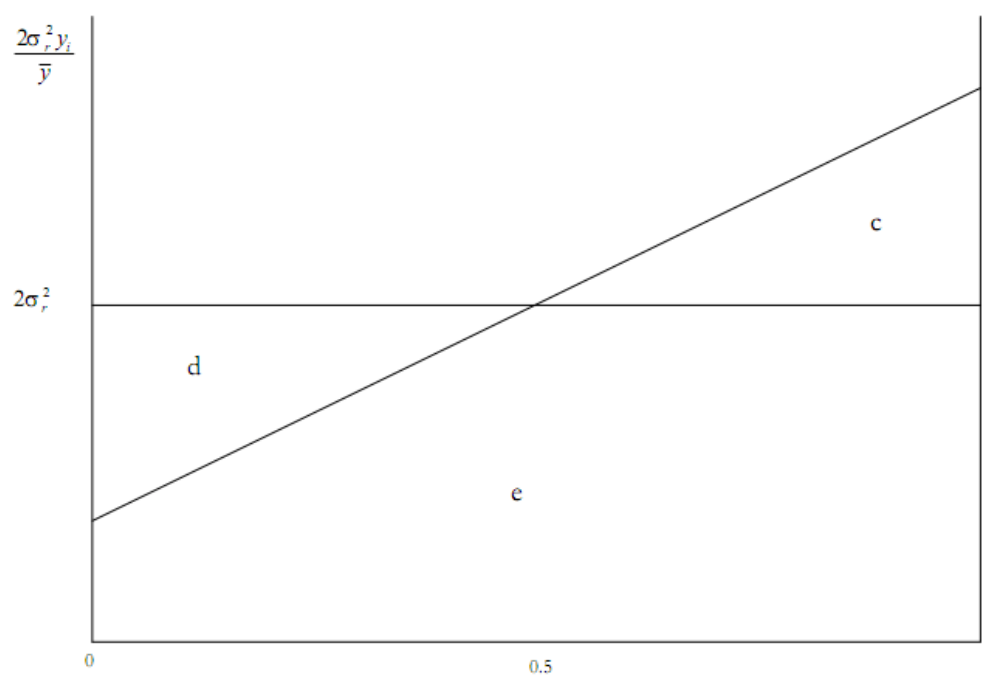

Fonte: Koolman e van Doorslaer (2004, p. 651)

A área c é sempre igual a $1 / 8$ vezes a área $\hat{\beta}_{1}\left(r_{n}-r_{1}\right)$, que para grandes amostras é igual $1 / 8$ vezes o coeficiente de inclinação $\hat{\beta}_{1}$, uma vez que $\operatorname{plim}\left(r_{n}-\right.$ $\left.r_{1}\right)=1$. Tomando esse resultado e a equação (3.4) tem-se que:

$$
R_{l}=\frac{(100 / 8) \widehat{\beta_{1}}}{2 \sigma_{r}^{2}}=\frac{100}{16 \sigma_{r}^{2}} I C
$$


Desde que $|c|<|e|, R_{l}$ varia entre $-50 \%$ e $50 \%$ da variável de interesse transformada $(y)$. Como a variável y transformada do lado esquerdo da equação (3.4) não está em uma escala natural, sua interpretação permanece difícil, o que torna necessário usar o $\operatorname{plim} \sigma_{r}^{2}=1 / 12$ para reduzir a variável transformada a $\frac{1}{6} \frac{y_{i}}{\bar{y}}$. Para encontrar a percentagem de todo y que necessita ser redistribuído, multiplica-se a área c por seis e chega-se a:

$$
R_{l}=\frac{300}{4} \hat{\beta}_{1}=75 I C
$$

Em grandes amostras e com a redistribuição linear de $y$ com relação a $r$, a percentagem a ser linearmente distribuída é igual 3/4 do IC.

\subsection{MENSURAÇÃo DE DESIGUALDADES HORIZONTAIS (INIQUIDADES) NA UTILIZAÇÃo DE CUIDADOS}

O uso de serviços de saúde varia de acordo com as necessidades individuais determinadas por características demográficas e de morbidade. Dessa maneira, a desigualdade estimada com base na equação (3.4) pode estar capturando diferenças nessas variáveis, tornando necessária a padronização dos índices de concentração pelas necessidades de uso. Somente assim é possível a obtenção de uma medida de desigualdade que reflita apenas as desigualdades relacionadas à condição socioeconômica. A padronização, em suma, resulta em uma medida de iniquidade que permite avaliar desigualdades no uso para indivíduos com as mesmas necessidades de saúde.

O primeiro passo para a elaboração dessa medida consiste em estimar a demanda por serviços de saúde. Supondo um modelo de variável explicativa linear tem-se:

$$
y_{i}=\alpha_{1}+\beta_{1} \operatorname{lninc}_{i}+\sum_{j} \delta_{j} x_{j, i}+\sum_{k} \gamma_{k} z_{k, i}+\varepsilon_{i}
$$

Em que a variável dependente, $y_{i}$, é uma variável de utilização do cuidados de saúde (número de consultas médicas/número de internações hospitalares, por exemplo) e as variáveis explicativas são dividas em três tipos: o logaritmo da renda familiar individual $i\left(\operatorname{lninc}_{i}\right)$, um conjunto de $j$ variáveis de necessidade $\left(x_{j}\right)$, características demográficas e de morbidade, e um conjunto de $k$ variáveis $\left(z_{k}\right)$ que representam os determinantes sociais da desigualdade na utilização, por estarem correlacionadas com o uso de cuidados de saúde e com a variável rank da distribuição de renda. 
O logaritmo da renda indica a existência de uma relação côncava entre renda e saúde, ou seja, a saúde tende a crescer com a renda, mas a taxas decrescentes. $\mathrm{O}$ vetor $x_{j}$ contém as variáveis pelas quais se intenta padronizar, enquanto o vetor $z_{k}$ reúne as variáveis pelas quais não se quer padronizar, mas pelas quais é necessário se controlar para evitar um possível viés nos coeficientes das variáveis de necessidades. $\alpha_{1}, \beta_{1}, \delta_{j} \mathrm{e}$ $\gamma_{k}$ representam os parâmetros a serem estimados, enquanto $\varepsilon_{i}$ corresponde ao termo do erro.

A equação (3.8) gera os valores previstos das necessidades, ou seja, o uso esperado do individuo i com base em suas características de necessidade. Combinando as estimativas dos coeficientes obtidos dessa equação com os valores observados de $x_{j, i}$ e com as médias amostrais de $\operatorname{lninc}_{i}$ e de $z_{k}$, chega-se aos valores previstos nas necessidades, ou valores de utilização "x-esperado":

$$
\hat{y}_{i}^{X}=\hat{\alpha}_{1}+\hat{\beta}_{1} \operatorname{lninc}_{i}^{m}+\sum_{j} \hat{\delta}_{j} x_{j, i}+\sum_{k} \hat{\gamma}_{k} z_{k, i}^{m}
$$

Esse valor indica a quantidade de cuidado médico que o individuo deveria receber se fosse tratado como os outros que em média tivessem as mesmas características. A estimativa do uso padronizado pelas necessidades, $\hat{y}_{i}^{I S}$, necessária para o cálculo do índice de iniquidade, será obtida como a diferença entre a utilização efetiva e a utilização "x-esperada" mais a média do $y_{i}$ observado:

$$
\hat{y}_{i}^{I S}=y_{i}-\hat{y}_{i}^{X}+\bar{y}
$$

O valor previsto para o uso padronizado nas necessidades $\left(\hat{y}_{i}^{I S}\right)$ é, então, usado para obter o índice de iniquidade horizontal (ICwv) de WAGSTAFF e van DOORSLAER (2000). Essa medida é calculada da mesma forma que o índice de concentração não padronizado (IC) e possui interpretação similar. Um valor positivo do ICwv indica iniquidade horizontal no uso a favor dos mais ricos, um valor negativo representa iniquidade no uso a favor dos mais pobres e um ICwv igual a zero ou não significante sinaliza a ausência de iniquidade, ou seja, o uso e as necessidades são proporcionalmente distribuídos na distribuição de renda.

\subsection{DECOMPOSIÇÃO DA DESIGUALDADE NA UTILIZAÇÃO DE CUIDADOS}

Supondo que o uso de cuidados de saúde siga um modelo linear, as estimativas das contribuições de cada variável explicativa são obtidas conforme descrito na equação (3.8). Desse modo, dada a relação linear entre $y_{i}$ e os vetores $x_{j}$ e $z_{k}$, Wagstaff, van 
Doorslaer e Watanabe (2003) demonstram que o índice de concentração pode ser decomposto em

$$
I C=\eta_{r} C_{\text {lninc }}+\sum_{j} \eta_{j} C_{x, j}+\sum_{k} \eta_{k} C_{z k}+G C_{\varepsilon} / \bar{y}
$$

Em que o primeiro termo denota a contribuição parcial da desigualdade de renda, o segundo representa a contribuição parcial das variáveis de necessidade, o terceiro a contribuição parcial de outras variáveis e, por fim, o índice de concentração generalizado para o termo do erro, $\varepsilon$. Assim, o índice de concentração previsto no uso de cuidados médicos é igual a uma soma ponderada da desigualdade em cada um de seus determinantes: renda, necessidades, demais determinantes socioeconômicos e um componente residual.

Essa decomposição também mostra que a contribuição de cada determinante para a desigualdade pode ser decomposta em duas partes: (i) seu impacto sobre o uso, medido pela elasticidade, e (ii) seu grau de distribuição desigual entre a renda, medido pelo índice de concentração.

Os índices de concentração de cada determinante são computados seguindo a equação (3.4), enquanto a elasticidade será obtida com base nos coeficientes parciais da elasticidade do uso de cuidado usando os coeficientes da regressão, estimados pela equação (3.8).

As elasticidades do uso de cuidado de cada um dos determinantes de necessidade são definidas como:

$$
\eta_{j}=\delta_{j} x_{j}^{m} / y^{m}
$$

Em que $\delta_{j}$ é o coeficiente da regressão linear, $y^{m}$ é a média ponderada de $y$ e $x_{j}^{m}$ é a média ponderada de $x_{j}$. Essas elasticidades denotam a mudança percentual em $y$ resultante de uma mudança percentual em $x_{j}$. As elasticidades do logaritmo da renda e do conjunto de variáveis de não necessidade, $z_{k}$, são definidas de forma análoga.

No contexto de um modelo linear para o uso de cuidados de saúde, a equação (3.11) também fornece uma estimativa alternativa para a iniquidade horizontal, dada pelo IC menos a soma da contribuição de fatores de necessidade $\left(\sum_{j} \eta_{j} C_{x, j}\right)$.

Um problema da aplicação do enfoque linear de decomposição das variáveis de cuidados de saúde decorre do fato de as medidas de uso normalmente assumirem valores inteiros e não negativos. São assim, por exemplo, o número de consultas médicas e o número de internações hospitalares, o que torna mais apropriado o emprego de modelos não lineares. Uma forma geral para esses modelos pode ser escrita como: 


$$
y_{i}=G\left(\beta_{1} \operatorname{lninc}_{i}+\sum_{j} \delta_{j} x_{j, i}+\sum_{k} \gamma_{k} z_{k, i}\right)+\varepsilon_{i}
$$

Apesar da decomposição não ser diretamente aplicada à equação (3.13), a representação por aproximação linear permite restaurar o arcabouço de decomposição definido na equação (3.11) pela representação de efeitos marginais avaliados na média. Para tanto, é definida uma aproximação de um modelo linear de utilização é como:

$$
y_{i}=\beta_{1}^{m} \operatorname{lninc}_{i}+\sum_{j} \delta_{j}^{m} x_{j, i}+\sum_{k} \gamma_{k}^{m} z_{k, i}+\varepsilon_{i}
$$

Em que $\beta_{1}^{m}$ é o efeito parcial para a renda, $\delta_{j}^{m}$ e $\gamma_{k}^{m}$ são os efeitos parciais para os fatores de necessidade e não necessidades, respectivamente.

Uma particularidade da decomposição para modelos não lineares, entretanto, é a não unicidade das contribuições decorrente da aproximação linear dos efeitos parciais, que são calculados para valores particulares como as médias. Como resultado, a estimativa da iniquidade deduzida pela decomposição (IC menos $\left.\sum_{j} \eta_{j} C_{x, j}\right)$ é ligeiramente diferente daquela obtida pelos ICwv.

O enfoque de decomposição também pode ser útil para explicar diferenças entre unidades geográficas ou ao longo do tempo. A definição do índice de concentração baseada nos determinantes da desigualdade também permite que seja analisado o quanto da mudança no índice de concentração total é atribuído a mudanças nos índices de concentração dos determinantes da desigualdade no uso. Desse modo, Wagstaff, van Doorslaer e Watanabe (2003) sugerem uma decomposição do tipo Oaxaca (1973) para explicar mudanças na desigualdade ao longo do tempo, que também pode ser utilizada para explicar diferenças entre unidades em corte transversal (van DOORSLAER; KOOLMAN, 2004). 


\section{BASE DE DADOS E MÉTODO EMPÍRICO}

\subsection{BASE DE DADOS E DEFINIÇÃO DAS VARIÁVEIS}

A Pesquisa Nacional por Amostra de Domicílio (PNAD) do IBGE (Instituto Brasileiro de Geografia e Estatística) tem como objetivo o levantamento de características socioeconômicas da população, realizando anualmente ${ }^{14}$ o levantamento de informações populacionais em todas as unidades da Federação. Alguns temas possuem periodicidade permanente, como educação, trabalho e rendimentos. Outros são levantados de acordo com as necessidades de informação, possuindo periodicidade variável e sendo abordadas em suplementos como as questões referentes a migração, saúde, fecundidade, dentre outras características da população. As informações referentes ao acesso e utilização de serviços de saúde e ao estado de saúde são coletadas em suplementos de saúde realizados em parceria com o Ministério da Saúde e possuem periodicidade quinquenal desde 1998.

Nos anos 1998 e 2003, as pesquisas cobriram apenas a área urbana da Região Norte, com exceção do Estado do Tocantins que foi retratado em sua totalidade. Desse modo, as informações referentes à Região Norte envolvem apenas a parcela da população que vive na área urbana. Na PNAD 1998 foram entrevistadas 344.975 pessoas em 112.434 unidades domiciliares, enquanto na PNAD 2003 foram pesquisadas 384. 834 pessoas e 133.255 domicílios. A PNAD 2008 incorporou a área rural da Região Norte. Com isso foram pesquisadas 391.868 pessoas e 150.591 unidades domiciliares, distribuídas por todas as unidades da Federação. Em todos os anos, a amostra foi restrita aos indivíduos com dez anos ou mais e com declaração de rendimento.

A utilização dos serviços de consultas médicas é retratada pelas questões "Nos doze últimos meses, consultou médico?" e "Quantas vezes consultou médico nos últimos doze meses?". A primeira questão informa a probabilidade de contato inicial para cuidado médico, enquanto a segunda fornece a frequência do cuidado médico. A soma dessas questões fornece uma medida da utilização total, incluindo os indivíduos que não tiveram nenhum tipo de cuidados de saúde. A utilização de internações é mensurada de forma semelhante: "Nos doze últimos meses, esteve internado?" e "Nos doze últimos meses, quantas vezes esteve internado?”.

\footnotetext{
${ }^{14}$ Com exceção dos anos de realização do Censo Populacional.
} 
A condição socioeconômica será definida pela posição no rendimento mensal familiar per capita (rendimento mensal familiar/número de componentes da família), determinada por uma variável rank do rendimento, que ordena os indivíduos pela posição no rendimento familiar per capita. Não fizeram parte da amostra os indivíduos sem declaração de rendimento.

Para identificação dos determinantes da desigualdade, as variáveis explicativas da utilização foram classificadas em função do tipo de contribuição para a desigualdade: determinantes de necessidade e determinantes sociais ou de não necessidade.

No grupo de variáveis de necessidade, estão as variáveis demográficas e de morbidade. O grupo de não necessidade envolve a dimensão social da utilização. Neste são consideradas variáveis que afetam a utilização diretamente pela relação com a variável rank (calculada com base no rendimento familiar per capita) e com as variáveis de necessidade.

As variáveis demográficas são representadas por 12 dummies específicas sexoidade. Três questões são usada para avaliar a condição de saúde na PNAD: a) De um modo geral, considera seu estado de saúde como muito bom, bom, regular, ruim ou muito ruim; b) Nas duas últimas semanas, deixou de realizar quaisquer de suas atividades habituais por motivo de saúde; e c) Questões referentes as 12 doenças crônicas abordadas nos questionários, algum médico ou profissional de saúde disse que tem... ${ }^{15}$. Essas questões resultaram em quatro dummies para a percepção do estado de saúde individual, uma dummy para a presença de limitação das atividades habituais e, por último, uma dummy para a presença de uma das doze doenças crônicas referidas no questionário.

Foram consideradas como determinantes sociais o logaritmo do rendimento familiar per capita, os anos de estudo, a condição de atividade no mercado de trabalho $^{16}$, a posse de plano de saúde e o local de residência. Assim, foram criadas

\footnotetext{
${ }^{15}$ As doze doenças crônicas abordadas nos questionários são: doença de coluna ou costas, artrite ou reumatismo, câncer, diabetes, bronquite ou asma, hipertensão, doença do coração, insuficiência renal crônica, depressão, tuberculose, tendinite ou tenossinovite e cirrose.

${ }^{16}$ As informações sobre condição de atividade, ocupação e posição de ocupação se referem à semana de referência.
} 
quatro dummies para a escolaridade, nove para situação no mercado de trabalho, uma para posse de plano de saúde e cinco dummies regionais. ${ }^{17}$

Quadro 4.1 - Definição das variáveis de utilização, de necessidade e de não necessidade Variáveis de utilização de cuidado médico

consulta Nos últimos doze meses, consultou médico?

nconsulta Quantas vezes consultou médico, nos últimos doze meses?

tconsulta Soma das duas questões referentes à consulta médica (utilização total)

internação Nos últimos doze meses, esteve internado?

ninternacao Quantas vezes esteve internado, nos últimos doze meses?

tinternacao Soma das duas questões referentes à internação hospitalar (utilização total)

Dummies de necessidade

m18_29 1 se homem entre 18 e 29 anos, 0 caso contrário

m30_44 1 se homem entre 30 e 44 anos, 0 caso contrário

m45_59 1 se homem entre 45 e 59 anos, 0 caso contrário

m60_69 1 se homem entre 60 e 69 anos, 0 caso contrário

m70+ $\quad 1$ se homem com 70 ou mais, 0 caso contrário

f10_17 1 se mulher entre 10 e 17 anos, 0 caso contrário

f18_29 1 se mulher entre 18 e 29 anos, 0 caso contrário

f30_44 1 se mulher entre 30 e 44 anos, 0 caso contrário

f45_59 1 se mulher entre 45 e 59 anos, 0 caso contrário

f60_69 1 se mulher entre 60 e 69 anos, 0 caso contrário

f70+ $\quad 1$ se mulher com 70 ou mais, 0 caso contrário

Bom 1 se estado de saúde bom, 0 caso contrário

Regular $\quad 1$ se estado de saúde regular, 0 caso contrário

Ruim 1 se estado de saúde ruim, 0 caso contrário

Mruim 1 se estado de saúde muito ruim, 0 caso contrário

limitação 1 para limitação de atividade diária, 0 caso contrário

Crônica 1 para presença de alguma doença crônica, 0 caso contrário

Renda familiar per capita e dummies sociais

lrendapc logaritmo da renda per capita

fundamental 1 se concluiu de 2 a 8 anos, 0 caso contrário

médio $\quad 1$ se concluiu de 9 a 11 anos, 0 caso contrário

superior 1 se concluiu 12 ou mais anos, 0 caso contrário

desocupado 1 se desocupado, 0 caso contrário

ccarteira 1 se empregado com carteira, 0 caso contrário

fpublico 1 se funcionário público ou militar, 0 caso contrário

doméstico 1 se doméstico com ou sem carteira, 0 caso contrário

scarteira 1 se empregado sem carteira, 0 caso contrário

cprópria 1 se trabalhador por conta própria, 0 caso contrário

empregador 1 se empregador, 0 caso contrário

Outra $\quad 1$ se produção ou construção para consumo ou não remunerado, 0 caso contrário

Plano 1 para posse de plano de saúde, 0 caso contrário

norte $\quad 1$ se uf da região norte, 0 caso contrário

Sudeste $\quad 1$ se uf da região sudeste, 0 caso contrário

Sul 1 se uf da região sul, 0 caso contrário

Centrooeste 1 se uf da região centro-oeste, 0 caso contrário

\footnotetext{
${ }^{17}$ Foram tomadas como referências as categorias: m10_17(homem com idade entre 10 e 17 anos), estado de saúde muito bom, sem instrução ou menos de um ano de estudo, inativa e residente na Região Nordeste.
} 


\subsection{MÉTODO EMPÍRICO}

A mensuração do uso de serviços de saúde ocorre pela contagem de eventos inteiros e não negativos. Frequentemente, a distribuição dessa variável tende a ser assimétrica a direita, com uma extensa quantidade de zeros e uma longa cauda à direita Este comportamento é observado pela distribuição das consultas médicas e internações hospitalares (Gráficos 4.1 e 4.2) que possuem apenas valores inteiros e não negativos, com muitos indivíduos declarando pouco ou nenhum uso durante os últimos dozes meses.

Gráfico 4.1 - Distribuição da utilização total de consultas médicas

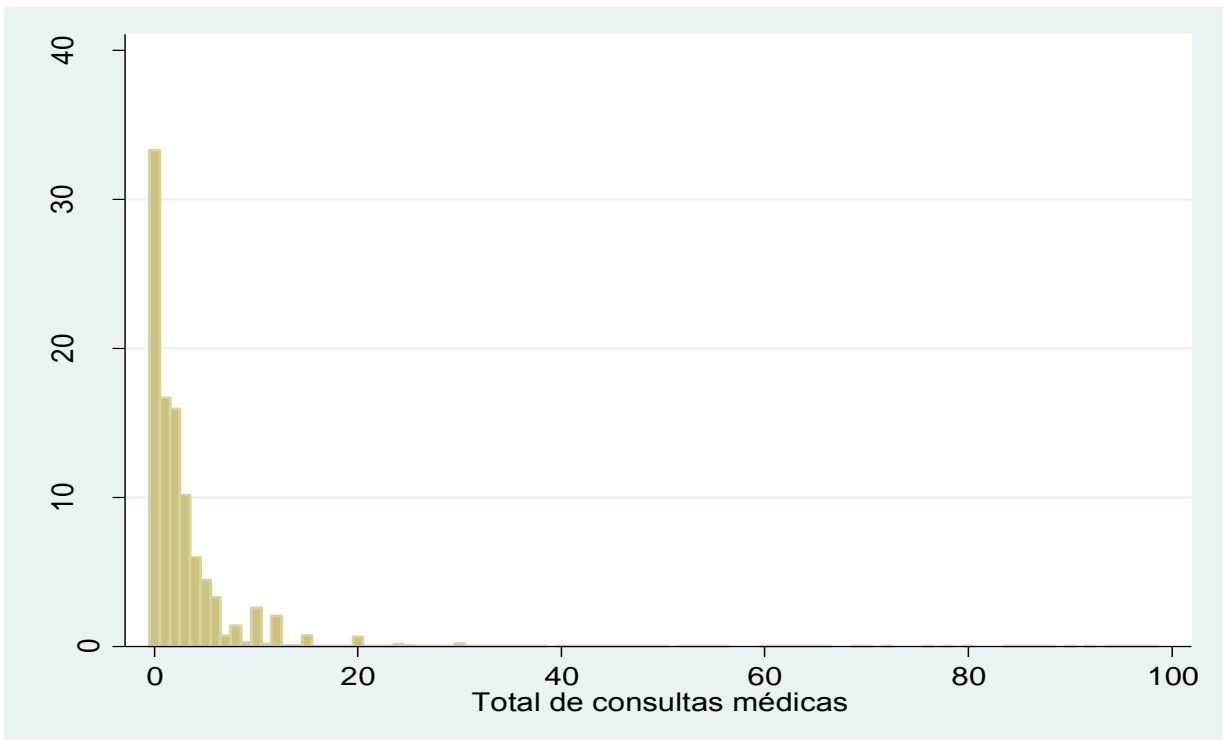

Fonte: Elaboração da autora com base nos dados da PNAD 2008

Gráfico 4.2 - Distribuição da utilização total de internações hospitalares

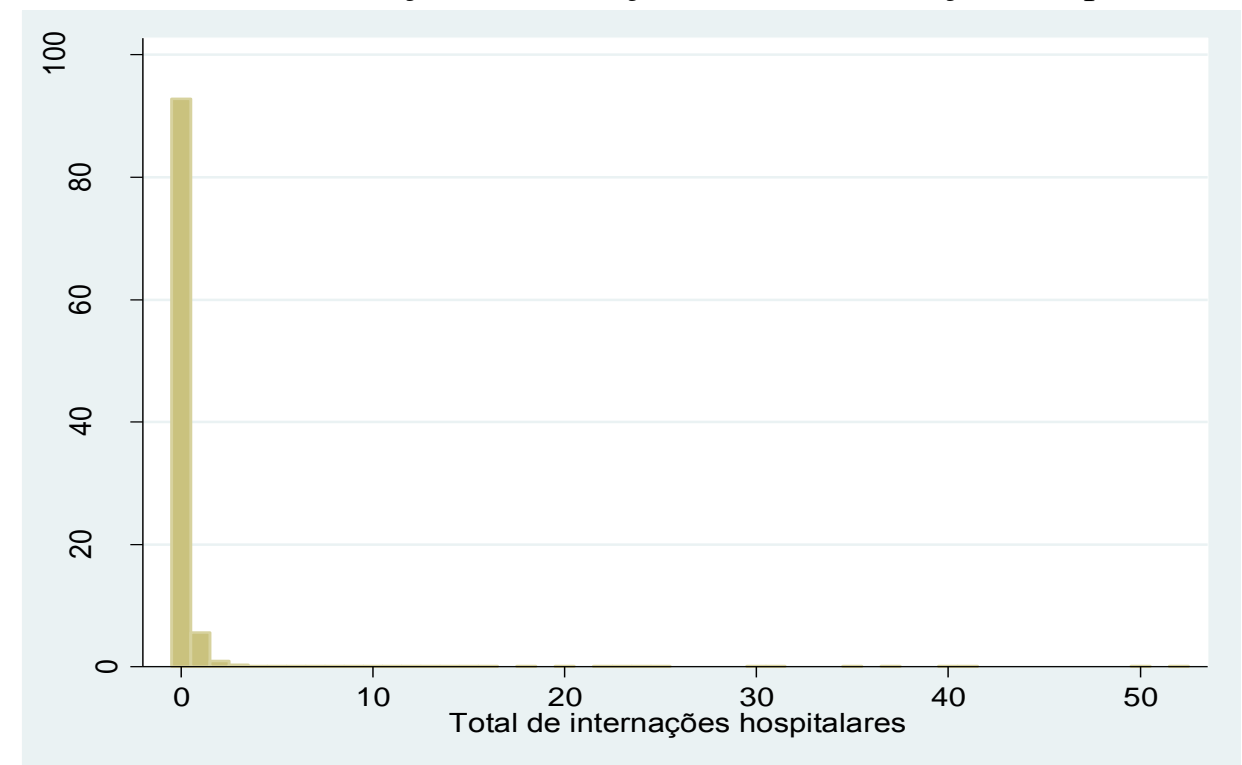

Fonte: Elaboração da autora com base nos dados da PNAD 2008 
A natureza discreta dos dados de uso de cuidados de saúde necessita de estimadores particulares. O enfoque mais básico assume um processo de Poisson para a probabilidade de observar um determinado evento condicional a intervalo fixo.

A distribuição de Poisson, descrita como a probabilidade de ocorrência do evento $y_{i}$, condicional a um conjunto de características, $X_{i}$, é dada por

$$
\operatorname{Pr}\left(Y=y_{i} / X_{i}\right)=\exp \left(-\lambda_{i}\right) \lambda_{i}^{y_{i}} / y_{i} !, \text { para } y_{i}=0,1, \ldots
$$

Em que exp () é um função exponencial, $y_{i}$ ! representando fatorial de $y_{i}$ e $\lambda_{i}$ é a média condicional da contagem, especificada como

$$
\lambda_{i}=E\left[y_{i} / X_{i}\right]=\exp \left(x^{\prime} \beta\right)
$$

Em que $\beta$ representa $\mathrm{o}$ coeficiente e o vetor $x$ corresponde às variáveis explicativas. Entretanto, a distribuição de Poisson assume a propriedade de equidispersão, ou seja, $E\left[y_{i} / X_{i}\right]=V\left[y_{i} / X_{i}\right]=\lambda_{i}$, propriedade comumente violada em dados de utilização de cuidados de saúde em que, frequentemente, se observa overdispersion dos dados, ou seja, $E\left[y_{i} / X_{i}\right]<V\left[y_{i} / X_{i}\right]$.

A relação variância/média de 7,97 e 3,33 para o número de consultas médicas e internações hospitalares, respectivamente, sugere presença de overdispersion nos dados. Essa hipótese foi testada assumindo uma overdispersion com a forma (CAMERON; TRIVEDI, 2005, p. 670-671):

$V\left[y_{i} / X_{i}\right]=\lambda_{i}+\alpha f\left(\lambda_{i}\right)$

Em que $\alpha$ é um parâmetro desconhecido e $f\left(\lambda_{i}\right)$ é uma função da média, comumente, $f(\lambda)=\lambda^{2}$ ou $f(\lambda)=\lambda$.

O teste para $H_{0}: \alpha=0$ contra $H_{A}: \alpha>0$ pode ser implementado, estimando-se um modelo de Poisson, estabelecendo os valores estimados e, por fim, testando a significância do coeficiente $\alpha$ da regressão auxiliar de mínimos quadrados sem constante

$\frac{\left(y_{i}-\widehat{\lambda}_{i}\right)^{2}-y_{i}}{\widehat{\lambda}_{i}}=\alpha \frac{g\left(\hat{\lambda}_{i}\right)}{\widehat{\lambda}_{i}}+u_{i}$

Desse modo, não foi possível rejeitar a hipótese nula de que os dados de consultas médicas e internações hospitalares possuem overdispersion (Ver Apêndice E). 
Tabela 4.1 - Distribuição de frequência do número de consultas médicas

\begin{tabular}{|c|c|c|c|}
\hline Total de consultas & Frequência & Percentual & Acumulada \\
\hline $\mathrm{O}$ & 106.351 & 33,31 & 33,31 \\
\hline 1 & 53.375 & 16,72 & 50,03 \\
\hline 2 & 50.976 & 15,97 & 65,99 \\
\hline 3 & 32.545 & 10,19 & 76,18 \\
\hline 4 & 19.223 & 6,02 & 82,20 \\
\hline 5 & 14.349 & 4,49 & 86,70 \\
\hline 6 & 10.549 & 3,30 & 90,00 \\
\hline 7 & 2.371 & 0,74 & 90,75 \\
\hline 8 & 4.590 & 1,44 & 92,18 \\
\hline 9 & 978 & 0,31 & 92,49 \\
\hline 10 & 8.384 & 2,63 & 95,12 \\
\hline 11 & 605 & 0,19 & 95,30 \\
\hline 12 & 6.652 & 2,08 & 97,39 \\
\hline 13 & 284 & 0,09 & 97,48 \\
\hline 14 & 296 & 0,09 & 97,57 \\
\hline 15 & 2.377 & 0,74 & 98,31 \\
\hline 16 & 221 & 0,07 & 98,38 \\
\hline 17 & 65 & 0,02 & 98,40 \\
\hline 18 & 198 & 0,06 & 98,47 \\
\hline 19 & 15 & o & 98,47 \\
\hline 20 & 2.113 & 0,66 & 99,13 \\
\hline 21 & 25 & 0,01 & 99,14 \\
\hline 22 & 65 & 0,02 & 99,16 \\
\hline 23 & 23 & O,O1 & 99,17 \\
\hline 24 & 588 & 0,18 & 99,35 \\
\hline 25 & 282 & 0,09 & 99,44 \\
\hline 26 & 29 & 0,01 & 99,45 \\
\hline 27 & 11 & O & 99,45 \\
\hline 28 & 27 & $\mathbf{O}, 01$ & 99,46 \\
\hline 29 & 5 & O & 99,46 \\
\hline 30 & 701 & 0,22 & 99,68 \\
\hline 31 & 3 & O & 99,68 \\
\hline 32 & 19 & 0.01 & 99,69 \\
\hline 33 & 4 & o & 99,69 \\
\hline 34 & 2 & O & 99,69 \\
\hline 35 & 55 & 0,02 & 99,71 \\
\hline 36 & 141 & 0,04 & 99,75 \\
\hline 37 & 1 & o & 99,75 \\
\hline 38 & 7 & O & 99,75 \\
\hline 40 & 215 & 0,07 & 99,82 \\
\hline 41 & 7 & O & 99,82 \\
\hline 42 & 9 & O & 99,83 \\
\hline 43 & 2 & O & 99,83 \\
\hline 44 & 9 & O & 99,83 \\
\hline 45 & 21 & O,O1 & 99,84 \\
\hline 46 & 4 & O & 99,84 \\
\hline 47 & 1 & O & 99,84 \\
\hline 48 & 132 & 0,04 & 99,88 \\
\hline 49 & 4 & O & 99,88 \\
\hline 50 & 153 & 0,05 & 99,93 \\
\hline 52 & 13 & O & 99,93 \\
\hline 53 & 1 & O & 99,93 \\
\hline 54 & 6 & O & 99,94 \\
\hline 55 & 4 & O & 99,94 \\
\hline 56 & 5 & O & 99,94 \\
\hline 60 & 74 & 0,02 & 99,96 \\
\hline 61 & 1 & O & 99,96 \\
\hline 62 & 3 & O & 99,96 \\
\hline 63 & 1 & O & 99,96 \\
\hline 64 & 1 & O & 99,96 \\
\hline 65 & 1 & O & 99,96 \\
\hline 66 & 1 & O & 99,96 \\
\hline 69 & 1 & O & 99,96 \\
\hline 70 & 12 & O & 99,97 \\
\hline 72 & 7 & O & 99,97 \\
\hline 76 & 1 & O & 99,97 \\
\hline 78 & 3 & O & 99,97 \\
\hline 80 & 15 & O & 99,98 \\
\hline 84 & 1 & O & 99,98 \\
\hline 85 & 2 & O & 99,98 \\
\hline 86 & 1 & O & 99,98 \\
\hline 87 & 1 & O & 99,98 \\
\hline 88 & 1 & O & 99,98 \\
\hline 90 & 20 & 0,01 & 99,98 \\
\hline 92 & 2 & O & 99,98 \\
\hline 94 & 1 & O & 99,99 \\
\hline 95 & 2 & O & 99,99 \\
\hline 96 & 20 & 0,01 & 99,99 \\
\hline 97 & 2 & O & 99,99 \\
\hline 98 & 23 & 0,01 & 100 \\
\hline média & 2,78 & & \\
\hline variância & 22,16 & & \\
\hline variância/média & 7,97 & & \\
\hline Total & 319.288 & 100 & \\
\hline
\end{tabular}

Fonte: Elaboração da autora com base nos dados da PNAD 2008 
Tabela 4.2 - Distribuição de frequência do número de internações hospitalares

\begin{tabular}{|c|c|c|c|}
\hline Total de internações & Frequência & Percentual & Acumulada \\
\hline 0 & 296.299 & 92,80 & 92,80 \\
\hline 1 & 17.995 & 5,64 & 98,44 \\
\hline 2 & 2.941 & 0,92 & 99,36 \\
\hline 3 & 1.107 & 0,35 & 99,70 \\
\hline 4 & 359 & 0,11 & 99,82 \\
\hline 5 & 216 & 0,07 & 99,88 \\
\hline 6 & 113 & 0,04 & 99,92 \\
\hline 7 & 48 & 0,02 & 99,93 \\
\hline 8 & 47 & 0,01 & 99,95 \\
\hline 9 & 8 & 0 & 99,95 \\
\hline 10 & 62 & 0,02 & 99,97 \\
\hline 11 & 4 & 0 & 99,97 \\
\hline 12 & 22 & 0,01 & 99,98 \\
\hline 13 & 2 & 0 & 99,98 \\
\hline 14 & 8 & 0 & 99,98 \\
\hline 15 & 18 & 0,01 & 99,99 \\
\hline 16 & 2 & 0 & 99,99 \\
\hline 18 & 1 & 0 & 99,99 \\
\hline 20 & 11 & 0 & 99,99 \\
\hline 22 & 1 & 0 & 99,99 \\
\hline 23 & 1 & 0 & 99,99 \\
\hline 24 & 1 & 0 & 99,99 \\
\hline 25 & 5 & 0 & 99,99 \\
\hline 30 & 9 & 0 & 100 \\
\hline 31 & 1 & 0 & 100 \\
\hline 35 & 1 & 0 & 100 \\
\hline 37 & 1 & 0 & 100 \\
\hline 40 & 2 & 0 & 100 \\
\hline 41 & 1 & 0 & 100 \\
\hline 50 & 1 & 0 & 100 \\
\hline 52 & 1 & 0 & 100 \\
\hline média & 0,10 & & \\
\hline variância & 0,33 & & \\
\hline variância/média & 3,33 & & \\
\hline Total & 319,288 & 100 & \\
\hline
\end{tabular}

Fonte: Elaboração da autora com base nos dados da PNAD 2008

A hipótese de equidispersion no modelo de Poisson foi, então, relaxada introduzindo um efeito individual não observado dentro da função (4.1) que permite capturar a natureza discreta, censurada e a overdispersion dos dados. Desse modo, a distribuição de $y_{i}$ condicionada em $X_{i}$ e o efeito não observado $\left(u_{i}\right)$ permanecem como uma distribuição de Poisson

$$
f\left(y_{i} / X_{i}, u_{i}\right)=\exp \left(-\lambda_{i} u_{i}\right)\left(\lambda_{i} u_{i}\right)^{y_{i}} / y_{i} \text { ! }
$$


Na equação (4.5), $\lambda_{i}$ deixa de ser determinística e passa a ser aleatória, $\lambda_{i}=$ $\exp \left(\mathrm{x}^{\prime} \beta\right) \exp \left(\mathrm{u}_{\mathrm{i}}\right)$. Se $g\left(u_{i}\right)$ representa a densidade de probabilidade para $u_{i}$, então a densidade marginal pode ser obtida integrando $f\left(y_{i} / X_{i}, u_{i}\right)$ com respeito a $u_{i}$

$$
f\left(y_{i} / X_{i}\right)=\int_{0}^{\infty} \frac{e^{-\lambda_{i} u_{i}\left(\lambda_{i} u_{i}\right)^{y_{i}}}}{\lambda_{i}} g\left(u_{i}\right) d u_{i}
$$

Desse modo, a densidade marginal dependerá da forma assumida por $g\left(u_{i}\right)$. Assumindo, como em Greene (2000), que $g\left(u_{i}\right)$ tenha uma distribuição gama igual a

$$
g\left(u_{i}\right)=\frac{\alpha^{\alpha}}{\Gamma(\alpha)} e^{-\alpha u_{i}} u_{i}^{\alpha-1}
$$

Chega-se a uma forma de distribuição binomial negativa, correspondente ao modelo binomial negativo (Negbin II), descrito em Cameron e Trivedi (1986) ${ }^{18}$. Logo, a densidade para $y_{i}$ é igual a

$$
f\left(y_{i} / X_{i}\right)=\frac{\Gamma\left(\alpha+y_{i}\right)}{\Gamma\left(y_{i}+1\right)}\left(\frac{\lambda_{i}}{\lambda_{i}+\alpha}\right)^{y_{i}}\left(1-r_{i}\right)^{\alpha}, \text { em que } r_{i}=\frac{\lambda_{i}}{\lambda_{i}+\alpha}
$$

Portanto, a distribuição terá média e variância iguais, respectivamente, a

$$
\begin{aligned}
& E\left[y_{i} / \lambda_{i}, \alpha\right]=\lambda_{i} \\
& V\left[y_{i} / \lambda_{i}, \alpha\right]=\lambda_{i}\left(1+(1 / \alpha) \lambda_{i}^{2}\right.
\end{aligned}
$$

Em que $\alpha$ representa o parâmetro de overdispersion dos dados, que quando igual a zero indica ausência de overdispersion, resultando em média igual à variância como no modelo de Poisson. Assim, na presença de overdispersion, o modelo binomial negativo deverá produzir estimativas consistentes e eficientes, tendo sido aplicado extensivamente em estudos de utilização de cuidados de saúde (GERDTHAM, 1997; POLHMEIER; ULRICH, 1995; CAMERON et al., 1988; CAMERON; TRIVEDI, 1986).

No entanto, Mullahy (1997), empregando a mesma base de dados que Cameron e Trivedi (1988), encontra que o excesso de zero em modelos de contagem, comumente, assumido como fonte da overdispersion, na verdade, é uma implicação estrita da heterogeneidade não observada. Esse resultado "intrínseco da heterogeneidade não observada" ocorre em função do tipo de cuidado e das razões para a não utilização.

Para Mullahy (1997), tal fato representa uma deficiência do modelo de Poisson (ou binomial negativo), devendo ser adotado um modelo hurdle como alternativa, em que a suposição de que o excesso de zero e os resultados positivos possuem o mesmo

\footnotetext{
${ }^{18}$ No Negbin II, a variância é uma função quadrática da média $\lambda_{i}\left(1+(1 / \alpha) \lambda_{i}^{2}\right.$, enquanto, no Negbin I, a variância é proporcional a media, $\lambda_{i}\left(1+(1 / \alpha) \lambda_{i}\right.$.
} 
processo gerador de dados é relaxada. Nesse caso, o excesso de zero é determinado por uma função densidade de probabilidade, $f_{1}($.$) , tal que \operatorname{Pr}[y=0]=f_{1}(0)$, e os resultados positivos por uma densidade truncada, $f_{2}(y / y>0)=f_{2}(y) /\left(1-f_{2}(0)\right)$, multiplicada por $\operatorname{Pr}[y>0]=1-f_{1}(0)$ para permitir que as probabilidades some uma unidade (CAMERON; TRIVEDI, 2005). Logo,

$g(y)= \begin{cases}f_{1}(0) & \text {, se } y=0 \\ \frac{1-f_{1}(0)}{1-f_{2}(0)} f_{2}(y), & \text { se } y \geq 1\end{cases}$

A especificação do modelo hurdle pode ser dada por uma versão Poisson ou binomial negativa, dependendo da densidade adotada para $f_{2}($.$) . A estimação por$ máxima verossimilhança ocorre de forma separada pela maximização dos dois termos na probabilidade, um correspondente aos zeros e outro aos resultados positivos, sendo $f_{1}\left(\right.$. ), especificada como uma função probit ou logit, enquanto $f_{2}($.$) é descrita por um$ modelo Poisson ou binomial negativo truncado.

Desse modo, a interpretação do modelo reflete o processo de decisão de utilização como um processo em etapas geradas separadamente. $\mathrm{Na}$ primeira parte, o paciente toma a decisão de procurar o médico, mas os contatos subsequentes podem ser determinados por mecanismos diferentes, normalmente, definidos pelo profissional de saúde.

Como também se pretende mensurar a desigualdade na utilização total, foram adotadas as duas formas de especificação: modelos do tipo hurdle para a utilização do cuidado com um processo em etapas e um modelo binomial negativo para a utilização total.

\subsubsection{INFERÊNCIA ESTATÍSTICA}

Em geral, estudos que têm a PNAD como fonte de dados assumem que os dados são obtidos por meio de amostra aleatória simples com reposição, ou seja, considera-se que as observações são independentes e identicamente distribuídas (iid). A PNAD, entretanto, possui desenho amostral complexo e a desconsideração dessa característica pode conduzir a estimativas viesadas da variância, alterando inclusive a significância dos parâmetros.

Uma amostragem complexa como a realizada na PNAD envolve estratificação, amostragem em conglomeração ou cluster (multiestágios) e probabilidade de seleção diferente. Na PNAD, é realizada uma estratificação geográfica na qual o País é dividido em 36 estratos naturais: (i) 18 unidades da Federação formam cada uma delas um 
estrato independente e (ii) as outras nove (Pará, Ceará, Pernambuco, Bahia, Minas Gerais, Rio de Janeiro, São Paulo, Paraná e Rio Grande do Sul) dão origem a dois estratos, um formado por todos os municípios da região metropolitana e outro com os demais municípios da unidade.

Nos nove estratos formados pelas regiões metropolitanas, o plano de amostragem é realizado em dois estágios e os psus (unidade primária de amostragem) são formados pelos setores censitários. Nos outros 27 estratos, a amostragem é realizada em três estágios: no primeiro estágio, os municípios são os psus, que são classificados em autorrepresentativos (probabilidade 1 de pertencer à amostra) e não representativos. Os não representativos passam por um processo de estratificação em que a seleção ocorre com reposição e com probabilidade proporcional ao tamanho da população no último censo demográfico. No segundo estágio, setores censitários são selecionados em cada município por probabilidade proporcional e com reposição. Finalmente, no último estágio, em cada setor censitário, são selecionadas unidades domiciliares com equiprobabilidade para investigação das características dos moradores e de habitação.

Desse modo, conforme argumentam van Doorslaer, Koolman e Jones (2003), dados o desenho complexo da amostra e a composição dos termos de contribuição (dada pelo produto das elasticidades pelos índices de concentração de cada determinante) recomenda-se pelo procedimento de bootstrap para amostras complexas na obtenção das estimativas dos erros-padrão dos termos de contribuição.

Um problema da aplicação de bootstrap em dados da PNAD são os estratos com psu único presentes nas unidades da Federação que originaram dois estratos ${ }^{19}$. Para resolver esse problema, os estratos com psus únicos são identificados e agrupados em um novo estrato na mesma unidade da Federação. Finalmente, a estimativa dos errospadrão envolveu a criação de 100 variáveis pesos, aplicados na estimação da equação de uso ponderada pelos pesos replicados e dos índices de concentração (IC) e de iniquidade (ICwv) que também são ponderados por esses pesos.

\footnotetext{
19 A estimativa dos erros-padrão que incorpora o desenho amostral necessita que sejam levantadas informações sobre o estrato e o psu (unidade primária de amostragem), além da identificação dos municípios em autorrepresentativo e não representativo. Para detalhes sobre o plano amostral da Pnad, ver Silva, Pessoa e Lila (2002), e sobre o procedimento de cálculo dos desvios-padrão por boostrap em amostras complexas no Stata, consultar Neder (2010).
} 


\section{Mensuração e Decomposição das Desigualdades Sociais NOS CUIDADOS DE SAÚDE}

\subsection{EVIDÊNCIAS DE DESIGUALDADES NA ENTREGA DE CUIDADOS DE SAÚDE}

Os indicadores de utilização mostram que a criação do SUS propiciou um importante ganho em termos de cobertura (Tabela 2.2), mas resta saber se a entrega do cuidado é equitativa ou, se é um reflexo da estrutura social desigual do País. Dentre as características do sistema de saúde brasileiro que podem contribuir para a existência de desigualdades sociais na entrega estão: o sistema de saúde suplementar que duplica a oferta de serviços para os portadores de plano de saúde e as desigualdades regionais na distribuição da oferta de serviços do SUS.

Em busca de evidências de desigualdades no atendimento relacionada à renda, são desenhadas curvas de concentração ${ }^{20}$ das variáveis de atendimento por motivo de consulta e internação contra a renda familiar per capita para os três anos em que houve suplemento de saúde na PNAD. O atendimento também foi dividido em SUS e não SUS com a finalidade de identificar diferenças no padrão de desigualdade entre os dois atendimentos.

O Gráfico 5.1 mostra as curvas de concentração para o atendimento por motivo de $\operatorname{consultas}^{21}$. A localização abaixo da linha da perfeita igualdade indica que o consumo de consultas favorece os indivíduos em melhor posição na distribuição de renda. A disposição das curvas de atendimento seguiu o mesmo padrão durante os três anos, revelando uma persistência de desigualdade relacionada à renda em favor dos mais ricos quando se trata de atendimento de consultas.

\footnotetext{
${ }^{20}$ Campino et al. (1999) empregaram curvas de concentração para analisar a equidade no acesso à utilização de serviços de saúde no Brasil.

${ }^{21}$ No atendimento por motivo de consulta, foram consideradas tanto as consultas médicas quanto as odontológicas.
} 
Gráfico 5.1 - Curva de concentração para o atendimento por motivo de consulta - 1998, 2003 e 2008.

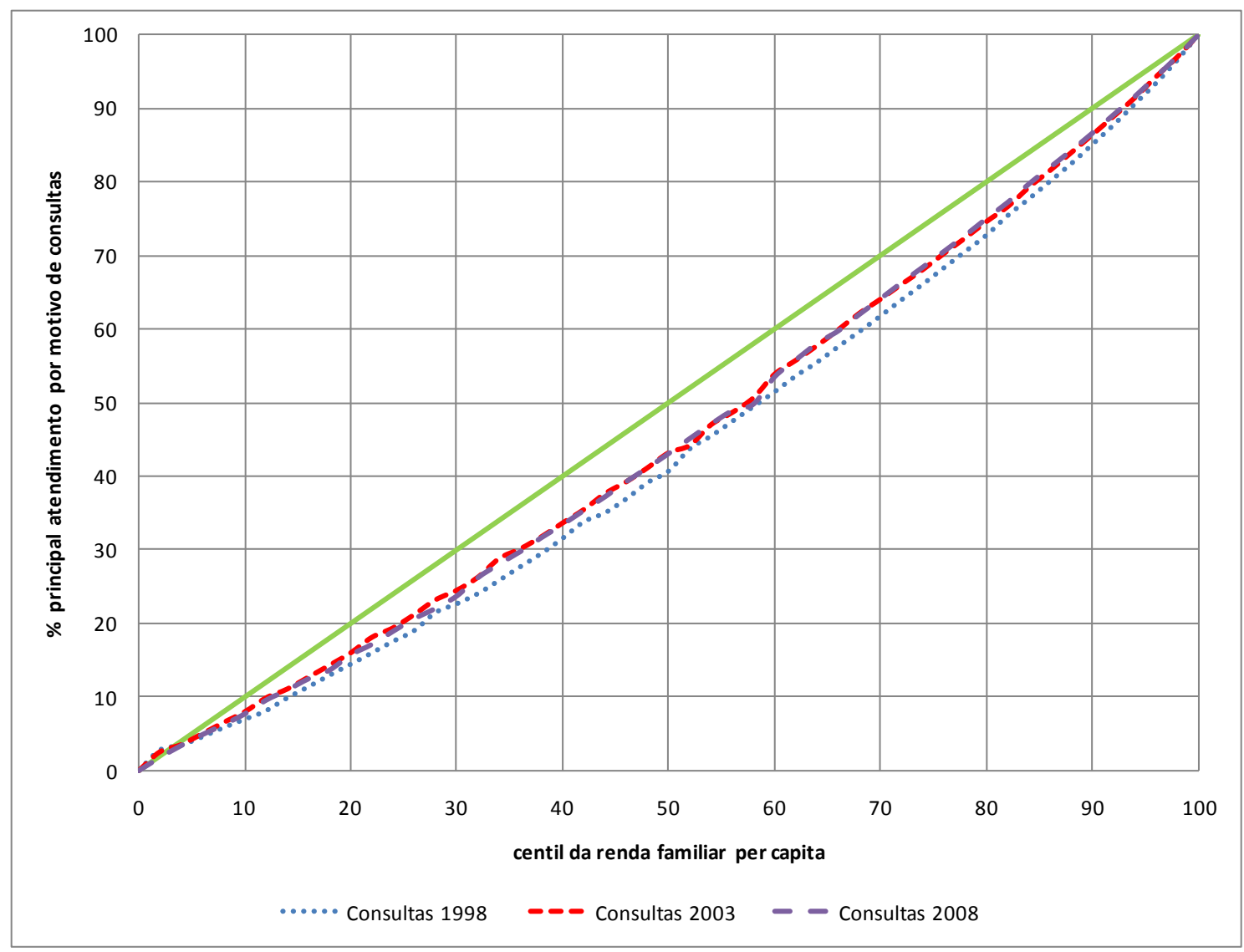

Fonte: Elaboração da autora com base nos dados das Pnads.

No Gráfico 5.2, observa-se que a concentração das consultas SUS segue a linha da perfeita igualdade até o percentil 10. Desse ponto, em diante, a proporção acumulada de consultas é maior do que a proporção acumulada da população, representando uma concentração desse atendimento a favor daqueles em pior posição na distribuição de renda. De outra parte, a curva para consultas não SUS indica concentração em favor dos que se encontram em melhor posição. 
Gráfico 5.2 - Curva de concentração para consultas SUS e não SUS, Brasil - 1998, 2003 e 2008.

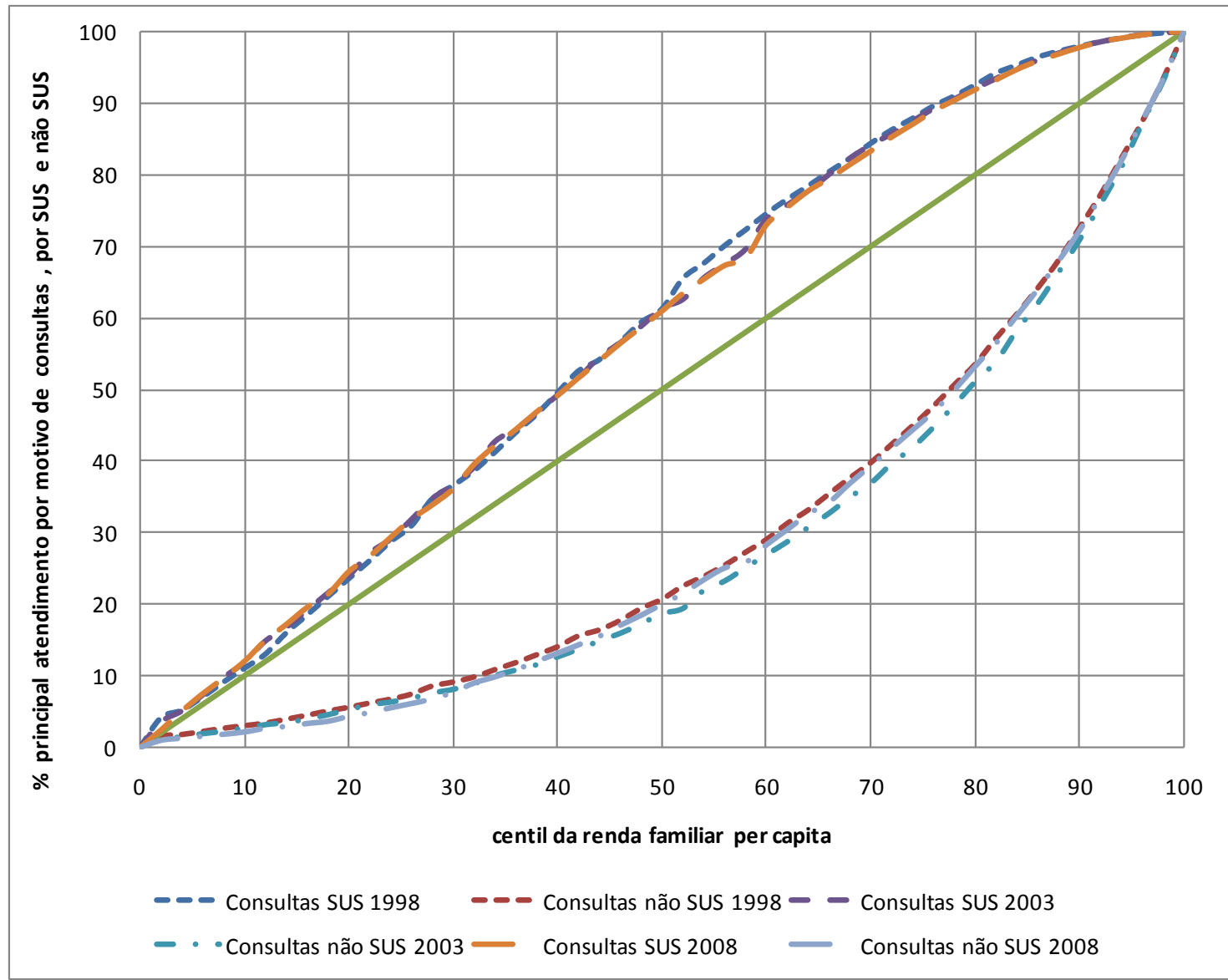

Fonte: Elaboração da autora com base nos dados das Pnads.

As curvas para o atendimento por internação estão muito próximas da linha da perfeita igualdade, sugerindo apenas uma incipiente desigualdade relacionada à renda para o ano de 1998 (Gráfico 5.3). 
Gráfico 5.3 - Curva de concentração por motivo de internação, Brasil - 1998, 2003 e 2008.

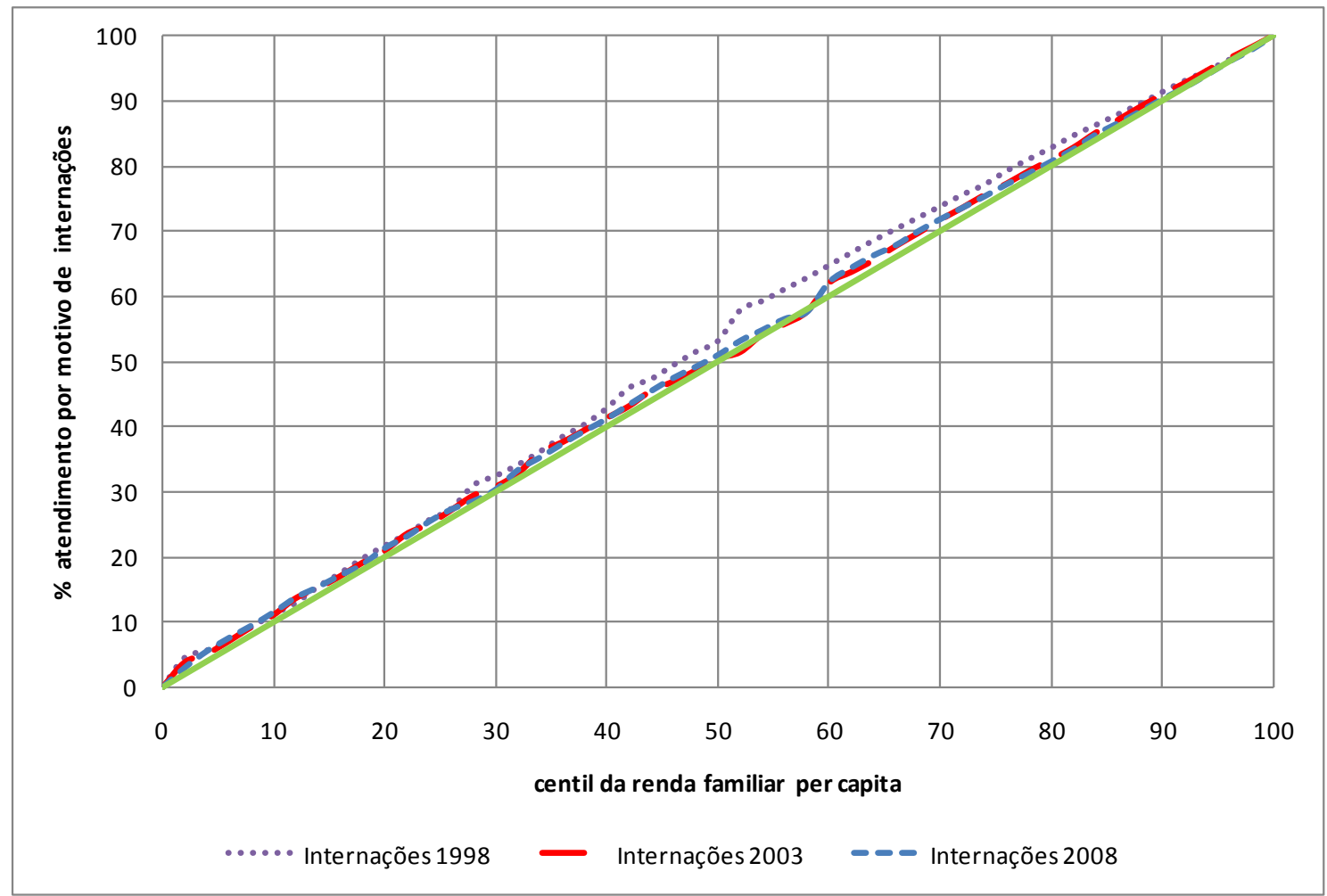

Fonte: Elaboração da autora com base nos dados das Pnads.

No Gráfico 5.4, observa-se que o atendimento não SUS acumulava apenas $20 \%$ das internações até o percentil 50 da renda familiar per capita, ao passo que nas internações SUS o percentil 50 ultrapassava $60 \%$ do atendimento. Fica evidente que existe distinção relacionada à renda entre o atendimento de internação SUS e não SUS, de tal modo que as internações SUS possuem uma distribuição pró-pobre, enquanto as internações não SUS são favoráveis aos mais ricos. 
Gráfico 5.4 - Curva de concentração para internações SUS e não SUS, Brasil - 1998, 2003 e 2008.

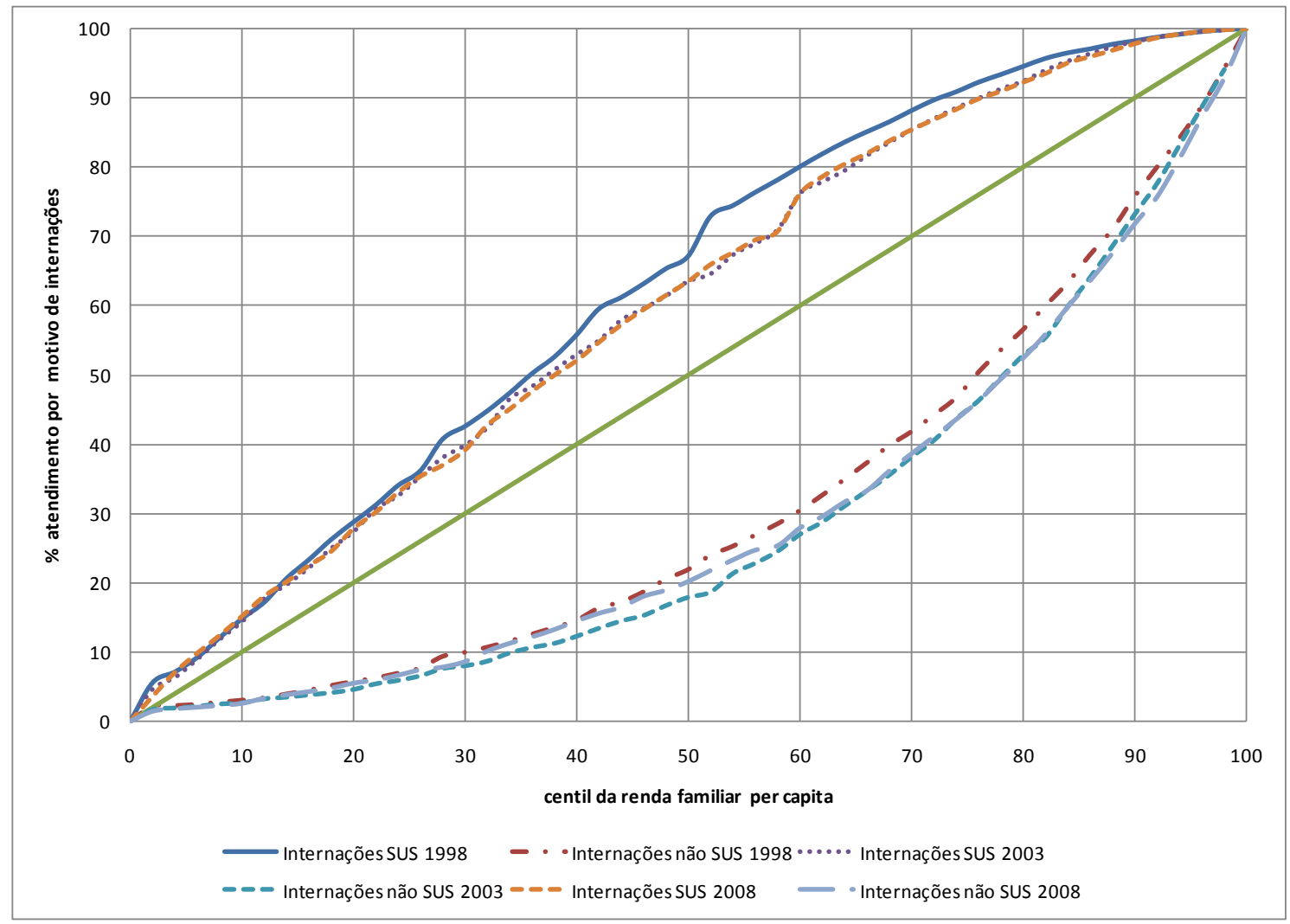

Fonte: Elaboração da autora com base nos dados das Pnads.

Outra forma de manifestação de desigualdades sociais na entrega são as diferenças inter-regionais na oferta de recursos físicos e humanos. A dimensão regional das desigualdades sociais é particularmente relevante em países com acentuada desigualdade regional na distribuição de recursos, em que a variação regional na oferta de serviços de saúde pode resultar em barreiras de acesso para os indivíduos residentes em localidades mais pobres.

Indicadores de recursos humanos (médicos e dentistas) e recursos físicos (capacidade instalada de leitos hospitalares) foram usados para analisar a distribuição na oferta de serviços de saúde. Esses indicadores confirmam o aumento da cobertura assistencial no Brasil, mas também revelam clara desigualdade na distribuição regional da oferta, manifestada tanto na entrega SUS quanto na não SUS.

No Gráfico 5.5, encontra-se a distribuição geográfica da oferta de médicos, na qual se observa a maior concentração de médicos nas regiões mais desenvolvidas. A média das regiões Sul e Sudeste situa-se acima da média nacional, tanto na entrega SUS quanto na não SUS. A região Norte é a mais carente, com quase toda a oferta provida pelo sistema de saúde público. 
Gráfico 5.5 - Distribuição de médicos (por mil habitantes), regiões e Brasil - 2005 e 2010

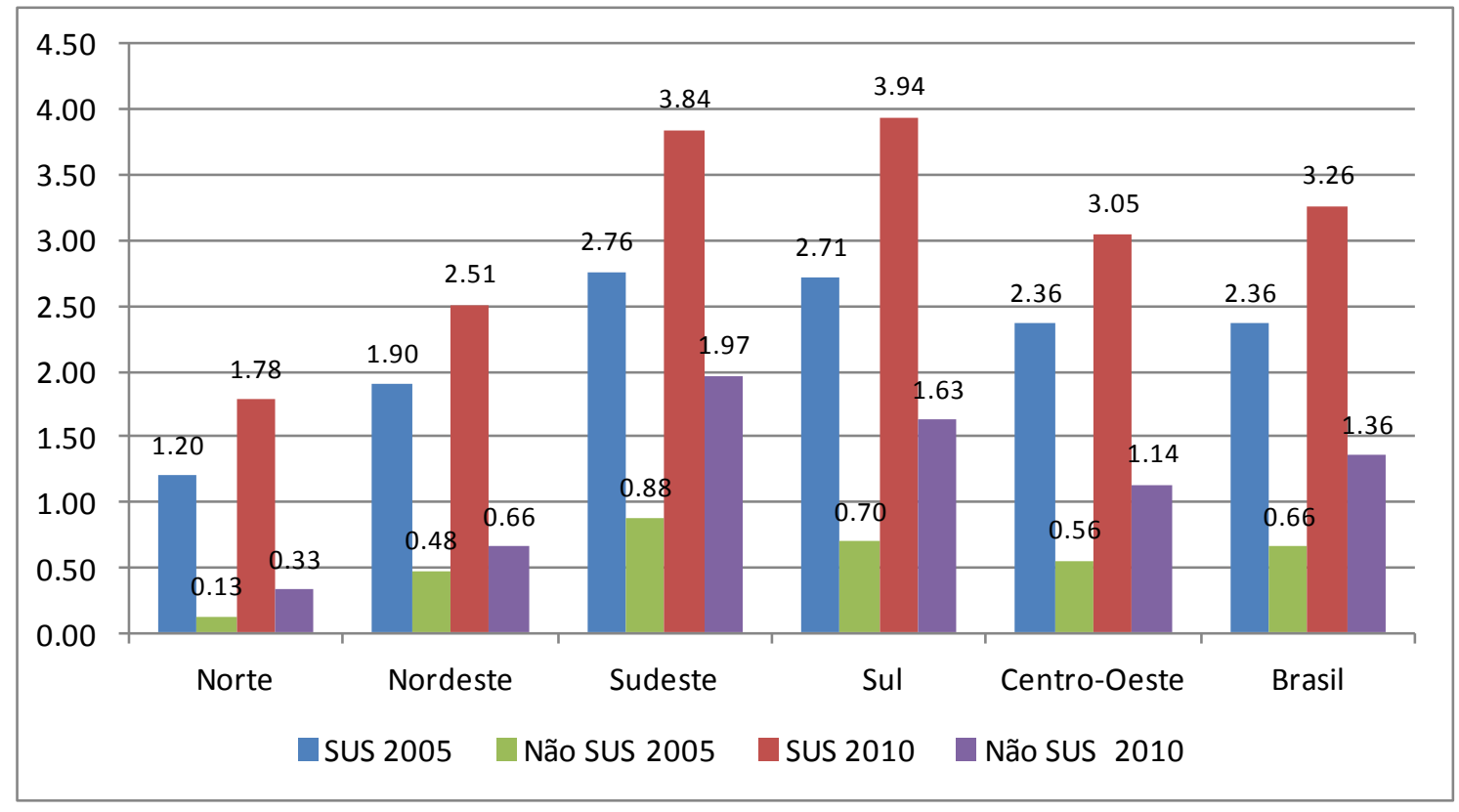

Fonte: Elaboração da autora com base nos dados do Ministério da Saúde/Cadastro Nacional dos Estabelecimentos de Saúde do Brasil e do IBGE/ População residente.

A concentração regional na distribuição de dentistas (Gráfico 5.6) segue um quadro muito similar ao da distribuição de médicos. Um ponto que chama atenção é o crescimento da oferta não SUS em todas as regiões. Em 2010, a oferta não SUS passa a responder por mais da metade da oferta de dentistas das regiões Centro-Oeste e Sul.

Gráfico 5.6 - Distribuição de dentistas (por mil habitantes), regiões e Brasil - 2005 e 2010

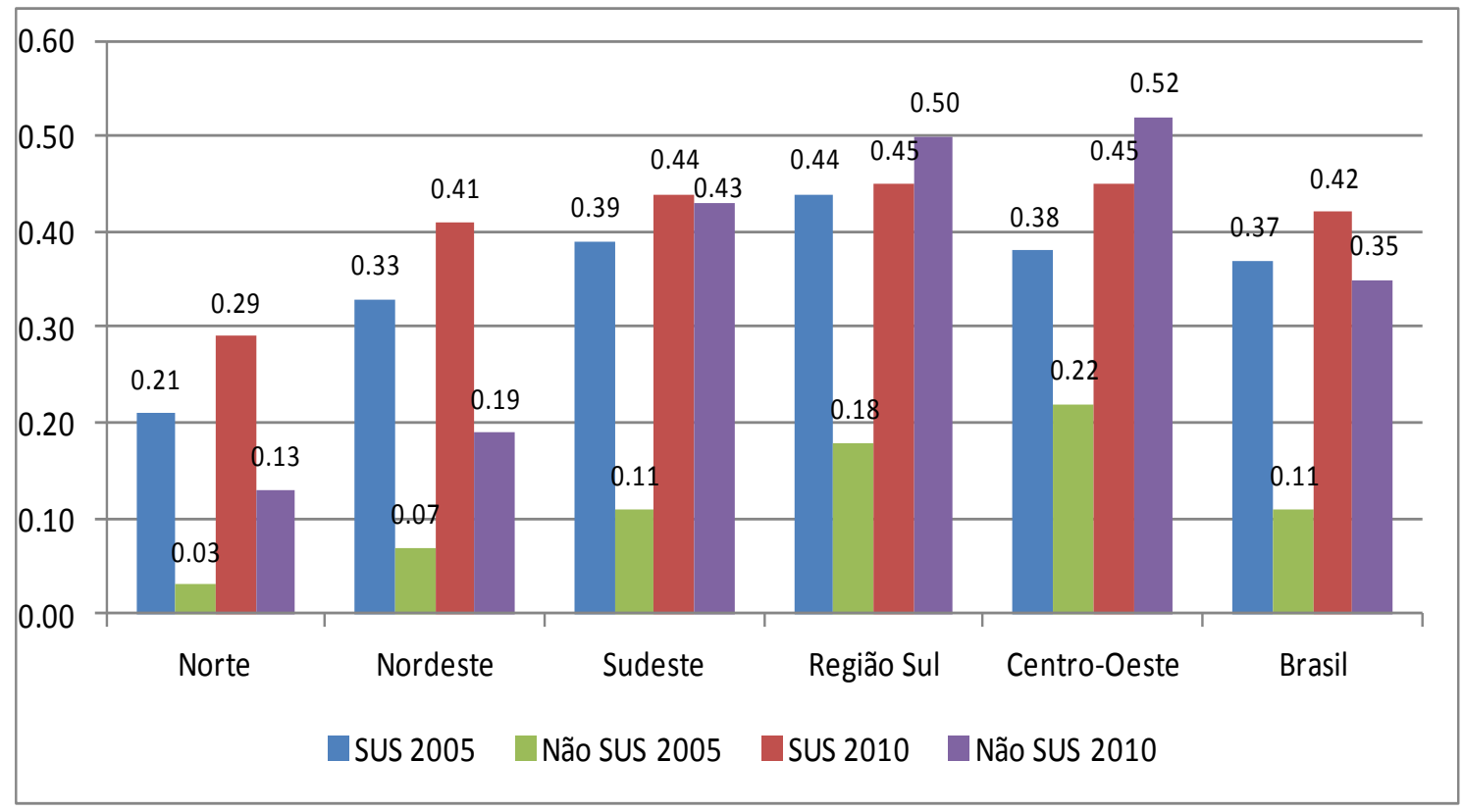

Fonte: Elaboração da autora com base nos dados do Ministério da Saúde/Cadastro Nacional dos Estabelecimentos de Saúde do Brasil e do IBGE/ População residente. 
Na distribuição de leitos hospitalares, observam-se menor concentração regional e decréscimo no número de leitos da rede pública, entre o período de 2005 e 2010 (Gráfico 5.7). No âmbito regional, ressalta-se a distribuição de leitos SUS por habitante no Nordeste, que, ao contrário da distribuição de recursos humanos, está situada acima da média nacional.

Gráfico 5.7 - Distribuição de Leitos (por mil habitantes), regiões e Brasil - 2005 e 2010

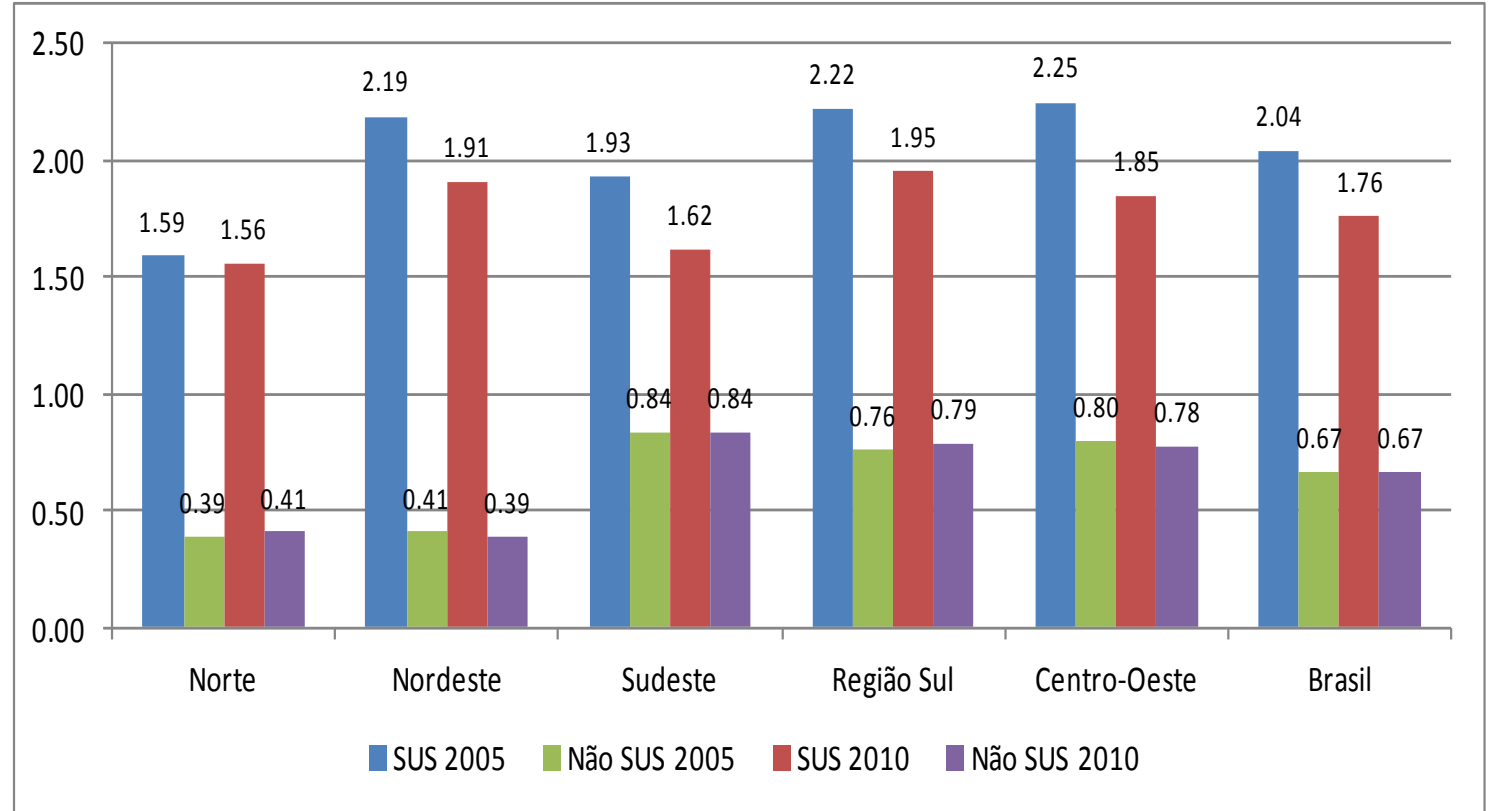

Fontes: Elaboração da autora com base nos dados do Ministério da Saúde/Cadastro Nacional dos Estabelecimentos de Saúde do Brasil e do IBGE/ População residente.

A segmentação social entre os usuários da rede SUS e não SUS, e a desigualdade geográfica na distribuição da oferta de cuidados com a saúde representam, portanto, as primeiras evidências de que no Brasil a entrega de cuidados de saúde é um reflexo da estrutura social desigual do País.

\subsection{EVOLUÇÃO DAS DESIGUALDADE SOCIAIS NA UTILIZAÇÃO DE CUIDADOS DE SAÚDE}

A mensuração das desigualdades sociais na utilização de consultas médicas e internações hospitalares será aferida por duas medidas de concentração: o índice de concentração (IC) e o índice de desigualdade horizontal ou iniquidade (ICwv).

Como as pessoas mais pobres normalmente possuem maiores necessidades de cuidado, também tendem a utilizar mais os serviços de cuidados de saúde do que pessoas em melhor condição econômica. Desse modo, o grau de desigualdade estimado pelos índices de concentração pode estar subestimando a desigualdade no uso relacionada à renda. Para uma medida que reflita apenas as desigualdades sociais em 
saúde, são calculados índices de desigualdade horizontal ou iniquidade (ICwv), que verifica violações do princípio de equidade horizontal relacionada à renda, mensurando a desigualdade em uma variável de utilização padronizada por um conjunto de variáveis representativas das necessidades de uso (características demográficas e de morbidade).

A análise desses indicadores seguirá uma perspectiva regional de modo a revelar diferenças no grau de iniquidade entre regiões e unidades da Federação. Para acompanhar a evolução no grau das desigualdades sociais em saúde, os índices foram calculados para os três anos em que houve suplemento de saúde na PNAD (1998, 2003, 2008), encontrando-se apresentados nas Tabelas 5.1-5.2.

Tabela 5.1 - Índices de desigualdade horizontal na utilização total de consultas médicas, Brasil, Regiões e Unidades da Federação - 1998, 2003 e 2008.

\begin{tabular}{|c|c|c|c|c|c|c|}
\hline \multirow{2}{*}{$\begin{array}{c}\text { Brasil, Regiões } \\
\text { e UFs }\end{array}$} & \multicolumn{2}{|c|}{1998} & \multicolumn{2}{|c|}{2003} & \multicolumn{2}{|c|}{2008} \\
\hline & IC & ICwv & IC & ICwv & IC & ICwv \\
\hline Brasil & $\begin{array}{r}0,0717 * * * \\
(0,00337)\end{array}$ & $\begin{array}{r}\mathbf{0 , 1 0 9} * * * \\
(\mathbf{0 , 0 0 3 0 3 )}\end{array}$ & $\begin{array}{r}0,0468 * * * \\
(0,00332)\end{array}$ & $\begin{array}{r}\mathbf{0 , 0 8 8 7} * * * \\
(\mathbf{0 , 0 0 2 7 8 )}\end{array}$ & $\begin{array}{r}\mathbf{0 , 0 7 3 8} * * * \\
(0,00271)\end{array}$ & $\begin{array}{r}\mathbf{0 , 0 7 9 7 * * *} \\
(0,00254)\end{array}$ \\
\hline Norte & $\begin{array}{r}0,0510 * * * \\
(0,0111)\end{array}$ & $\begin{array}{r}0,0777 * * * \\
(0,0104)\end{array}$ & $\begin{array}{r}0,0195 * * \\
(0,00911)\end{array}$ & $\begin{array}{r}0,0413 * * * \\
(0,00926)\end{array}$ & $\begin{array}{r}0,0659 * * * \\
(0,00674)\end{array}$ & $\begin{array}{r}0,0587 * * * \\
(0,00610)\end{array}$ \\
\hline Rondônia & $\begin{array}{r}0,0165 \\
(0,0339)\end{array}$ & $\begin{array}{r}0,0491 \\
(0,0345)\end{array}$ & $\begin{array}{r}0,0174 \\
(0,0205)\end{array}$ & $\begin{array}{r}0,0698 * * * \\
(0,0159)\end{array}$ & $\begin{array}{r}0,0508 * * * \\
(0,0160)\end{array}$ & $\begin{array}{r}0,0706 * * * \\
(0,0150)\end{array}$ \\
\hline Acre & $\begin{array}{l}0,0772 * \\
(0,0446)\end{array}$ & $\begin{array}{r}0,101 * * * \\
(0,0389)\end{array}$ & $\begin{array}{r}0,0511 * * \\
(0,0218)\end{array}$ & $\begin{array}{r}0,101 * * * \\
(0,0217)\end{array}$ & $\begin{array}{r}0,0755 * * * \\
(0,0249)\end{array}$ & $\begin{array}{r}0,0676 * * * \\
(0,0230)\end{array}$ \\
\hline Amazonas & $\begin{array}{r}0,00940 \\
(0,0257)\end{array}$ & $\begin{array}{r}0,0558 * * * \\
(0,0206)\end{array}$ & $\begin{array}{r}0,0209 \\
(0,0180)\end{array}$ & $\begin{array}{r}0,0254 \\
(0,0176)\end{array}$ & $\begin{array}{r}0,0549 * * * \\
(0,0153)\end{array}$ & $\begin{array}{r}0,0486 * * * \\
(0,0136)\end{array}$ \\
\hline Roraima & $\begin{array}{r}0,00636 \\
(0,0270)\end{array}$ & $\begin{array}{c}0,0736^{*} \\
(0,0380)\end{array}$ & $\begin{array}{r}-0,0512 \\
(0,0415)\end{array}$ & $\begin{array}{r}-0,0221 \\
(0,0410)\end{array}$ & $\begin{array}{r}-0,000584 \\
(0,0207)\end{array}$ & $\begin{array}{r}-0,00932 \\
(0,0162)\end{array}$ \\
\hline Pará & $\begin{array}{r}0,0705 * * * \\
(0,0130)\end{array}$ & $\begin{array}{r}0,0908 * * * \\
(0,0116)\end{array}$ & $\begin{array}{r}0,0310 * * \\
(0,0137)\end{array}$ & $\begin{array}{r}0,0461 * * * \\
(0,0141)\end{array}$ & $\begin{array}{r}0,0883 * * * \\
(0,0114)\end{array}$ & $\begin{array}{r}0,0738 * * * \\
(0,0100)\end{array}$ \\
\hline Amapá & $\begin{array}{r}0,0459 \\
(0,0301)\end{array}$ & $\begin{array}{r}0,0753 * * \\
(0,0303)\end{array}$ & $\begin{array}{r}0,0108 \\
(0,0287)\end{array}$ & $\begin{array}{r}0,0304 \\
(0,0248)\end{array}$ & $\begin{array}{r}0,0790 * * * \\
(0,0242)\end{array}$ & $\begin{array}{r}0,0943 * * * \\
(0,0204)\end{array}$ \\
\hline Tocantins & $\begin{array}{r}0,0644 * * * \\
(0,0218)\end{array}$ & $\begin{array}{r}0,0818 * * * \\
(0,0209)\end{array}$ & $\begin{array}{r}-0,0123 \\
(0,0230)\end{array}$ & $\begin{array}{r}0,0131 \\
(0,0207)\end{array}$ & $\begin{array}{r}0,0209 \\
(0,0138)\end{array}$ & $\begin{array}{r}0,0113 \\
(0,0137)\end{array}$ \\
\hline Nordeste & $\begin{array}{r}0,0942 * * * \\
(0,00506)\end{array}$ & $\begin{array}{r}\mathbf{0 , 1 0 3} * * * \\
(0,00487)\end{array}$ & $\begin{array}{r}0,0676 * * * \\
(0,00559)\end{array}$ & $\begin{array}{r}\mathbf{0 , 0 7 6 4 * * *} \\
(\mathbf{0 , 0 0 4 9 2 )}\end{array}$ & $\begin{array}{r}0,0933 * * * \\
(0,00453)\end{array}$ & $\begin{array}{r}\mathbf{0 , 0 7 0 5 * * *} \\
(\mathbf{0 , 0 0 4 7 7 )}\end{array}$ \\
\hline Maranhão & $\begin{array}{r}0,104 * * * \\
(0,0197)\end{array}$ & $\begin{array}{r}0,102 * * * \\
(0,0213)\end{array}$ & $\begin{array}{r}0,0478 * \\
(0,0249)\end{array}$ & $\begin{array}{r}0,0506 * * * \\
(0,0187)\end{array}$ & $\begin{array}{r}0,0265 \\
(0,0192)\end{array}$ & $\begin{array}{r}0,0236 \\
(0,0209)\end{array}$ \\
\hline Piauí & $\begin{array}{r}0,0780 * * * \\
(0,0170)\end{array}$ & $\begin{array}{r}0,0853 * * * \\
(0,0136)\end{array}$ & $\begin{array}{r}0,0592 * * * \\
(0,0116)\end{array}$ & $\begin{array}{r}0,0721 * * * \\
(0,0225)\end{array}$ & $\begin{array}{r}0,0907 * * * \\
(0,0110)\end{array}$ & $\begin{array}{r}0,0530 * * * \\
(0,0120)\end{array}$ \\
\hline Ceará & $\begin{array}{r}0,0833 * * * \\
(0,0131)\end{array}$ & $\begin{array}{r}0,0858 * * * \\
(0,0125)\end{array}$ & $\begin{array}{r}0,0820 * * * \\
(0,0191)\end{array}$ & $\begin{array}{r}0,0580 * * * \\
(0,00983)\end{array}$ & $\begin{array}{l}0,117 * * * \\
(0,00799)\end{array}$ & $\begin{array}{r}0,0772 * * * \\
(0,00834)\end{array}$ \\
\hline $\begin{array}{l}\text { Rio Gde do } \\
\text { Norte }\end{array}$ & $\begin{array}{r}0,0685^{* * *} * \\
(0,0175)\end{array}$ & $\begin{array}{r}0,0814 * * * \\
(0,0170)\end{array}$ & $\begin{array}{r}0,0747 * * * \\
(0,0243)\end{array}$ & $\begin{array}{r}0,0825 * * * \\
(0,0180)\end{array}$ & $\begin{array}{r}0,135^{* * * *} \\
(0,0191)\end{array}$ & $\begin{array}{r}0,120 * * * \\
(0,0184)\end{array}$ \\
\hline Paraíba & $\begin{array}{r}0,0940 * * * \\
(0,0200)\end{array}$ & $\begin{array}{r}0,105 * * * \\
(0,0243)\end{array}$ & $\begin{array}{r}0,0575 * * * \\
(0,0113)\end{array}$ & $\begin{array}{r}0,0858 * * * \\
(0,0237)\end{array}$ & $\begin{array}{r}0,0845 * * * \\
(0,0108)\end{array}$ & $\begin{array}{r}0,0425 * * * \\
(0,0119)\end{array}$ \\
\hline
\end{tabular}


Conclusão

\begin{tabular}{|c|c|c|c|c|c|c|}
\hline \multirow{2}{*}{$\begin{array}{c}\text { Brasil, Regiões } \\
\text { e UFs }\end{array}$} & \multicolumn{2}{|c|}{1998} & \multicolumn{2}{|c|}{2003} & \multicolumn{2}{|c|}{2008} \\
\hline & IC & ICwv & IC & $\mathrm{ICwV}$ & IC & $\mathrm{ICwV}$ \\
\hline \multirow[t]{2}{*}{ Pernambuco } & $0,0730 * * *$ & $0,0923 * * *$ & $0,0476^{* *}$ & $0,0789 * * *$ & $0,0851 * * *$ & $0,0608 * * *$ \\
\hline & $(0,0132)$ & $(0,0134)$ & $(0,0218)$ & $(0,0114)$ & $(0,00852)$ & $(0,00798)$ \\
\hline \multirow[t]{2}{*}{ Alagoas } & $0,0611 * * *$ & $0,0752 * * *$ & $0,0617 * * *$ & $0,0550 * *$ & $0,0631 * * *$ & $0,0456^{* * *}$ \\
\hline & $(0,0220)$ & $(0,0205)$ & $(0,0179)$ & $(0,0232)$ & $(0,0172)$ & $(0,0165)$ \\
\hline \multirow[t]{2}{*}{ Sergipe } & $0,0799 * * *$ & $0,0830 * * *$ & $0,0758 * * *$ & $0,0701 * * *$ & $0,0573 * * *$ & $0,0383 * * *$ \\
\hline & $(0,0251)$ & $(0,0226)$ & $(0,0115)$ & $(0,0212)$ & $(0,0149)$ & $(0,0130)$ \\
\hline \multirow[t]{2}{*}{ Bahia } & $0,0924 * * *$ & $0,0970 * * *$ & $0,0151 * * *$ & $0,0891 * * *$ & $0,0979 * * *$ & $0,0839 * * *$ \\
\hline & $(0,0124)$ & $(0,0119)$ & $(0,00512)$ & $(0,0101)$ & $(0,00988)$ & $(0,00999)$ \\
\hline \multirow[t]{2}{*}{ Sudeste } & $\mathbf{0 , 0 3 0 0} * * *$ & $0,0770 * * *$ & $0,0233 * *$ & $0,0731 * * *$ & $0,0440 * * *$ & $0,0596 * * *$ \\
\hline & $(0,00465)$ & $(0,00443)$ & $(0,00964)$ & $(0,00446)$ & $(0,00411)$ & $(0,00354)$ \\
\hline \multirow[t]{2}{*}{ Minas Gerais } & $0,0252 * * *$ & $0,0747 * * *$ & $0,0400^{* *}$ & $0,0857 * * *$ & $0,0532 * * *$ & $0,0655^{* * *}$ \\
\hline & $(0,00733)$ & $(0,00682)$ & $(0,0166)$ & $(0,00792)$ & $(0,00733)$ & $(0,00706)$ \\
\hline \multirow[t]{2}{*}{ Espírito Santo } & $0,0840 * * *$ & $0,110 * * *$ & $0,0215^{* *}$ & $0,0960 * * *$ & $0,0651 * * *$ & $0,0790 * * *$ \\
\hline & $(0,0127)$ & $(0,0138)$ & $(0,0101)$ & $(0,0145)$ & $(0,0173)$ & $(0,0151)$ \\
\hline \multirow[t]{2}{*}{ Rio de Janeiro } & $0,0409 * * *$ & $0,0851 * * *$ & $-0,00611$ & $0,0657 * * *$ & $0,0839 * * *$ & $0,0856 * * *$ \\
\hline & $(0,00880)$ & $(0,00740)$ & $(0,00651)$ & $(0,00807)$ & $(0,00673)$ & $(0,00626)$ \\
\hline \multirow[t]{2}{*}{ São Paulo } & 0,00410 & $0,0476 * * *$ & $0,0156^{* *}$ & $0,0495 * * *$ & $0,0120 *$ & $0,0320 * * *$ \\
\hline & $(0,00750)$ & $(0,00695)$ & $(0,00638)$ & $(0,00587)$ & $(0,00672)$ & $(0,00604)$ \\
\hline \multirow[t]{2}{*}{ Sul } & $\mathbf{0 , 0 3 3 0} * * *$ & $0,0840 * * *$ & 0,0185 & $0,0720 * * *$ & $\mathbf{0 , 0 3 2 1} * * *$ & $\mathbf{0 , 0 5 8 5} * * *$ \\
\hline & $(0,00629)$ & $(0,00582)$ & $(0,0120)$ & $(0,00561)$ & $(0,00557)$ & $(0,00571)$ \\
\hline \multirow[t]{2}{*}{ Paraná } & $0,0238 * *$ & $0,0799 * * *$ & $-0,00907$ & $0,0846^{* * * *}$ & $0,0270 * * *$ & $0,0625 * * *$ \\
\hline & $(0,0112)$ & $(0,0102)$ & $(0,0138)$ & $(0,00982)$ & $(0,00879)$ & $(0,00878)$ \\
\hline \multirow[t]{2}{*}{ Santa Catarina } & $0,0298 * *$ & $0,0865 * * *$ & $0,0294 * * *$ & $0,0432 * * *$ & $-0,000658$ & $0,0252 *$ \\
\hline & $(0,0144)$ & $(0,0133)$ & $(0,00715)$ & $(0,0150)$ & $(0,0145)$ & $(0,01$ \\
\hline \multirow[t]{2}{*}{ Rio Gde do Sul } & $0,0469 * * *$ & $0,0914 * * *$ & $0,0131 *$ & $0,0771 * * *$ & $0,0557 * * *$ & $0,0783 * * *$ \\
\hline & $(0,00792)$ & $(0,00778)$ & $(0,00714)$ & $(0,00647)$ & $(0,00933)$ & $(0,00730)$ \\
\hline \multirow[t]{2}{*}{ Centro-Oeste } & $\mathbf{0 , 0 3 7 9} * * *$ & $0,0820 * * *$ & $-0,00845$ & $0,0664 * * *$ & $0,0628 * * *$ & $0,0836 * * *$ \\
\hline & $(\mathbf{0 , 0 0 8 1 7 )}$ & $(0,00771)$ & $(0,0164)$ & $(\mathbf{0 , 0 0 7 3 2 )}$ & $(\mathbf{0 , 0 0 7 3 5 )}$ & $(0,00660)$ \\
\hline \multirow[t]{2}{*}{ Mato Gr. do Sul } & 0,0261 & $0,0608 * * *$ & $-0,0164$ & $0,0496 * * *$ & $0,0278 *$ & $0,0383 * * *$ \\
\hline & $(0,0195)$ & $(0,0170)$ & $(0,0278)$ & $(0,0172)$ & $(0,0154)$ & $(0,0146)$ \\
\hline \multirow[t]{2}{*}{ Mato Grosso } & 0,0150 & $0,0511^{* *}$ & $-0,0258 * * *$ & 0,0104 & $0,0296 * *$ & $0,0520 * * *$ \\
\hline & $(0,0217)$ & $(0,0225)$ & $(0,00955)$ & $(0,0277)$ & $(0,0144)$ & $(0,0132)$ \\
\hline \multirow[t]{2}{*}{ Goiás } & $-0,00114$ & $0,0471 * * *$ & $0,113 * * *$ & $0,0427 * * *$ & $0,0434 * * *$ & $0,0633 * * *$ \\
\hline & $(0,0147)$ & $(0,0129)$ & $(0,0121)$ & $(0,0100)$ & $(0,00999)$ & $(0,00926)$ \\
\hline \multirow[t]{2}{*}{ Distrito Federal } & $0,0519 * * *$ & $0,0913 * * *$ & $0,0468 * * *$ & $0,149 * * *$ & $0,148 * * *$ & $0,165 * * *$ \\
\hline & $(0,0117)$ & $(0,0103)$ & $(0,00332)$ & $(0,0123)$ & $(0,0108)$ & $(0,0100)$ \\
\hline
\end{tabular}

Erros-padrão entre parênteses. *** $\mathrm{p}<0.01, * * \mathrm{p}<0.05, * \mathrm{p}<0.1$

Nota: Um modelo binomial negativo foi empregado no cálculo da utilidade padronizada nas necessidade.

Os índices de concentração (IC) mostraram uma utilização de consultas médicas fortemente concentrada nos grupos de renda mais alta, caracterizando uma desigualdade pró-rico ao longo do período para a maioria das unidades da Federação (Tabela 5.1). Apenas Roraima, Tocantins e Rio de Janeiro apresentaram índices de desigualdade favorável ao uso pelos mais pobres, mas esses não foram significantes.

O grau de concentração no uso de consultas médicas variou entre as regiões geográficas com pequenas variações entre as unidades da Federação da mesma região. 
Na Região Norte, poucos índices de concentração foram significantes. Apenas os estados do Pará e do Acre apresentaram índices significantes em todos os anos. A região Nordeste abriga as unidades da Federação com a maior concentração no consumo de consultas médicas, enquanto nas Regiões Sul e Sudeste estão as unidades como menor desigualdade no uso de consultas relacionada à renda.

Observa-se que aumenta a desigualdade na utilização relacionada à renda, quando são considerados indivíduos com as mesmas necessidades de uso, significando que os indivíduos mais ricos usam mais do que seria esperado com base em suas necessidades. Essas evidências são constatadas pelos índices de iniquidade (ICwv), que mensuram o grau de desigualdade no uso de consultas médicas relacionada à renda para indivíduos com as mesmas necessidades de saúde.

Esse fenômeno aparece em todas as regiões e ao longo de todo o período, embora muitos Estados da região Norte tenham apresentado ICwv estatisticamente insignificantes. Apenas os ICwv do Pará e do Acre foram significantes em todos os anos. Em 2008, é observada uma redução das iniquidades pró-rico no uso de consultas médicas para a maioria das unidades da Federação, sendo as maiores exceções o Distrito Federal, o Rio Grande do Norte e o Amapá, que além de experimentarem aumento da iniquidade, são também os estados com maior iniquidade pró-rico no uso de consultas médicas.

Uma comparação entre os resultados encontrados para o Brasil e na literatura internacional mostra que, quando se examina a desigualdade em consultas médicas em geral, observa-se uma desigualdade favorável aos mais ricos como a observada no Brasil. Entretanto, como as surveys internacionais da área de saúde trazem questões em separado para o uso de consultas médicas ao médico generalista e ao especialista, normalmente, a mensuração da desigualdade é investigada em separado, sendo observada desigualdade pró-pobre no uso de consultas ao clínico geral e desigualdade pró-rico no uso do especialista.

Nas internações hospitalares, observa-se um comportamento oposto ao encontrado para a utilização de consultas médicas. Os índices de concentração negativos sugerem que, quanto melhor a posição no rendimento familiar per capita, menor o consumo de internações hospitalares. Esse resultado permanece mesmo após a padronização pelas necessidades de uso. Assim, ao contrário do que aconteceu com a 
utilização de consultas médicas, indivíduos mais pobres consomem mais internação hospitalar do que o que seria esperado com base em suas necessidades.

Evidências no mesmo sentido são encontradas para o Brasil. Quando se analisa a estrutura de consumo entre grupos de renda, verifica-se que os grupos de renda mais alta consomem mais serviços ambulatoriais, enquanto o consumo de serviços hospitalares é maior entre os grupos de renda mais baixa (TRAVASSOS et al., 2000; NORONHA; ANDRADE， 2002; PALERMO; PORTUGAL; SOUZA， 2005; TRAVASSOS; OLIVEIRA; VIACAVA, 2006). Isso sugere que indivíduos mais ricos utilizam mais cuidados preventivos, enquanto indivíduos mais pobres recorrem mais a cuidados intensivos.

A comparação regional desses indicadores revela, ainda, uma utilização de serviços de internação menos desigual entre as regiões.

Tabela 5.2 - Índices de desigualdade horizontal para utilização total de internações hospitalares, Brasil, Regiões e Unidades da Federação - 1998, 2003 e 2008.

\begin{tabular}{|c|c|c|c|c|c|c|}
\hline \multirow{2}{*}{$\begin{array}{c}\text { Brasil, Regiões } \\
\text { e UFs }\end{array}$} & \multicolumn{2}{|c|}{1998} & \multicolumn{2}{|c|}{2003} & \multicolumn{2}{|c|}{2008} \\
\hline & $\mathrm{IC}$ & ICwv & $\mathrm{IC}$ & ICwv & $\mathrm{IC}$ & $\mathrm{ICwv}$ \\
\hline \multirow[t]{2}{*}{ Brasil } & $-0,0882 * * *$ & $-0,0336 * * *$ & $-0,0701 * * *$ & $-0,00371$ & $-0,0256 * * *$ & $-0,00355$ \\
\hline & $(0,00641)$ & $(\mathbf{0 , 0 0 6 0 2 )}$ & $(0,00653)$ & $(0,00615)$ & $(0,00726)$ & $(0,00730)$ \\
\hline \multirow[t]{2}{*}{ Norte } & $-0,0578 * * *$ & $-0,0169$ & $-0,0687 * * *$ & $-0,0302 * *$ & $-0,0399 * *$ & $-0,0212$ \\
\hline & $(0,0181)$ & $(0,0179)$ & $(0,0149)$ & $(0,0146)$ & $(\mathbf{0 , 0 2 0 0 )}$ & $(0,0181)$ \\
\hline \multirow[t]{2}{*}{ Rondônia } & $-0,0685$ & $-0,0217$ & $-0,0138$ & $0,0719 * *$ & $-0,0638$ & $-0,0299$ \\
\hline & $(0,0598)$ & $(0,0564)$ & $(0,0322)$ & $(0,0280)$ & $(0,0411)$ & $(0,0387)$ \\
\hline \multirow[t]{2}{*}{ Acre } & 0,0124 & 0,0176 & $-0,0104$ & 0,0371 & 0,00915 & 0,0538 \\
\hline & $(0,0660)$ & $(0,0628)$ & $(0,0549)$ & $(0,0513)$ & $(0,0557)$ & $(0,0529)$ \\
\hline \multirow[t]{2}{*}{ Amazonas } & $-0,0417$ & 0,0412 & $-0,102 * * *$ & $-0,0793 * *$ & $-0,0146$ & $-0,0155$ \\
\hline & $(0,0461)$ & $(0,0453)$ & $(0,0388)$ & $(0,0395)$ & $(0,0659)$ & $(0,0622)$ \\
\hline \multirow[t]{2}{*}{ Roraima } & $-0,0909$ & $-0,0885$ & $-0,308 * * *$ & $-0,280 * * *$ & $-0,0110$ & 0,00373 \\
\hline & $(0,0911)$ & $(0,0879)$ & $(0,0539)$ & $(0,0491)$ & $(0,0527)$ & $(0,0515)$ \\
\hline \multirow[t]{2}{*}{ Pará } & $-0,0408 *$ & $-0,0149$ & $-0,0472 * *$ & $-0,0209$ & $-0,0383$ & $-0,0241$ \\
\hline & $(0,0239)$ & $(0,0257)$ & $(0,0232)$ & $(0,0210)$ & $(0,0236)$ & $(0,0206)$ \\
\hline \multirow[t]{2}{*}{ Amapá } & $-0,0734$ & $-0,0594$ & $-0,0686$ & 0,0248 & $-0,0251$ & 0,00105 \\
\hline & $(0,0595)$ & $(0,0636)$ & $(0,0684)$ & $(0,122)$ & $(0,166)$ & $(0,162)$ \\
\hline \multirow[t]{2}{*}{ Tocantins } & $-0,0288$ & $-0,00278$ & $-0,0829 * * *$ & $-0,0485 * *$ & $-0,0799 *$ & $-0,0654$ \\
\hline & $(0,0331)$ & $(0,0328)$ & $(0,0239)$ & $(0,0220)$ & $(0,0411)$ & $(0,0415)$ \\
\hline \multirow[t]{2}{*}{ Nordeste } & $-0,0529 * * *$ & $-0,0360 * * *$ & $-0,0275 * * *$ & $-0,000297$ & $-0,0104$ & $-\mathbf{0 , 0 1 8 0}$ \\
\hline & $(0,0112)$ & $(0,0108)$ & $(0,00905)$ & $(0,00812)$ & $(0,0117)$ & $(0,0112)$ \\
\hline \multirow[t]{2}{*}{ Maranhão } & $-0,00861$ & $-0,00558$ & $-0,00145$ & 0,00327 & $-0,0650 *$ & $-0,0366$ \\
\hline & $(0,0342)$ & $(0,0310)$ & $(0,0376)$ & $(0,0372)$ & $(0,0373)$ & $(0,0370)$ \\
\hline \multirow[t]{2}{*}{ Piauí } & 0,000664 & 0,0160 & $-0,0366^{*}$ & $-0,0120$ & 0,0102 & $-0,0248$ \\
\hline & $(0,0253)$ & $(0,0255)$ & $(0,0205)$ & $(0,0241)$ & $(0,0256)$ & $(0,0250)$ \\
\hline \multirow[t]{2}{*}{ Ceará } & $-0,0774 * * *$ & $-0,0684 * *$ & $-0,0165$ & $-0,0311$ & $0,0502 * * *$ & 0,0136 \\
\hline & $(0,0292)$ & $(0,0287)$ & $(0,0397)$ & $(0,0190)$ & $(0,0193)$ & $(0,0190)$ \\
\hline
\end{tabular}


Conclusão

\begin{tabular}{|c|c|c|c|c|c|c|}
\hline \multirow{2}{*}{$\begin{array}{c}\text { Brasil, Regiões } \\
\text { e UFs }\end{array}$} & \multicolumn{2}{|c|}{1998} & \multicolumn{2}{|c|}{2003} & \multicolumn{2}{|c|}{2008} \\
\hline & IC & ICwv & IC & ICwv & IC & ICwv \\
\hline Rio Gde do & $-0,0262$ & 0,00185 & $-0,0494 * *$ & $-0,000616$ & $-0,0606^{*}$ & $-0,122 * * *$ \\
\hline Norte & $(0,0377)$ & $(0,0309)$ & $(0,0227)$ & $(0,0335)$ & $(0,0361)$ & $(0,0366)$ \\
\hline \multirow{2}{*}{ Paraíba } & $-0,0399$ & $-0,0328$ & $-0,0105$ & $-0,0326$ & $0,0700 * *$ & 0,0407 \\
\hline & $(0,0354)$ & $(0,0320)$ & $(0,0262)$ & $(0,0255)$ & $(0,0356)$ & $(0,0340)$ \\
\hline \multirow[t]{2}{*}{ Pernambuco } & $-0,0679 * * *$ & $-0,0400^{*}$ & $-0,0290$ & $0,0532 * *$ & $-0,0458$ & $-0,0332$ \\
\hline & $(0,0213)$ & $(0,0211)$ & $(0,0369)$ & $(0,0265)$ & $(0,0423)$ & $(0,0407)$ \\
\hline \multirow[t]{2}{*}{ Alagoas } & $-0,136^{* * *}$ & $-0,133 * * *$ & $-0,122 * * *$ & 0,0121 & $-0,0517$ & $-0,0647$ \\
\hline & $(0,0422)$ & $(0,0452)$ & $(0,0327)$ & $(0,0320)$ & $(0,0594)$ & $(0,0653)$ \\
\hline \multirow[t]{2}{*}{ Sergipe } & $-0,0890 * * *$ & $-0,0985 * * *$ & $-0,0238$ & $-0,0796 * * *$ & $-0,0159$ & $-0,00921$ \\
\hline & $(0,0313)$ & $(0,0258)$ & $(0,0178)$ & $(0,0295)$ & $(0,0429)$ & $(0,0385)$ \\
\hline \multirow[t]{2}{*}{ Bahia } & $-0,0513 * *$ & $-0,0395^{*}$ & $-0,0826 * * *$ & 0,00533 & $-0,00992$ & $-0,00942$ \\
\hline & $(0,0249)$ & $(0,0237)$ & $(0,0110)$ & $(0,0164)$ & $(0,0227)$ & $(0,0209)$ \\
\hline \multirow[t]{2}{*}{ Sudeste } & $-0,0949 * * *$ & $-0,0291 * * * *$ & $-0,0964 * * *$ & $-0,00156$ & $-\mathbf{0 , 0 2 8 5} * *$ & $-0,00211$ \\
\hline & $(0,0116)$ & $(\mathbf{0 , 0 1 1 3 )}$ & $(\mathbf{0 , 0 1 9 1 )}$ & $(\mathbf{0 , 0 1 0 3 )}$ & $(\mathbf{0 , 0 1 1 3 )}$ & $(0,0108)$ \\
\hline \multirow[t]{2}{*}{ Minas Gerais } & $-0,0998 * * *$ & $-0,0269$ & $-0,0754 *$ & $-0,00898$ & $-0,0424 * *$ & $-0,0262$ \\
\hline & $(0,0189)$ & $(0,0181)$ & $(0,0393)$ & $(0,0172)$ & $(0,0173)$ & $(0,0159)$ \\
\hline \multirow[t]{2}{*}{ Espírito Santo } & $-0,0766$ & $-0,00769$ & $-0,0390$ & $-0,00361$ & $-0,00142$ & 0,0300 \\
\hline & $(0,0517)$ & $(0,0533)$ & $(0,0263)$ & $(0,0408)$ & $(0,0503)$ & $(0,0479)$ \\
\hline \multirow[t]{2}{*}{ Rio de Janeiro } & $-0,0752 * * *$ & 0,000711 & $-0,0724 * * *$ & 0,0277 & 0,0269 & 0,0370 \\
\hline & $(0,0197)$ & $(0,0198)$ & $(0,0180)$ & $(0,0256)$ & $(0,0239)$ & $(0,0231)$ \\
\hline \multirow[t]{2}{*}{ São Paulo } & $-0,0786^{* * *}$ & $-0,0264^{*}$ & $-0,0763 * * *$ & $-0,000246$ & $-0,0120$ & 0,0197 \\
\hline & $(0,0153)$ & $(0,0150)$ & $(0,0162)$ & $(0,0169)$ & $(0,0187)$ & $(0,0176)$ \\
\hline \multirow[t]{2}{*}{ Sul } & $-\mathbf{0 , 1 2 0} * * *$ & $-0,0519 * * *$ & $-0,0612 * *$ & $\mathbf{0 , 0 0 6 3 9}$ & $-0,0409 * *$ & $\mathbf{0 , 0 0 3 7 7}$ \\
\hline & $(\mathbf{0 , 0 1 3 3 )}$ & & & $(0,0148)$ & $(\mathbf{0 , 0 1 7 5 )}$ & $(\mathbf{0 , 0 1 7 7 )}$ \\
\hline \multirow[t]{2}{*}{ Paraná } & $-0,120 * * *$ & $-0,0576 * * *$ & $-0,107 * * *$ & 0,0350 & $-0,0786 * * *$ & $-0,0254$ \\
\hline & $(0,0197)$ & $(0,0194)$ & $(0,0251)$ & $(0,0224)$ & $(0,0236)$ & $(0,0238)$ \\
\hline \multirow[t]{2}{*}{ Santa Catarina } & $-0,125 * * *$ & $-0,0530$ & $-0,0690 * * *$ & $-0,0364$ & 0,00877 & $0,0501 * *$ \\
\hline & $(0,0328)$ & & $(0,0214)$ & $(0,0247)$ & $(0,0280)$ & $(0,0248)$ \\
\hline \multirow[t]{2}{*}{ Rio Gde do Sul } & $-0,120 * * *$ & $-0,0539 * * *$ & $-0,130 * * *$ & 0,00364 & $-0,0132$ & 0,0261 \\
\hline & $(0,0189)$ & $(0,0170)$ & $(0,0155)$ & $(0,0196)$ & $(0,0288)$ & $(0,0287)$ \\
\hline \multirow[t]{2}{*}{ Centro-Oeste } & $-0,129 * * *$ & $-0,0582 * * *$ & $-0,121 * * *$ & $-0,0466 * * *$ & $-0,0444 * * *$ & $-0,00631$ \\
\hline & $(\mathbf{0 , 0 1 5 7 )}$ & $(\mathbf{0 , 0 1 5 6 )}$ & $(\mathbf{0 , 0 3 2 7})$ & $(\mathbf{0 , 0 1 4 5 )}$ & $(\mathbf{0 , 0 1 5 1 )}$ & $(0,0148)$ \\
\hline Mato Grosso & $-0,0814 * *$ & $-0,0408$ & $-0,0620 * *$ & $-0,0328$ & 0,0100 & 0,0348 \\
\hline \multirow{3}{*}{$\begin{array}{l}\text { Sul } \\
\text { Mato Grosso }\end{array}$} & $(0,0378)$ & $(0,0353)$ & $(0,0294)$ & $(0,0315)$ & $(0,0226)$ & $(0,0217)$ \\
\hline & $-0,0544^{*}$ & 0,00648 & $-0,152 * * *$ & $-0,0155$ & $-0,0440$ & 0,0143 \\
\hline & $(0,0309)$ & $(0,0291)$ & $(0,0227)$ & $(0,0262)$ & $(0,0327)$ & $(0,0363)$ \\
\hline \multirow[t]{2}{*}{ Goiás } & $-0,155^{* * *}$ & $-0,0730 * * *$ & $-0,0360$ & $-0,0587 * *$ & $-0,0348$ & $-0,00741$ \\
\hline & $(0,0245)$ & $(0,0244)$ & $(0,0305)$ & $(0,0239)$ & $(0,0223)$ & $(0,0219)$ \\
\hline \multirow[t]{2}{*}{ Distrito Federal } & $-0,0618 *$ & 0,00808 & $-0,0701 * * *$ & $0,0538^{*}$ & $-0,0401$ & $-0,0130$ \\
\hline & $(0,0353)$ & $(0,0322)$ & $(0,00653)$ & $(0,0293)$ & $(0,0287)$ & $(0,0274)$ \\
\hline
\end{tabular}

Erros-padrão entre parênteses. $* * * \mathrm{p}<0.01, * * \mathrm{p}<0.05, * \mathrm{p}<0.1$

Nota: Um modelo binomial negativo foi empregado no cálculo da utilidade padronizada nas necessidade.

Os elevados valores para os índices de concentração para a utilização de cuidados hospitalares, no entanto, também são acompanhados de altos desvio-padrão, tornado a maioria desses indicadores estaticamente não significantes. De acordo com van Doorslaer et al. (2000), a ausência de precisão das estimativas dos índices de iniquidade para o uso de internação pode ser resultado da insuficiente capacidade dos 
indicadores de necessidade de capturarem as necessidades de internação, normalmente, concentrada em menos de $10 \%$ da amostra total ${ }^{22}$. Isso pode acontecer porque variáveis que não fazem parte dos suplementos de saúde da PNAD, tais como características demográficas do profissional de saúde, experiência profissional e forma de pagamento do serviço ${ }^{23}$, podem explicar melhor as necessidades de internação.

\subsection{DETERMINANTES DA DESIGUALDADE NA UTILIZAÇÃO DE CUIDADOS DE SAÚDE}

A análise exploratória da evolução na concentração no consumo do cuidados de saúde relacionada à renda permitiu identificar o padrão de desigualdade na utilização de consultas médicas e internações hospitalares relacionado à renda, mas não possibilita que se estabeleça o que determina essas desigualdades. Para responder a essa questão, realizou-se a decomposição dos índices de concentração do uso de serviços de consultas médicas e internações hospitalares para o ano mais recente do suplemento de saúde.

A análise de decomposição da desigualdade na utilização considerou a estimação de um modelo binomial negativo para a utilização total e também um modelo do tipo hurdle, no qual a utilização é vista como um processo em duas etapas distintas: contato inicial e contatos subsequentes. Nesse caso, a estimação do uso de consultas médicas foi realizada, empregando-se um modelo logit para o uso positivo e um modelo binomial negativo truncado para o uso condicional de consultas médicas. Por sua vez, para o uso condicional de internações, foi aplicado um modelo Poisson truncado em razão da ausência de convergência nas interações do binomial negativo truncado.

Os determinantes do uso são classificados como de necessidade ou sociais, sendo esses últimos responsáveis pelas iniquidades no cuidado. A contribuição de cada determinante para a desigualdade é obtida pelo produto do impacto sobre o uso (elasticidade) pelo grau de desigualdade dentro da distribuição de renda (índice de concentração). Determinantes com contribuição positiva concorrem para uma desigualdade pró-rico (favorecem o uso pelos indivíduos em melhor condição socioeconômica), ao passo que contribuições negativas favorecem a desigualdade própobre.

Tabela 5.3 - Contribuição dos determinantes da utilização para a desigualdade no cuidados de saúde, Brasil - 2008

\footnotetext{
22 Segundo as informações da Pnad, em 2008, apenas 7,2\% da amostra esteve ao menos um dia internada.

${ }^{23}$ Usuários de planos de saúde possuem, em média, menor número de dias de internação do que os usuários do SUS, o que, normalmente, é atribuído às políticas dos planos de saúde.
} 


\begin{tabular}{|c|c|c|c|c|c|c|}
\hline \multirow{4}{*}{ Variáveis } & \multicolumn{3}{|c|}{ Consultas Médicas } & \multicolumn{3}{|c|}{ Internações Hospitalares } \\
\hline & \multirow{3}{*}{$\begin{array}{l}\text { Binomial } \\
\text { Negativo }\end{array}$} & \multicolumn{2}{|c|}{ Hurdle Binomial Negativo } & \multirow{3}{*}{$\begin{array}{l}\text { Binomial } \\
\text { Negativo }\end{array}$} & \multicolumn{2}{|c|}{ Hurdle Poisson } \\
\hline & & & Negbin & & & Poisson \\
\hline & & Logit & Truncado & & Logit & Truncado \\
\hline m18_29 & 0,0000 & $-0,0001 * * *$ & $0,0000^{*}$ & $0,0004 * * *$ & $0,0005 * * *$ & $-0,0001$ \\
\hline m30_44 & $0,0000^{*}$ & $0,0000 * * *$ & $0,0000 * * *$ & $0,0002 * * *$ & $0,0002 * * *$ & 0,0000 \\
\hline m45_59 & $0,0013 * * *$ & $-0,0004 * * *$ & $0,0011 * * *$ & $0,0045^{* * *}$ & $0,0053 * * *$ & $-0,0056$ \\
\hline m60_69 & $0,0028 * * *$ & $0,0006 * * *$ & $0,0017 * * *$ & $0,0066 * * *$ & $0,0083 * * *$ & $-0,0005$ \\
\hline $\mathrm{m} 70$ & $0,0004 * * *$ & $0,0003 * * *$ & $0,0002 * *$ & $0,0012 * * *$ & $0,0011 * * *$ & 0,0003 \\
\hline f10_17 & $-0,0047 * * *$ & $-0,0020 * * *$ & $-0,0024 * * *$ & $-0,0041 * * *$ & $-0,0032 * * *$ & $-0,0019$ \\
\hline f18_29 & $-0,0069 * * *$ & $-0,0020 * * *$ & $-0,0041 * * *$ & $-0,0126 * * *$ & $-0,0141 * * *$ & 0,0005 \\
\hline f30_44 & $-0,0032 * * *$ & $-0,0013 * * *$ & $-0,0016^{* * *}$ & $-0,0038 * * *$ & $-0,0045 * * *$ & 0,0004 \\
\hline f45_59 & $0,0078 * * *$ & $0,0035 * * *$ & $0,0039 * * *$ & $0,0057 * * *$ & $0,0068 * * *$ & $-0,0007$ \\
\hline f60_69 & $0,0084 * * *$ & $0,0038 * * *$ & $0,0043^{* * *}$ & $0,0044 * * *$ & $0,0065 * * *$ & $-0,0017$ \\
\hline $\mathrm{f} 70^{-}$ & $-0,0002$ & 0,0000 & $-0,0001$ & $0,0026^{* * *}$ & $0,0025^{* * *}$ & 0,0007 \\
\hline Bom & $-0,0010 * * *$ & $-0,0005 * * *$ & $-0,0006^{* * *}$ & $-0,0011 * * *$ & $-0,0011^{* * *}$ & $-0,0004$ \\
\hline Regular & $-0,0100 * * *$ & $-0,0035 * * *$ & $-0,0065 * * *$ & $-0,0117 * * *$ & $-0,0104 * * *$ & $-0,0042 * * *$ \\
\hline Ruim & $-0,0064 * * *$ & $-0,0012 * * *$ & $-0,0045 * * *$ & $-0,0091 * * *$ & $-0,0067 * * *$ & $-0,0028 * * *$ \\
\hline Mruim & $-0,0015 * * *$ & $-0,0002 * * *$ & $-0,0012 * * *$ & $-0,0023 * * *$ & $-0,0016^{* * *}$ & $-0,0007 * * *$ \\
\hline Limitação & $-0,0018 * * *$ & $-0,0010 * * *$ & $-0,0011 * * *$ & $-0,0039 * * *$ & $-0,0038 * * *$ & $-0,0007 * * *$ \\
\hline Crônica & $0,0125 * * *$ & $0,0069 * * *$ & $0,0072 * * *$ & $0,0104 * * *$ & $0,0090 * * *$ & $0,0050 * * *$ \\
\hline Lrendapc & $0,0237 * * *$ & $0,0202 * * *$ & $0,0082 * * *$ & $-0,0256^{* * *}$ & $-0,0288 * * *$ & $-0,0046$ \\
\hline fundamental & $-0,0016^{* *}$ & $-0,0054 * * *$ & $0,0012 *$ & 0,0000 & $-0,0018$ & 0,0010 \\
\hline Médio & $0,0024 * * *$ & $0,0032 * * *$ & 0,0002 & $-0,0010$ & $-0,0011$ & 0,0010 \\
\hline Superior & $0,0062 * * *$ & $0,0078 * * *$ & $0,0014^{*}$ & 0,0009 & 0,0004 & 0,0021 \\
\hline Desocupado & $0,0011 * * *$ & $0,0003 * * *$ & $0,0009 * * *$ & $0,0027 * * *$ & $0,0038 * * *$ & $-0,0003$ \\
\hline Ccarteira & $-0,0028 * * *$ & $0,0021 * * *$ & $-0,0044 * * *$ & $-0,0100 * * *$ & $-0,0102 * * *$ & $-0,0064 * * *$ \\
\hline Fpublico & $-0,0007 * * *$ & $0,0012 * * *$ & $-0,0012 * * *$ & $-0,0019 * * *$ & $-0,0016^{* * *}$ & $-0,0014 * *$ \\
\hline Domestico & $0,0008 * * *$ & $0,0002 * * *$ & $0,0007 * * *$ & $0,0019 * * *$ & $0,0021 * * *$ & $0,0007 * * *$ \\
\hline Scarteira & $0,0008 * * *$ & $0,0002 * * *$ & $0,0006^{* * *}$ & $0,0007 * * *$ & $0,0008 * * *$ & $0,0003^{*}$ \\
\hline Cpropria & $-0,0004 * * *$ & $-0,0002 * * *$ & $-0,0003 * * *$ & $-0,0005 * * *$ & $-0,0006 * * *$ & $-0,0002 * *$ \\
\hline empregador & $-0,0022 * * *$ & $-0,0004 * * *$ & $-0,0019 * * *$ & $-0,0014 * * *$ & $-0,0013 * * *$ & $-0,0013 * *$ \\
\hline Outra & $0,0025^{* * *}$ & $0,0011 * * *$ & $0,0018 * * *$ & $0,0018 * * *$ & $0,0023 * * *$ & 0,0004 \\
\hline Plano & $0,0364 * * *$ & $0,0233 * * *$ & $0,0193 * * *$ & $0,0287 * * *$ & $0,0371 * * *$ & $-0,0031$ \\
\hline Norte & $0,0011 * * *$ & $0,0008 * * *$ & $0,0006^{* *}$ & $-0,0022 * * *$ & $-0,0020 * * *$ & $-0,0010$ \\
\hline Sudeste & $0,0052 * * *$ & $0,0012 * * *$ & $0,0043 * * *$ & $-0,0002$ & 0,0010 & $-0,0004$ \\
\hline Sul & 0,0006 & $-0,0004$ & $0,0008^{*}$ & $0,0025^{* * *}$ & $0,0033 * * *$ & 0,0007 \\
\hline Centrooeste & $-0,0001$ & $-0,0001 * * *$ & $-0,0011$ & $0,0015^{* * *}$ & $0,0016^{* * *}$ & $0,0005^{* *}$ \\
\hline$G C_{\varepsilon}$ & 0,0035 & $-0,0039$ & $-0,0079$ & $-0,0109$ & $-0,0174$ & 0,0168 \\
\hline IC & $0,0739 * * *$ & $0,0542 * * *$ & $0,0198 * * *$ & $-0,0257 * * *$ & $-0,0176^{* * *}$ & $-0,00776^{* *}$ \\
\hline ICwv & $0,0797 * * *$ & $0,0507 * * *$ & $0,0405^{* * *}$ & $-0,0034$ & $-0,0056$ & $-0,0097 * *$ \\
\hline Observações & 319.288 & 319.288 & 212.937 & 319.288 & 319.288 & 22.989 \\
\hline
\end{tabular}

$* * * \mathrm{p}<0.01, * * \mathrm{p}<0.05 \mathrm{e}^{*} \mathrm{p}<0.1$

Os índices de concentração mostraram que variáveis de morbidade e a variável rank se relacionam de forma inversa, sugerindo, que quanto pior a posição na distribuição de renda, maiores são as necessidades de uso. A principal exceção foi dada pela presença de doença crônica (Tabela A.1). Uma das razões para a associação positiva entre essas variáveis pode estar no maior acesso a diagnóstico dos indivíduos de renda mais elevada. 
Como as variáveis de morbidade possuem impacto positivo sobre o uso, suas contribuições, com exceção da dummy para doença crônica, são no sentido de reduzir as desigualdades pró-rico e aumentar as desigualdades pró-pobre.

As dummies sexo-idade mostraram uma contribuição mais heterogênea, mas de, um do modo geral, as contribuições das dummies do sexo masculino são menos favoráveis ao uso pelos mais pobres do que as do sexo feminino.

A renda contribuiu para uma distribuição pró-rico do uso total de consultas médicas e uma distribuição pró-pobre do uso total de internações hospitalares. Esse resultado, entretanto, não necessariamente significa melhor utilização das internações pelos mais pobres; mas pode ser um indicativo de que os mais pobres só conseguem usufruir de cuidados quando precisam de tratamento intensivo.

Outro ponto que chama atenção é que a contribuição da renda nos contatos subsequentes é consideravelmente menor do que no contanto inicial (etapa) de acesso, sugerindo que a renda é um limitante mais de acesso do que da quantidade de cuidado.

Uma contribuição da renda menor do que o valor do ICwv indica que outras variáveis socioeconômicas contribuem para a desigualdade no uso considerada injusta, o que pode ser verificado nas contribuições significantes da escolaridade, da situação no mercado de trabalho, da posse de plano de saúde e da região de residência.

Pessoas mais escolarizadas possuem maior conhecimento médico, o que resulta em maior procura por serviços de saúde em relação a pessoas menos escolarizadas. Além disso, escolaridade mais elevada está associada a maiores rendimentos, resultando em uma contribuição positiva para a desigualdade. Esse resultado foi, especialmente, evidente para pessoas com escolaridade de nível superior; contudo, nem sempre a escolaridade aparece como determinante importante da desigualdade no uso, uma vez que ela também reflete as preferências ou gostos dos indivíduos.

Apesar de não haver uma relação direta entre a situação no mercado de trabalho e o cuidados de saúde, normalmente, encontra-se uma contribuição da situação no mercado de trabalho para a desigualdade na utilização. O sinal depende da relação entre a situação ocupacional e a renda e também do custo de oportunidade em procurar serviços de saúde.

As ocupações com maiores rendimentos (empregado com carteira, funcionário público, conta própria e empregadores) apresentaram uma relação positiva com a renda (Tabela A.1). Por outro lado, o custo de oportunidade nessas ocupações pode ser maior do que aquele em ocupações com menor remuneração. De outra parte, indivíduos em 
pior condição de saúde demandam mais serviços de saúde e encontram dificuldades em adquirir melhores empregos. Desse modo, a contribuição da ocupação para a desigualdade no uso deve ser interpretada com cuidado, uma vez que não é inteiramente exógena ao modelo.

A posse de plano de saúde foi o determinante social que mais contribuiu para uma desigualdade favorável àqueles em melhor condição econômica. Como a decisão de realizar um plano de saúde recebe influencia da condição de saúde, a contribuição deste determinante também pode estar encobrindo algum aspecto de morbidade.

O uso de serviços de saúde também é afetado pelas desigualdades regionais de renda, que são um reflexo das desigualdades socioeconômicas. Regiões mais pobres são dotadas de menor oferta de serviços médicos, o que, por sua vez, restringe o uso de pessoas residentes nessas regiões. O sinal da contribuição regional dependerá, pois, da situação econômica e de oferta de cuidados da região em relação à categoria de referência.

Por fim as contribuições remanescentes decorrem de fatores não incorporados ao modelo, agregadas em um termo residual, mensurado pelo índice de concentração generalizado do termo do erro, o qual fornece a medida do uso não explicado pelos fatores de necessidade e de não necessidade. Um valor próximo a zero desse termo significa um bom ajuste do modelo.

Essas contribuições podem variar em relação à etapa de cuidado e entre regiões, o que foi ilustrado pela comparação regional dos determinantes no contato inicial (acesso) e nos contatos subsequentes (quantidade de contatos).

Os determinantes de necessidade (as variáveis demográficas e de morbidade) contribuíram com mais da metade da desigualdade na probabilidade de consultar um médico no Brasil. Portanto, a desigualdade no uso favorável aos mais ricos decorre em grande parte da maior necessidade de cuidados nesse grupo.

Essa resultado controverso pode ser compreendido quando as características de necessidades são examinadas de forma desagregada. A contribuição das doenças crônicas $(0,0069)$, determinante de necessidade com contribuição pró-rico, aparece ao lado da posse de plano de saúde $(0,0233)$ e da renda $(0,0202)$ como um dos principais determinantes da desigualdade pró-rico na probabilidade de consultar um médico no Brasil (Tabela 5.3), o que reforça o argumento de que a maior utilização pelos grupos de 
renda mais alta, está associada a algum tipo de acompanhamento médico para tratamento de doenças crônicas. ${ }^{24}$

Quando se examina a desigualdade em âmbito regional, no entanto, o peso dos fatores de necessidades diminui, e a renda e a posse de plano de saúde surgem como determinantes mais relevantes na explicação da desigualdade na probabilidade de contatar um médico.

Gráfico 5.8 - Decomposição da desigualdade na probabilidade de contatar consultas médicas, Brasil e Regiões - 2008

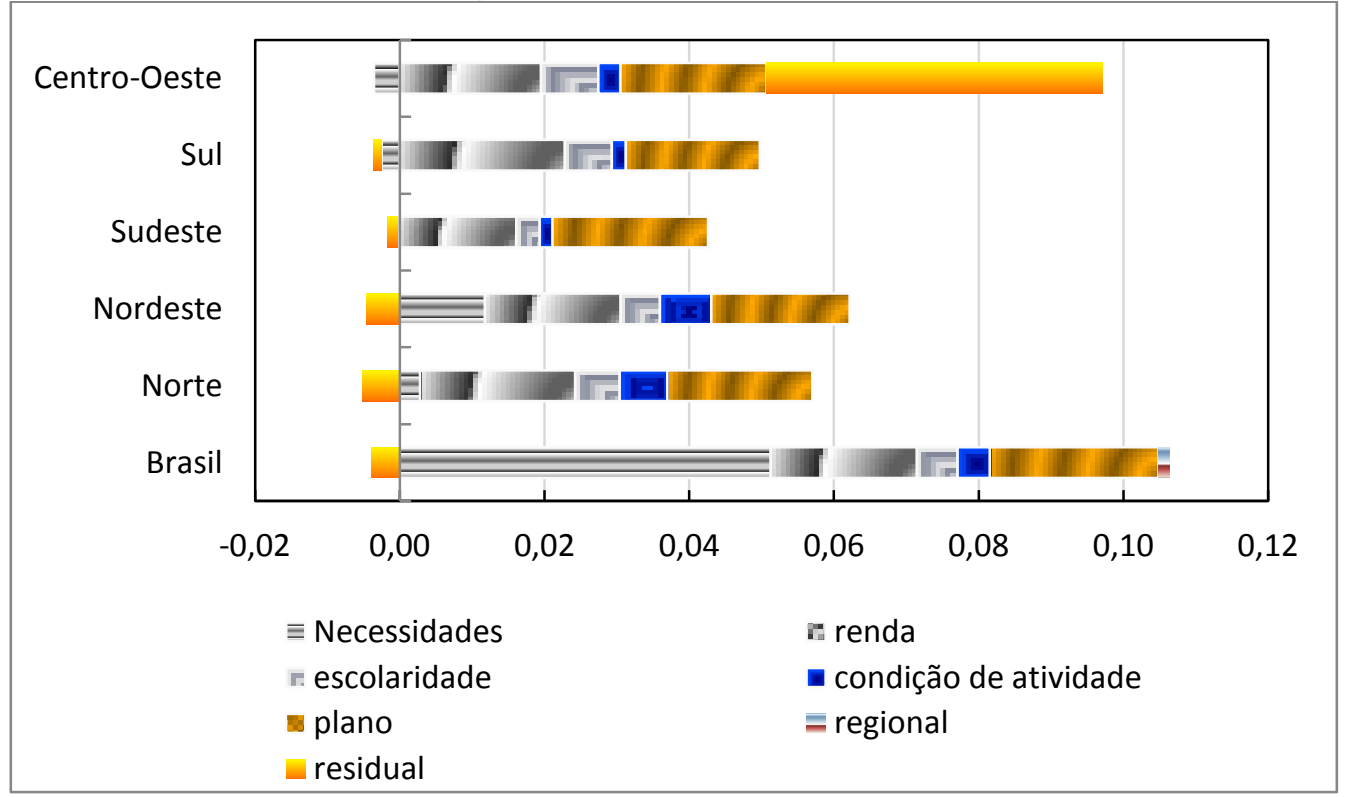

Obs.: Decomposição obtida pelo efeito marginal do modelo logit

Em relação à desigualdade na frequência de consultas médicas, visualiza-se: contribuição pró-pobre da condição de atividade, provavelmente, oriunda do maior custo de oportunidade das pessoas ativas em relação às inativas em manter a frequência no tratamento de saúde e a manutenção da renda como fonte relevante da desigualdade pró-rico, porém com uma contribuição menor do que a da posse de plano de saúde.

${ }^{24}$ Como comentado anteriormente, os grupos de renda mais alta possuem maior acesso a diagnósticos, o que também explica o peso desse determinante como variável explicativa do uso de consultas. Esse resultado, provavelmente, represente um maior aceso a diagnósticos pelos mais pobres e, não uma menor incidência de doenças crônicas nos mais pobres. 
Gráfico 5.9 - Decomposição da desigualdade na frequência de consultas médicas, Brasil e Regiões - 2008

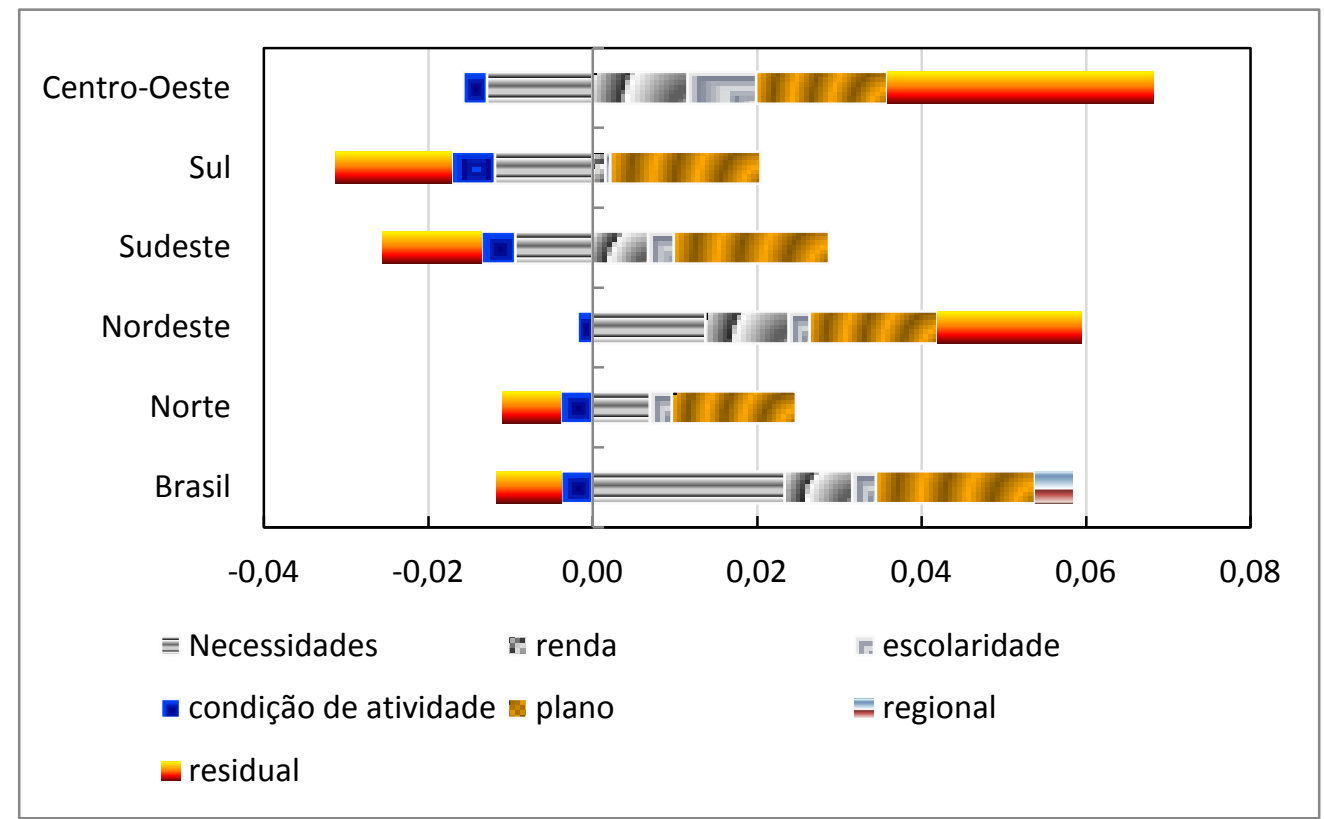

Obs.: Decomposição obtida pelo efeito marginal do modelo binomial negativo truncado

Com uma desigualdade favorável aos mais pobres na probabilidade de internação hospitalar, quase todos os determinantes de desigualdade apresentaram uma contribuição negativa, ou seja, favorecem o uso pelos mais pobres. A principal exceção foi dada pela contribuição do plano de saúde que ajudou a reduzir o grau da desigualdade pró-pobre na probabilidade de internação hospitalar. 
Gráfico 5.10 - Decomposição da desigualdade na probabilidade de contatar internações hospitalares, Brasil e Regiões - 2008

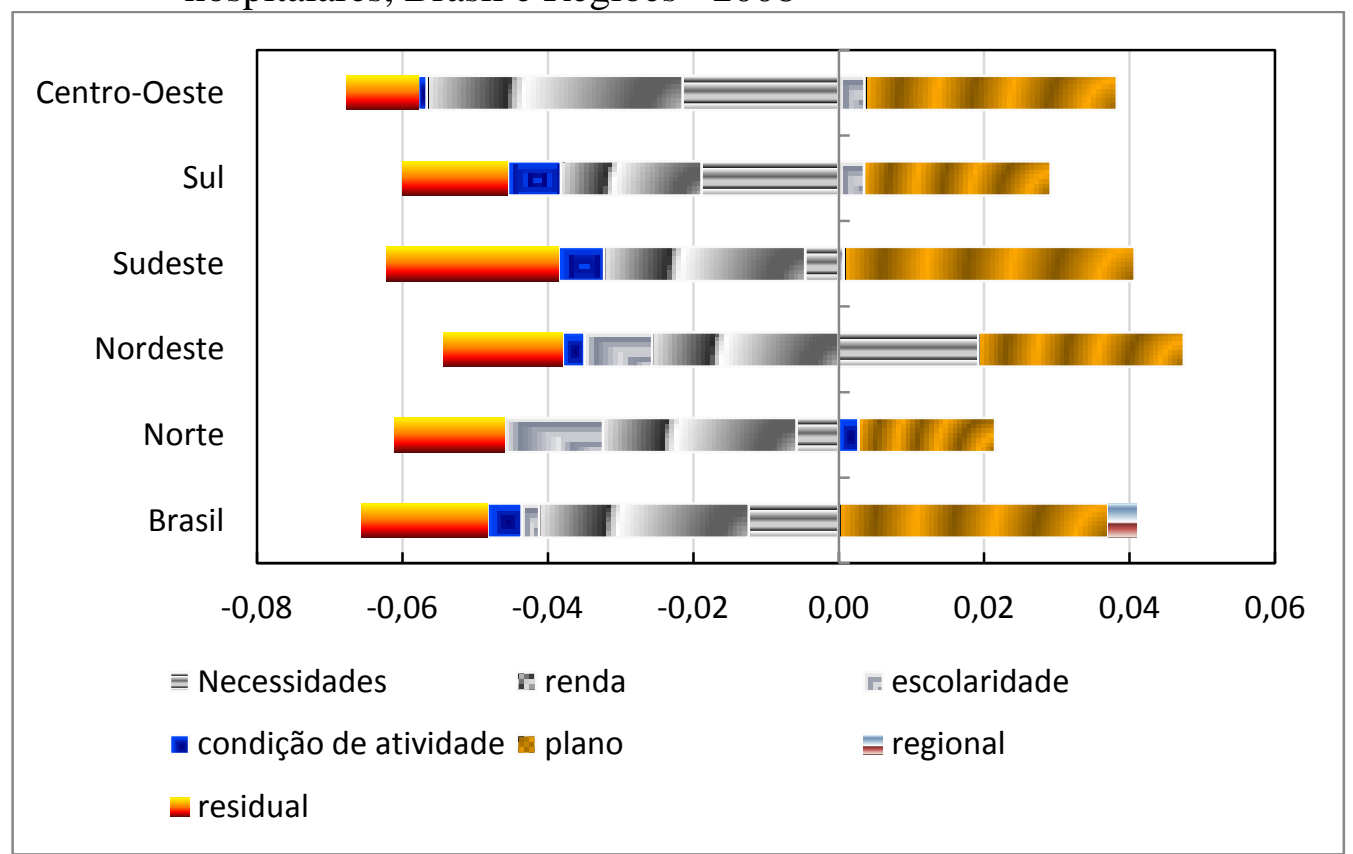

Obs.: Decomposição obtida pelo efeito marginal do modelo logit

A frequência de internações hospitalares também se mostrou favorável aos mais pobres, sendo os fatores de necessidade e de condição de atividade os que mais contribuíram para uma desigualdade pró-pobre.

Gráfico 5.11 - Decomposição da desigualdade na frequência de internações hospitalares, Brasil e Regiões - 2008

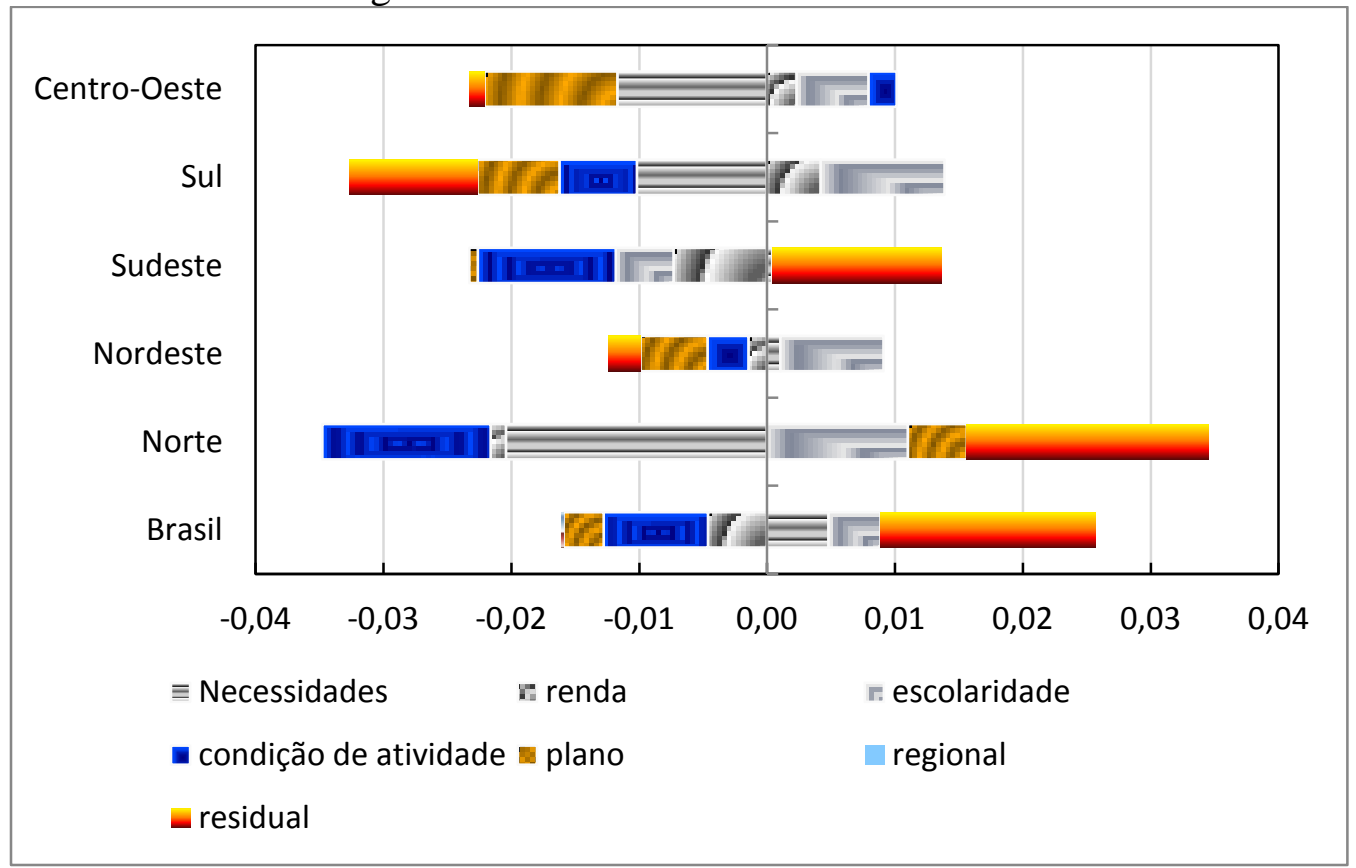

Obs.: Decomposição obtida pelo efeito marginal do modelo Poisson truncado

Ressalta-se, também, que, com exceção da desigualdade na probabilidade de consulta médicas, o termo residual teve contribuição relevante para a desigualdade no 
cuidado. Apesar de esse termo envolver todos os fatores não observados, grande parte dessa contribuição pode ser atribuída às características responsáveis pela decisão do profissional de saúde, mas que, por não constarem na base de dados não puderam ser incorporadas às estimativas. 


\section{CONCLUSÃo}

A Constituição Federal de 1988, com o objetivo de garantir saúde para toda a população brasileira, instituiu o Sistema Único de Saúde (SUS), único sistema público de saúde no mundo que oferece universalidade e integralidade na assistência. A literatura mostra que a despeito da oferta de uma cobertura universal, as desigualdades na utilização do cuidado relacionada à renda são persistentes, constituindo iniquidades por serem consideradas injustas e passíveis de serem evitadas. Mais do que isso, indica que historicamente essas desigualdades são ampliadas por desigualdades regionais na distribuição de recursos físicos e humanos.

Com efeito, o objetivo da tese é analisar o desempenho da entrega de cuidados de saúde no Brasil em termos de equidade, por meio de violações do princípio de equidade horizontal na utilização dos serviços de saúde e da decomposição dos determinantes da desigualdade na utilização relacionada à renda.

A hipótese de equidade horizontal no uso foi testada por índices de iniquidade, que mensuram desigualdades consideradas injustas, como as decorrentes da renda. Considerando a diferença regional na distribuição da oferta de recursos, os índices foram estabelecidos para cada região e unidade da Federação, com o intuito de capturar o aspecto regional das desigualdade de uso.

Desse modo, os índices de desigualdades para a utilização de consultas médicas não confirmam a hipótese de equidade horizontal na utilização para a maioria das unidades da Federação, tendo sido observado um padrão de iniquidade no uso de consultas médicas em favor daquelas pessoas em melhor condição econômica.

Em relação as internações hospitalares, o elevado valor negativo dos índices de iniquidade sugere um padrão de desigualdade no uso de internações favorável aos mais pobres; no entanto, como poucos estados apresentaram índices com significância estatística, não se pode chegar a uma conclusão segura a respeito da existência de iniquidade na utilização de internações hospitalares.

É importante observar que uma desigualdade favorável aos mais pobres na utilização de internações hospitalares não necessariamente representa um melhor uso das internações pelos indivíduos mais pobres, uma vez que também pode indicar que os mais pobres só conseguem receber cuidado quando necessitam de cuidados intensivos. Se for esse o caso, estados com elevado grau de iniquidade no uso de internações devem aumentar os investimentos em cuidados primários como forma de desonerar o 
atendimento hospitalar, sobrecarregado por atendimentos que poderiam ser realizados em unidades básicas de saúde.

A comparação regional mostra que a magnitude da iniquidade no uso de consultas varia entre regiões, mas há pouca variação entre unidades da Federação da mesma região. Na Região Nordeste estão os estados com maiores índices de iniquidade no uso de consultas, enquanto as Regiões Sul e Sudeste possuem os menores graus de iniquidade. As diferenças regionais no grau de desigualdade no uso de consultas médicas podem estar associadas tanto à maior concentração de renda nas regiões mais pobres, quanto à menor oferta do SUS nas regiões menos desenvolvidas.

Dados do DATASUS mostram que em 2010 a oferta de médicos por mil habitantes pelo SUS nas Regiões Sul e Sudeste era de 3,94 e 3,84, respectivamente, enquanto na Região Nordeste era de apenas 2,51. Esse resultado indica que a entrega de cuidados pelo SUS não é a mesma em todas as unidades da Federação, uma vez que esta depende tanto do financiamento como da gestão de cada localidade. Desse modo, os indivíduos que podem pagar com recursos próprios por uma consulta médica ou que são usuários de plano de saúde possuem uma taxa de utilização maior do que os usuários exclusivos do sistema público de saúde.

De outra parte, os índices de iniquidade mostraram que o uso de internações é mais homogênea entre regiões, com a Região Centro-Oeste apresentando o grau mais elevado de desigualdade relacionada à renda. Essa distribuição regional mais homogênea da iniquidade no uso de internações hospitalares pode ser resultado da melhor distribuição regional dos leitos hospitalares (Tabela A.15).

A preocupação aqui, contudo, é com a iniquidade no uso relacionada à renda derivada de características individuais que afetam o uso. Para entender como esses determinantes da utilização contribuem para a desigualdade, os índices de concentração foram decompostos em determinantes de necessidade de saúde e sociais.

Os determinantes de necessidade, em geral, contribuíram para um uso favorável aos mais pobres, dado que indivíduos mais pobres precisam mais de cuidados com a saúde. Enquanto, as contribuições dos determinantes sociais foi mais diversificada.

Se, por um lado, a renda tornou a distribuição de consultas médicas mais prórico, por outro, deixou a distribuição do uso de internação menos pró-pobre. Isso significa que quanto maior a renda, maior o uso de consultas médicas e menor a utilização de internações hospitalares. Esse resultado reforça o argumento de que pessoas mais pobres utilizam mais os cuidados intensivos do que os cuidados 
preventivos com a saúde. Além da renda, a escolaridade, a condição de atividade no mercado de trabalho, a posse de plano de saúde e o local de residência fornecem contribuições sociais para a desigualdade no uso do cuidado relacionado à renda.

A escolaridade exerce uma contribuição para a desigualdade muito similar à da renda. Níveis de escolaridade maiores contribuíram para acentuar o grau de desigualdade pró-rico e reduzir o pró-pobre no uso de consultas e de internações hospitalares, respectivamente. A maior utilização dos serviços de consulta médica pelas pessoas com nível de escolaridade pode ser atribuída a um maior conhecimento da importância de cuidados médicos, o que induz a um aumento da procura para o cuidado preventivo com a saúde.

Por sua vez, a condição de atividade, em geral, contribuiu para uma distribuição mais pró-pobre da distribuição de cuidado, significando que o fato de estar ocupado pode resultar em custo de oportunidade maior para os indivíduos com melhor condição socioeconômica.

As contribuições da posse de plano de saúde e do local de residência, contudo, são as que despertam maior interesse dos elaboradores de políticas públicas por serem alvo direto de atuações na área de saúde. Assim, as contribuições para uma utilização pró-rico da posse de plano de saúde e do local de residência poderiam ser reduzidas, por exemplo, por uma cobertura de saúde com foco em pessoas de baixa renda e pela ampliação de recursos físicos e humanos em áreas com escassez na oferta de serviços de saúde.

Nesse sentido, uma melhor a articulação entre o SUS e o sistema de saúde suplementar poderia direcionar os recursos do SUS para quem mais precisa. Talvez a melhor forma de realizar esse redirecionamento seja inibindo a duplicidade de acesso dos portadores de plano de saúde por meio de mecanismos que desestimulem os usuários de planos de saúde a usar os serviços do SUS. Medici (2011), por exemplo, propõe que seja mantida a opção de restituição do imposto de renda da pessoa física associada ao pagamento de planos de saúde, mas somente para aqueles que optarem por utilizar apenas o plano de saúde, sendo essa opção retirada daqueles que optarem pelo uso do SUS e do plano de saúde, simultaneamente.

Outra medida que pode induzir a uma melhor aplicação dos recursos do SUS é dada pelo aumento da participação de localidades mais pobres nas transferências federais de recursos da saúde. Nessa direção, uma proposta seria orientar as transferências do Fundo Nacional de Saúde para estados e municípios de acordo com a 
necessidades locais de saúde, de modo que fossem privilegiadas as localidades mais pobres na repartição dos recursos. Isso porque, como observam Mendes, Miranda e

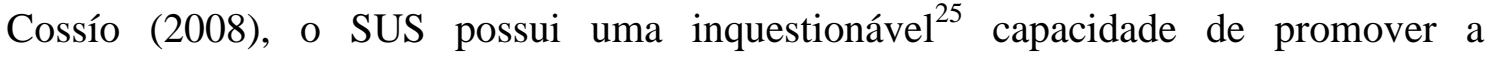
redistribuição regional dos recursos e serviços de saúde, especialmente, se houver a substituição de critérios populacionais por critérios de necessidade de saúde na distribuição das transferências do SUS.

Nesse aspecto, o caráter compensatório do SUS em relação ao nível de renda regional torna-se fundamental para o provimento de serviços de saúde onde falta capacidade para o financiamento da saúde ${ }^{26}$. Desse modo, para que a entrega de cuidados de saúde no Brasil seja de fato equitativa, não basta reduzir as desigualdades sociais, mas também devem ser considerados os aspectos da gestão e do financiamento da saúde pública no País. Futuras pesquisas deveram, portanto, incorporar aos indicadores de concentração informações que tratam do financiamento e da gestão descentralizada do SUS para que se alcance a equidade na utilização de cuidados de saúde em nível regional.

\footnotetext{
${ }^{25}$ As transferências condicionais obrigatórias, como as realizadas no âmbito do SUS "são mais adequadas que as transferências incondicionais quando o objetivo é induzir a melhoria de algum indicador social ou reduzir a desigualdade desses indicadores entre regiões ou estados (MENDES; MIRANDA; COSSÍO 2008).

${ }^{26}$ Desde 2004, a parcela da União para o financiamento de ações e serviços de saúde é igual ao valor empenhado no ano anterior, corrigido pela variação nominal do Produto Interno Bruto. Para os estados e o Distrito Federal, a contribuição é de $12 \%$ do produto da arrecadação dos impostos e dos recursos, definidos na EC/29 de 2000, deduzidas as parcelas que forem transferidas aos respectivos Municípios. Os municípios devem contribuir com quinze por cento do produto da arrecadação dos impostos e dos recursos conforme define a EC/29 de 2000.
} 


\section{REFERÊNCIAS}

ALMEIDA, C. M.; et al. Health sector reform in Brazil: a case study of inequity. International Journal of Health Services, v. 30, n. 1, p. 129-162, 2000.

ANDRADE, M. V.; MAIA, A C. Diferenciais de utilização do cuidado de saúde no sistema suplementar brasileiro. Estudos Econômicos, v. 39, nº 1, p. 7-38, 2009.

ANDRADE, M. V.; NORONHA, K. Uma nota sobre o principio da integralidade do SUS. In: BACHA, E. L.; Schwartzman, S. Brasil : a nova agenda social. Rio de Janeiro : LTC, 2011, cap. 2, p. 94-103.

BARROS, A. J. D.; BERTOLDI, A. D. Desigualdades na utilização e no acesso a serviços odontológicos. Ciência \& Saúde Coletiva, v. 7, n. 4, p. 709-712, 2002.

BLACKBURN, M. L. Interpreting the magnitude of changes in measures of income inequality. Journal of Econometrics, v. 42, n. 1, 21-25, 1989.

BRASIL. Constituição (1988). Constituição da República Federativa do Brasil. Brasília, DF: Senado, 1988.

Ministério da Saúde (MS). Saúde da Família: avaliação da implementação em dez grandes centros urbanos: síntese dos principais resultados. Brasília, 2005.

. Decreto $\mathrm{n}^{\circ}$ 99.060, de 7 de março de 1990. Dispõe sobre a vinculação do Instituto Nacional de Assistência Médica da Previdência Social - INAMPS ao Ministério da Saúde e dá outras providências. Diário Oficial da União, Brasília, DF, 7 $\begin{array}{lllll}\text { mar. } & 1990 . & \text { Seção } & \text { 1.Disponível }\end{array}$ http://www.planalto.gov.br/ccivil_03/decreto/1990-1994/D99060impressao.html>. Acesso em:01 out. 2011.

Lei $\mathrm{n}^{\circ}$ 8.080, de 19 de setembro de 1990. Dispõe sobre as condições para a promoção, proteção e recuperação da saúde, a organização e o financiamento dos serviços correspondentes e dá outras providências. Diário Oficial da União, Brasília, DF, 19 set. 1990. Disponível em:< http://www.planalto.gov.br/ccivil/leis/18080.htm> Acesso em: 10 out. 2010.

Lei $\mathrm{n}^{\circ}$ 8.142, de 28 de dezembro de 1990. Dispõe sobre a participação da comunidade na gestão do Sistema Único de Saúde (SUS) e sobre as transferências intergovernamentais de recursos financeiros na área da saúde e dá outras providências. Diário Oficial da União, Brasília, DF, 28 dez. 1990. Disponível em: < http://www.planalto.gov.br/ccivil_03/Leis/L8142.htm> Acesso em: 10 out. 2010.

Lei 8.689/93, de 27 de julho de 1993. Dispõe sobre a extinção do Instituto Nacional de Assistência Médica da Previdência Social (Inamps) e dá outras 
providências. Diário Oficial da União, Brasília, DF, 27 jul. 1993. Disponível em: < http://www.planalto.gov.br/ccivil_03/leis/L8689.htm>. Acesso em: 01 out. 2011.

Emenda Constitucional n ${ }^{\circ}$ 29, de 13 de setembro de 2000. Altera os arts. 34, 35, 156, 160, 167 e 198 da Constituição Federal e acrescenta artigo ao Ato das Disposições Constitucionais Transitórias, para assegurar os recursos mínimos para o financiamento das ações e serviços públicos de saúde. Diário Oficial da União,

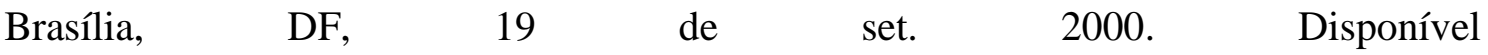
em:http://www.planalto.gov.br/ccivil_03/constituicao/emendas/emc/emc29.htm. Acesso em: 09 nov. 2011.

CAMERON, A. C.; TRIVEDI, P. K. Econometric models based on count data: comparisons and applications of some estimators and tests. Journal of Applied Econometrics, v. 1, n1, p.29-53, 1986.

Microeconometrics - Methods and Applications. Londres: Cambridge University Press, 2005. 1034p.

CAMERON, A. C. et al. A microeconometric model of the demand for health care and health insurance in Australia. The Review of Economic Studies, v. 55, n ${ }^{\circ}$ 1, p. 85-106, 1988.

CAMPINO, A. C. C. et al. Equity in health in LAC - Brazil. In: EquiLAC Project and Poverty and Equity in Health in Latin American and Caribbean: results of Country-Case Studies from Brazil, Ecuador, Guatemala, Jamaica, Mexico and Peru. Banco Mundial, Washington D. C. Programa das Nações Unidas para o Desenvolvimento (PNUD) e Organização Panamericana da Saúde (OPAS), 1999.

CULYER, A. J; WAGSTAFF, A. Equity and equality in health and health care. Journal of Health Economics, v. 12, p. 431-457, 1993.

DENAVAS-WALT, C.; D. PROCTOR, B. D.; SMITH, J. C. Income, Poverty, and Health Insurance Coverage in the United States: 2010. In: Census Bureau, Current Population Reports, P60-239, U.S. Government Printing Office. Washington, DC, 2011. Disponível em:< http://www.census.gov/prod/2011pubs/p60-239.pdf >. Acesso em: 02 jan. 2012.

DIAZ, M. Desigualdades socioeconômicas na saúde. Revista Brasileira de Economia, v. 57, n 1, p. 7-25, 2003.

GERDTHAM, UG. Equity in health care utilization: further tests based on hurdle models and Swedish micro data. Health Economics, v. 6, n 3, p. 303-319, 1997. 
GRANADOS, R. M.; AGUILERA, J. de D. J.; MARTÍN, J. J. M. Estimation of an index of regional health needs in Spain using count regression models with filter. Health Policy, v. 81, p. 4-16, 2007.

GRAVELLE, H. Measuring income related inequality in health: standardization and the partial concentration index. Health Economics, 12, p. 803-819, 2003.

GREENE, W. H. Econometric analysis. 4a. ed. Londres: Prentice-Hall, 2000. 1004p. 0-013-013297-7.

KOOLMAN; X.; van DOORSLAER, E. On the interpretation of a concentration index of inequality. Health Economics, v. 13, n. 7, p. 649-656, 2004.

Le GRAND, J. Inequalities in health - some international comparisons. European Economic Review, v. 31, p. 182-191, 1987.

JONES, A. M.; KOOLMAN, X; van DOORSLAER, E. The impact of having supplementary private insurance on the use of specialists in selected European countries. In: ANNALES D'ÉCONOMIE ET DE STATISTIQUE, nº 83/84, p. 251275, 2006. Disponível em: http://www.jstor.org/stable/20079170. Acesso em:12 set. 2011.

MARMOT, M. Social determinants of health inequalities. The Lancet, v 365, p.10991104,2005

MASSERIA, C.; GIANNONI, M. Equity in access to health care in Italy: a diseasebased approach. European Journal of Public Health, v. 20, n. 5, 504-510, 2010.

MEDICI, A. Propostas para melhorar a cobertura, a eficiência e a qualidade no setor de saúde. In: BACHA, E. L.; Schwartzman, S. Brasil : a nova agenda social. Rio de Janeiro : LTC, 2011, cap. 1, p. 23-92.

MENDES, M; MIRANDA, R. B; COSIO, F. B. Transferências intergovernamentais no Brasil: diagnóstico e proposta de reforma. Texto para discussão do Senado Federal.

Brasília: Senado $2008 . \quad$ Federal, Disponível em: <http://www.senado.gov.br/senado/conleg/textos_discussao/TD40-

MarcosMendes_RogerioBoueri_FernandoB.Cosio.pdf.>. Acesso em: 08 nov. 2011.

MESSIAS, E. Income inequality, illiteracy rate and life expectancy in Brazil. American Journal of Public Health, v. 93, n. 8, p. 1.294-1.296, 2003.

MULLAHY, J. Heterogeneity, excess zeros, and the structure of count data models. Journal of Applied Econometric. v. 12, p. 337-350, 1997.

NEDER, H. D. Análise de indicadores sociais utilizando o STATA. 2010. 154 p. Universidade Federal de Uberlândia, Uberlândia, 2010. Disponível em: < 
http://www.ecn26.ie.ufu.br/TEXTOS_ESTATISTICA/ANALISE_POLITICAS_SOCI AIS.pdf>. Acesso em: 11 nov. 2010.

NERI, M; SOARES, W. Desigualdade social e saúde no Brasil. Cadernos de Saúde Pública, v. 18, p. 77-87, 2002. Suplemento.

NORONHA, K. V. M. S.; ANDRADE, M. V. Desigualdades sociais em saúde: Evidências Empíricas sobre o caso brasileiro. Revista Econômica do Nordeste, v. 32, p. 877-897, 2001. Número Especial.

Desigualdade social no acesso aos serviços de saúde na região Sudeste do Brasil. In: SEMINÁRIO DE ECONOMIA MINEIRA, 10., 2002, Diamantina. Anais eletrônicos do X Seminário sobre economia mineira. Diamantina: Cedeplar, 2002. Disponível em:< http://www.cedeplar.ufmg.br/seminarios/seminario_diamantina/2002/D40.pdf>. Acesso em: 05 out. 2010. O efeito da distribuição de renda sobre o estado de saúde individual no Brasil. Pesquisa e Planejamento Econômico, v. 37, n.3, p. 521-556, 2007.

NUNES, et al. Medindo as desigualdades em saúde no Brasil: uma proposta de monitoramento. Brasília: Organização Pan-Americana de Saúde - OPAS/OMS, Instituto de Economia Aplicada - IPEA, 224p., 2001.

OLIVEIRA, M. D.; BEVAN, G. Measuring geographic inequities in the Portuguese health care system: an estimation of hospital care needs. Health Policy, v. 66, p. 277293, 2003.

PALERMO, P U.; PORTUGAL, M. S.; SOUZA, F. H. Um estudo sobre desigualdade no acesso à saúde na região Sul. In: ENCONTRO REGIONAL DE ECONOMIA, 10., 2005, Fortaleza. Anais do X Encontro Regional de Economia.

PARIS,V.; DEVAUX, M.; WEI, L. Health systems institutional characteristics: a survey de 29 OECD countries. OECD Health Working Papers, nº 50, OECD, 2010. Disponível em: < http://dx.doi.org/10.1787/5kmfxfq9qbnr-en> Acesso em: 20 dez. de 2011.

POHLMEIER, W.; ULRICH, V. An econometric model of the two-part decision making process in the demand for health care. The Journal of Human Resources, v. 30, n 2, p. 339-361, 1995.

PORTO, M. S. Equidad y distribución geográfica de recursos financieros en los sistemas de salud. Cadernos de Saúde Pública, v. 19, n. 4, p. 939-957, 2002. 
PORTO, S. M.; et al. Alocação equitativa de recursos financeiros: uma alternativa para o caso brasileiro. Saúde em Debate, Rio de Janeiro, v. 27, n. 65, p. 376-388, 2003.

SEN, A. Why health equity? Health Economics, v. 11, n. 8, p. 659-666, 2002.

SCHUTZ, R. R. On the measurement of income inequality. The American Economic Review, v. 41, n. 1, p.107-122, 1951.

SILVA, P. L. N.; PESSOA, D. G. C. LILA, M. F. Análise estatística de dados da PNAD: incorporando a estrutura do plano amostral. Ciência \& Saúde Coletiva, v. 7, $\mathrm{n}^{\circ}$ 4, p. 659-670, 2002.

SOUZA, R. R. Construindo o SUS: a lógica do financiamento e o processo de divisão de responsabilidades entre as esferas de governo. 2002. 100p. Dissertação (Mestrado Profissional em Administração de Saúde ) - Instituto de Medicina Social, Universidade do Estado do Rio de Janeiro, Rio de Janeiro. Disponível em: < http://bvsms.saude.gov.br/bvs/publicacoes/monografia_construindo_sus.pdf>. Acesso em: 15 set. 2011.

SZWARCWALD, C. L. et al. Income inequality and health: the case of Rio de Janeiro. Cadernos de Saúde Pública, v. 15, n. 1, p. 15-28, 1999.

TRAVASSOS, C.; et al. Desigualdades geográficas e sociais na utilização de serviços de saúde no Brasil. Ciência \& Saúde Coletiva, v. 5, n. 1, p. 133-149, 2000.

TRAVASSOS, C.; MARTINS, M. Uma revisão sobre os conceitos de acesso e utilização de serviços de saúde. Cadernos de Saúde Pública, v. 20, p. 190-198, 2004.

TRAVASSOS, C; OLIVEIRA, E. X. G.; VIACAVA, F. Desigualdades geográficas e sociais no acesso aos serviços de saúde no Brasil: 1998 e 2003. Ciência \& Saúde Coletiva, v 11, n 4, p. 975-986, 2006.

Van DOORSLAER, E.; et al. Equity in delivery of health care in Europe and US. Journal of Health Economics, v.19, p.553-583, 2000.

Van DOORSLAER, E; KOOLMAN, X. Explaining the differences in income-related health inequalities across European countries. Health Economics, v. 13, p. 609-628, 2004.

Van DOORSLAER, E; KOOLMAN, X; JONES, A. M. Explaining income-related inequalities in doctor utilization in Europe. Health Economics, v.13, n 7, p. 629-647, 2004.

Van DOORSLAER, E; MASSERIA, C. Income-related inequality in the use of medical care in 21 OECD countries. In: Towards high-performing health systems: policy studies. Paris: OECD, 2004, p. 109 - 166. 
Van DOORSLAER, E.; MASSERIA, C.; KOOLMAN, X. Inequalities in access to medical care by income in developed countries. CMJA v. 174, n 2, p. 177-83, 2006.

Van DOORSLAER, E.; WAGSTAFF, A.; RUTTEN, E. Equity in the finance and delivery of care: an international perspective. In: CULYER, A. J.; NEWHOUSE, J. P. Handbook of Health Economics, v. 1, parte B, cap. 34, p. 1803-1862, 2000.

WAGSTAFF, A; van DOORSLAER, E. Measuring and Testing for inequality in the Delivery of Health Care. The Journal of Human Resources, v. 35, n. 4, p. 716-733, 2000.

WAGSTAFF, A.; PACI, P.; van DOORSLAER, E. On the measurement of inequalities in health. Social Science Medicine, v. 33, n. 5, p. 545-557, 1991.

WAGSTAFF, A.; van DOORSLAER, E; PACI, P. Equity in the finance and delivery of health care: some tentative cross-country comparisons. Oxford Review of Economic Policy, v. 5, n.1, p. 89-112, 1989.

WAGSTAFF, A; van DOORSLAER, E, WATANABE, N. On decomposing the causes of health sector inequalities with an application to malnutrition inequalities in Vietnam. Journal of Econometrics, v 112, p. 207-223, 2003.

WHITEHEAD, M. The concepts and principles of equity and health. Copenhagen: World Health Organization Regional Office for Europe, 18p. 2000. Disponível em:< http://salud.ciee.flacso.org.ar/flacso/optativas/equity_and_health.pdf $>$. Acesso em: 10 nov. 2011. 


\section{APÊNDICE A - ESTIMATIVAS DE IC}

Tabela A.1 - Índices de concentração dos determinantes da utilização, Brasil e Regiões - 2008

\begin{tabular}{|c|c|c|c|c|c|c|}
\hline Variáveis & Brasil & Norte & Nordeste & Sudeste & Sul & Centro-Oeste \\
\hline \multirow[t]{2}{*}{ m10_17 } & $-0,251 * * *$ & $-0,202 * * *$ & $-0,245^{* * *}$ & $-0,269 * * *$ & $-0,232 * * *$ & $-0,212 * * *$ \\
\hline & $(0,00337)$ & $(0,00851)$ & $(0,00529)$ & $(0,00622)$ & $(0,00903)$ & $(0,00937)$ \\
\hline \multirow[t]{2}{*}{ m18_29 } & $0,0124 * * *$ & $0,0331 * * *$ & $0,0113^{* *}$ & $0,0342 * * *$ & $0,0453^{* * *}$ & $0,0356 * * *$ \\
\hline & $(0,00294)$ & $(0,00767)$ & $(0,00486)$ & $(0,00520)$ & $(0,00759)$ & $(0,00801)$ \\
\hline \multirow[t]{2}{*}{ m30_44 } & $0,00553^{*}$ & $0,0396 * * *$ & $-0,00666$ & 0,00218 & $-0,0234^{* * *}$ & $0,0375^{* * *}$ \\
\hline & $(0,00298)$ & $(0,00838)$ & $(0,00528)$ & $(0,00515)$ & $(0,00745)$ & $(0,00791)$ \\
\hline \multirow[t]{2}{*}{ m45_59 } & $0,134^{* * *}$ & $0,142 * * *$ & $0,101^{* * *}$ & $0,124 * * *$ & $0,118^{* * *}$ & $0,124 * * *$ \\
\hline & $(0,00355)$ & $(0,0114)$ & $(0,00684)$ & $(0,00581)$ & $(0,00829)$ & $(0,00980)$ \\
\hline \multirow[t]{2}{*}{ m60_69 } & $0,218 * * *$ & $0,274 * * *$ & $0,332 * * *$ & $0,195^{* * *}$ & $0,138 * * *$ & $0,154 * * *$ \\
\hline & $(0,00398)$ & $(0,0129)$ & $(0,00644)$ & $(0,00697)$ & $(0,0101)$ & $(0,0122)$ \\
\hline \multirow[t]{2}{*}{$\mathrm{m} 70$} & $0,219 * * *$ & $0,310 * * *$ & $0,380 * * *$ & $0,183 * * *$ & $0,109 * * *$ & $0,122 * * *$ \\
\hline & $(0,00576)$ & $(0,0178)$ & $(0,00860)$ & $(0,0103)$ & $(0,0156)$ & $(0,0175)$ \\
\hline \multirow[t]{2}{*}{ f10_17 } & $-0,262 * * *$ & $-0,211 * * *$ & $-0,252 * * *$ & $-0,281 * * *$ & $-0,254 * * *$ & $-0,254 * * *$ \\
\hline & $(0,00346)$ & $(0,00877)$ & $(0,00557)$ & $(0,00646)$ & $(0,00895)$ & $(0,00895)$ \\
\hline \multirow[t]{2}{*}{ f18_29 } & $-0,0712 * * *$ & $-0,0714^{* * *}$ & $-0,0762 * * *$ & $-0,0641 * * *$ & $-0,0288 * * *$ & $-0,0288 * * *$ \\
\hline & $(0,00304)$ & $(0,00798)$ & $(0,00502)$ & $(0,00541)$ & $(0,00791)$ & $(0,00790)$ \\
\hline \multirow[t]{2}{*}{ f30_44 } & $-0,0360 * * *$ & 0,00672 & $-0,0408 * * *$ & $-0,0563 * * *$ & $-0,0555^{* * *}$ & $-0,0248 * * *$ \\
\hline & $(0,00285)$ & $(0,00816)$ & $(0,00501)$ & $(0,00493)$ & $(0,00718)$ & $(0,00747)$ \\
\hline \multirow[t]{2}{*}{ f45_59 } & $0,144^{* * *}$ & $0,128 * * *$ & $0,134^{* * *}$ & $0,129 * * *$ & $0,127 * * *$ & $0,132 * * *$ \\
\hline & $(0,00329)$ & $(0,0108)$ & $(0,00612)$ & $(0,00537)$ & $(0,00777)$ & $(0,00938)$ \\
\hline \multirow[t]{2}{*}{ f60_69 } & $0,240 * * *$ & $0,284^{* * *}$ & $0,380 * * *$ & $0,194^{* * *}$ & $0,174^{* * *}$ & $0,163 * * *$ \\
\hline & $(0,00338)$ & $(0,0118)$ & $(0,00522)$ & $(0,00589)$ & $(0,00855)$ & $(0,0111)$ \\
\hline \multirow[t]{2}{*}{ f70 } & $0,256^{* * *}$ & $0,329 * * *$ & $0,412 * * *$ & $0,203 * * *$ & $0,169 * * *$ & $0,181^{* * *}$ \\
\hline & $(0,00487)$ & $(0,0168)$ & $(0,00722)$ & $(0,00859)$ & $(0,0125)$ & $(0,0164)$ \\
\hline \multirow[t]{2}{*}{ mbom } & $0,128 * * *$ & $0,112 * * *$ & $0,0472 * * *$ & $0,0952 * * *$ & $0,144^{* * *}$ & $0,152 * * *$ \\
\hline & $(0,00224)$ & $(0,00795)$ & $(0,00461)$ & $(0,00347)$ & $(0,00540)$ & $(0,00619)$ \\
\hline \multirow[t]{2}{*}{ Bom } & $-0,0113^{* * *}$ & $-0,00653^{* *}$ & $-0,0153 * * *$ & $-0,00585^{* * *}$ & $-0,0148 * * *$ & $-0,0145^{* * *}$ \\
\hline & $(0,00105)$ & $(0,00276)$ & $(0,00181)$ & $(0,00184)$ & $(0,00269)$ & $(0,00291)$ \\
\hline \multirow[t]{2}{*}{ regular } & $-0,0734 * * *$ & $-0,0366 * * *$ & 0,00218 & $-0,0818^{* * *}$ & $-0,0795 * * *$ & $-0,0916^{* * *}$ \\
\hline & $(0,00210)$ & $(0,00575)$ & $(0,00341)$ & $(0,00396)$ & $(0,00535)$ & $(0,00577)$ \\
\hline \multirow[t]{2}{*}{ Ruim } & $-0,127 * * *$ & $-0,0836 * * *$ & $-0,00649$ & $-0,151 * * *$ & $-0,160 * * *$ & $-0,152^{* * *}$ \\
\hline & $(0,00536)$ & $(0,0154)$ & $(0,00901)$ & $(0,0102)$ & $(0,0135)$ & $(0,0155)$ \\
\hline \multirow[t]{2}{*}{ mruim } & $-0,0895 * * *$ & $-0,107 * * *$ & $0,0376^{* *}$ & $-0,115 * * *$ & $-0,199 * * *$ & $-0,0900 * *$ \\
\hline & $(0,0108)$ & $(0,0336)$ & $(0,0182)$ & $(0,0197)$ & $(0,0259)$ & $(0,0358)$ \\
\hline \multirow[t]{2}{*}{ limitacao } & $-0,0426 * * *$ & $-0,0378 * * *$ & 0,00452 & $-0,0484 * * *$ & $-0,0719 * * *$ & $-0,0655^{* * *}$ \\
\hline & $(0,00366)$ & $(0,00988)$ & $(0,00633)$ & $(0,00662)$ & $(0,00890)$ & $(0,0101)$ \\
\hline \multirow[t]{2}{*}{ cronica } & $0,0794 * * *$ & $0,0859 * * *$ & $0,121 * * *$ & $0,0461 * * *$ & $0,0352 * * *$ & $0,0317 * * *$ \\
\hline & $(0,00150)$ & $(0,00500)$ & $(0,00289)$ & $(0,00252)$ & $(0,00350)$ & $(0,00421)$ \\
\hline \multirow[t]{2}{*}{ Irendapc } & $0,0946 * * *$ & $0,0920 * * *$ & $0,104 * * *$ & $0,0819 * * *$ & $0,0790 * * *$ & $0,0893 * * *$ \\
\hline & $(0,000112)$ & $(0,000312)$ & $(0,000225)$ & $(0,000179)$ & $(0,000254)$ & $(0,000316)$ \\
\hline \multirow[t]{2}{*}{ sestudo } & $-0,237 * * *$ & $-0,130 * * *$ & $-0,0755^{* * *}$ & $-0,241 * * *$ & $-0,245^{* * *}$ & $-0,178 * * *$ \\
\hline & $(0,00282)$ & $(0,00880)$ & $(0,00426)$ & $(0,00592)$ & $(0,00905)$ & $(0,00845)$ \\
\hline \multirow[t]{2}{*}{ fundamental } & $-0,156 * * *$ & $-0,144 * * *$ & $-0,152 * * *$ & $-0,173 * * *$ & $-0,166 * * *$ & $-0,176 * * *$ \\
\hline & $(0,00108)$ & $(0,00295)$ & $(0,00182)$ & $(0,00191)$ & $(0,00256)$ & $(0,00296)$ \\
\hline
\end{tabular}


Conclusão

\begin{tabular}{|c|c|c|c|c|c|c|}
\hline Variáveis & Brasil & Norte & Nordeste & Sudeste & Sul & Centro-Oeste \\
\hline \multirow[t]{2}{*}{ médio } & $0,131 * * *$ & $0,173^{* * *}$ & $0,198 * * *$ & $0,0809 * * *$ & $0,115^{* * *}$ & $0,0988 * * *$ \\
\hline & $(0,00174)$ & $(0,00489)$ & $(0,00327)$ & $(0,00289)$ & $(0,00449)$ & $(0,00481)$ \\
\hline \multirow[t]{2}{*}{ superior } & $0,588 * * *$ & $0,542 * * *$ & $0,645 * * *$ & $0,560 * * *$ & $0,514 * * *$ & $0,585^{* * *}$ \\
\hline & $(0,00259)$ & $(0,00915)$ & $(0,00600)$ & $(0,00419)$ & $(0,00613)$ & $(0,00691)$ \\
\hline \multirow[t]{2}{*}{ desocupado } & $-0,284 * * *$ & $-0,205 * * *$ & $-0,216 * * *$ & $-0,348 * * *$ & $-0,337 * * *$ & $-0,337 * * *$ \\
\hline & $(0,00502)$ & $(0,0151)$ & $(0,00835)$ & $(0,00833)$ & $(0,0145)$ & $(0,0146)$ \\
\hline \multirow[t]{2}{*}{ ccarteira } & $0,218 * * *$ & $0,257 * * *$ & $0,306^{* * *}$ & $0,134 * * *$ & $0,111^{* * *}$ & $0,125^{* * *}$ \\
\hline & $(0,00195)$ & $(0,00674)$ & $(0,00413)$ & $(0,00315)$ & $(0,00463)$ & $(0,00564)$ \\
\hline \multirow[t]{2}{*}{ fpublico } & $0,456 * * *$ & $0,487 * * *$ & $0,556 * * *$ & $0,425 * * *$ & $0,450 * * *$ & $0,494 * * *$ \\
\hline & $(0,00424)$ & $(0,0106)$ & $(0,00757)$ & $(0,00776)$ & $(0,0111)$ & $(0,0102)$ \\
\hline \multirow[t]{2}{*}{ domestico } & $-0,162 * * *$ & $-0,148 * * *$ & $-0,135^{* * *}$ & $-0,216 * * *$ & $-0,233^{* * *}$ & $-0,218 * * *$ \\
\hline & $(0,00458)$ & $(0,0134)$ & $(0,00815)$ & $(0,00737)$ & $(0,0113)$ & $(0,0104)$ \\
\hline \multirow[t]{2}{*}{ scarteira } & $-0,0469 * * *$ & $-0,00738$ & $-0,00738$ & $-0,0366 * * *$ & $-0,00956$ & $-0,0140^{*}$ \\
\hline & $(0,00325)$ & $(0,00503)$ & $(0,00503)$ & $(0,00609)$ & $(0,00900)$ & $(0,00850)$ \\
\hline \multirow[t]{2}{*}{ cpropria } & $0,0223 * * *$ & $0,0178 * *$ & $0,0208 * * *$ & $0,0948 * * *$ & $0,0656 * * *$ & $0,0606 * * *$ \\
\hline & $(0,00310)$ & $(0,00817)$ & $(0,00490)$ & $(0,00575)$ & $(0,00789)$ & $(0,00845)$ \\
\hline \multirow[t]{2}{*}{ empregador } & $0,579 * * *$ & $0,561^{* * *}$ & $0,582 * * *$ & $0,576^{* * *}$ & $0,556^{* * *}$ & $0,610^{* * *}$ \\
\hline & $(0,00540)$ & $(0,0174)$ & $(0,0119)$ & $(0,00905)$ & $(0,0118)$ & $(0,0122)$ \\
\hline \multirow[t]{2}{*}{ outra } & $-0,330 * * *$ & $0,0462 * * *$ & $-0,280 * * *$ & $-0,261 * * *$ & $-0,205^{* * *}$ & $-0,250 * * *$ \\
\hline & $(0,00441)$ & $(0,00837)$ & $(0,00608)$ & $(0,0115)$ & $(0,0110)$ & $(0,0155)$ \\
\hline \multirow[t]{2}{*}{ inativo } & $-0,0954 * * *$ & $-0,120 * * *$ & $-0,0660 * * *$ & $-0,0977 * * *$ & $-0,105 * * *$ & $-0,120 * * *$ \\
\hline & $(0,00144)$ & $(0,00380)$ & $(0,00238)$ & $(0,00250)$ & $(0,00386)$ & $(0,00420)$ \\
\hline \multirow[t]{2}{*}{ Plano } & $0,455^{* * *}$ & $0,529 * * *$ & $0,594 * * *$ & $0,351 * * *$ & $0,369 * * *$ & $0,436 * * *$ \\
\hline & $(0,00154)$ & $(0,00609)$ & $(0,00387)$ & $(0,00231)$ & $(0,00368)$ & $(0,00476)$ \\
\hline \multirow[t]{2}{*}{ Norte } & $-0,181 * * *$ & & & & & \\
\hline & $(0,00301)$ & & & & & \\
\hline \multirow[t]{2}{*}{ nordeste } & $-0,297 * * *$ & & & & & \\
\hline & $(0,00159)$ & & & & & \\
\hline \multirow[t]{2}{*}{ sudeste } & $0,151^{* * *}$ & & & & & \\
\hline & $(0,00133)$ & & & & & \\
\hline \multirow[t]{2}{*}{ Sul } & $0,181^{* * *}$ & & & & & \\
\hline & $(0,00247)$ & & & & & \\
\hline \multirow{2}{*}{ centrooeste } & $0,0762 * * *$ & & & & & \\
\hline & $(0,00307)$ & & & & & \\
\hline
\end{tabular}

Erros-padrão entre parênteses

$* * * \mathrm{p}<0.01, * * \mathrm{p}<0.05$ e $* \mathrm{p}<0.1$ 


\section{APÊNDICE B - EFEITOS MARGINAIS DOS DETERMINANTES}

Tabela B.1- Efeitos marginais dos determinantes da utilização do cuidado - Brasil

\begin{tabular}{|c|c|c|c|c|c|c|}
\hline \multirow{3}{*}{ Variáveis } & \multicolumn{3}{|c|}{ Consultas Médicas } & \multicolumn{3}{|c|}{ Internações Hospitalares } \\
\hline & \multirow[b]{2}{*}{$\begin{array}{l}\text { Binomial } \\
\text { Negativo }\end{array}$} & \multicolumn{2}{|c|}{ Hurdle Binomial Negativo } & \multirow[b]{2}{*}{$\begin{array}{l}\text { Binomial } \\
\text { Negativo }\end{array}$} & \multicolumn{2}{|c|}{ Hurdle Poisson } \\
\hline & & Logit & $\begin{array}{l}\text { Negbin } \\
\text { Truncado }\end{array}$ & & Logit & $\begin{array}{l}\text { Poisson } \\
\text { Truncado }\end{array}$ \\
\hline \multirow[t]{2}{*}{ m18_29 } & $-0,0453$ & $-0,0439 * * *$ & $0,119 *$ & $0,0277^{* * *}$ & $0,0250 * * *$ & $-0,0714$ \\
\hline & $(0,0448)$ & $(0,00538)$ & $(0,0682)$ & $(0,00519)$ & $(0,00362)$ & $(0,108)$ \\
\hline \multirow[t]{2}{*}{ m30_44 } & $0,0713^{*}$ & $-0,0354 * * *$ & $0,180 * * *$ & $0,0273 * * *$ & $0,0235^{* * *}$ & $-0,0447$ \\
\hline & $(0,0384)$ & $(0,00543)$ & $(0,0587)$ & $(0,00535)$ & $(0,00382)$ & $(0,127)$ \\
\hline \multirow[t]{2}{*}{ m45_59 } & $0,294 * * *$ & $-0,0203 * * *$ & $0,375^{* * *}$ & $0,0396 * * *$ & $0,0316^{* * *}$ & $-0,000687$ \\
\hline & $(0,0510)$ & $(0,00571)$ & $(0,0748)$ & $(0,00589)$ & $(0,00406)$ & $(0,125)$ \\
\hline \multirow[t]{2}{*}{ m60_69 } & $0,618 * * *$ & $0,0317^{* * *}$ & $0,556 * * *$ & $0,0556 * * *$ & $0,0481 * * *$ & $-0,0570$ \\
\hline & $(0,0593)$ & $(0,00721)$ & $(0,0784)$ & $(0,00859)$ & $(0,00561)$ & $(0,131)$ \\
\hline \multirow[t]{2}{*}{ m70 } & $0,202 * * *$ & $0,0386 * * *$ & $0,161 * *$ & $0,0227 * * *$ & $0,0152 * * *$ & 0,0790 \\
\hline & $(0,0518)$ & $(0,00782)$ & $(0,0701)$ & $(0,00550)$ & $(0,00346)$ & $(0,0793)$ \\
\hline \multirow[t]{2}{*}{ f10_17 } & $0,591 * * *$ & $0,0602 * * *$ & $0,444 * * *$ & $0,0192^{* * *}$ & $0,0104^{* * *}$ & 0,125 \\
\hline & $(0,0458)$ & $(0,00422)$ & $(0,0613)$ & $(0,00506)$ & $(0,00333)$ & $(0,159)$ \\
\hline \multirow[t]{2}{*}{ f18_29 } & $2,197 * * *$ & $0,151 * * *$ & $1,938 * * *$ & $0,151^{* * *}$ & $0,116^{* * *}$ & $-0,0826$ \\
\hline & $(0,0728)$ & $(0,00354)$ & $(0,0863)$ & $(0,00930)$ & $(0,00631)$ & $(0,109)$ \\
\hline \multirow[t]{2}{*}{ f30_44 } & $1,847 * * *$ & $0,182 * * *$ & $1,338 * * *$ & $0,0816 * * *$ & $0,0659 * * *$ & $-0,108$ \\
\hline & $(0,0573)$ & $(0,00359)$ & $(0,0723)$ & $(0,00654)$ & $(0,00472)$ & $(0,104)$ \\
\hline \multirow[t]{2}{*}{ f45_59 } & $1,511 * * *$ & $0,161 * * *$ & $1,135 * * *$ & $0,0414 * * *$ & $0,0340 * * *$ & $-0,0759$ \\
\hline & $(0,0578)$ & $(0,00373)$ & $(0,0776)$ & $(0,00578)$ & $(0,00379)$ & $(0,119)$ \\
\hline \multirow[t]{2}{*}{ f60_69 } & $1,342 * * *$ & $0,144 * * *$ & $1,029 * * *$ & $0,0263 * * *$ & $0,0266 * * *$ & $-0,140$ \\
\hline & $(0,0685)$ & $(0,00483)$ & $(0,0846)$ & $(0,00625)$ & $(0,00443)$ & $(0,114)$ \\
\hline \multirow[t]{2}{*}{$\mathrm{f} 70$} & $-0,0603$ & 0,00257 & $-0,0602$ & $0,0320 * * *$ & $0,0208 * * *$ & 0,117 \\
\hline & $(0,0396)$ & $(0,00876)$ & $(0,0518)$ & $(0,00672)$ & $(0,00343)$ & $(0,0870)$ \\
\hline \multirow[t]{2}{*}{ Bom } & $0,457 * * *$ & $0,0531 * * *$ & $0,440 * * *$ & $0,0185 * * *$ & $0,0130 * * *$ & 0,103 \\
\hline & $(0,0231)$ & $(0,00309)$ & $(0,0324)$ & $(0,00233)$ & $(0,00142)$ & $(0,0910)$ \\
\hline \multirow[t]{2}{*}{ Regular } & $1,813 * * *$ & $0,151^{* * *}$ & $1,774 * * *$ & $0,0802 * * *$ & $0,0489 * * *$ & $0,403 * * *$ \\
\hline & $(0,0430)$ & $(0,00316)$ & $(0,0559)$ & $(0,00490)$ & $(0,00254)$ & $(0,106)$ \\
\hline \multirow[t]{2}{*}{ Ruim } & $3,951 * * *$ & $0,185^{* * *}$ & $4,152 * * *$ & $0,215^{* * *}$ & $0,107^{* * *}$ & $0,904 * * *$ \\
\hline & $(0,127)$ & $(0,00449)$ & $(0,149)$ & $(0,0159)$ & $(0,00611)$ & $(0,208)$ \\
\hline \multirow[t]{2}{*}{ Mruim } & $5,491 * * *$ & $0,175^{* * *}$ & $6,263 * * *$ & $0,311 * * *$ & $0,148 * * *$ & $1,336 * * *$ \\
\hline & $(0,246)$ & $(0,00773)$ & $(0,282)$ & $(0,0285)$ & $(0,0110)$ & $(0,305)$ \\
\hline Limitação & $1,386 * * *$ & $0,178 * * *$ & $1,292 * * *$ & $0,114 * * *$ & $0,0773 * * *$ & $0,280 * * *$ \\
\hline & $(0,0330)$ & $(0,00295)$ & $(0,0401)$ & $(0,00446)$ & $(0,00250)$ & $(0,0375)$ \\
\hline Crônica & $1,243 * * *$ & $0,166^{* * *}$ & $1,079 * * *$ & $0,0390 * * *$ & $0,0232 * * *$ & $0,260 * * *$ \\
\hline & $(0,0229)$ & $(0,00233)$ & $(0,0270)$ & $(0,00220)$ & $(0,00121)$ & $(0,0378)$ \\
\hline Lrendapc & $0,121 * * *$ & $0,0248^{* * *}$ & $0,0629 * * *$ & $-0,00495^{* * *}$ & $-0,00381^{* * *}$ & $-0,0124$ \\
\hline & $(0,00983)$ & $(0,00145)$ & $(0,0151)$ & $(0,000845)$ & $(0,000591)$ & $(0,0162)$ \\
\hline fundamental & $0,0566 * *$ & $0,0458 * * *$ & $-0,0645^{*}$ & $-4,29 e-05$ & 0,00161 & $-0,0182$ \\
\hline & $(0,0284)$ & $(0,00407)$ & $(0,0385)$ & $(0,00241)$ & $(0,00155)$ & $(0,0354)$ \\
\hline Médio & $0,184 * * *$ & $0,0600 * * *$ & 0,0289 & $-0,00277$ & $-0,00210$ & 0,0394 \\
\hline & $(0,0306)$ & $(0,00424)$ & $(0,0420)$ & $(0,00274)$ & $(0,00178)$ & $(0,0436)$ \\
\hline Superior & $0,257 * * *$ & $0,0771 * * *$ & $0,0872 *$ & 0,00138 & 0,000448 & 0,0454 \\
\hline & $(0,0376)$ & $(0,00451)$ & $(0,0503)$ & $(0,00325)$ & $(0,00220)$ & $(0,0565)$ \\
\hline desocupado & $-0,239 * * *$ & $-0,0145^{* * *}$ & $-0,286 * * *$ & $-0,0221 * * *$ & $-0,0213^{* * *}$ & 0,0345 \\
\hline & $(0,0337)$ & $(0,00558)$ & $(0,0481)$ & $(0,00288)$ & $(0,00162)$ & $(0,0748)$ \\
\hline
\end{tabular}


Conclusão

\begin{tabular}{|c|c|c|c|c|c|c|}
\hline \multirow{3}{*}{ Variáveis } & \multicolumn{3}{|c|}{ Consultas Médicas } & \multicolumn{3}{|c|}{ Internações Hospitalares } \\
\hline & \multirow{2}{*}{$\begin{array}{l}\text { Binomial } \\
\text { Negativo }\end{array}$} & \multicolumn{2}{|c|}{ Hurdle Binomial Negativo } & \multirow{2}{*}{$\begin{array}{l}\text { Binomial } \\
\text { Negativo }\end{array}$} & \multicolumn{2}{|c|}{ Hurdle Poisson } \\
\hline & & I ogit & Negbin & & I ogit & Poisson \\
\hline \multirow[t]{2}{*}{ ccarteira } & $-0,181^{* * *}$ & $0,0322 * * *$ & $-0,426 * * *$ & $-0,0242 * * *$ & $-0,0170 * * *$ & $-0,216 * * *$ \\
\hline & $(0,0204)$ & $(0,00354)$ & $(0,0276)$ & $(0,00166)$ & $(0,00123)$ & $(0,0314)$ \\
\hline \multirow[t]{2}{*}{ fpublico } & $-0,102^{* * *}$ & $0,0440 * * *$ & $-0,266^{* * *}$ & $-0,0110 * * *$ & $-0,00631 * * *$ & $-0,112 * *$ \\
\hline & $(0,0306)$ & $(0,00597)$ & $(0,0419)$ & $(0,00250)$ & $(0,00189)$ & $(0,0530)$ \\
\hline \multirow[t]{2}{*}{ domestico } & $-0,342 * * *$ & $-0,0225 * * *$ & $-0,476 * * *$ & $-0,0306 * * *$ & $-0,0230 * * *$ & $-0,155^{* * *}$ \\
\hline & $(0,0305)$ & $(0,00524)$ & $(0,0441)$ & $(0,00198)$ & $(0,00149)$ & $(0,0454)$ \\
\hline \multirow[t]{2}{*}{ scarteira } & $-0,455^{* * *}$ & $-0,0308^{* * *}$ & $-0,508 * * *$ & $-0,0156 * * *$ & $-0,0126 * * *$ & $-0,105^{*}$ \\
\hline & $(0,0236)$ & $(0,00393)$ & $(0,0361)$ & $(0,00251)$ & $(0,00138)$ & $(0,0606)$ \\
\hline \multirow[t]{2}{*}{ cpropria } & $-0,447^{* * *}$ & $-0,0455^{* * *}$ & $-0,438 * * *$ & $-0,0206 * * *$ & $-0,0158^{* * *}$ & $-0,0876 * *$ \\
\hline & $(0,0176)$ & $(0,00352)$ & $(0,0262)$ & $(0,00200)$ & $(0,00132)$ & $(0,0388)$ \\
\hline \multirow[t]{2}{*}{ empregador } & $-0,424 * * *$ & $-0,0201 * * *$ & $-0,555^{* * *}$ & $-0,0105 * * *$ & $-0,00665 * * *$ & $-0,133^{* *}$ \\
\hline & $(0,0332)$ & $(0,00709)$ & $(0,0533)$ & $(0,00340)$ & $(0,00239)$ & $(0,0587)$ \\
\hline \multirow[t]{2}{*}{ outra } & $-0,383 * * *$ & $-0,0401 * * *$ & $-0,415^{* * *}$ & $-0,0105^{* * *}$ & $-0,00931^{* * *}$ & $-0,0298$ \\
\hline & $(0,0299)$ & $(0,00534)$ & $(0,0423)$ & $(0,00304)$ & $(0,00168)$ & $(0,0612)$ \\
\hline \multirow[t]{2}{*}{ plano } & $0,847 * * *$ & $0,130 * * *$ & $0,675 * * *$ & $0,0253 * * *$ & $0,0224 * * *$ & $-0,0383$ \\
\hline & $(0,0230)$ & $(0,00294)$ & $(0,0284)$ & $(0,00205)$ & $(0,00142)$ & $(0,0323)$ \\
\hline \multirow[t]{2}{*}{ norte } & $-0,220 * * *$ & $-0,0391 * * *$ & $-0,175^{* *}$ & $0,0164 * * *$ & $0,0104 * * *$ & 0,103 \\
\hline & $(0,0523)$ & $(0,00724)$ & $(0,0736)$ & $(0,00480)$ & $(0,00298)$ & $(0,0648)$ \\
\hline \multirow[t]{2}{*}{ nordeste } & $0,226 * * *$ & $0,0129 * * *$ & $0,277 * * *$ & $-0,000407$ & 0,00112 & $-0,00859$ \\
\hline & $(0,0364)$ & $(0,00499)$ & $(0,0468)$ & $(0,00246)$ & $(0,00156)$ & $(0,0419)$ \\
\hline \multirow[t]{2}{*}{ sul } & 0,0663 & $-0,00925$ & $0,130 *$ & $0,00972 * * *$ & $0,00883 * * *$ & 0,0367 \\
\hline & $(0,0572)$ & $(0,00681)$ & $(0,0735)$ & $(0,00320)$ & $(0,00208)$ & $(0,0548)$ \\
\hline \multirow[t]{2}{*}{ centrooeste } & $-0,0417$ & $-0,0177^{* * *}$ & $-0,000802$ & $0,0287^{* * *}$ & $0,0205^{* * *}$ & $0,133 * *$ \\
\hline & $(0,0439)$ & $(0,00672)$ & $(0,0584)$ & $(0,00401)$ & $(0,00248)$ & $(0,0582)$ \\
\hline Observações & 319.288 & 319.288 & 212.937 & 319.288 & 319.288 & 22.989 \\
\hline
\end{tabular}

Erros-padrão entre parênteses

$* * * \mathrm{p}<0.01, * * \mathrm{p}<0.05 \mathrm{e}^{*} \mathrm{p}<0.1$ 
Tabela B.2 - Efeitos marginais dos determinantes da utilização do cuidado, Região Norte - 2008

\begin{tabular}{|c|c|c|c|c|c|c|}
\hline \multirow{3}{*}{ Variáveis } & \multicolumn{3}{|c|}{ Consultas Médicas } & \multicolumn{3}{|c|}{ Internações Hospitalares } \\
\hline & \multirow[b]{2}{*}{$\begin{array}{l}\text { Binomial } \\
\text { Negativo }\end{array}$} & \multicolumn{2}{|c|}{ Hurdle Binomial Negativo } & \multirow[b]{2}{*}{$\begin{array}{l}\text { Binomial } \\
\text { Negativo }\end{array}$} & \multicolumn{2}{|c|}{ Hurdle Poisson } \\
\hline & & Logit & $\begin{array}{l}\text { Negbin } \\
\text { Truncado }\end{array}$ & & Logit & $\begin{array}{l}\text { Poisson } \\
\text { Truncado }\end{array}$ \\
\hline \multirow[t]{2}{*}{ m18_29 } & $-0,0515$ & $-0,0428 * * *$ & 0,0552 & $0,0304 * *$ & $0,0352 * * *$ & $-0,0873$ \\
\hline & $(0,0882)$ & $(0,0141)$ & $(0,151)$ & $(0,0132)$ & $(0,0103)$ & $(0,127)$ \\
\hline \multirow[t]{2}{*}{ m30_44 } & $0,155^{* *}$ & $-0,0263^{*}$ & $0,261 * *$ & $0,0290 * *$ & $0,0307^{* * *}$ & $-0,0855$ \\
\hline & $(0,0685)$ & $(0,0135)$ & $(0,123)$ & $(0,0137)$ & $(0,00877)$ & $(0,172)$ \\
\hline \multirow[t]{2}{*}{ m45_59 } & $0,604 * * *$ & 0,0118 & $0,815^{* * *}$ & $0,0340 * *$ & $0,0326 * * *$ & $-0,0249$ \\
\hline & $(0,129)$ & $(0,0170)$ & $(0,197)$ & $(0,0162)$ & $(0,00983)$ & $(0,156)$ \\
\hline \multirow[t]{2}{*}{ m60_69 } & $0,868 * * *$ & $0,0385^{* *}$ & $1,102 * * *$ & $0,0811 * *$ & $0,0464 * * *$ & 0,224 \\
\hline & $(0,127)$ & $(0,0186)$ & $(0,221)$ & $(0,0321)$ & $(0,0155)$ & $(0,250)$ \\
\hline \multirow[t]{2}{*}{ m70 } & 0,172 & 0,0176 & 0,219 & $-0,00513$ & 0,0184 & $-0,332 * * *$ \\
\hline & $(0,158)$ & $(0,0317)$ & $(0,239)$ & $(0,0147)$ & $(0,0119)$ & $(0,108)$ \\
\hline \multirow[t]{2}{*}{ f10_17 } & $0,655^{* * *}$ & $0,0878 * * *$ & $0,476 * * *$ & $0,0476 * * *$ & $0,0300 * * *$ & 0,310 \\
\hline & $(0,103)$ & $(0,0101)$ & $(0,143)$ & $(0,0159)$ & $(0,00854)$ & $(0,333)$ \\
\hline \multirow[t]{2}{*}{ f18_29 } & $2,059 * * *$ & $0,202 * * *$ & $1,743 * * *$ & $0,173 * * *$ & $0,144 * * *$ & $-0,162^{*}$ \\
\hline & $(0,135)$ & $(0,0106)$ & $(0,183)$ & $(0,0206)$ & $(0,0145)$ & $(0,0952)$ \\
\hline \multirow[t]{2}{*}{ f30_44 } & $1,565 * * *$ & $0,200 * * *$ & $1,157^{* * *}$ & $0,0771 * * *$ & $0,0639 * * *$ & $-0,0285$ \\
\hline & $(0,115)$ & $(0,00979)$ & $(0,150)$ & $(0,0141)$ & $(0,00948)$ & $(0,118)$ \\
\hline \multirow[t]{2}{*}{ f45_59 } & $1,583 * * *$ & $0,184 * * *$ & $1,368 * * *$ & 0,0145 & $0,0226 * * *$ & $-0,199 *$ \\
\hline & $(0,149)$ & $(0,0121)$ & $(0,186)$ & $(0,0111)$ & $(0,00803)$ & $(0,121)$ \\
\hline \multirow[t]{2}{*}{ f60_69 } & $1,858 * * *$ & $0,167 * * *$ & $1,838 * * *$ & $0,0756^{* *}$ & $0,0379 * * *$ & 0,0828 \\
\hline & $(0,210)$ & $(0,0205)$ & $(0,261)$ & $(0,0355)$ & $(0,0125)$ & $(0,239)$ \\
\hline \multirow[t]{2}{*}{ f70 } & $-0,0736$ & 0,0446 & $-0,148$ & $-0,00368$ & $0,0153^{*}$ & $-0,245^{* *}$ \\
\hline & $(0,116)$ & $(0,0372)$ & $(0,149)$ & $(0,0148)$ & $(0,00914)$ & $(0,110)$ \\
\hline \multirow[t]{2}{*}{ bom } & $0,370 * * *$ & $0,0582 * * *$ & $0,355^{* * *}$ & $0,0231 * * *$ & $0,00806^{*}$ & $0,765^{* * *}$ \\
\hline & $(0,0731)$ & $(0,0124)$ & $(0,108)$ & $(0,00614)$ & $(0,00435)$ & $(0,225)$ \\
\hline \multirow[t]{2}{*}{ regular } & $1,188 * * *$ & $0,172 * * *$ & $1,007 * * *$ & $0,106 * * *$ & $0,0496 * * *$ & $1,163 * * *$ \\
\hline & $(0,108)$ & $(0,0137)$ & $(0,126)$ & $(0,0144)$ & $(0,00794)$ & $(0,266)$ \\
\hline \multirow[t]{2}{*}{ ruim } & $2,957 * * *$ & $0,233 * * *$ & $2,964 * * *$ & $0,275 * * *$ & $0,108^{* * *}$ & $2,326 * * *$ \\
\hline & $(0,262)$ & $(0,0176)$ & $(0,294)$ & $(0,0489)$ & $(0,0161)$ & $(0,685)$ \\
\hline mruim & $3,632 * * *$ & $0,214 * * *$ & $4,216 * * *$ & $0,348 * * *$ & $0,110 * * *$ & $4,504^{* * *}$ \\
\hline & $(0,498)$ & $(0,0235)$ & $(0,594)$ & $(0,0855)$ & $(0,0314)$ & $(1,312)$ \\
\hline limitacao & $1,012 * * *$ & $0,195 * * *$ & $0,864 * * *$ & $0,122 * * *$ & $0,0730 * * *$ & $0,362 * * *$ \\
\hline & $(0,0862)$ & $(0,0107)$ & $(0,102)$ & $(0,0208)$ & $(0,00847)$ & $(0,136)$ \\
\hline cronica & $0,957 * * *$ & $0,174 * * *$ & $0,789 * * *$ & $0,0389 * * *$ & $0,0273 * * *$ & 0,101 \\
\hline & $(0,0596)$ & $(0,00813)$ & $(0,0706)$ & $(0,00600)$ & $(0,00399)$ & $(0,0911)$ \\
\hline Irendapc & $0,0790 * * *$ & $0,0263^{* * *}$ & 0,000101 & $-0,00564^{*}$ & $-0,00395^{*}$ & $-0,00364$ \\
\hline & $(0,0231)$ & $(0,00496)$ & $(0,0312)$ & $(0,00319)$ & $(0,00219)$ & $(0,0413)$ \\
\hline fundamental & $0,156^{* *}$ & $0,0420 * * *$ & 0,128 & $-0,00420$ & $-0,00151$ & $-0,192^{*}$ \\
\hline & $(0,0693)$ & $(0,0124)$ & $(0,0907)$ & $(0,00799)$ & $(0,00478)$ & $(0,107)$ \\
\hline medio & $0,364 * * *$ & $0,0723 * * *$ & $0,314 * * *$ & $-0,00358$ & $-0,00930 * *$ & 0,0739 \\
\hline & $(0,0853)$ & $(0,0142)$ & $(0,117)$ & $(0,00893)$ & $(0,00452)$ & $(0,138)$ \\
\hline superior & $0,257^{* *}$ & $0,0806 * * *$ & 0,114 & $-0,0162^{* *}$ & $-0,0154 * * *$ & $-0,0337$ \\
\hline & $(0,101)$ & $(0,0160)$ & $(0,146)$ & $(0,00815)$ & $(0,00546)$ & $(0,138)$ \\
\hline desocupado & $-0,128$ & $-0,0115$ & $-0,183$ & $-0,0261 * * *$ & $-0,0253 * * *$ & 0,115 \\
\hline & $(0,0791)$ & $(0,0201)$ & $(0,127)$ & $(0,00935)$ & $(0,00564)$ & $(0,128)$ \\
\hline ccarteira & $-0,0337$ & $0,0594^{* * *}$ & $-0,328 * * *$ & $-0,0229 * * *$ & $-0,0135 * * *$ & $-0,295 * * *$ \\
\hline & $(0,0710)$ & $(0,0136)$ & $(0,0817)$ & $(0,00713)$ & $(0,00452)$ & $(0,106)$ \\
\hline
\end{tabular}


Conclusão

\begin{tabular}{|c|c|c|c|c|c|c|}
\hline \multirow{4}{*}{ Variáveis } & \multicolumn{3}{|c|}{ Consultas Médicas } & \multicolumn{3}{|c|}{ Internações Hospitalares } \\
\hline & \multirow{3}{*}{$\begin{array}{l}\text { Binomial } \\
\text { Negativo }\end{array}$} & \multicolumn{2}{|c|}{ Hurdle Binomial Negativo } & \multirow{3}{*}{$\begin{array}{l}\text { Binomial } \\
\text { Negativo }\end{array}$} & \multicolumn{2}{|c|}{ Hurdle Poisson } \\
\hline & & & Negbin & & & Poisson \\
\hline & & Logit & Truncado & & Logit & Truncado \\
\hline \multirow[t]{2}{*}{ fpublico } & $-0,00718$ & $0,0562 * * *$ & $-0,180$ & 0,0115 & 0,0126 & $-0,182$ \\
\hline & $(0,0892)$ & $(0,0160)$ & $(0,116)$ & $(0,0156)$ & $(0,00905)$ & $(0,134)$ \\
\hline \multirow[t]{2}{*}{ domestico } & $-0,361 * * *$ & $-0,0361 * *$ & $-0,513 * * *$ & $-0,0368 * * *$ & $-0,0247 * * *$ & $-0,274 * *$ \\
\hline & $(0,0612)$ & $(0,0183)$ & $(0,0938)$ & $(0,00679)$ & $(0,00481)$ & $(0,108)$ \\
\hline \multirow[t]{2}{*}{ scarteira } & $-0,451 * * *$ & $-0,0507 * * *$ & $-0,521 * * *$ & $-0,0127$ & $-0,00501$ & $-0,297 * * *$ \\
\hline & $(0,0535)$ & $(0,0130)$ & $(0,0684)$ & $(0,00806)$ & $(0,00567)$ & $(0,0850)$ \\
\hline \multirow[t]{2}{*}{ cpropria } & $-0,432 * * *$ & $-0,0549 * * *$ & $-0,489 * * *$ & $-0,0133$ & $-0,0139 * *$ & 0,0792 \\
\hline & $(0,0460)$ & $(0,00945)$ & $(0,0692)$ & $(0,00918)$ & $(0,00573)$ & $(0,172)$ \\
\hline \multirow[t]{2}{*}{ empregador } & $-0,385 * * *$ & $-0,0262$ & $-0,522 * * *$ & $-0,00750$ & $-0,00456$ & $-0,189$ \\
\hline & $(0,0876)$ & $(0,0211)$ & $(0,139)$ & $(0,0138)$ & $(0,00825)$ & $(0,159)$ \\
\hline \multirow[t]{2}{*}{ outra } & $-0,352 * * *$ & $-0,0537 * * *$ & $-0,378 * * *$ & $-0,00586$ & $-0,00536$ & 0,116 \\
\hline & $(0,0610)$ & $(0,0172)$ & $(0,0991)$ & $(0,0121)$ & $(0,00571)$ & $(0,258)$ \\
\hline \multirow[t]{2}{*}{ plano } & $0,916 * * *$ & $0,168 * * *$ & $0,786 * * *$ & $0,0214 * * *$ & $0,0191 * * *$ & 0,0957 \\
\hline & $(0,0792)$ & $(0,0127)$ & $(0,0981)$ & $(0,00670)$ & $(0,00434)$ & $(0,118)$ \\
\hline Observações & 40.240 & 40.240 & 24.636 & 40.240 & 40.240 & 2.984 \\
\hline
\end{tabular}

Erros-padrão entre parênteses

$* * * \mathrm{p}<0.01, * * \mathrm{p}<0.05 \mathrm{e}^{*} \mathrm{p}<0.1$ 
Tabela B.3 - Efeitos marginais dos determinantes da utilização do cuidado, Região Nordeste 2008

\begin{tabular}{|c|c|c|c|c|c|c|}
\hline \multirow{3}{*}{ Variáveis } & \multicolumn{3}{|c|}{ Consultas Médicas } & \multicolumn{3}{|c|}{ Internações Hospitalares } \\
\hline & \multirow[b]{2}{*}{$\begin{array}{l}\text { Binomial } \\
\text { Negativo }\end{array}$} & \multicolumn{2}{|c|}{ Hurdle Binomial Negativo } & \multirow[b]{2}{*}{$\begin{array}{l}\text { Binomial } \\
\text { Negativo }\end{array}$} & \multicolumn{2}{|c|}{ Hurdle Poisson } \\
\hline & & Logit & $\begin{array}{l}\text { Negbin } \\
\text { Truncado }\end{array}$ & & Logit & $\begin{array}{l}\text { Poisson } \\
\text { Truncado }\end{array}$ \\
\hline \multirow[t]{2}{*}{ m18_29 } & $-0,0953$ & $-0,0390 * * *$ & $-0,0436$ & 0,00891 & $0,0166 * * *$ & $-0,297 * * *$ \\
\hline & $(0,0606)$ & $(0,00878)$ & $(0,0896)$ & $(0,00749)$ & $(0,00505)$ & $(0,115)$ \\
\hline \multirow[t]{2}{*}{ m30_44 } & $-0,0313$ & $-0,0478 * * *$ & 0,0985 & 0,00679 & $0,0122 * *$ & $-0,271 * *$ \\
\hline & $(0,0643)$ & $(0,00848)$ & $(0,100)$ & $(0,00825)$ & $(0,00539)$ & $(0,133)$ \\
\hline \multirow[t]{2}{*}{ m45_59 } & $0,119 *$ & $-0,0465 * * *$ & $0,290 * * *$ & $0,0163 *$ & $0,0185^{* * *}$ & $-0,242 *$ \\
\hline & $(0,0656)$ & $(0,00951)$ & $(0,106)$ & $(0,00981)$ & $(0,00592)$ & $(0,140)$ \\
\hline \multirow[t]{2}{*}{ m60_69 } & $0,503 * * *$ & 0,0132 & $0,565 * * *$ & 0,00451 & $0,0260 * * *$ & $-0,460 * * *$ \\
\hline & $(0,0918)$ & $(0,0118)$ & $(0,128)$ & $(0,00933)$ & $(0,00653)$ & $(0,0980)$ \\
\hline \multirow[t]{2}{*}{ m70 } & 0,154 & $0,0365^{* *}$ & 0,102 & $0,0387 * * *$ & $0,0259 * * *$ & 0,201 \\
\hline & $(0,0949)$ & $(0,0148)$ & $(0,128)$ & $(0,0119)$ & $(0,00707)$ & $(0,151)$ \\
\hline \multirow[t]{2}{*}{ f10_17 } & $0,505 * * *$ & $0,0659 * * *$ & $0,342 * * *$ & 0,000802 & 0,00444 & $-0,254^{* *}$ \\
\hline & $(0,0666)$ & $(0,00724)$ & $(0,0951)$ & $(0,00586)$ & $(0,00396)$ & $(0,117)$ \\
\hline \multirow[t]{2}{*}{ f18_29 } & $2,187 * * *$ & $0,173^{* * *}$ & $1,995 * * *$ & $0,122 * * *$ & $0,105^{* * *}$ & $-0,290 * *$ \\
\hline & $(0,106)$ & $(0,00638)$ & $(0,141)$ & $(0,0143)$ & $(0,00953)$ & $(0,133)$ \\
\hline \multirow[t]{2}{*}{ f30_44 } & $1,698 * * *$ & $0,198 * * *$ & $1,242 * * *$ & $0,0421 * * *$ & $0,0446 * * *$ & $-0,342 * * *$ \\
\hline & $(0,0893)$ & $(0,00702)$ & $(0,117)$ & $(0,00941)$ & $(0,00627)$ & $(0,116)$ \\
\hline \multirow[t]{2}{*}{ f45_59 } & $1,382 * * *$ & $0,166^{* * *}$ & $1,109 * * *$ & $0,0166^{*}$ & $0,0222 * * *$ & $-0,299 * *$ \\
\hline & $(0,0919)$ & $(0,00648)$ & $(0,123)$ & $(0,00878)$ & $(0,00536)$ & $(0,127)$ \\
\hline \multirow[t]{2}{*}{ f60_69 } & $1,277^{* * *}$ & $0,135^{* * *}$ & $1,154 * * *$ & 0,00139 & $0,0184^{* * *}$ & $-0,393 * * *$ \\
\hline & $(0,116)$ & $(0,00996)$ & $(0,155)$ & $(0,00834)$ & $(0,00651)$ & $(0,109)$ \\
\hline \multirow[t]{2}{*}{$\mathrm{f} 70$} & $-0,177 * * *$ & $-0,00560$ & $-0,248 * * *$ & $0,0217 * *$ & $0,0152 * * *$ & $-0,00427$ \\
\hline & $(0,0574)$ & $(0,0153)$ & $(0,0802)$ & $(0,00931)$ & $(0,00543)$ & $(0,110)$ \\
\hline \multirow[t]{2}{*}{ bom } & $0,341 * * *$ & $0,0580 * * *$ & $0,212 * * *$ & $0,0198 * * *$ & $0,0134 * * *$ & 0,127 \\
\hline & $(0,0531)$ & $(0,00882)$ & $(0,0682)$ & $(0,00375)$ & $(0,00239)$ & $(0,123)$ \\
\hline \multirow[t]{2}{*}{ regular } & $1,452 * * *$ & $0,163 * * *$ & $1,262 * * *$ & $0,0790 * * *$ & $0,0436 * * *$ & $0,511 * * *$ \\
\hline & $(0,0997)$ & $(0,00792)$ & $(0,114)$ & $(0,00832)$ & $(0,00429)$ & $(0,152)$ \\
\hline \multirow[t]{2}{*}{ ruim } & $3,145 * * *$ & $0,198 * * *$ & $3,034 * * *$ & $0,224 * * *$ & $0,100 * * *$ & $1,195^{* * *}$ \\
\hline & $(0,212)$ & $(0,0104)$ & $(0,230)$ & $(0,0288)$ & $(0,00908)$ & $(0,333)$ \\
\hline mruim & $4,357 * * *$ & $0,192 * * *$ & $4,665 * * *$ & $0,318 * * *$ & $0,134 * * *$ & $1,645^{* * *}$ \\
\hline & $(0,351)$ & $(0,0143)$ & $(0,393)$ & $(0,0433)$ & $(0,0156)$ & $(0,452)$ \\
\hline limitacao & $1,021 * * *$ & $0,166 * * *$ & $0,936 * * *$ & $0,0895 * * *$ & $0,0622 * * *$ & $0,198 * * *$ \\
\hline & $(0,0525)$ & $(0,00636)$ & $(0,0661)$ & $(0,00701)$ & $(0,00395)$ & $(0,0711)$ \\
\hline cronica & $1,163 * * *$ & $0,178 * * *$ & $0,988 * * *$ & $0,0462 * * *$ & $0,0243 * * *$ & $0,358 * * *$ \\
\hline & $(0,0351)$ & $(0,00490)$ & $(0,0413)$ & $(0,00422)$ & $(0,00186)$ & $(0,0667)$ \\
\hline Irendapc & $0,114 * * *$ & $0,0224 * * *$ & $0,0758 * * *$ & $-0,00275^{*}$ & $-0,00314 * * *$ & $-0,00381$ \\
\hline & $(0,0168)$ & $(0,00264)$ & $(0,0267)$ & $(0,00160)$ & $(0,000982)$ & $(0,0291)$ \\
\hline fundamental & 0,0609 & $0,0417 * * *$ & $-0,0647$ & 0,000675 & 0,00187 & 0,00505 \\
\hline & $(0,0388)$ & $(0,00615)$ & $(0,0565)$ & $(0,00366)$ & $(0,00204)$ & $(0,0664)$ \\
\hline medio & $0,171 * * *$ & $0,0624 * * *$ & $-0,00957$ & $-0,0115^{* * *}$ & $-0,00708 * * *$ & $-0,0213$ \\
\hline & $(0,0490)$ & $(0,00713)$ & $(0,0653)$ & $(0,00388)$ & $(0,00270)$ & $(0,0696)$ \\
\hline superior & $0,306^{* * *}$ & $0,0859 * * *$ & 0,126 & 0,00104 & $-0,00304$ & 0,287 \\
\hline & $(0,0648)$ & $(0,00914)$ & $(0,0867)$ & $(0,00623)$ & $(0,00336)$ & $(0,182)$ \\
\hline desocupado & $-0,304 * * *$ & $-0,0184 *$ & $-0,403 * * *$ & $-0,0201 * * *$ & $-0,0198 * * *$ & 0,00818 \\
\hline & $(0,0482)$ & $(0,00973)$ & $(0,0653)$ & $(0,00524)$ & $(0,00275)$ & $(0,118)$ \\
\hline ccarteira & $-0,0797^{* *}$ & $0,0539 * * *$ & $-0,374 * * *$ & $-0,0201 * * *$ & $-0,0157 * * *$ & $-0,0663$ \\
\hline & $(0,0360)$ & $(0,00668)$ & $(0,0504)$ & $(0,00358)$ & $(0,00241)$ & $(0,0736)$ \\
\hline
\end{tabular}


Conclusão

\begin{tabular}{|c|c|c|c|c|c|c|}
\hline \multirow{3}{*}{ Variáveis } & \multicolumn{3}{|c|}{ Consultas Médicas } & \multicolumn{3}{|c|}{ Internações Hospitalares } \\
\hline & \multirow[b]{2}{*}{$\begin{array}{l}\text { Binomial } \\
\text { Negativo }\end{array}$} & \multicolumn{2}{|c|}{ Hurdle Binomial Negativo } & \multirow[b]{2}{*}{$\begin{array}{l}\text { Binomial } \\
\text { Negativo }\end{array}$} & \multicolumn{2}{|c|}{ Hurdle Poisson } \\
\hline & & Logit & $\begin{array}{l}\text { Negbin } \\
\text { Truncado }\end{array}$ & & Logit & $\begin{array}{l}\text { Poisson } \\
\text { Truncado }\end{array}$ \\
\hline \multirow[t]{2}{*}{ fpublico } & $-0,101^{*}$ & $0,0511^{* * *}$ & $-0,274 * * *$ & $-0,0110 * *$ & $-0,00334$ & $-0,171$ \\
\hline & $(0,0537)$ & $(0,0123)$ & $(0,0753)$ & $(0,00503)$ & $(0,00403)$ & $(0,147)$ \\
\hline \multirow[t]{2}{*}{ domestico } & $-0,388 * * *$ & $-0,0350 * * *$ & $-0,429 * * *$ & $-0,0300 * * *$ & $-0,0229 * * *$ & $-0,169 * *$ \\
\hline & $(0,0309)$ & $(0,00680)$ & $(0,0429)$ & $(0,00361)$ & $(0,00258)$ & $(0,0807)$ \\
\hline \multirow[t]{2}{*}{ scarteira } & $-0,276 * * *$ & $-0,000378$ & $-0,417 * * *$ & $-0,0110 * *$ & $-0,0118 * * *$ & 0,0107 \\
\hline & $(0,0705)$ & $(0,0152)$ & $(0,101)$ & $(0,00521)$ & $(0,00220)$ & $(0,157)$ \\
\hline \multirow[t]{2}{*}{ cpropria } & $-0,364 * * *$ & $-0,0329 * * *$ & $-0,497^{* * *}$ & $-0,0176 * * *$ & $-0,0132 * * *$ & $-0,0475$ \\
\hline & $(0,0380)$ & $(0,00896)$ & $(0,0559)$ & $(0,00359)$ & $(0,00210)$ & $(0,0691)$ \\
\hline \multirow[t]{2}{*}{ empregador } & $-0,487 * * *$ & $-0,0423 * * *$ & $-0,562 * * *$ & $-0,0113^{*}$ & $-0,00425$ & $-0,267 * * *$ \\
\hline & $(0,0332)$ & $(0,00632)$ & $(0,0510)$ & $(0,00637)$ & $(0,00481)$ & $(0,0802)$ \\
\hline \multirow[t]{2}{*}{ outra } & $-0,387 * * *$ & $-0,0529 * * *$ & $-0,383 * * *$ & $-0,0102 * *$ & $-0,00737^{* * *}$ & $-0,127^{*}$ \\
\hline & $(0,0495)$ & $(0,00948)$ & $(0,0638)$ & $(0,00421)$ & $(0,00265)$ & $(0,0724)$ \\
\hline \multirow[t]{2}{*}{ plano } & $0,924^{* * *}$ & $0,153 * * *$ & $0,776 * * *$ & $0,0254 * * *$ & $0,0231 * * *$ & $-0,0924$ \\
\hline & $(0,0404)$ & $(0,00661)$ & $(0,0499)$ & $(0,00480)$ & $(0,00301)$ & $(0,0626)$ \\
\hline Observações & 101.830 & 101.830 & 65.723 & 101.830 & 101.830 & 6.746 \\
\hline
\end{tabular}

Erros-padrão entre parênteses

$* * * \mathrm{p}<0.01, * * \mathrm{p}<0.05 \mathrm{e}^{*} \mathrm{p}<0.1$ 
Tabela B.4 - Efeitos marginais dos determinantes da utilização do cuidado, Região Sudeste 2008

\begin{tabular}{|c|c|c|c|c|c|c|}
\hline \multirow{3}{*}{ Variáveis } & \multicolumn{3}{|c|}{ Consultas Médicas } & \multicolumn{3}{|c|}{ Internações Hospitalares } \\
\hline & \multirow[b]{2}{*}{$\begin{array}{l}\text { Binomial } \\
\text { Negativo }\end{array}$} & \multicolumn{2}{|c|}{ Hurdle Binomial Negativo } & \multirow[b]{2}{*}{$\begin{array}{l}\text { Binomial } \\
\text { Negativo }\end{array}$} & \multicolumn{2}{|c|}{ Hurdle Poisson } \\
\hline & & Logit & $\begin{array}{l}\text { Negbin } \\
\text { Truncado }\end{array}$ & & Logit & $\begin{array}{l}\text { Poisson } \\
\text { Truncado }\end{array}$ \\
\hline \multirow[t]{2}{*}{ m18_29 } & $-0,0990$ & $-0,0502 * * *$ & 0,133 & $0,0455^{* * *}$ & $0,0287^{* * *}$ & $0,501^{* *}$ \\
\hline & $(0,0805)$ & $(0,00746)$ & $(0,133)$ & $(0,00932)$ & $(0,00603)$ & $(0,204)$ \\
\hline \multirow[t]{2}{*}{ m30_44 } & 0,0673 & $-0,0327 * * *$ & 0,175 & $0,0465 * * *$ & $0,0357 * * *$ & $0,256^{*}$ \\
\hline & $(0,0719)$ & $(0,00899)$ & $(0,113)$ & $(0,00822)$ & $(0,00596)$ & $(0,149)$ \\
\hline \multirow[t]{2}{*}{ m45_59 } & $0,294 * * *$ & $-0,0180 * *$ & $0,350 * * *$ & $0,0656 * * *$ & $0,0444 * * *$ & $0,506 * *$ \\
\hline & $(0,0951)$ & $(0,00908)$ & $(0,132)$ & $(0,0107)$ & $(0,00686)$ & $(0,214)$ \\
\hline \multirow[t]{2}{*}{ m60_69 } & $0,689 * * *$ & $0,0274^{* *}$ & $0,634 * * *$ & $0,105^{* * *}$ & $0,0720 * * *$ & $0,468 * *$ \\
\hline & $(0,107)$ & $(0,0120)$ & $(0,134)$ & $(0,0177)$ & $(0,00918)$ & $(0,237)$ \\
\hline \multirow[t]{2}{*}{ m70 } & $0,158 *$ & $0,0464 * * *$ & 0,0536 & 0,0150 & $0,0104 * *$ & 0,00735 \\
\hline & $(0,0892)$ & $(0,0137)$ & $(0,116)$ & $(0,00955)$ & $(0,00506)$ & $(0,138)$ \\
\hline \multirow[t]{2}{*}{ f10_17 } & $0,594^{* * *}$ & $0,0540 * * *$ & $0,427 * * *$ & $0,0443 * * *$ & $0,0202 * * *$ & $0,853 * * *$ \\
\hline & $(0,0875)$ & $(0,00620)$ & $(0,116)$ & $(0,0112)$ & $(0,00657)$ & $(0,281)$ \\
\hline \multirow[t]{2}{*}{ f18_29 } & $2,083 * * *$ & $0,129 * * *$ & $1,805 * * *$ & $0,181 * * *$ & $0,124 * * *$ & $0,261^{*}$ \\
\hline & $(0,133)$ & $(0,00546)$ & $(0,160)$ & $(0,0182)$ & $(0,0105)$ & $(0,144)$ \\
\hline \multirow[t]{2}{*}{ f30_44 } & $1,915^{* * *}$ & $0,164 * * *$ & $1,399 * * *$ & $0,124 * * *$ & $0,0881 * * *$ & $0,241^{*}$ \\
\hline & $(0,109)$ & $(0,00499)$ & $(0,138)$ & $(0,0135)$ & $(0,00873)$ & $(0,144)$ \\
\hline \multirow[t]{2}{*}{ f45_59 } & $1,552 * * *$ & $0,144 * * *$ & $1,167 * * *$ & $0,0757 * * *$ & $0,0500 * * *$ & $0,391 * *$ \\
\hline & $(0,101)$ & $(0,00546)$ & $(0,128)$ & $(0,0104)$ & $(0,00604)$ & $(0,181)$ \\
\hline \multirow[t]{2}{*}{ f60_69 } & $1,331 * * *$ & $0,135 * * *$ & $0,974 * * *$ & $0,0465 * * *$ & $0,0343^{* * *}$ & 0,168 \\
\hline & $(0,115)$ & $(0,00728)$ & $(0,133)$ & $(0,0106)$ & $(0,00722)$ & $(0,148)$ \\
\hline \multirow[t]{2}{*}{$\mathrm{f} 70$} & $-0,00415$ & 0,00705 & 0,0174 & $0,0341 * * *$ & $0,0209 * * *$ & $0,252^{*}$ \\
\hline & $(0,0728)$ & $(0,0137)$ & $(0,0971)$ & $(0,0108)$ & $(0,00531)$ & $(0,129)$ \\
\hline \multirow[t]{2}{*}{ bom } & $0,568 * * *$ & $0,0494 * * *$ & $0,583 * * *$ & $0,0106 * * *$ & $0,00836 * * *$ & 0,00863 \\
\hline & $(0,0406)$ & $(0,00445)$ & $(0,0531)$ & $(0,00351)$ & $(0,00195)$ & $(0,131)$ \\
\hline \multirow[t]{2}{*}{ regular } & $2,207 * * *$ & $0,138 * * *$ & $2,257 * * *$ & $0,0607 * * *$ & $0,0427^{* * *}$ & 0,170 \\
\hline & $(0,0737)$ & $(0,00527)$ & $(0,0862)$ & $(0,00720)$ & $(0,00366)$ & $(0,160)$ \\
\hline \multirow[t]{2}{*}{ ruim } & $4,960 * * *$ & $0,185^{* * *}$ & $5,268 * * *$ & $0,166 * * *$ & $0,101 * * *$ & $0,411^{*}$ \\
\hline & $(0,242)$ & $(0,00546)$ & $(0,275)$ & $(0,0234)$ & $(0,0108)$ & $(0,246)$ \\
\hline mruim & $6,617^{* * *}$ & $0,155^{* * *}$ & $7,626 * * *$ & $0,267 * * *$ & $0,141 * * *$ & $0,865^{* *}$ \\
\hline & $(0,456)$ & $(0,0139)$ & $(0,516)$ & $(0,0419)$ & $(0,0173)$ & $(0,391)$ \\
\hline limitacao & $1,584 * * *$ & $0,175 * * *$ & $1,475 * * *$ & $0,119 * * *$ & $0,0822 * * *$ & $0,296 * * *$ \\
\hline & $(0,0609)$ & $(0,00462)$ & $(0,0730)$ & $(0,00665)$ & $(0,00427)$ & $(0,0499)$ \\
\hline cronica & $1,335^{* * *}$ & $0,153 * * *$ & $1,169 * * *$ & $0,0333 * * *$ & $0,0191 * * *$ & $0,295 * * *$ \\
\hline & $(0,0367)$ & $(0,00366)$ & $(0,0445)$ & $(0,00287)$ & $(0,00173)$ & $(0,0537)$ \\
\hline Irendapc & $0,117 * * *$ & $0,0229 * * *$ & $0,0597 * *$ & $-0,00542 * * *$ & $-0,00391 * * *$ & $-0,0212$ \\
\hline & $(0,0201)$ & $(0,00257)$ & $(0,0298)$ & $(0,00149)$ & $(0,00116)$ & $(0,0278)$ \\
\hline fundamental & $-0,0231$ & $0,0446 * * *$ & $-0,155^{* *}$ & 0,000942 & 0,00174 & 0,00889 \\
\hline & $(0,0561)$ & $(0,00729)$ & $(0,0723)$ & $(0,00465)$ & $(0,00276)$ & $(0,0595)$ \\
\hline medio & $0,124^{* *}$ & $0,0521 * * *$ & 0,00220 & 0,00193 & 0,000599 & 0,0837 \\
\hline & $(0,0608)$ & $(0,00724)$ & $(0,0833)$ & $(0,00517)$ & $(0,00292)$ & $(0,0898)$ \\
\hline superior & $0,150 * *$ & $0,0618^{* * *}$ & 0,00566 & 0,00133 & 0,00263 & $-0,101$ \\
\hline & $(0,0703)$ & $(0,00737)$ & $(0,0913)$ & $(0,00588)$ & $(0,00372)$ & $(0,0869)$ \\
\hline desocupado & $-0,242 * * *$ & $-0,0175^{*}$ & $-0,232 * * *$ & $-0,0193 * * *$ & $-0,0215^{* * *}$ & 0,149 \\
\hline & $(0,0665)$ & $(0,00909)$ & $(0,0896)$ & $(0,00466)$ & $(0,00255)$ & $(0,123)$ \\
\hline ccarteira & $-0,210 * * *$ & $0,0235^{* * *}$ & $-0,426 * * *$ & $-0,0235^{* * *}$ & $-0,0161 * * *$ & $-0,260 * * *$ \\
\hline & $(0,0377)$ & $(0,00519)$ & $(0,0501)$ & $(0,00235)$ & $(0,00171)$ & $(0,0410)$ \\
\hline
\end{tabular}


Conclusão

\begin{tabular}{|c|c|c|c|c|c|c|}
\hline \multirow{3}{*}{ Variáveis } & \multicolumn{3}{|c|}{ Consultas Médicas } & \multicolumn{3}{|c|}{ Internações Hospitalares } \\
\hline & \multirow{2}{*}{$\begin{array}{l}\text { Binomial } \\
\text { Negativo }\end{array}$} & \multicolumn{2}{|c|}{ Hurdle Binomial Negativo } & \multirow[b]{2}{*}{$\begin{array}{l}\text { Binomial } \\
\text { Negativo }\end{array}$} & \multicolumn{2}{|c|}{ Hurdle Poisson } \\
\hline & & Logit & $\begin{array}{l}\text { Negbin } \\
\text { Truncado }\end{array}$ & & I ogit & Poisson \\
\hline \multirow{2}{*}{ fpublico } & $-0,172 * * *$ & $0,0346 * * *$ & $-0,322 * * *$ & $-0,0175 * * *$ & $-0,0120 * * *$ & $-0,136 *$ \\
\hline & $(0,0594)$ & $(0,00966)$ & $(0,0756)$ & $(0,00403)$ & $(0,00332)$ & $(0,0697)$ \\
\hline \multirow[t]{2}{*}{ domestico } & $-0,350 * * *$ & $-0,0147^{*}$ & $-0,502 * * *$ & $-0,0284 * * *$ & $-0,0210 * * *$ & $-0,176 * * *$ \\
\hline & $(0,0531)$ & $(0,00875)$ & $(0,0698)$ & $(0,00322)$ & $(0,00228)$ & $(0,0673)$ \\
\hline \multirow[t]{2}{*}{ scarteira } & $-0,413 * * *$ & $-0,0177 * * *$ & $-0,477^{* * *}$ & $-0,0157 * * *$ & $-0,0125 * * *$ & $-0,114$ \\
\hline & $(0,0489)$ & $(0,00668)$ & $(0,0679)$ & $(0,00357)$ & $(0,00244)$ & $(0,0709)$ \\
\hline \multirow[t]{2}{*}{ cpropria } & $-0,425 * * *$ & $-0,0462 * * *$ & $-0,356 * * *$ & $-0,0208 * * *$ & $-0,0156 * * *$ & $-0,151 * *$ \\
\hline & $(0,0375)$ & $(0,00690)$ & $(0,0547)$ & $(0,00315)$ & $(0,00219)$ & $(0,0588)$ \\
\hline \multirow[t]{2}{*}{ empregador } & $-0,458 * * *$ & $-0,0188^{*}$ & $-0,588 * * *$ & $-0,00222$ & $-0,000400$ & $-0,106$ \\
\hline & $(0,0630)$ & $(0,0108)$ & $(0,0964)$ & $(0,00549)$ & $(0,00401)$ & $(0,0837)$ \\
\hline \multirow[t]{2}{*}{ outra } & $-0,400 * * *$ & $-0,0182$ & $-0,505^{* * *}$ & $-0,00288$ & $-0,00845^{* * *}$ & 0,162 \\
\hline & $(0,0666)$ & $(0,0123)$ & $(0,0889)$ & $(0,00595)$ & $(0,00319)$ & $(0,131)$ \\
\hline \multirow[t]{2}{*}{ plano } & $0,870 * * *$ & $0,121 * * *$ & $0,657 * * *$ & $0,0249 * * *$ & $0,0224 * * *$ & $-0,00756$ \\
\hline & $(0,0347)$ & $(0,00402)$ & $(0,0439)$ & $(0,00247)$ & $(0,00182)$ & $(0,0459)$ \\
\hline Observações & 93.880 & 93.880 & 65.969 & 93.880 & 93.880 & 6.548 \\
\hline
\end{tabular}

Erros-padrão entre parênteses

$* * * \mathrm{p}<0.01, * * \mathrm{p}<0.05 \mathrm{e}^{*} \mathrm{p}<0.1$ 
Tabela B.5 - Efeitos marginais dos determinantes da utilização do cuidado, Região Sul - 2008

\begin{tabular}{|c|c|c|c|c|c|c|}
\hline \multirow{3}{*}{ Variáveis } & \multicolumn{3}{|c|}{ Consultas Médicas } & \multicolumn{3}{|c|}{ Internações Hospitalares } \\
\hline & \multirow[b]{2}{*}{$\begin{array}{l}\text { Binomial } \\
\text { Negativo }\end{array}$} & \multicolumn{2}{|c|}{ Hurdle Binomial Negativo } & \multirow[b]{2}{*}{$\begin{array}{l}\text { Binomial } \\
\text { Negativo }\end{array}$} & \multicolumn{2}{|c|}{ Hurdle Poisson } \\
\hline & & Logit & $\begin{array}{l}\text { Negbin } \\
\text { Truncado }\end{array}$ & & Logit & $\begin{array}{l}\text { Poisson } \\
\text { Truncado }\end{array}$ \\
\hline \multirow[t]{2}{*}{ m18_29 } & $0,311^{* * *}$ & $-0.0381 * * *$ & $0.619 * * *$ & $0.0450 * * *$ & $0.0343^{* * *}$ & 0.119 \\
\hline & $(0,120)$ & $(0.0137)$ & (0.169) & $(0.0140)$ & $(0.0103)$ & (0.198) \\
\hline \multirow[t]{2}{*}{ m30_44 } & $0,309 * * *$ & $-0.0294 * *$ & $0.473 * * *$ & $0.0466 * * *$ & $0.0249 * *$ & $0.594^{*}$ \\
\hline & $(0,0942)$ & $(0.0126)$ & $(0.149)$ & $(0.0165)$ & $(0.0105)$ & $(0.350)$ \\
\hline \multirow[t]{2}{*}{ m45_59 } & $0,488 * * *$ & -0.0145 & $0.548 * * *$ & $0.0548^{* * *}$ & $0.0362 * * *$ & 0.351 \\
\hline & $(0,103)$ & $(0.0123)$ & $(0.146)$ & $(0.0173)$ & (0.0108) & $(0.272)$ \\
\hline \multirow[t]{2}{*}{ m60_69 } & $0,544 * * *$ & $0.0384 * *$ & $0.328 * *$ & $0.0722 * * *$ & $0.0461 * * *$ & $0.474 *$ \\
\hline & $(0,136)$ & (0.0168) & $(0.162)$ & (0.0217) & (0.0133) & $(0.282)$ \\
\hline \multirow[t]{2}{*}{ m70 } & $0,353 * *$ & 0.0298 & $0.407^{* *}$ & 0.0196 & 0.0100 & 0.250 \\
\hline & $(0,146)$ & (0.0183) & (0.194) & (0.0152) & $(0.00851)$ & $(0.228)$ \\
\hline \multirow[t]{2}{*}{ f10_17 } & $0,708 * * *$ & $0.0467^{* * *}$ & $0.728 * * *$ & -0.000875 & -0.00494 & 0.408 \\
\hline & $(0,130)$ & $(0.0108)$ & $(0.169)$ & $(0.00987)$ & $(0.00671)$ & $(0.291)$ \\
\hline \multirow[t]{2}{*}{ f18_29 } & $2,572 * * *$ & $0.132 * * *$ & $2.393 * * *$ & $0.158 * * *$ & $0.107 * * *$ & $0.403 *$ \\
\hline & $(0,193)$ & $(0.00775)$ & $(0.235)$ & $(0.0271)$ & $(0.0168)$ & $(0.219)$ \\
\hline \multirow[t]{2}{*}{ f30_44 } & $2,286 * * *$ & $0.180 * * *$ & $1.712 * * *$ & $0.0922 * * *$ & $0.0684 * * *$ & 0.201 \\
\hline & $(0,162)$ & $(0.00946)$ & $(0.180)$ & $(0.0171)$ & (0.0114) & (0.192) \\
\hline \multirow[t]{2}{*}{ f45_59 } & $1,710 * * *$ & $0.161^{* * *}$ & $1.245^{* * *}$ & $0.0447 * * *$ & $0.0349 * * *$ & 0.193 \\
\hline & $(0,135)$ & $(0.00926)$ & $(0.160)$ & $(0.0136)$ & (0.0100) & $(0.205)$ \\
\hline \multirow[t]{2}{*}{ f60_69 } & $1,353 * * *$ & $0.140 * * *$ & $0.927 * * *$ & $0.0378 * * *$ & $0.0294 * * *$ & 0.388 \\
\hline & $(0,144)$ & $(0.0121)$ & (0.179) & (0.0138) & (0.00943) & $(0.345)$ \\
\hline \multirow[t]{2}{*}{$\mathrm{f} 70$} & $-0,00587$ & -0.0138 & 0.0619 & $0.0446 * * *$ & $0.0299 * * *$ & 0.0123 \\
\hline & $(0,115)$ & $(0.0245)$ & $(0.148)$ & $(0.0150)$ & (0.00805) & $(0.241)$ \\
\hline \multirow[t]{2}{*}{ bom } & $0,420 * * *$ & $0.0491 * * *$ & $0.349 * * *$ & $0.0307 * * *$ & $0.0237 * * *$ & 0.0829 \\
\hline & $(0,0529)$ & $(0.00840)$ & $(0.0651)$ & $(0.00512)$ & (0.00337) & (0.170) \\
\hline \multirow[t]{2}{*}{ regular } & $1,948 * * *$ & $0.156^{* * *}$ & $1.763 * * *$ & $0.116^{* * *}$ & $0.0717^{* * *}$ & $0.516^{* *}$ \\
\hline & $(0,0989)$ & $(0.00813)$ & $(0.122)$ & $(0.0134)$ & (0.00723) & $(0.210)$ \\
\hline \multirow[t]{2}{*}{ ruim } & $3,950 * * *$ & $0.173 * * *$ & $3.965 * * *$ & $0.289 * * *$ & $0.132 * * *$ & $1.345^{* * *}$ \\
\hline & $(0,277)$ & $(0.00983)$ & $(0.345)$ & (0.0397) & $(0.0145)$ & (0.510) \\
\hline mruim & $5,873 * * *$ & $0.162^{* * *}$ & $6.314 * * *$ & $0.372 * * *$ & $0.198 * * *$ & $1.169 * *$ \\
\hline & $(0,684)$ & $(0.0255)$ & $(0.647)$ & (0.0598) & (0.0261) & $(0.517)$ \\
\hline limitacao & $1,759 * * *$ & $0.200 * * *$ & $1.573 * * *$ & $0.124 * * *$ & $0.0874 * * *$ & $0.292 * * *$ \\
\hline & $(0,0881)$ & $(0.00616)$ & $(0.0952)$ & $(0.0105)$ & (0.00653) & (0.0705) \\
\hline cronica & $1,306 * * *$ & $0.161^{* * *}$ & $1.075^{* * *}$ & $0.0307^{* * *}$ & $0.0218 * * *$ & 0.0553 \\
\hline & $(0,0609)$ & $(0.00602)$ & $(0.0667)$ & $(0.00494)$ & (0.00348) & (0.0835) \\
\hline Irendapc & $0,127 * * *$ & $0.0329 * * *$ & 0.0146 & $-0.00488^{*}$ & $-0.00305^{*}$ & 0.0130 \\
\hline & $(0,0274)$ & $(0.00365)$ & (0.0351) & (0.00269) & $(0.00162)$ & $(0.0428)$ \\
\hline fundamental & $-0,0496$ & $0.0262 * *$ & -0.104 & -0.00747 & -0.00233 & -0.0727 \\
\hline & $(0,0774)$ & $(0.0124)$ & $(0.0881)$ & $(0.00667)$ & (0.00408) & $(0.111)$ \\
\hline medio & $-0,00704$ & $0.0491^{* * *}$ & $-0.183^{*}$ & -0.00364 & 0.000216 & -0.0361 \\
\hline & $(0,0830)$ & $(0.0117)$ & (0.0998) & $(0.00702)$ & $(0.00431)$ & $(0.123)$ \\
\hline superior & 0,154 & $0.0721 * * *$ & -0.0114 & 0.00149 & 0.000741 & 0.124 \\
\hline & $(0,106)$ & (0.0128) & $(0.126)$ & $(0.00818)$ & (0.00499) & (0.158) \\
\hline desocupado & $-0,227^{* *}$ & 0.00775 & $-0.362 * * *$ & $-0.0288 * * *$ & $-0.0207 * * *$ & -0.147 \\
\hline & $(0,103)$ & $(0.0140)$ & $(0.118)$ & $(0.00672)$ & $(0.00525)$ & $(0.152)$ \\
\hline ccarteira & $-0,267 * * *$ & $0.0340 * * *$ & $-0.530 * * *$ & $-0.0314 * * *$ & $-0.0215^{* * *}$ & $-0.249 * * *$ \\
\hline & $(0,0520)$ & $(0.00849)$ & (0.0581) & (0.00313) & (0.00243) & $(0.0684)$ \\
\hline
\end{tabular}




\begin{tabular}{|c|c|c|c|c|c|c|}
\hline \multirow{4}{*}{ Variáveis } & \multicolumn{3}{|c|}{ Consultas Médicas } & \multicolumn{3}{|c|}{ Internações Hospitalares } \\
\hline & \multirow{3}{*}{$\begin{array}{l}\text { Binomial } \\
\text { Negativo }\end{array}$} & \multicolumn{2}{|c|}{ Hurdle Binomial Negativo } & \multirow{3}{*}{$\begin{array}{l}\text { Binomial } \\
\text { Negativo }\end{array}$} & \multicolumn{2}{|c|}{ Hurdle Poisson } \\
\hline & & & Negbin & & & Poisson \\
\hline & & Logit & Truncado & & Logit & Truncado \\
\hline \multirow[t]{2}{*}{ fpublico } & $-0,167^{*}$ & $0,0509 * * *$ & $-0,362 * * *$ & 0,00114 & $-0,00187$ & 0,0963 \\
\hline & $(0,0862)$ & $(0,0119)$ & $(0,106)$ & $(0,00808)$ & $(0,00538)$ & $(0,125)$ \\
\hline \multirow[t]{2}{*}{ domestico } & $-0,330 * * *$ & $-0,0282 * *$ & $-0,417 * * *$ & $-0,0310 * * *$ & $-0,0257 * * *$ & 0,0233 \\
\hline & $(0,103)$ & $(0,0143)$ & $(0,139)$ & $(0,00518)$ & $(0,00416)$ & $(0,162)$ \\
\hline \multirow[t]{2}{*}{ scarteira } & $-0,409 * * *$ & $-0,0216 * *$ & $-0,440 * * *$ & $-0,0262 * * *$ & $-0,0175^{* * *}$ & $-0,230 * * *$ \\
\hline & $(0,0666)$ & $(0,00973)$ & $(0,0966)$ & $(0,00428)$ & $(0,00353)$ & $(0,0668)$ \\
\hline \multirow[t]{2}{*}{ cpropria } & $-0,519 * * *$ & $-0,0461 * * *$ & $-0,493 * * *$ & $-0,0279 * * *$ & $-0,0201 * * *$ & $-0,136^{*}$ \\
\hline & $(0,0521)$ & $(0,0103)$ & $(0,0655)$ & $(0,00468)$ & $(0,00372)$ & $(0,0809)$ \\
\hline \multirow[t]{2}{*}{ empregador } & $-0,535 * * *$ & $-0,0298 *$ & $-0,644 * * *$ & $-0,0359 * * *$ & $-0,0258 * * *$ & $-0,309 * * *$ \\
\hline & $(0,0837)$ & $(0,0156)$ & $(0,107)$ & $(0,00537)$ & $(0,00419)$ & $(0,113)$ \\
\hline \multirow[t]{2}{*}{ outra } & $-0,291 * * *$ & $-0,0191$ & $-0,368 * * *$ & $-0,0204 * * *$ & $-0,0164 * * *$ & $-0,0898$ \\
\hline & $(0,0720)$ & $(0,0153)$ & $(0,0999)$ & $(0,00581)$ & $(0,00411)$ & $(0,109)$ \\
\hline \multirow[t]{2}{*}{ plano } & $0,889 * * *$ & $0,114 * * *$ & $0,726 * * *$ & $0,0202 * * *$ & $0,0174 * * *$ & $-0,0851$ \\
\hline & $(0,0540)$ & $(0,00726)$ & $(0,0694)$ & $(0,00408)$ & $(0,00289)$ & $(0,0652)$ \\
\hline Observações & 48.028 & 48.028 & 33.317 & 48.028 & 48.028 & 3.647 \\
\hline
\end{tabular}

Erros-padrão entre parênteses

$* * * \mathrm{p}<0.01, * * \mathrm{p}<0.05 \mathrm{e}^{*} \mathrm{p}<0.1$ 
Tabela B.6 - Efeitos marginais dos determinantes da utilização do cuidado, Região CentroOeste -2008

\begin{tabular}{|c|c|c|c|c|c|c|}
\hline \multirow{3}{*}{ Variáveis } & \multicolumn{3}{|c|}{ Consultas Médicas } & \multicolumn{3}{|c|}{ Internações Hospitalares } \\
\hline & \multirow[b]{2}{*}{$\begin{array}{l}\text { Binomial } \\
\text { Negativo }\end{array}$} & \multicolumn{2}{|c|}{ Hurdle Binomial Negativo } & \multirow[b]{2}{*}{$\begin{array}{l}\text { Binomial } \\
\text { Negativo }\end{array}$} & \multicolumn{2}{|c|}{ Hurdle Poisson } \\
\hline & & Logit & $\begin{array}{l}\text { Negbin } \\
\text { Truncado }\end{array}$ & & Logit & $\begin{array}{l}\text { Poisson } \\
\text { Truncado }\end{array}$ \\
\hline \multirow[t]{2}{*}{ m18_29 } & $-0,203 * * *$ & $-0,0496 * * *$ & $-0,162$ & 0,0153 & 0,0154 & $-0,229$ \\
\hline & $(0,0736)$ & $(0,0120)$ & $(0,115)$ & $(0,0148)$ & $(0,0106)$ & $(0,186)$ \\
\hline \multirow[t]{2}{*}{ m30_44 } & $-0,108$ & $-0,0412 * * *$ & $-0,116$ & 0,0144 & 0,00664 & 0,0588 \\
\hline & $(0,0965)$ & $(0,0134)$ & $(0,153)$ & $(0,0151)$ & $(0,0103)$ & $(0,240)$ \\
\hline \multirow[t]{2}{*}{ m45_59 } & 0,122 & $-0,0158$ & 0,0558 & $0,0305^{*}$ & $0,0191 *$ & 0,0530 \\
\hline & $(0,111)$ & $(0,0157)$ & $(0,176)$ & $(0,0168)$ & $(0,0113)$ & $(0,244)$ \\
\hline \multirow[t]{2}{*}{ m60_69 } & $0,523 * * *$ & $0,0588^{* * *}$ & 0,257 & $0,0409 * *$ & $0,0324 * *$ & $-0,103$ \\
\hline & $(0,130)$ & $(0,0162)$ & $(0,184)$ & $(0,0190)$ & $(0,0139)$ & $(0,206)$ \\
\hline \multirow[t]{2}{*}{ m70 } & $0,343^{* *}$ & 0,0267 & $0,432 * *$ & $0,0594 * *$ & 0,0171 & $0,635^{*}$ \\
\hline & $(0,146)$ & $(0,0207)$ & $(0,203)$ & $(0,0258)$ & $(0,0117)$ & $(0,331)$ \\
\hline \multirow[t]{2}{*}{ f10_17 } & $0,578 * * *$ & $0,0682 * * *$ & $0,370 * *$ & 0,0152 & 0,00298 & 0,113 \\
\hline & $(0,106)$ & $(0,0102)$ & $(0,179)$ & $(0,0140)$ & $(0,00863)$ & $(0,231)$ \\
\hline \multirow[t]{2}{*}{ f18_29 } & $2,000 * * *$ & $0,167 * * *$ & $1,557 * * *$ & $0,172 * * *$ & $0,120 * * *$ & $-0,0365$ \\
\hline & $(0,142)$ & $(0,00904)$ & $(0,191)$ & $(0,0269)$ & $(0,0162)$ & $(0,187)$ \\
\hline \multirow[t]{2}{*}{ f30_44 } & $1,491 * * *$ & $0,193 * * *$ & $0,851 * * *$ & $0,0878 * * *$ & $0,0574 * * *$ & 0,0373 \\
\hline & $(0,121)$ & $(0,00881)$ & $(0,170)$ & $(0,0198)$ & $(0,0123)$ & $(0,213)$ \\
\hline \multirow[t]{2}{*}{ f45_59 } & $1,302 * * *$ & $0,181 * * *$ & $0,732 * * *$ & $0,0429 * *$ & $0,0202 * *$ & 0,125 \\
\hline & $(0,125)$ & $(0,0127)$ & $(0,164)$ & $(0,0212)$ & $(0,00990)$ & $(0,283)$ \\
\hline \multirow[t]{2}{*}{ f60_69 } & $1,176 * * *$ & $0,166^{* * *}$ & $0,661 * * *$ & 0,0214 & $0,0234 * *$ & $-0,156$ \\
\hline & $(0,142)$ & $(0,0139)$ & $(0,185)$ & $(0,0152)$ & $(0,0111)$ & $(0,175)$ \\
\hline \multirow[t]{2}{*}{ f70 } & $-0,0345$ & 0,0162 & $-0,0250$ & $0,0437 * * *$ & $0,0209 * *$ & $0,396 * *$ \\
\hline & $(0,0933)$ & $(0,0290)$ & $(0,122)$ & $(0,0164)$ & $(0,0102)$ & $(0,186)$ \\
\hline \multirow[t]{2}{*}{ bom } & $0,316^{* * *}$ & $0,0360 * * *$ & $0,337 * * *$ & $0,0347 * * *$ & $0,0204 * * *$ & $0,252^{* *}$ \\
\hline & $(0,0463)$ & $(0,00751)$ & $(0,0676)$ & $(0,00547)$ & $(0,00388)$ & $(0,119)$ \\
\hline \multirow[t]{2}{*}{ regular } & $1,517 * * *$ & $0,137 * * *$ & $1,529 * * *$ & $0,111 * * *$ & $0,0595 * * *$ & $0,553 * * *$ \\
\hline & $(0,0946)$ & $(0,00776)$ & $(0,117)$ & $(0,0120)$ & $(0,00661)$ & $(0,167)$ \\
\hline \multirow[t]{2}{*}{ ruim } & $3,184 * * *$ & $0,146 * * *$ & $3,626 * * *$ & $0,258 * * *$ & $0,118 * * *$ & $1,037 * * *$ \\
\hline & $(0,245)$ & $(0,0168)$ & $(0,298)$ & $(0,0362)$ & $(0,0132)$ & $(0,308)$ \\
\hline mruim & $4,584 * * *$ & $0,214 * * *$ & $5,172 * * *$ & $0,402 * * *$ & $0,180 * * *$ & $1,625^{* * *}$ \\
\hline & $(0,616)$ & $(0,0178)$ & $(0,788)$ & $(0,0761)$ & $(0,0355)$ & $(0,511)$ \\
\hline limitacao & $1,466 * * *$ & $0,190 * * *$ & $1,343 * * *$ & $0,139 * * *$ & $0,0900 * * *$ & $0,285 * * *$ \\
\hline & $(0,102)$ & $(0,0105)$ & $(0,117)$ & $(0,0104)$ & $(0,00645)$ & $(0,0646)$ \\
\hline cronica & $1,164 * * *$ & $0,158 * * *$ & $1,016 * * *$ & $0,0642 * * *$ & $0,0419 * * *$ & $0,207^{*}$ \\
\hline & $(0,0546)$ & $(0,00768)$ & $(0,0657)$ & $(0,00716)$ & $(0,00376)$ & $(0,109)$ \\
\hline Irendapc & $0,120 * * *$ & $0,0245^{* * *}$ & $0,0880 * * *$ & $-0,00722 * * *$ & $-0,00580 * * *$ & 0,00662 \\
\hline & $(0,0248)$ & $(0,00442)$ & $(0,0324)$ & $(0,00273)$ & $(0,00199)$ & $(0,0336)$ \\
\hline fundamental & 0,0280 & $0,0271^{* *}$ & $-0,0286$ & $-0,00432$ & 0,00331 & $-0,128$ \\
\hline & $(0,0566)$ & $(0,0117)$ & $(0,0728)$ & $(0,00983)$ & $(0,00422)$ & $(0,106)$ \\
\hline medio & $0,150 * *$ & $0,0373 * * *$ & 0,0977 & $-0,00881$ & $-0,00163$ & $-0,0838$ \\
\hline & $(0,0660)$ & $(0,0126)$ & $(0,0778)$ & $(0,0117)$ & $(0,00516)$ & $(0,120)$ \\
\hline superior & $0,458 * * *$ & $0,0858 * * *$ & $0,367 * * *$ & 0,00428 & 0,00609 & $-0,00689$ \\
\hline & $(0,0877)$ & $(0,0124)$ & $(0,114)$ & $(0,0134)$ & $(0,00630)$ & $(0,126)$ \\
\hline desocupado & $-0,0508$ & $-0,000630$ & $-0,0689$ & $-0,0212 * * *$ & $-0,0174 * * *$ & $-0,130$ \\
\hline & $(0,0847)$ & $(0,0131)$ & $(0,114)$ & $(0,00762)$ & $(0,00522)$ & $(0,0790)$ \\
\hline ccarteira & $-0,0885$ & $0,0414 * * *$ & $-0,310 * * *$ & $-0,0222 * * *$ & $-0,0179 * * *$ & $-0,0175$ \\
\hline & $(0,0558)$ & $(0,00899)$ & $(0,0730)$ & $(0,00648)$ & $(0,00421)$ & $(0,113)$ \\
\hline
\end{tabular}


Conclusão

\begin{tabular}{|c|c|c|c|c|c|c|}
\hline \multirow{4}{*}{ Variáveis } & \multicolumn{3}{|c|}{ Consultas Médicas } & \multicolumn{3}{|c|}{ Internações Hospitalares } \\
\hline & \multirow{3}{*}{$\begin{array}{l}\text { Binomial } \\
\text { Negativo }\end{array}$} & \multicolumn{2}{|c|}{ Hurdle Binomial Negativo } & \multirow{3}{*}{$\begin{array}{l}\text { Binomial } \\
\text { Negativo }\end{array}$} & \multicolumn{2}{|c|}{ Hurdle Poisson } \\
\hline & & & Negbin & & & Poisson \\
\hline & & Logit & Truncado & & Logit & Truncado \\
\hline \multirow[t]{2}{*}{ fpublico } & 0,0807 & $0,0463 * * *$ & $-0,0232$ & $-0,0134^{*}$ & $-0,00416$ & $-0,210$ \\
\hline & $(0,0943)$ & $(0,0125)$ & $(0,111)$ & $(0,00785)$ & $(0,00624)$ & $(0,135)$ \\
\hline \multirow[t]{2}{*}{ domestico } & $-0,218 * * *$ & $-0,0181$ & $-0,324 * * *$ & $-0,0391 * * *$ & $-0,0297 * * *$ & $-0,146$ \\
\hline & $(0,0703)$ & $(0,0133)$ & $(0,0919)$ & $(0,00565)$ & $(0,00345)$ & $(0,108)$ \\
\hline \multirow[t]{2}{*}{ scarteira } & $-0,351 * * *$ & $-0,0319 * *$ & $-0,352 * * *$ & $-0,0130 *$ & $-0,0112 * *$ & $-0,0274$ \\
\hline & $(0,0661)$ & $(0,0125)$ & $(0,0914)$ & $(0,00685)$ & $(0,00491)$ & $(0,108)$ \\
\hline \multirow[t]{2}{*}{ cpropria } & $-0,402 * * *$ & $-0,0452 * * *$ & $-0,403 * * *$ & $-0,0209 * * *$ & $-0,0162 * * *$ & $-0,0261$ \\
\hline & $(0,0560)$ & $(0,0123)$ & $(0,0692)$ & $(0,00583)$ & $(0,00397)$ & $(0,0976)$ \\
\hline \multirow[t]{2}{*}{ empregador } & $-0,350 * * *$ & $-0,0277$ & $-0,413 * * *$ & 0,00129 & $-0,00323$ & 0,255 \\
\hline & $(0,0968)$ & $(0,0185)$ & $(0,136)$ & $(0,00955)$ & $(0,00848)$ & $(0,158)$ \\
\hline \multirow[t]{2}{*}{ outra } & $-0,243 * *$ & $-0,0325^{*}$ & $-0,273^{* *}$ & $-0,0156 * *$ & $-0,0102$ & $-0,140$ \\
\hline & $(0,0966)$ & $(0,0189)$ & $(0,129)$ & $(0,00717)$ & $(0,00640)$ & $(0,0960)$ \\
\hline \multirow[t]{2}{*}{ plano } & $0,753 * * *$ & $0,122 * * *$ & $0,583 * * *$ & $0,0290 * * *$ & $0,0275^{* * *}$ & $-0,142 * *$ \\
\hline & $(0,0522)$ & $(0,00798)$ & $(0,0614)$ & $(0,00523)$ & $(0,00401)$ & $(0,0558)$ \\
\hline Observações & 35.310 & 35.310 & 23.292 & 35.310 & 35.310 & 3.064 \\
\hline
\end{tabular}

Erros-padrão entre parênteses

$* * * \mathrm{p}<0.01, * * \mathrm{p}<0.05 \mathrm{e}^{*} \mathrm{p}<0.1$ 


\section{APÊNDICE C - CONTRIBUIÇÃO DOS DETERMINANTES PARA A DESIGUALDADE, REGIÕES}

Tabela C.1 - Contribuição dos determinantes da utilização para a desigualdade no cuidado, Região Norte - 2008

\begin{tabular}{|c|c|c|c|c|c|c|}
\hline \multirow{4}{*}{ Variáveis } & \multicolumn{3}{|c|}{ Consultas Médicas } & \multicolumn{3}{|c|}{ Internações Hospitalares } \\
\hline & \multirow{3}{*}{$\begin{array}{l}\text { Binomial } \\
\text { Negativo }\end{array}$} & \multicolumn{2}{|c|}{ Hurdle Binomial Negativo } & \multirow{3}{*}{$\begin{array}{l}\text { Binomial } \\
\text { Negativo }\end{array}$} & \multicolumn{2}{|c|}{ Hurdle Poisson } \\
\hline & & & Negbin & & & Poisson \\
\hline & & Logit & Truncado & & Logit & Truncado \\
\hline m18_29 & $-0,0001$ & $-0,0003 * * *$ & 0,0001 & $0,0013 * *$ & $0,0022 * * *$ & $-0,0003$ \\
\hline $\mathrm{m} 3044$ & $0,0003 * *$ & $-0,0002 *$ & $0,0003 * *$ & $0,0013 * *$ & $0,0021 * * *$ & $-0,0003$ \\
\hline m45_59 & $0,0028 * * *$ & 0,0002 & $0,0023 * * *$ & $0,0032 * *$ & $0,0047 * * *$ & $-0,0002$ \\
\hline m60_69 & $0,0043 * * *$ & $0,0007 * *$ & $0,0034 * * *$ & $0,0084 * *$ & $0,0072 * * *$ & 0,0017 \\
\hline $\mathrm{m} 70$ & 0,0004 & 0,0001 & 0,0003 & $-0,0002$ & 0,0013 & $-0,0011 * * *$ \\
\hline f10_17 & $-0,0064 * * *$ & $-0,0033 * * *$ & $-0,0029 * * *$ & $-0,0097 * * *$ & $-0,0093 * * *$ & $-0,0047$ \\
\hline f18_29 & $-0,0088 * * *$ & $-0,0033 * * *$ & $-0,0046 * * *$ & $-0,0153 * * *$ & $-0,0193 * * *$ & $0,0011 *$ \\
\hline f30_44 & $0,0006^{* * *}$ & $0,0003 * * *$ & $0,0003 * * *$ & $0,0006 * * *$ & $0,0008 * * *$ & 0,0000 \\
\hline f45_59 & $0,0066 * * *$ & $0,0029 * * *$ & $0,0035^{* * *}$ & 0,0012 & $0,0030 * * *$ & $-0,0013 *$ \\
\hline f60_69 & $0,0104 * * *$ & $0,0035^{* * *}$ & $0,0063 * * *$ & $0,0087 * *$ & $0,0066 * * *$ & 0,0007 \\
\hline f70 & $-0,0002$ & 0,0005 & $-0,0002$ & $-0,0002$ & $0,0013 *$ & $-0,0010^{* *}$ \\
\hline bom & $-0,0006 * * *$ & $-0,0004 * * *$ & $-0,0004 * * *$ & $-0,0008 * * *$ & $-0,0004^{*}$ & $-0,0019 * * *$ \\
\hline regular & $-0,0043 * * *$ & $-0,0024 * * *$ & $-0,0022 * * *$ & $-0,0079 * * *$ & $-0,0056^{* * *}$ & $-0,0065^{* * *}$ \\
\hline ruim & $-0,0041 * * *$ & $-0,0012 * * *$ & $-0,0025 * * *$ & $-0,0080 * * *$ & $-0,0047 * * *$ & $-0,0050 * * *$ \\
\hline mruim & $-0,0013 * * *$ & $-0,0003 * * *$ & $-0,0009 * * *$ & $-0,0026 * * *$ & $-0,0013 * * *$ & $-0,0025 * * *$ \\
\hline limitação & $-0,0015 * * *$ & $-0,0011 * * *$ & $-0,0008 * * *$ & $-0,0038 * * *$ & $-0,0034 * * *$ & $-0,0008 * * *$ \\
\hline crônica & $0,0101 * * *$ & $0,0070 * * *$ & $0,0051 * * *$ & $0,0085 * * *$ & $0,0091 * * *$ & 0,0016 \\
\hline lrendapc & $0,0169 * * *$ & $0,0214 * * *$ & 0,0000 & $-0,0251 *$ & $-0,0266^{*}$ & $-0,0012$ \\
\hline fundamental & $-0,0051 * *$ & $-0,0053 * * *$ & $-0,0026$ & 0,0029 & 0,0016 & $0,0097 *$ \\
\hline médio & $0,0074 * * *$ & $0,0056 * * *$ & $0,0039 * * *$ & $-0,0015$ & $-0,0059 * *$ & 0,0023 \\
\hline superior & $0,0049 * *$ & $0,0058 * * *$ & 0,0013 & $-0,0064 * *$ & $-0,0092 * * *$ & $-0,0010$ \\
\hline desocupado & 0,0004 & 0,0002 & 0,0004 & $0,0019 * * *$ & $0,0028 * * *$ & $-0,0006$ \\
\hline ccarteira & $-0,0005$ & $0,0032 * * *$ & $-0,0029 * * *$ & $-0,0068 * * *$ & $-0,0061 * * *$ & $-0,0065 * * *$ \\
\hline fpublico & $-0,0001$ & $0,0025^{* * *}$ & $-0,0013$ & 0,0027 & 0,0046 & $-0,0032$ \\
\hline domestico & $0,0008 * * *$ & $0,0003 * *$ & $0,0007 * * *$ & $0,0017 * * *$ & $0,0017 * * *$ & $0,0009 * *$ \\
\hline scarteira & $-0,0010 * * *$ & $-0,0004 * * *$ & $-0,0007 * * *$ & $-0,0006$ & $-0,0004$ & $-0,0010 * * *$ \\
\hline cpropria & $-0,0004 * * *$ & $-0,0002 * * *$ & $-0,0003 * * *$ & $-0,0003$ & $-0,0005^{* *}$ & 0,0001 \\
\hline empregador & $-0,0019 * * *$ & $-0,0005$ & $-0,0016 * * *$ & $-0,0008$ & $-0,0007$ & $-0,0014$ \\
\hline outra & $0,0027 * * *$ & $0,0016^{* * *}$ & $0,0018 * * *$ & 0,0009 & 0,0013 & $-0,0014$ \\
\hline plano & $0,0287 * * *$ & $0,0200 * * *$ & $0,0151 * * *$ & $0,0139 * * *$ & $0,0188 * * *$ & 0,0046 \\
\hline$G C_{\varepsilon}$ & 0,0049 & $-0,0051$ & $-0,0070$ & $-0,0071$ & $-0,0151$ & 0,0189 \\
\hline IC & $0,0658 * * *$ & $0,0519 * * *$ & $0,0139 * * *$ & $-0,0397 * * *$ & $-0,0396 * * *$ & $-0,000203$ \\
\hline ICwv & $0,0587 * * *$ & $0,0490 * * *$ & $0,0185^{* * *}$ & $-0,0210$ & $-0,0296 * * *$ & 0,0039 \\
\hline Observações & 40.240 & 40.240 & 24.636 & 40.240 & 40.240 & 2.984 \\
\hline
\end{tabular}


Tabela C.2 - Contribuição dos determinantes da utilização para a desigualdade no cuidado, Região Nordeste - 2008

\begin{tabular}{|c|c|c|c|c|c|c|}
\hline \multirow{4}{*}{ Variáveis } & \multicolumn{3}{|c|}{ Consultas Médicas } & \multicolumn{3}{|c|}{ Internações Hospitalares } \\
\hline & \multirow{3}{*}{$\begin{array}{l}\text { Binomial } \\
\text { Negativo }\end{array}$} & \multicolumn{2}{|c|}{ Hurdle Binomial Negativo } & \multirow{3}{*}{$\begin{array}{l}\text { Binomial } \\
\text { Negativo }\end{array}$} & \multicolumn{2}{|c|}{ Hurdle Poisson } \\
\hline & & & Negbin & & & Poisson \\
\hline & & Logit & Truncado & & Logit & Truncado \\
\hline m18_29 & $-0,0001$ & $-0,0001 * * *$ & 0,0000 & 0,0001 & $0,0004 * * *$ & $-0,0003 * * *$ \\
\hline m30_44 & 0,0000 & $0,0001 * * *$ & 0,0000 & $-0,0001$ & $-0,0001 * *$ & $0,0002 * *$ \\
\hline m45_59 & $0,0004 *$ & $-0,0006 * * *$ & $0,0006 * * *$ & $0,0013^{*}$ & $0,0022 * * *$ & $-0,0013^{*}$ \\
\hline m60_69 & $0,0035 * * *$ & 0,0004 & $0,0025 * * *$ & 0,0009 & $0,0070 * * *$ & $-0,0058 * * *$ \\
\hline $\mathrm{m} 70$ & 0,0005 & $0,0005 * *$ & 0,0002 & $0,0038 * * *$ & $0,0036 * * *$ & 0,0013 \\
\hline f10_17 & $-0,0047 * * *$ & $-0,0025 * * *$ & $-0,0020 * * *$ & $-0,0002$ & $-0,0016$ & $0,0043 * *$ \\
\hline f18_29 & $-0,0085^{* * *}$ & $-0,0027 * * *$ & $-0,0050 * * *$ & $-0,0131 * * *$ & $-0,0160 * * *$ & $0,0021 * *$ \\
\hline f30_44 & $-0,0035 * * *$ & $-0,0016 * * *$ & $-0,0016^{* * *}$ & $-0,0024 * * *$ & $-0,0036 * * *$ & $0,0013 * * *$ \\
\hline f45_59 & $0,0063 * * *$ & $0,0030 * * *$ & $0,0032 * * *$ & $0,0021 *$ & $0,0040 * * *$ & $-0,0025^{* *}$ \\
\hline f60_69 & $0,0128 * * *$ & $0,0055^{* * *}$ & $0,0075^{* * *}$ & 0,0004 & $0,0073 * * *$ & $-0,0072 * * *$ \\
\hline $\mathrm{f} 70$ & $-0,0009 * * *$ & $-0,0001$ & $-0,0008 * * *$ & $0,0030 * *$ & $0,0030 * * *$ & 0,0000 \\
\hline bom & $-0,0011 * * *$ & $-0,0007 * * *$ & $-0,0004 * * *$ & $-0,0017 * * *$ & $-0,0017 * * *$ & $-0,0007$ \\
\hline regular & $0,0003 * * *$ & $0,0001 * * *$ & $0,0002 * * *$ & $0,0004 * * *$ & $0,0003 * * *$ & $0,0002 * * *$ \\
\hline ruim & $-0,0004 * * *$ & $-0,0001 * * *$ & $-0,0002 * * *$ & $-0,0007 * * *$ & $-0,0004 * * *$ & $-0,0003 * * *$ \\
\hline mruim & $0,0006 * * *$ & $0,0001 * * *$ & $0,0004 * * *$ & $0,0012 * * *$ & $0,0007 * * *$ & $0,0004 * * *$ \\
\hline limitação & $0,0002 * * *$ & $0,0001 * * *$ & $0,0001 * * *$ & $0,0004 * * *$ & $0,0004 * * *$ & $0,0001 * * *$ \\
\hline crônica & $0,0168 * * *$ & $0,0104 * * *$ & $0,0092 * * *$ & $0,0184 * * *$ & $0,0138 * * *$ & $0,0094 * * *$ \\
\hline lrendapc & $0,0235 * * *$ & $0,0188 * * *$ & $0,0101 * * *$ & $-0,0157^{*}$ & $-0,0256^{* * *}$ & $-0,0014$ \\
\hline fundamental & $-0,0018$ & $-0,0051 * * *$ & 0,0013 & $-0,0006$ & $-0,0022$ & $-0,0003$ \\
\hline médio & $0,0031 * * *$ & $0,0046^{* * *}$ & $-0,0001$ & $-0,0057 * * *$ & $-0,0050 * * *$ & $-0,0007$ \\
\hline superior & $0,0053 * * *$ & $0,0060 * * *$ & 0,0014 & 0,0005 & $-0,0021$ & 0,0090 \\
\hline desocupado & $0,0011^{* * *}$ & $0,0003^{*}$ & $0,0010 * * *$ & $0,0021 * * *$ & $0,0029 * * *$ & $-0,0001$ \\
\hline ccarteira & $-0,0011^{* *}$ & $0,0030 * * *$ & $-0,0033 * * *$ & $-0,0076 * * *$ & $-0,0084 * * *$ & $-0,0017$ \\
\hline fpublico & $-0,0007 *$ & $0,0015 * * *$ & $-0,0013 * * *$ & $-0,0022 * *$ & $-0,0010$ & $-0,0023$ \\
\hline domestico & $0,0007 * * *$ & $0,0002 * * *$ & $0,0006^{* * *}$ & $0,0015 * * *$ & $0,0016^{* * *}$ & $0,0006^{* *}$ \\
\hline scarteira & $0,0002 * * *$ & 0,0001 & $0,0001 * * *$ & $0,0001 * *$ & $0,0002 * * *$ & 0,0000 \\
\hline cpropria & $-0,0004 * * *$ & $-0,0002 * * *$ & $-0,0003 * * *$ & $-0,0005^{* * *}$ & $-0,0006 * * *$ & $-0,0001$ \\
\hline empregador & $0,0000 * * *$ & $-0,0011 * * *$ & $-0,0013 * * *$ & $-0,0007 *$ & $-0,0020$ & $0,0000 * * *$ \\
\hline outra & $0,0022 * * *$ & $0,0025 * * *$ & $0,0029 * * *$ & $0,0030 * *$ & $0,0024 * * *$ & $0,0022^{*}$ \\
\hline plano & $0,0191 * * *$ & $0,0155^{* * *}$ & $0,0217 * * *$ & $0,0283 * * *$ & $-0,0052 * * *$ & 0,0191 \\
\hline$G C_{\varepsilon}$ & 0,0099 & $-0,0046$ & 0,0175 & $-0,0192$ & $-0,0164$ & $-0,0025$ \\
\hline IC & $0,0934 * * *$ & $0,0576 * * *$ & $0,0356 * * *$ & $-0,0102$ & $-0,00690$ & $-0,00324$ \\
\hline $\mathrm{ICwv}$ & $0,0705^{* * *}$ & $0,0458 * * *$ & $0,0365^{* * *}$ & $-0,0180$ & $-0,0228 * * *$ & $-0,0023$ \\
\hline Observações & 101.830 & 101.830 & 65.723 & 101.830 & 101.830 & 6.746 \\
\hline
\end{tabular}
$* * * \mathrm{p}<0.01, * * \mathrm{p}<0.05 \mathrm{e} * \mathrm{p}<0.1$ 
Tabela C.3 - Contribuição dos determinantes da utilização para a desigualdade no cuidado, Região Sudeste - 2008

\begin{tabular}{|c|c|c|c|c|c|c|}
\hline \multirow{4}{*}{ Variáveis } & \multicolumn{3}{|c|}{ Consultas Médicas } & \multicolumn{3}{|c|}{ Internações Hospitalares } \\
\hline & \multirow{3}{*}{$\begin{array}{l}\text { Binomial } \\
\text { Negativo }\end{array}$} & \multicolumn{2}{|c|}{ Hurdle Binomial Negativo } & \multirow{3}{*}{$\begin{array}{l}\text { Binomial } \\
\text { Negativo }\end{array}$} & \multicolumn{2}{|c|}{ Hurdle Poisson } \\
\hline & & & Negbin & & & Poisson \\
\hline & & Logit & Truncado & & Logit & Truncado \\
\hline m18_29 & $-0,0001$ & $-0,0003 * * *$ & 0,0001 & $0,0018 * * *$ & $0,0016 * * *$ & $0,0014 * *$ \\
\hline m30_44 & 0,0000 & $0,0000 * * *$ & 0,0000 & $0,0001 * * *$ & $0,0001 * * *$ & $0,0000 *$ \\
\hline m45_59 & $0,0011 * * *$ & $-0,0003 * *$ & $0,0010 * * *$ & $0,0078 * * *$ & $0,0076 * * *$ & $0,0042 * *$ \\
\hline m60_69 & $0,0027 * * *$ & $0,0005 * *$ & $0,0017 * * *$ & $0,0124 * * *$ & $0,0122 * * *$ & $0,0039 * *$ \\
\hline $\mathrm{m} 70$ & $0,0003 *$ & $0,0003 * * *$ & 0,0001 & 0,0007 & $0,0007 * *$ & 0,0000 \\
\hline f10_17 & $-0,0041 * * *$ & $-0,0016 * * *$ & $-0,0021 * * *$ & $-0,0094 * * *$ & $-0,0062 * * *$ & $-0,0126^{* * *}$ \\
\hline f18_29 & $-0,0051 * * *$ & $-0,0014 * * *$ & $-0,0031 * * *$ & $-0,0136 * * *$ & $-0,0134 * * *$ & $-0,0014 *$ \\
\hline f30_44 & $-0,0049 * * *$ & $-0,0018 * * *$ & $-0,0025 * * *$ & $-0,0096 * * *$ & $-0,0098 * * *$ & $-0,0013^{*}$ \\
\hline f45_59 & $0,0072 * * *$ & $0,0029 * * *$ & $0,0038 * * *$ & $0,0107 * * *$ & $0,0101 * * *$ & $0,0039 * *$ \\
\hline f60_69 & $0,0069 * * *$ & $0,0030 * * *$ & $0,0035^{* * *}$ & $0,0073 * * *$ & $0,0078 * * *$ & 0,0019 \\
\hline $\mathrm{f} 70$ & 0,0000 & 0,0001 & 0,0000 & $0,0026 * * *$ & $0,0023 * * *$ & $0,0014 *$ \\
\hline bom & $-0,0006^{* * *}$ & $-0,0002 * * *$ & $-0,0004 * * *$ & $-0,0003 * * *$ & $-0,0004 * * *$ & 0,0000 \\
\hline regular & $-0,0109 * * *$ & $-0,0030 * * *$ & $-0,0078 * * *$ & $-0,0091 * * *$ & $-0,0092 * * *$ & $-0,0018$ \\
\hline ruim & $-0,0072 * * *$ & $-0,0012 * * *$ & $-0,0054 * * *$ & $-0,0074 * * *$ & $-0,0064 * * *$ & $-0,0013^{*}$ \\
\hline mruim & $-0,0021 * * *$ & $-0,0002 * * *$ & $-0,0017 * * *$ & $-0,0026 * * *$ & $-0,0020 * * *$ & $-0,0006^{* *}$ \\
\hline limitação & $-0,0020 * * *$ & $-0,0010 * * *$ & $-0,0013 * * *$ & $-0,0046 * * *$ & $-0,0045^{* * *}$ & $-0,0008 * * *$ \\
\hline crônica & $0,0076^{* * *}$ & $0,0038 * * *$ & $0,0047 * * *$ & $0,0058 * * *$ & $0,0048 * * *$ & $0,0036^{* * *}$ \\
\hline lrendapc & $0,0189 * * *$ & $0,0161 * * *$ & $0,0068 * *$ & $-0,0267 * * *$ & $-0,0277 * * *$ & $-0,0073$ \\
\hline fundamental & 0,0006 & $-0,0054 * * *$ & $0,0030 * *$ & $-0,0008$ & $-0,0021$ & $-0,0005$ \\
\hline médio & $0,0010 * *$ & $0,0018 * * *$ & 0,0000 & 0,0005 & 0,0002 & 0,0014 \\
\hline superior & $0,0038 * *$ & $0,0068 * * *$ & 0,0001 & 0,0010 & 0,0029 & $-0,0054$ \\
\hline desocupado & $0,0014 * * *$ & $0,0004^{*}$ & $0,0009 * * *$ & $0,0033 * * *$ & $0,0053 * * *$ & $-0,0018$ \\
\hline ccarteira & $-0,0023 * * *$ & $0,0011 * * *$ & $-0,0033 * * *$ & $-0,0079 * * *$ & $-0,0078 * * *$ & $-0,0061 * * *$ \\
\hline fpublico & $-0,0009 * * *$ & $0,0008 * * *$ & $-0,0012 * * *$ & $-0,0028 * * *$ & $-0,0028 * * *$ & $-0,0015^{*}$ \\
\hline domestico & $0,0011 * * *$ & $0,0002^{*}$ & $0,0011 * * *$ & $0,0027 * * *$ & $0,0029 * * *$ & $0,0012 * * *$ \\
\hline scarteira & $0,0004 * * *$ & $0,0001 * * *$ & $0,0004 * * *$ & $0,0005 * * *$ & $0,0006 * * *$ & 0,0003 \\
\hline cpropria & $-0,0013 * * *$ & $-0,0006 * * *$ & $-0,0008 * * *$ & $-0,0019 * * *$ & $-0,0021 * * *$ & $-0,0010 * *$ \\
\hline empregador & $-0,0022 * * *$ & $-0,0004 *$ & $-0,0020 * * *$ & $-0,0003$ & $-0,0001$ & $-0,0011$ \\
\hline outra & $0,0009 * * *$ & 0,0002 & $0,0008 * * *$ & 0,0002 & $0,0008 * * *$ & $-0,0008$ \\
\hline plano & $0,0356 * * *$ & $0,0215 * * *$ & $0,0189 * * *$ & $0,0311 * * *$ & $0,0400 * * *$ & $-0,0007$ \\
\hline$G C_{\varepsilon}$ & $-0,0017$ & $-0,0014$ & $-0,0120$ & $-0,0201$ & $-0,0237$ & 0,0132 \\
\hline IC & $0,0439 * * *$ & $0,0408 * * *$ & 0,00322 & $-0,0285^{* * *}$ & $-0,0181 * *$ & $-0,00962$ \\
\hline $\mathrm{ICwv}$ & $0,0597 * * *$ & $0,0403 * * *$ & $0,0280 * * *$ & $-0,0021$ & $-0,0006$ & $-0,0153 * *$ \\
\hline Observações & 93.880 & 93.880 & 65.969 & 93.880 & 93.880 & 6.548 \\
\hline
\end{tabular}
$* * * \mathrm{p}<0.01, * * \mathrm{p}<0.05 \mathrm{e} * \mathrm{p}<0.1$ 
Tabela C.4 - Contribuição dos determinantes da utilização para a desigualdade no cuidado, Região Sul - 2008

\begin{tabular}{|c|c|c|c|c|c|c|}
\hline \multirow{4}{*}{ Variáveis } & \multicolumn{3}{|c|}{ Consultas Médicas } & \multicolumn{3}{|c|}{ Internações Hospitalares } \\
\hline & \multirow{3}{*}{$\begin{array}{l}\text { Binomial } \\
\text { Negativo }\end{array}$} & \multicolumn{2}{|c|}{ Hurdle Binomial Negativo } & \multirow{3}{*}{$\begin{array}{l}\text { Binomial } \\
\text { Negativo }\end{array}$} & \multicolumn{2}{|c|}{ Hurdle Poisson } \\
\hline & & & Negbin & & & Poisson \\
\hline & & Logit & Truncado & & Logit & Truncado \\
\hline m18_29 & $0,0005 * * *$ & $-0,0003 * * *$ & $0,0007 * * *$ & $0,0020 * * *$ & $0,0023 * * *$ & $0,0004 * * *$ \\
\hline m30_44 & $-0,0003 * * *$ & $0,0001 * *$ & $-0,0003 * * *$ & $-0,0012 * * *$ & $-0,0010 * *$ & $-0,0012 *$ \\
\hline m45_59 & $0,0019 * * *$ & $-0,0002$ & $0,0015 * * *$ & $0,0058 * * *$ & $0,0057 * * *$ & 0,0028 \\
\hline m60_69 & $0,0015 * * *$ & $0,0005 * *$ & $0,0006 * *$ & $0,0054 * * *$ & $0,0052 * * *$ & $0,0027 *$ \\
\hline $\mathrm{m} 70$ & $0,0003 * *$ & 0,0001 & $0,0002 * *$ & 0,0005 & 0,0004 & 0,0005 \\
\hline f10_17 & $-0,0047 * * *$ & $-0,0014 * * *$ & $-0,0033 * * *$ & 0,0002 & 0,0013 & $-0,0056$ \\
\hline f18_29 & $-0,0027 * * *$ & $-0,0006 * * *$ & $-0,0017 * * *$ & $-0,0045 * * *$ & $-0,0046 * * *$ & $-0,0009 *$ \\
\hline f30_44 & $-0,0055^{* * *} *$ & $-0,0019 * * *$ & $-0,0028 * * *$ & $-0,0061 * * *$ & $-0,0067 * * *$ & $-0,0010$ \\
\hline f45_59 & $0,0078 * * *$ & $0,0033 * * *$ & $0,0039 * * *$ & $0,0056 * * *$ & $0,0065^{* * *}$ & 0,0018 \\
\hline f60_69 & $0,0059 * * *$ & $0,0027 * * *$ & $0,0028 * * *$ & $0,0045 * * *$ & $0,0053 * * *$ & 0,0035 \\
\hline $\mathrm{f} 70$ & 0,0000 & $-0,0001$ & 0,0001 & $0,0023 * * *$ & $0,0023 * * *$ & 0,0000 \\
\hline bom & $-0,0011 * * *$ & $-0,0006^{* * *}$ & $-0,0006^{* * *}$ & $-0,0021 * * *$ & $-0,0024 * * *$ & $-0,0004$ \\
\hline regular & $-0,0103 * * *$ & $-0,0037 * * *$ & $-0,0064 * * *$ & $-0,0166^{* * *}$ & $-0,0154 * * *$ & $-0,0056^{* *}$ \\
\hline ruim & $-0,0072 * * *$ & $-0,0014 * * *$ & $-0,0050 * * *$ & $-0,0145 * * *$ & $-0,0098 * * *$ & $-0,0051 * * *$ \\
\hline mruim & $-0,0034 * * *$ & $-0,0004 * * *$ & $-0,0026^{* * *}$ & $-0,0059 * * *$ & $-0,0047 * * *$ & $-0,0014 * *$ \\
\hline limitação & $-0,0036^{* * *}$ & $-0,0018 * * *$ & $-0,0022 * * *$ & $-0,0069 * * *$ & $-0,0073 * * *$ & $-0,0012 * * *$ \\
\hline crônica & $0,0058 * * *$ & $0,0032 * * *$ & $0,0033 * * *$ & $0,0038 * * *$ & $0,0040 * * *$ & 0,0005 \\
\hline lrendapc & $0,0197 * * *$ & $0,0228 * * *$ & 0,0016 & $-0,0208^{*}$ & $-0,0193 *$ & 0,0042 \\
\hline fundamental & 0,0014 & $-0,0033 * *$ & 0,0021 & 0,0058 & 0,0027 & 0,0043 \\
\hline médio & $-0,0001$ & $0,0021 * * *$ & $-0,0012 *$ & $-0,0010$ & 0,0001 & $-0,0007$ \\
\hline superior & 0,0037 & $0,0077 * * *$ & $-0,0002$ & 0,0010 & 0,0007 & 0,0061 \\
\hline desocupado & $0,0008 * *$ & $-0,0001$ & $0,0009 * * *$ & $0,0028 * * *$ & $0,0030 * * *$ & 0,0011 \\
\hline ccarteira & $-0,0023 * * *$ & $0,0013 * * *$ & $-0,0032 * * *$ & $-0,0074 * * *$ & $-0,0076 * * *$ & $-0,0045 * * *$ \\
\hline fpublico & $-0,0010^{*}$ & $0,0013 * * *$ & $-0,0014 * * *$ & 0,0002 & $-0,0004$ & 0,0011 \\
\hline domestico & $0,0010 * * *$ & $0,0004 * *$ & $0,0008 * * *$ & $0,0025^{* * *}$ & $0,0031 * * *$ & $-0,0001$ \\
\hline scarteira & $0,0001 * * *$ & $0,0000^{* *}$ & $0,0001 * * *$ & $0,0002 * * *$ & $0,0002 * * *$ & $0,0001 * * *$ \\
\hline cpropria & $-0,0013 * * *$ & $-0,0005 * * *$ & $-0,0008 * * *$ & $-0,0018 * * *$ & $-0,0020 * * *$ & $-0,0007 *$ \\
\hline empregador & $-0,0033 * * *$ & $-0,0008^{*}$ & $-0,0027 * * *$ & $-0,0060 * * *$ & $-0,0064 * * *$ & $-0,0039 * * *$ \\
\hline outra & $0,0013 * * *$ & 0,0004 & $0,0011 * * *$ & $0,0024 * * *$ & $0,0029 * * *$ & 0,0008 \\
\hline plano & $0,0322 * * *$ & $0,0185 * * *$ & $0,0182 * * *$ & $0,0200 * * *$ & $0,0256 * * *$ & $-0,0064$ \\
\hline$G C_{\varepsilon}$ & $-0,0052$ & $-0,0012$ & $-0,0174$ & $-0,0110$ & $-0,0145$ & $-0,0013$ \\
\hline IC & $0,0321 * * *$ & $0,0461 * * *$ & $-0,0141 * * *$ & $-0,0410 * * *$ & $-0,0308 * * *$ & $-0,0100$ \\
\hline ICwV & $0,0585^{* * *}$ & $0,0470 * * *$ & $0,0197 * * *$ & 0,0036 & $-0,0025$ & $-0,0004$ \\
\hline Observações & 48.028 & 48.028 & 33.317 & 48.028 & 48.028 & 3.647 \\
\hline
\end{tabular}
$* * * \mathrm{p}<0.01, * * \mathrm{p}<0.05 \mathrm{e} * \mathrm{p}<0.1$ 
Tabela C.5 - Contribuição dos determinantes da utilização para a desigualdade no cuidado, Região Centro-Oeste - 2008

\begin{tabular}{|c|c|c|c|c|c|c|}
\hline \multirow{4}{*}{ Variáveis } & \multicolumn{3}{|c|}{ Consultas Médicas } & \multicolumn{3}{|c|}{ Internações Hospitalares } \\
\hline & \multirow{3}{*}{$\begin{array}{l}\text { Binomial } \\
\text { Negativo }\end{array}$} & \multicolumn{2}{|c|}{ Hurdle Binomial Negativo } & \multirow{3}{*}{$\begin{array}{l}\text { Binomial } \\
\text { Negativo }\end{array}$} & \multicolumn{2}{|c|}{ Hurdle Poisson } \\
\hline & & & Negbin & & & Poisson \\
\hline & & Logit & Truncado & & Logit & Truncado \\
\hline m18_29 & $-0,0003 * * *$ & $-0,0003 * * *$ & $-0,0002$ & 0,0005 & 0,0008 & $-0,0007$ \\
\hline m30_44 & $-0,0002$ & $-0,0003 * * *$ & $-0,0001$ & 0,0006 & 0,0004 & 0,0002 \\
\hline m45_59 & 0,0005 & $-0,0003$ & 0,0002 & $0,0025^{*}$ & $0,0024 *$ & 0,0004 \\
\hline m60_69 & $0,0016 * * *$ & $0,0007 * * *$ & 0,0005 & $0,0025^{* *}$ & $0,0030 * *$ & $-0,0005$ \\
\hline $\mathrm{m} 70$ & $0,0003 * *$ & 0,0001 & $0,0003 * *$ & $0,0012 * *$ & 0,0005 & $0,0011 *$ \\
\hline f10_17 & $-0,0043 * * *$ & $-0,0020 * * *$ & $-0,0018 * *$ & $-0,0023$ & $-0,0007$ & $-0,0015$ \\
\hline f18_29 & $-0,0047 * * *$ & $-0,0016 * * *$ & $-0,0024 * * *$ & $-0,0082 * * *$ & $-0,0086^{* * *}$ & 0,0002 \\
\hline f30_44 & $-0,0020 * * *$ & $-0,0011 * * *$ & $-0,0008 * * *$ & $-0,0025 * * *$ & $-0,0024 * * *$ & $-0,0001$ \\
\hline f45_59 & $0,0061 * * *$ & $0,0034 * * *$ & $0,0023 * * *$ & $0,0041 * *$ & $0,0029 * *$ & 0,0010 \\
\hline f60_69 & $0,0041 * * *$ & $0,0023 * * *$ & $0,0015^{* * *}$ & 0,0015 & $0,0025^{* *}$ & $-0,0010$ \\
\hline $\mathrm{f} 70$ & $-0,0001$ & 0,0001 & 0,0000 & $0,0015^{* * *}$ & $0,0011 * *$ & $0,0012 * *$ \\
\hline bom & $-0,0009 * * *$ & $-0,0004 * * *$ & $-0,0007 * * *$ & $-0,0021 * * *$ & $-0,0018 * * *$ & $-0,0013 * *$ \\
\hline regular & $-0,0112 * * *$ & $-0,0040 * * *$ & $-0,0074 * * *$ & $-0,0166 * * *$ & $-0,0133 * * *$ & $-0,0072 * * *$ \\
\hline ruim & $-0,0058 * * *$ & $-0,0011 * * *$ & $-0,0044 * * *$ & $-0,0096 * * *$ & $-0,0066^{* * *}$ & $-0,0033 * * *$ \\
\hline mruim & $-0,0010 * * *$ & $-0,0002 * * *$ & $-0,0007 * * *$ & $-0,0018 * * *$ & $-0,0012 * * *$ & $-0,0006^{* * *}$ \\
\hline limitação & $-0,0031 * * *$ & $-0,0016^{* * *}$ & $-0,0018 * * *$ & $-0,0059 * * *$ & $-0,0057 * * *$ & $-0,0010 * * *$ \\
\hline crônica & $0,0049 * * *$ & $0,0027 * * *$ & $0,0028 * * *$ & $0,0055^{* * *}$ & $0,0053 * * *$ & $0,0015^{*}$ \\
\hline lrendapc & $0,0239 * * *$ & $0,0195 * * *$ & $0,0116^{* * *}$ & $-0,0292 * * *$ & $-0,0352 * * *$ & 0,0023 \\
\hline fundamental & $-0,0009$ & $-0,0036^{* *}$ & 0,0006 & 0,0029 & $-0,0034$ & 0,0075 \\
\hline médio & $0,0016^{* *}$ & 0,0016 *** & 0,0007 & $-0,0019$ & $-0,0005$ & $-0,0015$ \\
\hline superior & $0,0133 * * *$ & $0,0100 * * *$ & $0,0070 * * *$ & 0,0025 & 0,0054 & $-0,0004$ \\
\hline desocupado & 0,0003 & 0,0000 & 0,0002 & $0,0023 * * *$ & $0,0028 * * *$ & 0,0012 \\
\hline ccarteira & $-0,0008$ & $0,0016^{* * *}$ & $-0,0019 * * *$ & $-0,0042 * * *$ & $-0,0051^{* * *}$ & $-0,0003$ \\
\hline fpublico & 0,0009 & $0,0020 * * *$ & $-0,0002$ & $-0,0029 *$ & $-0,0013$ & $-0,0039$ \\
\hline domestico & $0,0009 * * *$ & 0,0003 & $0,0009 * * *$ & $0,0032 * * *$ & $0,0037 * * *$ & 0,0010 \\
\hline scarteira & $0,0002 * * *$ & $0,0001 * *$ & $0,0001 * * *$ & $0,0002 *$ & $0,0002 * *$ & 0,0000 \\
\hline cpropria & $-0,0010 * * *$ & $-0,0005 * * *$ & $-0,0007 * * *$ & $-0,0011 * * *$ & $-0,0013 * * *$ & $-0,0001$ \\
\hline empregador & $-0,0026 * * *$ & $-0,0008$ & $-0,0020 * * *$ & 0,0002 & $-0,0007$ & 0,0033 \\
\hline outra & $0,0009 * *$ & $0,0005^{*}$ & $0,0007 * *$ & $0,0012 * *$ & 0,0012 & 0,0009 \\
\hline plano & $0,0312 * * *$ & $0,0202 * * *$ & $0,0159 * * *$ & $0,0244 * * *$ & $0,0347 * * *$ & $-0,0104 * *$ \\
\hline$G C_{\varepsilon}$ & 0,0112 & $-0,0042$ & $-0,0005$ & $-0,0130$ & $-0,0102$ & $-0,0010$ \\
\hline IC & $0,0628 * * *$ & $0,0429 * * *$ & $0,0196 * * *$ & $-0,0444 * * *$ & $-0,0313 * * *$ & $-0,0129$ \\
\hline $\mathrm{ICwv}$ & 0,0836 *** & $0,0454 * * *$ & $0,0470 * * *$ & $-0,0065$ & $-0,0058$ & $-0,0103$ \\
\hline Observações & 35.310 & 35.310 & 23.292 & 35.310 & 35.310 & 3.064 \\
\hline
\end{tabular}
$* * * \mathrm{p}<0.01, * * \mathrm{p}<0.05 \mathrm{e} * \mathrm{p}<0.1$ 


\section{APÊNDICE D - DISTRIBUIÇÃO DE RECURSOS HUMANOS E FÍSICOS - REGIÕES, UF E BRASIL}

Tabela D.1 - Distribuição de Médicos (por mil habitantes), Regiões, UF e Brasil - 2005 e 2010

\begin{tabular}{|c|c|c|c|c|c|c|}
\hline \multirow[t]{2}{*}{ Região/UF } & \multicolumn{3}{|c|}{2005} & \multicolumn{3}{|c|}{2010} \\
\hline & SUS & Não SUS & Total & SUS & Não SUS & Total \\
\hline Norte & 1,20 & $\mathbf{0 , 1 3}$ & 1,33 & 1,78 & $\mathbf{0 , 3 3}$ & 2,12 \\
\hline Rondônia & 1,10 & 0,28 & 1,38 & 1,76 & 0,48 & 2,24 \\
\hline Acre & 1,46 & 0,08 & 1,55 & 2,34 & 0,40 & 2,74 \\
\hline Amazonas & 0,96 & 0,09 & 1,05 & 1,94 & 0,33 & 2,27 \\
\hline Roraima & 1,73 & 0,01 & 1,74 & 2,78 & 0,15 & 2,93 \\
\hline Pará & 1,18 & 0,11 & 1,28 & 1,47 & 0,31 & 1,78 \\
\hline Amapá & 1,36 & 0,27 & 1,63 & 2,46 & 0,30 & 2,76 \\
\hline Tocantins & 1,69 & 0,22 & 1,91 & 2,16 & 0,36 & 2,52 \\
\hline Nordeste & 1,90 & 0,48 & 2,38 & 2,51 & 0,66 & 3,17 \\
\hline Maranhão & 1,24 & 0,20 & 1,44 & 1,29 & 0,29 & 1,58 \\
\hline Piauí & 2,22 & 0,17 & 2,39 & 2,34 & 0,28 & 2,62 \\
\hline Ceará & 1,45 & 0,43 & 1,88 & 2,34 & 0,72 & 3,05 \\
\hline Rio Gde do Norte & 2,20 & 0,97 & 3,17 & 3,09 & 0,70 & 3,79 \\
\hline Paraíba & 2,52 & 0,79 & 3,32 & 2,91 & 0,74 & 3,65 \\
\hline Pernambuco & 1,98 & 0,57 & 2,56 & 2,64 & 0,92 & 3,57 \\
\hline Alagoas & 2,34 & 0,25 & 2,58 & 2,59 & 0,56 & 3,15 \\
\hline Sergipe & 2,78 & 0,62 & 3,41 & 4,58 & 1,05 & 5,63 \\
\hline Bahia & 1,90 & 0,48 & 2,38 & 2,56 & 0,67 & 3,23 \\
\hline Sudeste & 2,76 & $\mathbf{0 , 8 8}$ & 3,64 & 3,84 & 1,97 & 5,82 \\
\hline Minas Gerais & 3,05 & 0,63 & 3,68 & 4,03 & 1,69 & 5,72 \\
\hline Espírito Santo & 2,80 & 1,69 & 4,49 & 3,61 & 2,63 & 6,23 \\
\hline Rio de Janeiro & 2,26 & 1,00 & 3,26 & 3,34 & 1,63 & 4,97 \\
\hline São Paulo & 2,80 & 0,89 & 3,69 & 3,97 & 2,18 & 6,16 \\
\hline Região Sul & 2,71 & $\mathbf{0 , 7 0}$ & 3,41 & 3,94 & 1,63 & $\mathbf{5 , 5 7}$ \\
\hline Paraná & 2,77 & 0,72 & 3,48 & 3,59 & 1,55 & 5,15 \\
\hline Santa Catarina & 2,57 & 0,87 & 3,44 & 3,78 & 1,96 & 5,75 \\
\hline Rio Gde do Sul & 2,72 & 0,60 & 3,32 & 4,37 & 1,52 & 5,89 \\
\hline Centro-Oeste & 2,36 & 0,56 & 2,92 & 3,05 & 1,14 & 4,19 \\
\hline Mato Gr. do Sul & 2,47 & 0,62 & 3,09 & 3,43 & 1,28 & 4,71 \\
\hline Mato Grosso & 2,14 & 0,35 & 2,49 & 2,46 & 1,05 & 3,51 \\
\hline Goiás & 2,51 & 0,40 & 2,91 & 3,12 & 0,75 & 3,87 \\
\hline Distrito Federal & 2,16 & 1,11 & 3,27 & 3,23 & 2,03 & 5,26 \\
\hline Brasil & 2,36 & 0,66 & 3,02 & 3,26 & 1,36 & 4,62 \\
\hline
\end{tabular}

Fonte: Ministério da Saúde - Cadastro Nacional dos Estabelecimentos de Saúde do Brasil - CNES 
Tabela D.2 - Distribuição de Dentistas (por mil habitantes), Regiões, UF e Brasil 2005 e 2010

\begin{tabular}{|c|c|c|c|c|c|c|}
\hline \multirow[t]{2}{*}{ Região/UF } & \multicolumn{3}{|c|}{2005} & \multicolumn{3}{|c|}{2010} \\
\hline & SUS & Não SUS & Total & SUS & Não SUS & Total \\
\hline Norte & $\mathbf{0 , 2 1}$ & $\mathbf{0 , 0 3}$ & $\mathbf{0 , 2 3}$ & $\mathbf{0 , 2 9}$ & $\mathbf{0 , 1 3}$ & $\mathbf{0 , 4 2}$ \\
\hline Rondônia & 0,18 & 0,03 & 0,21 & 0,26 & 0,20 & 0,46 \\
\hline Acre & 0,30 & 0,04 & 0,33 & 0,34 & 0,15 & 0,49 \\
\hline Amazonas & 0,23 & 0,03 & 0,26 & 0,32 & 0,15 & 0,46 \\
\hline Roraima & 0,39 & 0,00 & 0,39 & 0,46 & 0,10 & 0,55 \\
\hline Pará & 0,15 & 0,01 & 0,17 & 0,22 & 0,11 & 0,33 \\
\hline Amapá & 0,15 & 0,02 & 0,17 & 0,31 & 0,07 & 0,38 \\
\hline Tocantins & 0,40 & 0,09 & 0,49 & 0,53 & 0,17 & 0,70 \\
\hline Nordeste & $\mathbf{0 , 3 3}$ & $\mathbf{0 , 0 7}$ & $\mathbf{0 , 4 0}$ & $\mathbf{0 , 4 1}$ & $\mathbf{0 , 1 9}$ & $\mathbf{0 , 6 0}$ \\
\hline Maranhão & 0,22 & 0,02 & 0,24 & 0,32 & 0,06 & 0,38 \\
\hline Piauí & 0,39 & 0,02 & 0,41 & 0,51 & 0,07 & 0,58 \\
\hline Ceará & 0,25 & 0,09 & 0,34 & 0,36 & 0,28 & 0,64 \\
\hline Rio Gde do Norte & 0,44 & 0,10 & 0,54 & 0,53 & 0,24 & 0,77 \\
\hline Paraíba & 0,59 & 0,10 & 0,69 & 0,62 & 0,17 & 0,79 \\
\hline Pernambuco & 0,38 & 0,06 & 0,43 & 0,40 & 0,19 & 0,59 \\
\hline Alagoas & 0,42 & 0,01 & 0,43 & 0,46 & 0,21 & 0,67 \\
\hline Sergipe & 0,41 & 0,06 & 0,47 & 0,41 & 0,24 & 0,66 \\
\hline Bahia & 0,25 & 0,10 & 0,35 & 0,38 & 0,21 & 0,58 \\
\hline Sudeste & $\mathbf{0 , 3 9}$ & 0,11 & $\mathbf{0 , 5 0}$ & 0,44 & 0,43 & $\mathbf{0 , 8 7}$ \\
\hline Minas Gerais & 0,47 & 0,18 & 0,65 & 0,50 & 0,44 & 0,94 \\
\hline Espírito Santo & 0,48 & 0,22 & 0,70 & 0,52 & 0,50 & 1,02 \\
\hline Rio de Janeiro & 0,29 & 0,05 & 0,34 & 0,43 & 0,22 & 0,66 \\
\hline São Paulo & 0,39 & 0,09 & 0,48 & 0,41 & 0,49 & 0,90 \\
\hline Região Sul & 0,44 & 0,18 & 0,62 & 0,45 & $\mathbf{0 , 5 0}$ & 0,95 \\
\hline Paraná & 0,48 & 0,26 & 0,74 & 0,46 & 0,60 & 1,06 \\
\hline Santa Catarina & 0,54 & 0,33 & 0,87 & 0,51 & 0,62 & 1,13 \\
\hline Rio Gde do Sul & 0,35 & 0,03 & 0,37 & 0,41 & 0,33 & 0,74 \\
\hline Centro-Oeste & $\mathbf{0 , 3 8}$ & 0,22 & $\mathbf{0 , 5 9}$ & 0,45 & $\mathbf{0 , 5 2}$ & 0,96 \\
\hline Mato Gr. do Sul & 0,50 & 0,18 & 0,68 & 0,67 & 0,31 & 0,98 \\
\hline Mato Grosso & 0,33 & 0,05 & 0,38 & 0,41 & 0,25 & 0,66 \\
\hline Goiás & 0,37 & 0,07 & 0,43 & 0,44 & 0,38 & 0,82 \\
\hline Distrito Federal & 0,33 & 0,82 & 1,15 & 0,28 & 1,35 & 1,63 \\
\hline Brasil & $\mathbf{0 , 3 7}$ & $\mathbf{0 , 1 1}$ & 0,47 & $\mathbf{0 , 4 2}$ & 0,35 & $\mathbf{0 , 7 8}$ \\
\hline
\end{tabular}

Fonte: Ministério da Saúde - Cadastro Nacional dos Estabelecimentos de Saúde do Brasil - CNES 
Tabela D.3 - Distribuição de Leitos (por mil habitantes), Regiões, UF e Brasil - 2005 e 2010

\begin{tabular}{|c|c|c|c|c|c|c|}
\hline \multirow{2}{*}{ Região/UF } & \multicolumn{3}{|c|}{2005} & \multicolumn{3}{|c|}{2010} \\
\hline & SUS & Não SUS & Total & SUS & Não SUS & Total \\
\hline Norte & $\mathbf{1 , 5 9}$ & $\mathbf{0 , 3 9}$ & 1,98 & 1,56 & 0,41 & 1,96 \\
\hline Rondônia & 1,64 & 0,79 & 2,43 & 1,83 & 0,67 & 2,51 \\
\hline Acre & 1,96 & 0,16 & 2,12 & 1,92 & 0,18 & 2,10 \\
\hline Amazonas & 1,56 & 0,33 & 1,88 & 1,48 & 0,24 & 1,72 \\
\hline Roraima & 1,57 & 0,03 & 1,61 & 1,82 & 0,03 & 1,85 \\
\hline Pará & 1,55 & 0,40 & 1,95 & 1,50 & 0,52 & 2,02 \\
\hline Amapá & 1,47 & 0,24 & 1,71 & 1,37 & 0,25 & 1,61 \\
\hline Tocantins & 1,69 & 0,27 & 1,96 & 1,53 & 0,23 & 1,76 \\
\hline Nordeste & 2,19 & $\mathbf{0 , 4 1}$ & 2,60 & 1,91 & $\mathbf{0 , 3 9}$ & 2,30 \\
\hline Maranhão & 2,48 & 0,43 & 2,90 & 1,99 & 0,30 & 2,29 \\
\hline Piauí & 2,56 & 0,34 & 2,89 & 2,27 & 0,36 & 2,63 \\
\hline Ceará & 1,96 & 0,41 & 2,37 & 1,71 & 0,52 & 2,23 \\
\hline Rio Gde do Norte & 2,41 & 0,45 & 2,86 & 2,06 & 0,31 & 2,37 \\
\hline Paraíba & 2,74 & 0,50 & 3,23 & 2,16 & 0,37 & 2,53 \\
\hline Pernambuco & 2,25 & 0,49 & 2,74 & 2,04 & 0,49 & 2,53 \\
\hline Alagoas & 1,91 & 0,28 & 2,19 & 1,75 & 0,28 & 2,03 \\
\hline Sergipe & 1,91 & 0,28 & 2,19 & 1,48 & 0,40 & 1,87 \\
\hline Bahia & 1,99 & 0,39 & 2,38 & 1,82 & 0,35 & 2,17 \\
\hline Sudeste & 1,93 & 0,84 & 2,77 & 1,62 & 0,84 & 2,47 \\
\hline Minas Gerais & 1,96 & 0,61 & 2,58 & 1,64 & 0,63 & 2,27 \\
\hline Espírito Santo & 1,79 & 0,60 & 2,39 & 1,56 & 0,65 & 2,21 \\
\hline Rio de Janeiro & 2,45 & 1,04 & 3,49 & 2,00 & 1,05 & 3,06 \\
\hline São Paulo & 1,73 & 0,90 & 2,63 & 1,47 & 0,88 & 2,35 \\
\hline Região Sul & 2,22 & 0,76 & 2,98 & 1,95 & 0,79 & 2,74 \\
\hline Paraná & 2,34 & 0,73 & 3,08 & 2,01 & 0,78 & 2,79 \\
\hline Santa Catarina & 2,17 & 0,62 & 2,79 & 1,81 & 0,65 & 2,46 \\
\hline Rio Gde do Sul & 2,14 & 0,86 & 3,00 & 1,96 & 0,88 & 2,84 \\
\hline Centro-Oeste & 2,25 & $\mathbf{0 , 8 0}$ & 3,05 & 1,85 & 0,78 & 2,63 \\
\hline Mato Gr, do Sul & 2,30 & 0,70 & 3,00 & 1,52 & 0,82 & 2,35 \\
\hline Mato Grosso & 1,97 & 0,65 & 2,62 & 1,58 & 0,58 & 2,16 \\
\hline Goiás & 2,47 & 0,87 & 3,34 & 2,11 & 0,83 & 2,94 \\
\hline Distrito Federal & 2,04 & 0,91 & 2,94 & 1,90 & 0,84 & 2,74 \\
\hline Brasil & 2,04 & 0,67 & 2,71 & 1,76 & 0,67 & 2,43 \\
\hline
\end{tabular}

Fonte: Ministério da Saúde - Cadastro Nacional dos Estabelecimentos de Saúde do Brasil - CNES 


\section{APÊNDICE E - TESTES DE OVERDISPERSION}

Tabela E.1 -Teste de overdispersão para a variável tconsulta - Amostra Brasil

\begin{tabular}{llllc}
\hline ystar & Coeficiente & Erro Padrão & $\mathrm{t}$ & $\mathrm{P}>|\mathrm{t}|$ \\
\hline muhat & 1.340711 & 0.0241681 & 55.47 & 0.000 \\
& & & \\
\hline \multirow{2}{*}{ Tabela E.2 } & Teste de overdispersão para a variável tinternacao - Amostra Brasil \\
\hline ystar & Coeficiente & Erro Padrão & $\mathrm{t}$ & $\mathrm{P}>|\mathrm{t}|$ \\
\hline muhat & 6.823611 & 0.6218902 & 10.97 & 0.000 \\
\hline
\end{tabular}

Tabela E.3 - Teste de overdispersão para a variável tconsulta - Amostra Norte

\begin{tabular}{llll}
\hline$y s t a r$ & Coeficiente & $\mathrm{P}>|\mathrm{t}|$
\end{tabular}

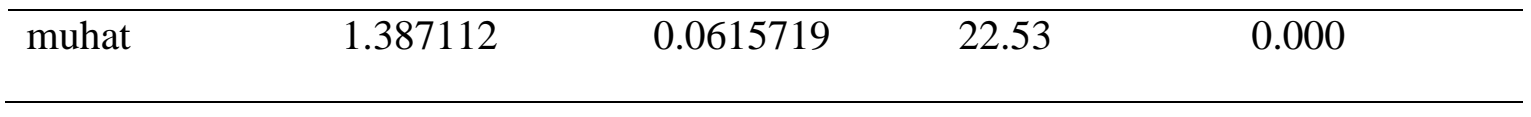

Tabela E.4 - Teste de overdispersão para a variável tinternacao - Amostra Norte

\begin{tabular}{lllll}
\hline ystar & Coeficiente & Erro Padrão & $\mathrm{t}$ & $\mathrm{P}>|\mathrm{t}|$ \\
\hline muhat & 8.518767 & 2.354939 & 3.62 & 0.000
\end{tabular}

Tabela E.5 - Teste de overdispersão para a variável tconsulta - Amostra Nordeste

\begin{tabular}{lllll}
\hline ystar & Coeficiente & Erro Padrão & $\mathrm{t}$ & $\mathrm{P}>|\mathrm{t}|$ \\
\hline muhat & 1.432726 & 0.0370689 & 38.65 & 0.000 \\
\hline & & & \\
\hline \multicolumn{2}{l}{ Tabela E.6 - Teste de overdispersão } & para a variável tinternacao - Amostra Nordeste \\
\hline ystar & Coeficiente & Erro Padrão & $\mathrm{t}$ & $\mathrm{P}>|\mathrm{t}|$ \\
\hline muhat & 7.753432 & 1.097554 & 7.06 & 0.000 \\
\hline
\end{tabular}

Tabela E.7 - Teste de overdispersão para a variável tconsulta - Amostra Sudeste

\begin{tabular}{lllll}
\hline ystar & Coeficiente & Erro Padrão & $\mathrm{t}$ & $\mathrm{P}>|\mathrm{t}|$ \\
\hline muhat & 1.152473 & 0.041586 & 27.71 & 0.000
\end{tabular}

Tabela E.8 - Teste de overdispersão para a variável tinternacao - Amostra Sudeste

\begin{tabular}{lllll}
\hline ystar & Coeficiente & Erro Padrão & $\mathrm{t}$ & $\mathrm{P}>|\mathrm{t}|$ \\
\hline muhat & 6.443477 & 0.8175399 & 7.88 & 0.000
\end{tabular}


Tabela E. 9 - Teste de overdispersão para a variável tconsulta - Amostra Sul

\begin{tabular}{lllll}
\hline ystar & Coeficiente & Erro Padrão & $\mathrm{t}$ & $\mathrm{P}>|\mathrm{t}|$ \\
\hline muhat & 1.532101 & 0.081077 & 18.90 & 0.000
\end{tabular}

Tabela E. 10 - Teste de overdispersão para a variável tinternacao - Amostra Sul

\begin{tabular}{lllll}
\hline ystar & Coeficiente & Erro Padrão & $\mathrm{t}$ & $\mathrm{P}>|\mathrm{t}|$ \\
\hline muhat & 6.225485 & 0.8888464 & 7.00 & 0.000 \\
\hline
\end{tabular}

Tabela E. 11 - Teste de overdispersão para a variável tconsulta - Amostra Centro-Oeste

\begin{tabular}{lllll}
\hline ystar & Coeficiente & Erro Padrão & $\mathrm{t}$ & $\mathrm{P}>|\mathrm{t}|$ \\
\hline muhat & 1.263573 & 0.0619917 & 20.38 & 0.000
\end{tabular}

Tabela E. 12 - Teste de overdispersão para a variável tinternacao - Amostra CentroOeste

\begin{tabular}{lllll}
\hline ystar & Coeficiente & Erro Padrão & $\mathrm{t}$ & $\mathrm{P}>|\mathrm{t}|$ \\
\hline muhat & 5.251758 & 1.719353 & 3.05 & 0.002 \\
\hline
\end{tabular}




\section{APÊNDICE F - TESTE DE RAZÃO DE VEROSSIMILHANÇA}

Quadro F. 1 - Teste de razão de verossimilhança

\begin{tabular}{|c|}
\hline 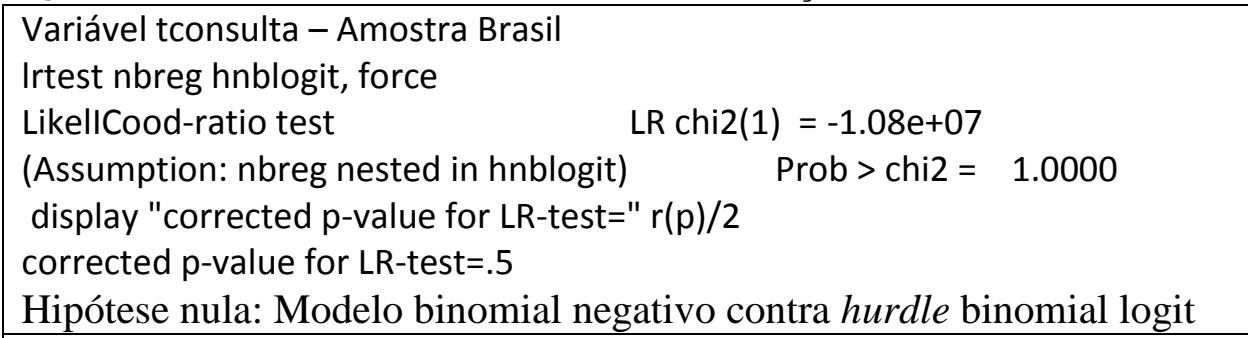 \\
\hline 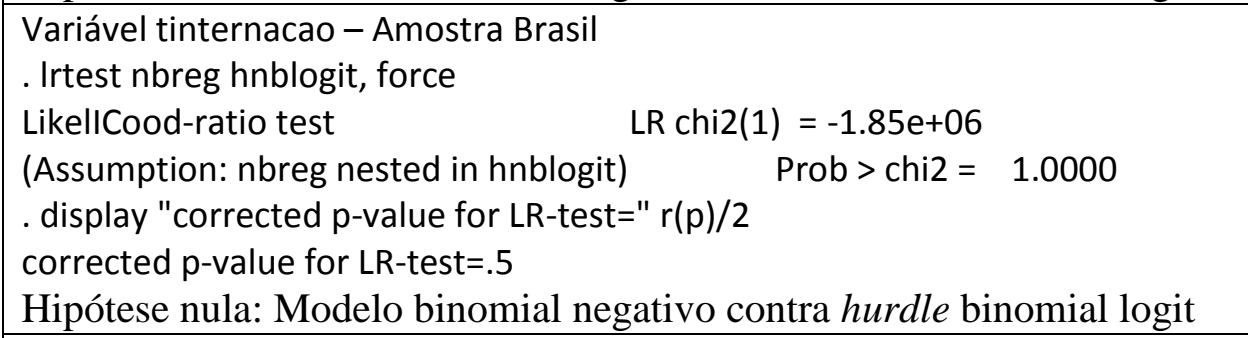 \\
\hline $\begin{array}{l}\text { Variável tconsulta }- \text { Amostra Norte } \\
\text {. Irtest nbreg hnblogit, force } \\
\text { LikellCood-ratio test } \quad \text { LR chi2 }(31)=484003.68 \\
\text { (Assumption: nbreg nested in hnblogit) } \quad \text { Prob }>\text { chi2 }=0.0000 \\
\text {. display "corrected } p \text {-value for LR-test=" } r(p) / 2 \\
\text { corrected } p \text {-value for LR-test }=0 \\
\text { Hipótese nula: Modelo binomial negativo contra hurdle binomial logit }\end{array}$ \\
\hline 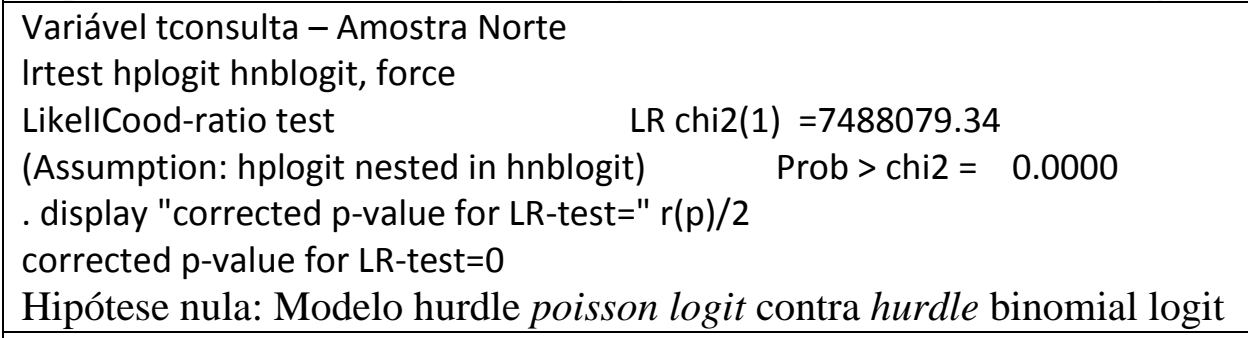 \\
\hline 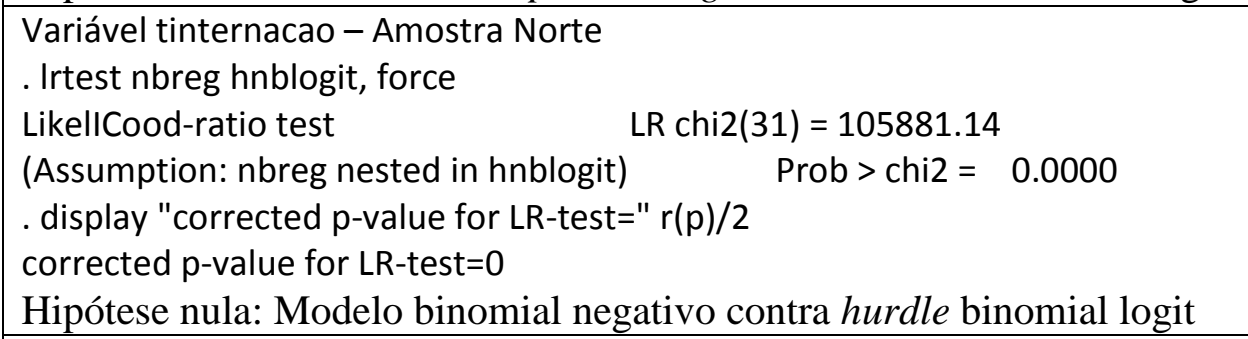 \\
\hline 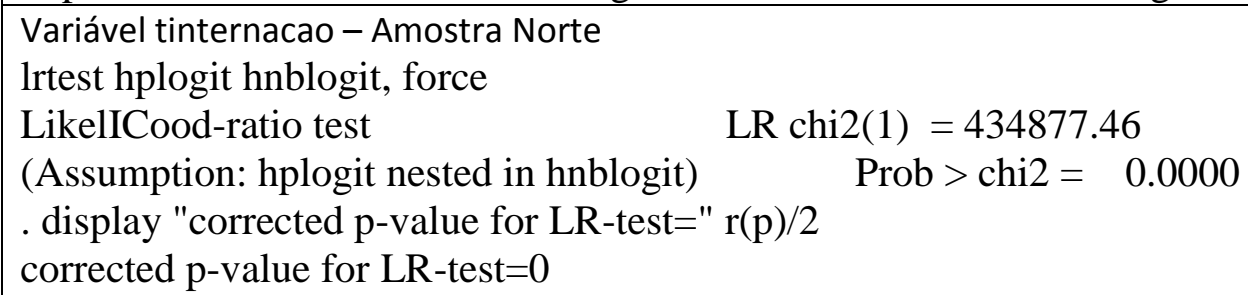 \\
\hline
\end{tabular}

Continua 
Quadro F. 1 - Teste de razão de verossimilhança

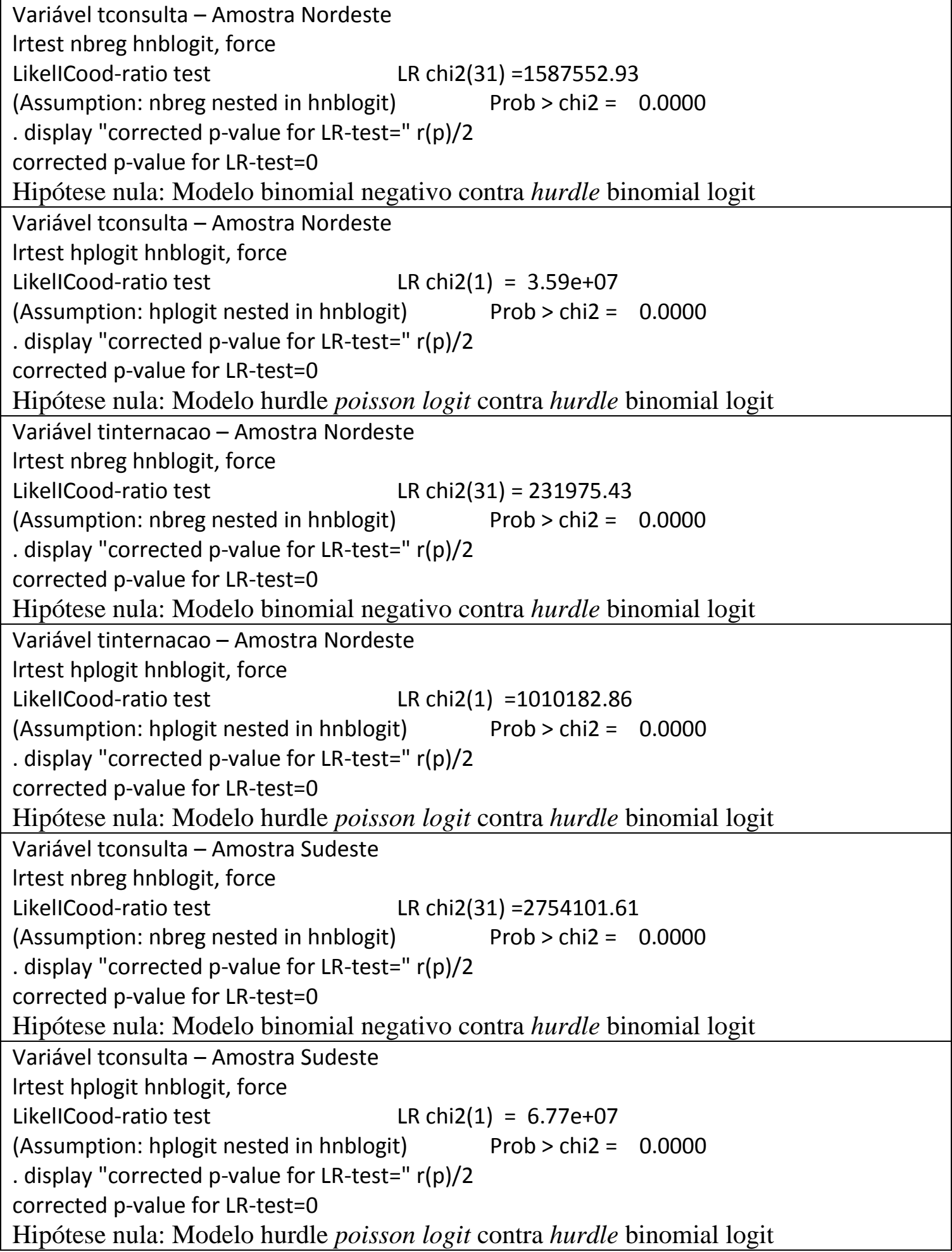


Quadro F. 1 - Teste de razão de verossimilhança

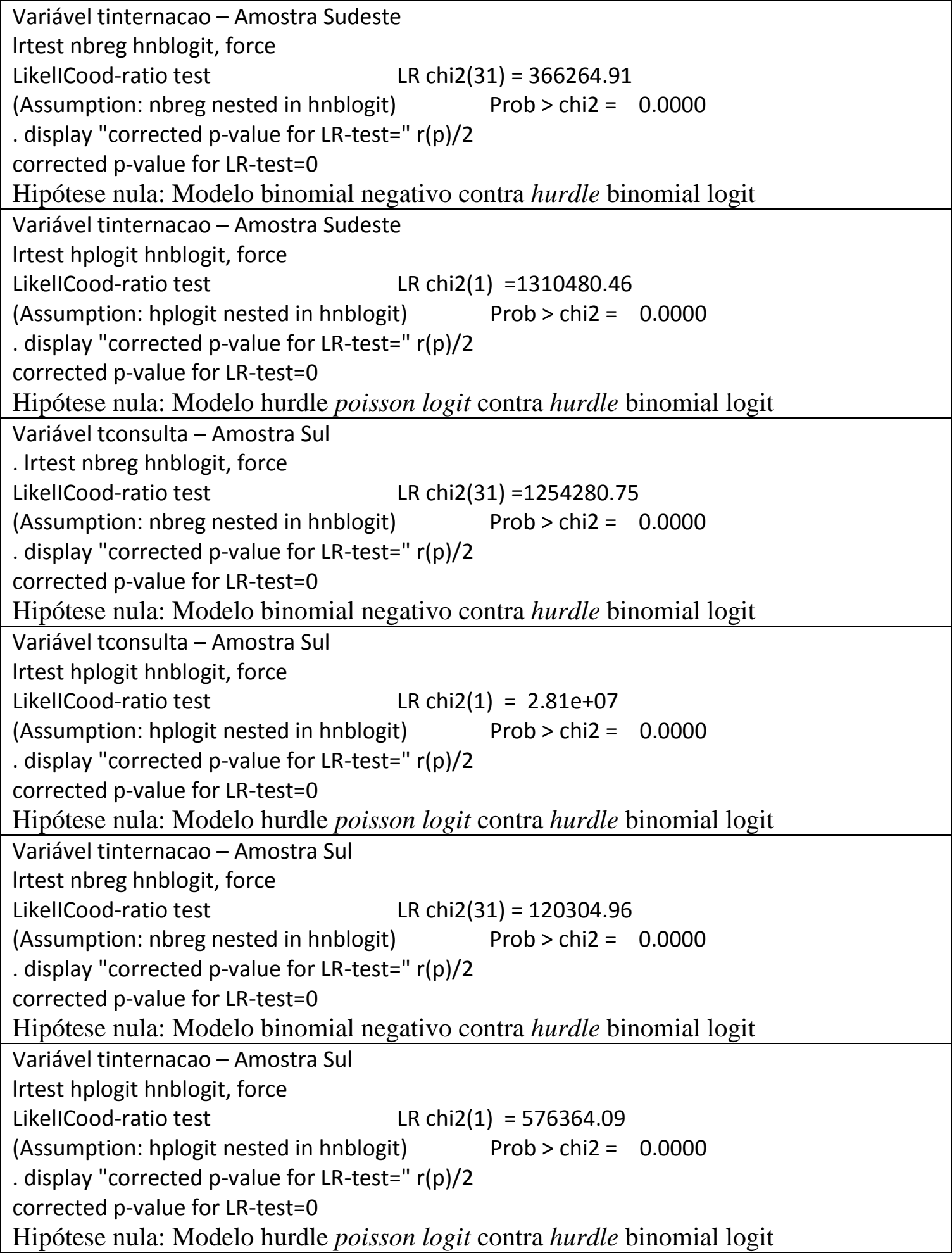


Quadro F. 1 - Teste de razão de verossimilhança

\begin{tabular}{|c|}
\hline $\begin{array}{l}\text { Variável tconsulta - Amostra Centro-Oeste } \\
\text { Irtest nbreg hnblogit, force }\end{array}$ \\
\hline $\begin{array}{ll}\text { LikellCood-ratio test } \quad \text { LR chi2 } 2(30)=452877.38\end{array}$ \\
\hline $\begin{array}{l}\text { (Assumption: nbreg nested in hnblogit) } \quad \text { Prob }>\text { chi2 }=0.0000 \\
\text {. display "corrected } p \text {-value for LR-test=" } r(p) / 2 \\
\text { corrected } p \text {-value for LR-test }=0 \\
\text { Hipótese nula: Modelo binomial negativo contra hurdle binomial logit }\end{array}$ \\
\hline $\begin{array}{l}\text { Variável tconsulta - Amostra Centro-Oeste } \\
\text { Irtest hplogit hnblogit, force }\end{array}$ \\
\hline LikellCood-ratio test $\quad$ LR chi2 $2(1)=9761798.94$ \\
\hline $\begin{array}{l}\text { (Assumption: hplogit nested in hnblogit) } \quad \text { Prob }>\text { chi2 }=0.0000 \\
\text {. display "corrected } p \text {-value for LR-test=" } r(p) / 2 \\
\text { corrected } p \text {-value for LR-test }=0 \\
\text { Hipótese nula: Modelo hurdle poisson logit contra hurdle binomial logit }\end{array}$ \\
\hline $\begin{array}{l}\text { Variável tinternacao - Amostra Centro-Oeste } \\
\text {. Irtest nbreg hnblogit, force }\end{array}$ \\
\hline LikellCood-ratio test $\quad$ LR chi2 $(31)=90629.86$ \\
\hline $\begin{array}{l}\text { (Assumption: nbreg nested in hnblogit) } \quad \text { Prob }>\text { chi2 }=0.0000 \\
\text {. display "corrected } p \text {-value for LR-test=" } r(p) / 2 \\
\text { corrected } p \text {-value for LR-test }=0 \\
\text { Hipótese nula: Modelo binomial negativo contra hurdle binomial logit }\end{array}$ \\
\hline $\begin{array}{l}\text { Variável tinternacao - Amostra Centro-Oeste } \\
\text { Irtest hplogit hnblogit, force }\end{array}$ \\
\hline LikellCood-ratio test $\quad$ LR chi2 $(1)=333904.13$ \\
\hline $\begin{array}{l}\text { (Assumption: hplogit nested in hnblogit) } \quad \text { Prob }>\text { chi2 }=0.0000 \\
\text {. display "corrected } p \text {-value for LR-test=" } r(p) / 2 \\
\text { corrected } p \text {-value for LR-test }=0\end{array}$ \\
\hline
\end{tabular}




\section{APÊNDICE G - ESTATÍSTICAS DESCRITIVAS - 2008}

Tabela G.1 - Estatísticas descritivas - 2008

\begin{tabular}{|c|c|c|c|c|}
\hline Variável & Média & Desvio-padrão & Mínimo & Máximo \\
\hline consulta & 0,667 & 0,471 & 0 & 1 \\
\hline nconsulta & 4,171 & 5,239 & 1 & 98 \\
\hline tconsulta & 2,781 & 4,708 & 0 & 98 \\
\hline internacao & 0,072 & 0,258 & 0 & 1 \\
\hline ninternacao & 1,460 & 1,608 & 1 & 52 \\
\hline tinternacao & 0,105 & 0,573 & 0 & 52 \\
\hline m10_17 & 0,091 & 0,288 & 0 & 1 \\
\hline m18_29 & 0,124 & 0,330 & 0 & 1 \\
\hline m30_44 & 0,125 & 0,331 & 0 & 1 \\
\hline m45_59 & 0,087 & 0,282 & 0 & 1 \\
\hline m60_69 & 0,054 & 0,226 & 0 & 1 \\
\hline $\mathrm{m} 70$ & 0,023 & 0,149 & 0 & 1 \\
\hline f10_17 & 0,087 & 0,281 & 0 & 1 \\
\hline f18_29 & 0,126 & 0,332 & 0 & 1 \\
\hline f30_44 & 0,137 & 0,343 & 0 & 1 \\
\hline f45_59 & 0,098 & 0,297 & 0 & 1 \\
\hline f60_69 & 0,070 & 0,255 & 0 & 1 \\
\hline $\mathrm{f} 70^{-}$ & 0,032 & 0,176 & 0 & 1 \\
\hline mbom & 0,205 & 0,404 & 0 & 1 \\
\hline bom & 0,539 & 0,498 & 0 & 1 \\
\hline regular & 0,212 & 0,409 & 0 & 1 \\
\hline ruim & 0,035 & 0,183 & 0 & 1 \\
\hline mruim & 0,008 & 0,092 & 0 & 1 \\
\hline limitacao & 0,084 & 0,277 & 0 & 1 \\
\hline crônica & 0,345 & 0,475 & 0 & 1 \\
\hline lrendapc & 5,909 & 1,005 & 0,6931 & 11,9184 \\
\hline sestudo & 0,102 & 0,302 & 0 & 1 \\
\hline fundamental & 0,506 & 0,500 & 0 & 1 \\
\hline médio & 0,278 & 0,448 & 0 & 1 \\
\hline superior & 0,115 & 0,319 & 0 & 1 \\
\hline desocupado & 0,047 & 0,212 & 0 & 1 \\
\hline ccarteira & 0,191 & 0,393 & 0 & 1 \\
\hline fpublico & 0,042 & 0,201 & 0 & 1 \\
\hline domestico & 0,041 & 0,199 & 0 & 1 \\
\hline scarteira & 0,113 & 0,317 & 0 & 1 \\
\hline cpropria & 0,117 & 0,322 & 0 & 1 \\
\hline empregador & 0,024 & 0,154 & 0 & 1 \\
\hline outra & 0,076 & 0,264 & 0 & 1 \\
\hline inativo & 0,382 & 0,486 & 0 & 1 \\
\hline plano & 0,253 & 0,435 & 0 & 1 \\
\hline norte & 0,126 & 0,332 & 0 & 1 \\
\hline nordeste & 0,228 & 0,420 & 0 & 1 \\
\hline sudeste & 0,294 & 0,456 & 0 & 1 \\
\hline sul & 0,150 & 0,357 & 0 & 1 \\
\hline centrooeste & 0,111 & 0,314 & 0 & 1 \\
\hline
\end{tabular}

Fonte: Elaboração da Autora com base nos dados da PNAD 2008. 


\section{ANEXO - PROVA DA REDISTRIBUIÇÃo LINEAR DO IC}

De acordo com Koolman e Van Doorslaer (2004, p.655), para grandes amostras e com redistribuição linear de y em relação à $\mathrm{r}$, a percentagem a ser linearmente distribuída para equalizar a distribuição é igual a 3/4 de IC. Digamos que o y relativo de um individuo i seja representado por

$l\left(r_{i}\right)=\frac{y_{i}}{\bar{y}}=\alpha_{4}+\beta_{4} r_{i}+\varepsilon_{4, i}$ para $r \epsilon(0,1)$

Em que $\beta_{4}=\frac{\beta_{2}}{\bar{y}}$

De uma regressão por MQO obtém-se uma estimativa "rank-prevista" do y relativo, igual a $\hat{l}\left(r_{i}\right)$, A curva de concentração predita $\hat{L}\left(r_{i}\right)$, é obtida pela integração de sobre $r_{i}$,

$\hat{L}\left(r_{i}\right)=\int_{0}^{1} \hat{l}\left(r_{i}\right) d r=\int_{0}^{1} \frac{\hat{l}\left(r_{i}\right)}{\bar{y}} d r=\hat{\alpha}_{4} r_{i}+\frac{1}{2} \hat{\beta}_{4} r_{i}^{2}+q$

Como $\hat{L}\left(r_{i}\right)$ será igual a zero em $r=0$, q será igual a zero, a percentagem a ser linearmente distribuída (Rl) é definida como a diferença máxima entre a diagonal $D\left(r_{i}\right)$ e $\widehat{L}\left(r_{i}\right)$ se e somente se $d^{2} \widehat{L}\left(r_{i}\right) / d r^{2} \leq 0$ ou $d^{2} \widehat{L}\left(r_{i}\right) / d r^{2} \geq 0$ para todo $r \in(0,1)$, Neste caso, Rl pode ser estimado como

$\widehat{R l}=\max \left[D\left(r_{i}\right)-\widehat{L}\left(r_{i}\right)\right]=\max \left[r_{i}-\hat{\alpha}_{4} r_{i}+\frac{1}{2} \hat{\beta}_{4} r_{i}^{2}\right]$

A diferença máxima pode ser encontrada diferenciando a equação (A.1) com respeito a $r$ e igualando a zero, ou seja,

$\frac{d D}{d r}-\frac{d \hat{L}}{d r}=1-\frac{\hat{y}_{i}}{\bar{y}}=1-\left(\hat{\alpha}_{4}+\hat{\beta}_{4} r_{i}\right)=0$

A equação (A.5) será zero somente na média de $\hat{y}_{i}$ em que $\hat{l}\left(r_{i}\right)$ é igual a 1 , e seu valor de uma função linear ira ser convertido em apenas uma média de $r$, Desde que $p l i m \bar{r}=1 / r$, substituir $\bar{r}=1 / 2$ na equação (A.4) fornece

$\widehat{R l}=D\left(\frac{1}{2}\right)-\hat{L}\left(\frac{1}{2}\right)=\frac{1}{2}-\frac{1}{2} \hat{\alpha}_{4}-\frac{1}{8} \hat{\beta}_{4}$

Utilizando

$\hat{\alpha}_{4}=E\left[l\left(r_{i}\right)\right]-\beta_{4} r=\sum_{i=1}^{n} \frac{y_{i}}{n \bar{y}}-\hat{\beta}_{4} \bar{r}=1-\hat{\beta}_{4} \hat{r}$

Obtêm-se

$\widehat{R l}=\frac{1}{2}-\frac{1}{2}+\frac{1}{4} \beta_{4}-\frac{1}{8} \beta_{4}=\frac{1}{8} \beta_{4}$

Usando a equação (A.2) segue que

$\widehat{R l}=\frac{1}{8} \beta_{4}=\frac{\widehat{\beta}_{2}}{8 \bar{y}}=\frac{3}{4} \frac{\widehat{\beta}_{2}}{6 \bar{y}} \approx \frac{3}{2} \sigma_{r}^{2} \frac{\widehat{\beta}_{2}}{\bar{y}}$

Desde que $\operatorname{plim} \hat{\sigma}_{r}^{2}=\frac{1}{12}$, o plim $\widehat{R l}=\frac{3}{4} I C$ 